USER-CENTERED DESIGN OF A MOBILE APPLICATION USING A COMBINATION OF AUGMENTED REALITY AND MAPS FOR GEO-FIELDWORK EDUCATION 



\title{
USER-CENTERED DESIGN OF A MOBILE APPLICATION USING A COMBINATION OF AUGMENTED REALITY AND MAPS FOR GEO-FIELDWORK EDUCATION
}

\author{
DISSERTATION
}

to obtain

the degree of doctor at the University of Twente, on the authority of the rector magnificus, prof.dr. T.T.M. Palstra, on account of the decision of the Doctorate Board, to be publicly defended

on Thursday 10 September 2020 at 14:45 hrs

by

Xiaoling Wang

born on 1 April 1987

in Shanxi, China 
This thesis has been approved by

Prof. dr. Menno-Jan Kraak, supervisor

Dr. Corné P. J. M. van Elzakker, co-supervisor

ITC dissertation number 384

ITC, P.O. Box 217, 7500 AE Enschede, The Netherlands

ISBN 978-90-365-5049-9

DOI $10.3990 / 1.9789036550499$

Cover designed by Simon Cordt

Printed by ITC Printing Department

Copyright (C) 2020 by Xiaoling Wang

\section{UNIVERSITY OF TWENTE.}

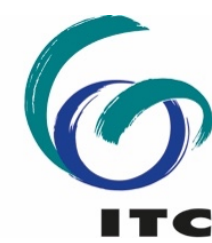


Graduation committee:

\section{Chairman/Secretary}

Prof.dr. F. D. van der Meer

\section{Supervisor(s)}

Prof. dr. M.-J. Kraak

\section{Co-supervisor(s)}

Dr. C. P. J. M. van Elzakker

Members

Prof. dr. J. Blanford

Prof. dr. P. Y. Georgiadou

Prof. dr. T. Beneker

Prof. dr. S. Bleisch
University of Twente

University of Twente

University of Twente

University of Twente

University of Twente

Utrecht University

University of Applied Sciences and Arts

Northwestern Switzerland 

To my family / 献给我的家人 / An meine Familie 



\section{Acknowledgements}

Looking back on my doctoral research, I would like to thank those individuals who provided guidance, support, and help through my entire $\mathrm{PhD}$ research project.

I would like to give my thanks to the China Scholarship Council for funding my research project aboard. Without the financial support, I would have not had the opportunity to embark on this $\mathrm{PhD}$ research in the first place. I also gratefully acknowledge the additional fellowship I received from the ITC Foundation Scholarship Program.

First and foremost, I would like to sincerely thank my supervisor, Dr. Corné van Elzakker, for your inspiring supervision and invaluable feedback on every piece of my research work. I really appreciate all the discussions we had. I am very grateful for the insightful advice and constructive suggestions you gave me to get over all the difficulties and obstacles I met. Thank you for your consistent support and motivation through the tough research period from the beginning till the end. Whenever you had the chance, during conferences, lectures, or meetings you introduced and connected me with other scholars. Thanks to your expertise, I gradually became more interested and determined to move towards my professional direction in user experience and usability research. I wish to express all the gratitude from the bottom of my heart to you as my supervisor for my $\mathrm{PhD}$ research project. Thank you for all your efforts, patience, sincerity and kindness.

My sincere gratitude also goes to my promotor, Prof. Dr. Menno-Jan Kraak, for all your support from the beginning of my application, the qualifier, publications, to writing this thesis. Without your support, I would not have had the opportunity from start to finish, here at ITC, in the Netherlands. With your holistic comments and suggestions, you helped to shape the direction of my thesis. I highly appreciate your patience and encouragement.

My special thanks go to my husband, Simon Benjamin Cordt. As a software developer, your tremendous help in developing a prototype of the mobile application GeoFARA marks an important contribution to my thesis. Whenever I had any requests regarding GeoFARA, I could always seek your help. You were always patient, supportive and provided sound solutions to pressing issues. I am extremely grateful for your assistance to level up my entire $\mathrm{PhD}$ project.

I also thank Efiom Edem Ekpenyong for your help collecting data with respect to the comparisons between traditional maps and new mobile tools in field learning. I am thankful to Prof. Zhou Shangyi from Beijing Normal University for enabling me to conduct two ethnographic studies in the human geography fieldtrips. Special thanks also go to my master thesis supervisor Zhu Liang for connecting me with local fieldwork 
organizers. I am also grateful to Prof. Ben Derudder and Jorn Koelemaij from Ghent University for assisting me in conducting a post-fieldwork online survey among undergraduates. I further appreciate Dr. Kristien Oom's support for introducing me and my research to this fieldwork. Without my experience collecting first-hand data from the three fieldtrips, it wouldn't have been possible to obtain the user requirements for my research project. I also acknowledge the Rijks Museum Twente for providing me with historical pictures and maps of the Enschede region, which represent an integral part of the GeoFARA imagery contents. I would also like to thank Dr. Robert Roth from University of Wisconsin-Madison for providing expert review on the UI of GeoFARA and his aid in the set-up of the evaluation of GeoFARA. Last but not least, Yuhao Jiang, thank you for your interest and efforts in developing the automated eye tracking data analysis approach. With your automated data processing approach, analyzing the large volume of the mobile eye tracking data became so much easier.

Thanks to the vibrant and intercultural environment ITC provided, I got to know and engage with people from different parts around the world. During the GIP department's informative research meetings, I learned to appreciate my colleague's input and helpful suggestions on my scientific work. Sincere thanks to Jolanda Kuipers for her endless help and support. I would also like to express my special thanks to Loes Colenbrander for assisting me during my PhD research. Thanks also go to the ITC Library, the Student Affairs office, the ITC Hotel, and the Finance Department. I am very grateful to Marga Koelen. Outings and coffee breaks with ITC PhD fellows were always full of fun. Xi, Xiaolong, Xu, Yifang, Elnaz, Matthew, Dewi, Peiqi, Jing, Yifei, Manuel, Zhihua, Dimitris, Junping, Yuhang, Yanwen, Norhakim, Aji, Getachew, Ieva, Nga, and more - I will always look back on our time together in Enschede with joy!

I would like to thank my family and friends. My parents Xian and Xiuqing deserve my deepest gratitude. Thank you for providing me with a healthy environment to grow up, your true support and love. I would also like to give my very special thanks to my brother Guoliang for taking care of everything while I was far away from home. Special thanks go to my close friend Nan. We have studied together for so many years, embarked our journey to the Netherlands together and travelled across Europe. Thank you for always cheering me up. I am very proud to call you my best friend over all these years.

Lastly, I want to express my special thanks to my beloved husband Simon Cordt. I am so happy we have met. Thank you for your endless love. You have been my driver, my software developer, my visual designer, my English, German and Dutch tutor. My gratitude to you is beyond what my words can express. My thanks also go to my extended family, my mother-in-law Inge Cordt, as well as my family Friedrich-Willhelm and Marie-Luise Cordt. Thank you all for your moral support. 


\section{Table of Contents}

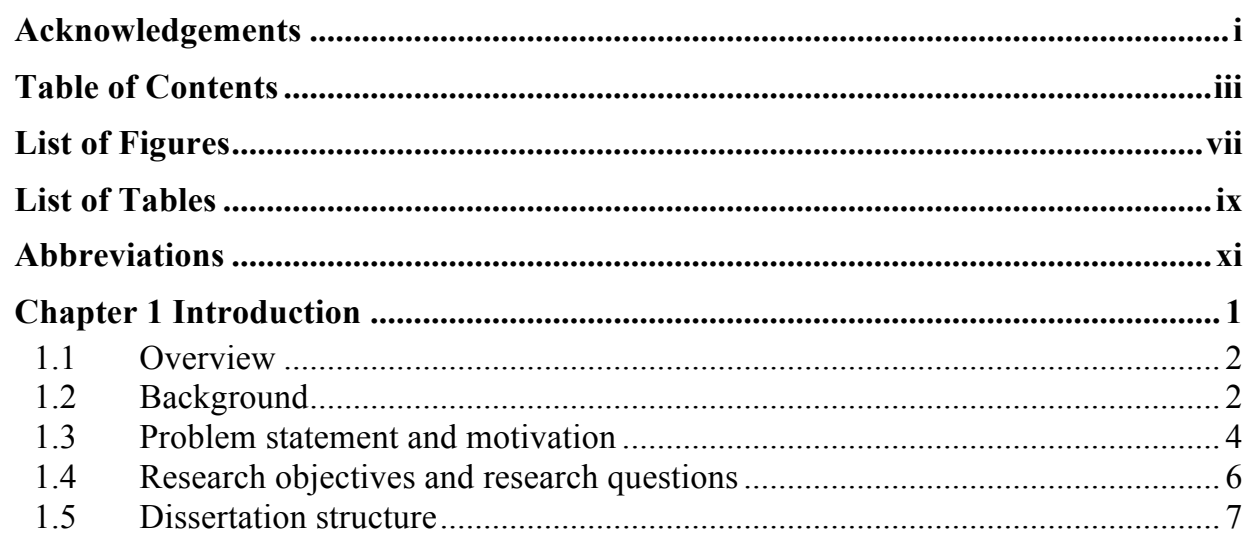

Chapter 2 Learning Geography with Visual Tools in Geography Fieldwork...........9

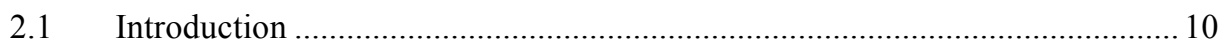

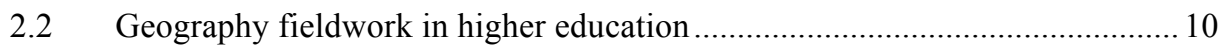

2.2.1 Types of geography fieldwork .................................................... 11

2.2.2 Objectives of geography fieldwork................................................ 14

2.2.3 Stages of geography fieldwork ........................................................ 15

2.2.4 A conceptual model of field education ............................................. 17

2.2.5 Fieldwork of this research - urban geography fieldwork....................... 18

2.3 Spatial cognition in the field: A geographical perspective.............................21

2.4 The use of visual tools in geography fieldwork ........................................... 23

2.4.1 A brief summary of visualization tools in human geography fieldwork 24

2.4.2 Online survey: The use of visualization tools in geography fieldwork .. 30

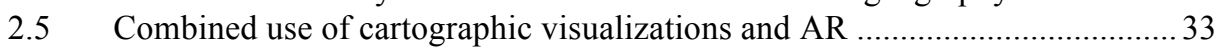

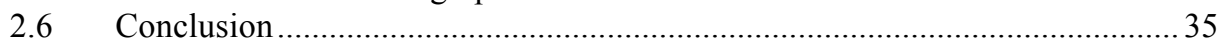

Chapter 3 Research Methodology: A User-Centered Design Approach ................... 37

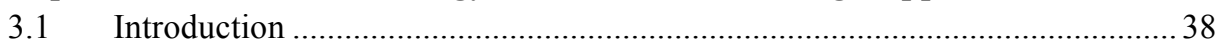

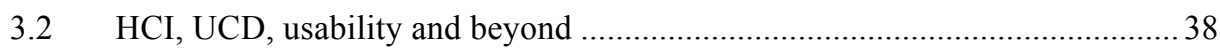

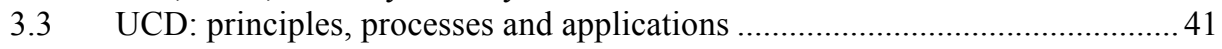

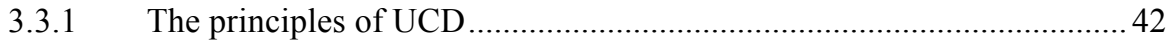

3.3.2 The interactive process of UCD ...................................................... 45

3.3.3 Applying UCD in producing mobile applications ............................... 48

$3.4 \quad$ Usability, mobile usability and mobile application usability .........................50

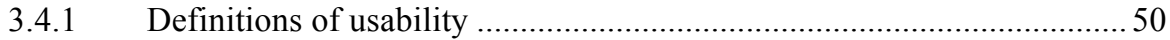

3.4.2 Mobile usability and mobile application usability................................. 53

3.5 General overview of UCD research methods and techniques ..........................5 55

3.6 UCD methods and techniques for GeoFARA ......................................... 58

3.6.1 Stage 1 - Analyzing CoU and user requirements for GeoFARA ........... 58

3.6.2 Stage 2 - Producing design solutions of GeoFARA..............................6 60

3.6.3 Stage 3 - Evaluating the prototype of GeoFARA ................................ 61

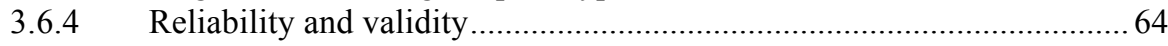

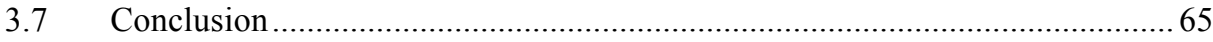


Chapter 4 Specifying the Context of Use and Analyzing the User Requirements.. 67

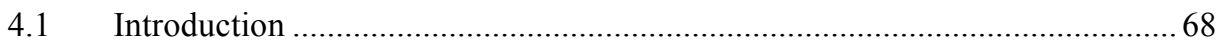

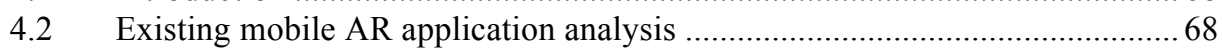

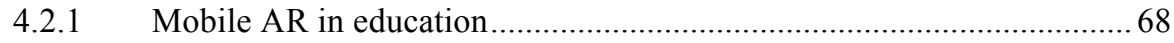

4.2.2 Mobile AR applications for outdoor educational use ........................... 70

4.2.3 Analysis of the existing mobile AR fieldwork applications .................... 74

4.3 Specifying the context-of-use for GeoFARA ................................................ 74

4.4 Analyzing user requirements through various methods ................................. 78

4.4.1 An online survey of geography fieldwork organizers............................ 78

4.4.2 A field study of examining the usage of an existing mobile application 78

4.4.3 An ethnographic study during a real human geography fieldwork......... 81

4.4.4 Post-fieldwork surveys among undergraduates of two universities ........88

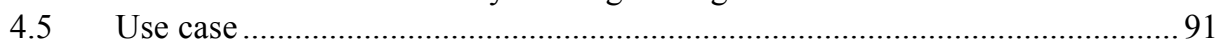

4.5.1 Learning objectives of the case-study fieldwork ................................. 91

4.5.2 Questions to be answered during the case-study fieldwork.................... 91

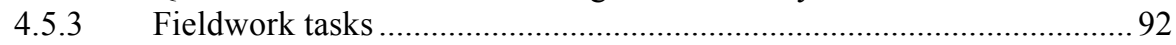

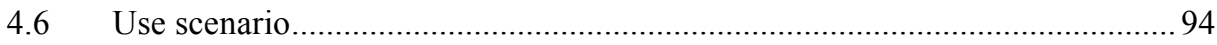

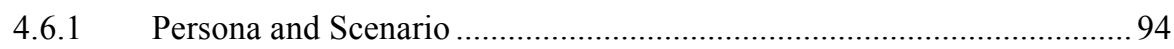

4.6.2 User tasks and user requirements................................................... 95

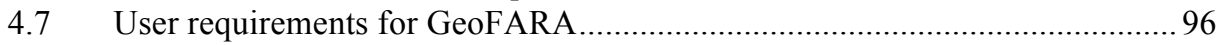

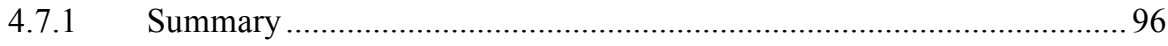

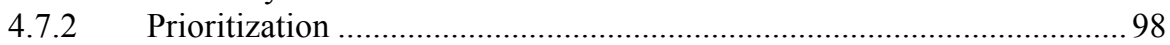

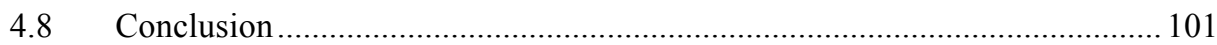

Chapter 5 Producing Design Solution: Conceptual Design and Prototype

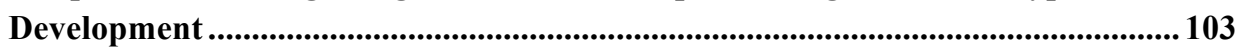

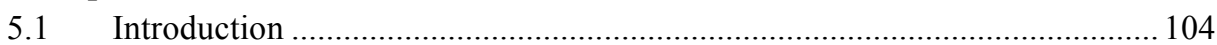

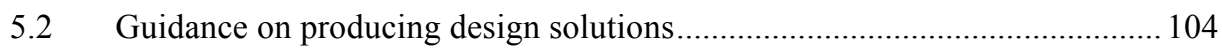

5.2.1 ISO's recommendations on producing design solutions...................... 105

5.2.2 "The Element of User Experience" model......................................... 105

5.2.3 The design solution of GeoFARA …................................................. 107

5.3 The scope of GeoFARA ........................................................................ 107

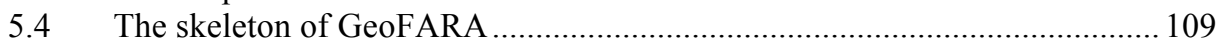

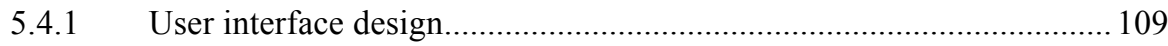

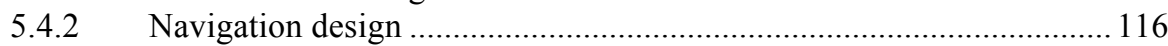

5.5 A prototype of GeoFARA …................................................................. 117

5.6 Decisions across the design solution of GeoFARA ..................................... 121

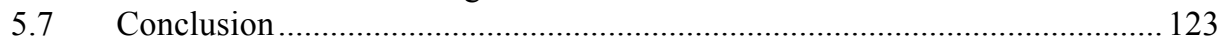

Chapter 6 Evaluating the Design Solution ...........................................................125

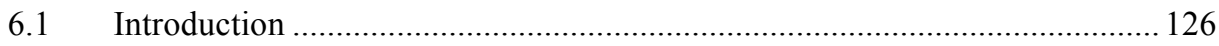

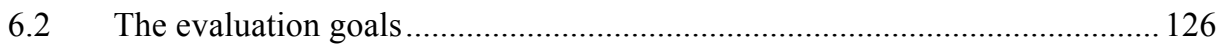

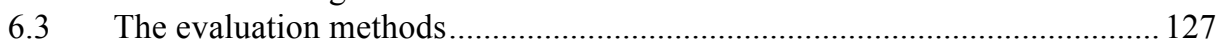

6.3.1 Mixed methods to achieve the evaluation goals ................................ 127

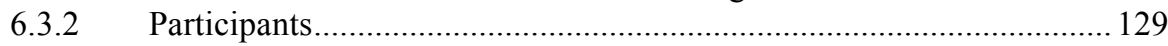

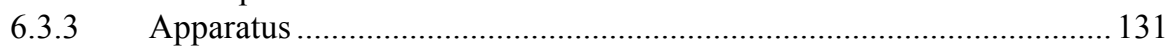

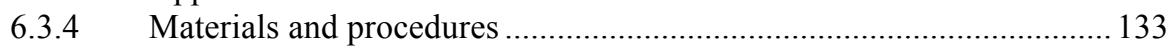

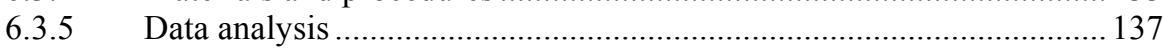

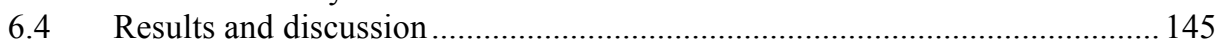




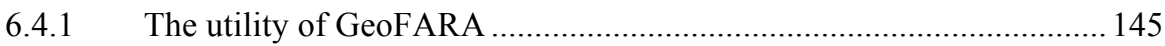

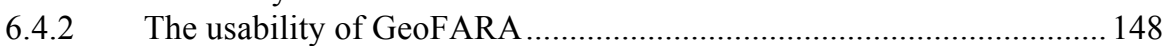

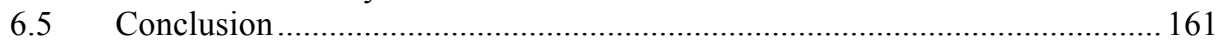

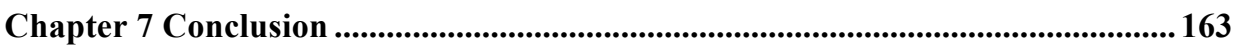

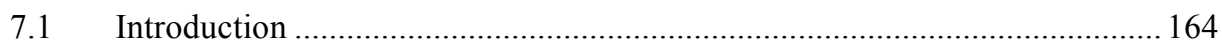

7.2 An overview of the UCD methodology for design research ......................... 164

7.3 Revisit of the research objectives and research questions .............................. 166

7.3.1 The use context, user needs and user requirements ............................ 167

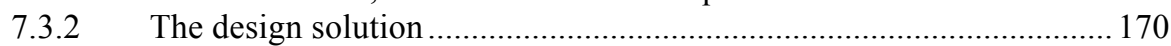

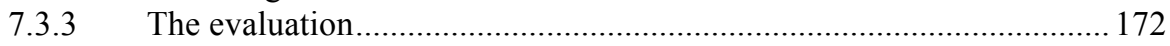

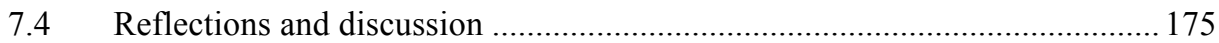

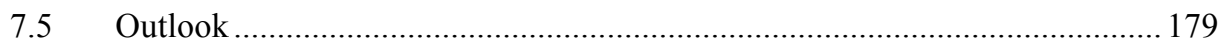

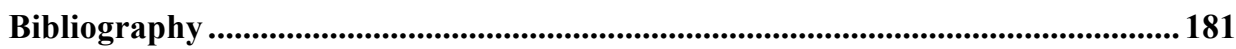

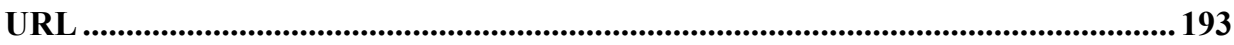

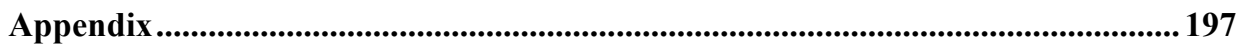

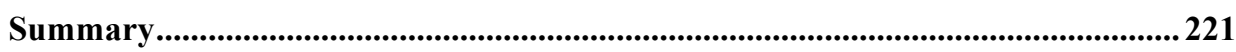

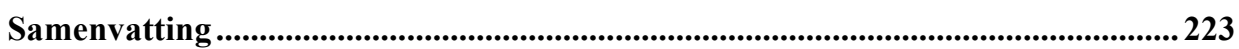

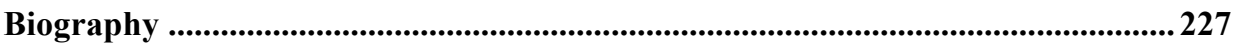




\section{List of Figures}

Figure 1.1 The perspectives of geography ................................................................. 2

Figure 1.2 A reality-virtuality continuum ................................................................. 4

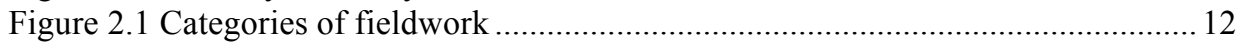

Figure 2.2 Israel's (2009) conceptual model of field education .................................... 17

Figure 2.3 An added dimension (technology usage) to Israel's (2009) conceptual model of field education

Figure 2.4 An added dimension (theme) to Israel's (2009) conceptual model of field education

Figure 2.5 The ten dimensions of the adjusted conceptual model based on Israel's (2009) conceptual model of field education ............................................................ 18

Figure 2.6 The nature of urban geography............................................................... 19

Figure 2.7 The geography fieldwork of this research in the adjusted conceptual model of

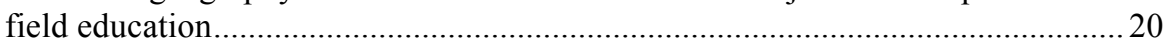

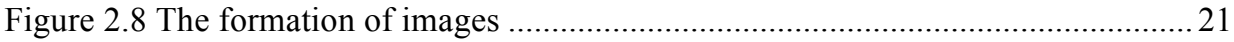

Figure 2.9 The elements of visual display and visual expansion in spatial cognition .... 22

Figure 2.10 Relating the map to the surroundings ..................................................... 24

Figure 2.11 An example of maps used to show the upcoming fieldtrip sites during preparation stage

Figure 2.12 An example of maps used during the actual fieldwork stage to support conducting tasks

Figure 2.13 An example of maps used after fieldwork to show the fieldwork results ... 26

Figure 2.14 An example of photos used in a human geography fieldwork ...................27

Figure 2.15 An example of videos used in geography fieldwork ...............................28

Figure 2.16 An example of virtual reality used in geography fieldwork........................29

Figure 2.17 The current use and interested-to-use of visualizations in the three stages of human geography fieldwork

Figure 2.18 The combined use of cartographic visualizations and mobile AR in a mobile

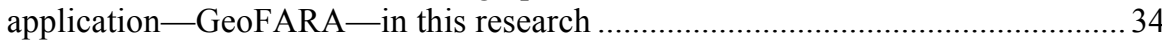

Figure 3.1 Initial developments and major milestones of some user- and usabilityrelated fields since 1971

Figure 3.2 The activities and iterative process of UCD in ISO 13407 .........................46

Figure 3.3 The activities and iterative process of UCD in ISO 9241-210 _....................46

Figure 3.4 The iterative UCD process with detailed activities at each stage ...................47

Figure 3.5 The iterative UCD process for geospatial technologies ............................. 48

Figure 3.6 A conceptual model of user, mobile devices, and environment interactions 49

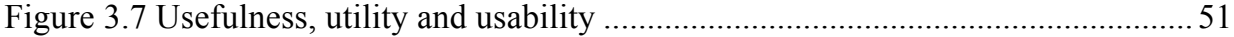

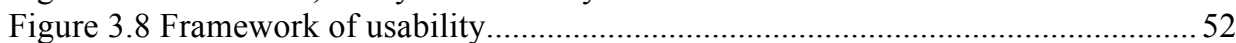

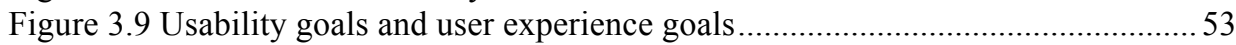

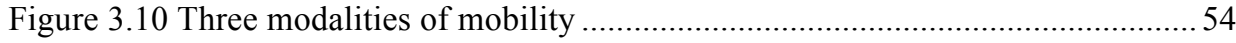

Figure 3.11 A landscape of user research methods..................................................... 57

Figure 4.1 OpenStreetMap paper prints (left) and Locus mobile application (right) used in the field experiment .................................................................................. 79

Figure 4.2 Mapping activities with the paper map (left) and the Locus mobile

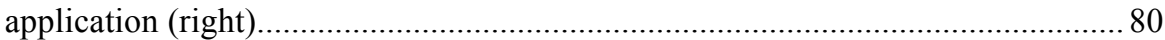

Figure 4.3 A participant were drawing a mental map................................................ 80 
Figure 4.4 Maps used in different stages of the BNU human geography fieldwork ...... 85 Figure 4.5 The fieldwork areas (in Amsterdam) of the human geography fieldwork organized by Ghent University.....

Figure 4.6 The fieldwork areas (in Beijing) of the human geography fieldwork organized Beijing Normal University

Figure 5.1 "The Elements of User Experience" Model ................................................ 106

Figure 5.2 An old map (a) and a digital map (b) of the fieldwork area within the city Enschede

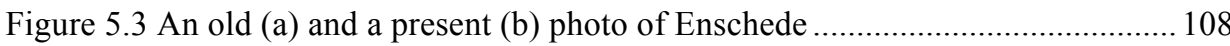

Figure 5.4 GeoFARA's "main view" with the collapsed action button ......................... 110

Figure 5.5 GeoFARA's "main view” with expanded action button ............................ 110

Figure 5.6 GeoFARA's "navigation drawer” view.................................................. 111

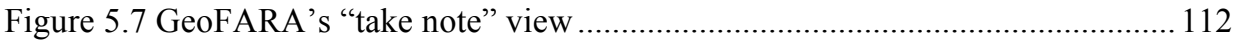

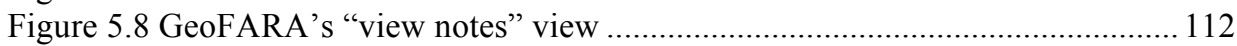

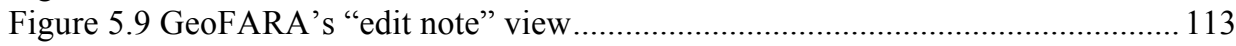

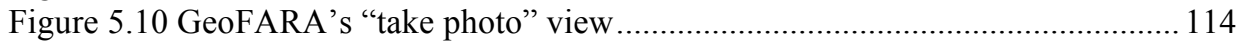

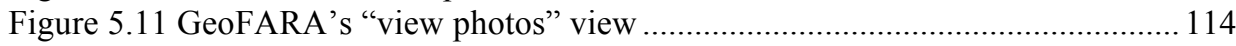

Figure 5.12 GeoFARA's "single image" view ............................................................ 115

Figure 5.13 The navigation design of GeoFARA: a site map.................................... 116

Figure 5.14 The two dimensions of prototyping .................................................... 117

Figure 5.15 An example of the information about a POI in GeoFARA ........................ 119

Figure 5.16 The "radar" and the "slider" in the prototype of GeoFARA ...................... 120

Figure 5.17 Schematic illustration of visible and invisible POIs in AR ....................... 120

Figure 5.18 The login interface of the prototype of GeoFARA …............................... 121

Figure 6.1 The setting of evaluating GeoFARA in the field...................................... 131

Figure 6.2 Tobii Pro Glasses 2 hardware .................................................................... 132

Figure 6.3 Tobii Pro Glasses Controller and its features ......................................... 133

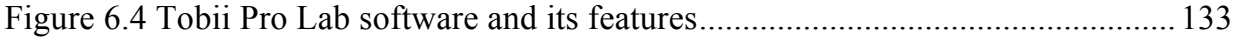

Figure 6.5 The geography fieldwork area of this research ......................................... 134

Figure 6.6 The office setup (a) and the field setup (b) for the GeoFARA evaluation study.....

Figure 6.7 The pre-fieldwork and the post-fieldwork mental maps of one participant 138

Figure 6.8 Spatial objects defined in a sketch map...................................................... 139

Figure 6.9 Examples of heat maps (left) and gaze plots (right) .................................. 141

Figure 6.10 A screenshot of using Tobii Pro Lab software to automated map gaze points on the raw eye tracking video ..................................................................... 141

Figure 6.11 Interpreting SUS scores in terms of grades, adjectives, acceptability....... 143

Figure 6.12 The recorded user log actions on GeoFARA ............................................ 143

Figure 6.13 Results from the SUS survey of GeoFARA ............................................. 149

Figure 6.14 Processing a clip of one participant's eye tracking while the participant was using GeoFARA around the POI Villa Schuttersveld ......................................... 154

Figure 6.15 The mobile eye tracking results of one participant (P6) based on applying Jiang's (2020) analysis approach ...................................................................... 155

Figure 6.16 The where and when of the participants' gazes on GeoFARA and its use context.

Figure 6.17 Two of the usability problems of GeoFARA identified from eye tracking 


\section{List of Tables}

Table 2.1 Typical fieldwork activities in the environmental and natural sciences......... 12

Table 2.2 Summary of different perspectives of objectives of geography fieldwork..... 15

Table 2.3 Three stages of geography fieldwork............................................................. 16

Table 2.4 Some important applications of spatial cognition......................................... 23

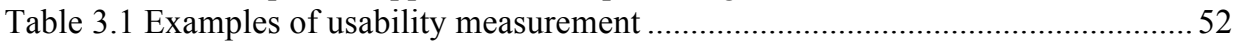

Table 3.2 General overview of UCD research methods and techniques .......................56

Table 3.3 Methods and techniques of specifying the CoU and analyzing the user

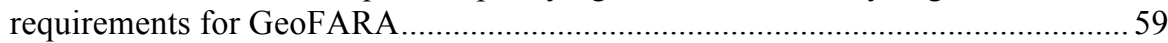

Table 3.4 Methods of producing design solution of GeoFARA ....................................60

Table 3.5 Methods and techniques of evaluating the prototype of GeoFARA............... 62

Table 4.1 Some examples of existing mobile AR applications for geography fieldwork

Table 4.2 Purposes of analyzing the CoU at different design stages

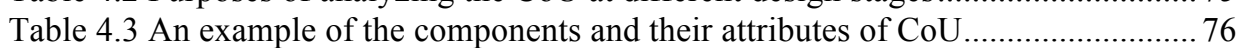

Table 4.4 The CoU of GeoFARA description and specification .................................. 77

Table 4.5 Examples of interview questions in the BNU human geography fieldwork .. 83

Table 4.6 Questions that need to be answered to meet the fieldwork objectives ...........92

Table 4.7 Fieldwork tasks to be executed during the case-study fieldwork and how GeoFARA can assist with that ....................................................................... 93

Table 4.8 The entire user requirements for GeoFARA.............................................. 97

Table 4.9 The user requirement prioritization for GeoFARA ...................................... 99

Table 6.1 The use of mixed methods to achieve the evaluation goals........................ 128

Table 6.2 The characteristics of the participants selected for evaluating GeoFARA ... 130

Table 6.3 The specifications of the smartphone used for evaluating GeoFARA ......... 131

Table 6.4 The SUS usability rating questionnaire for evaluating GeoFARA and an example showing the answers (labelled in blue, underline) given by one participant

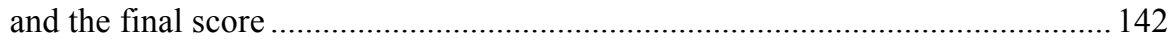

Table 6.5 The coding scheme for the interview analysis ......................................... 145

Table 6.6 Comparing the pre- and post-fieldwork mental maps of each participant.... 146

Table 6.7 The frequency of codes including utility in the interview analysis .............. 147

Table 6.8 The SUS score of GeoFARA rated by each participant .............................. 149

Table 6.9 The frequency of codes about the usability of GeoFARA in the interview

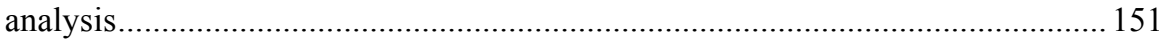

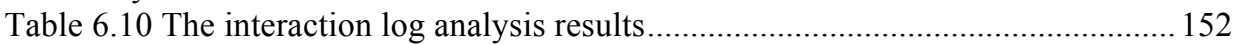

Table 6.11 Usability problems of GeoFARA and design recommendations................ 160 


\section{Abbreviations}

\begin{tabular}{|c|c|}
\hline API & Application Programming Interface \\
\hline AR & Augmented Reality \\
\hline $\mathrm{BNU}$ & Beijing Normal University \\
\hline BYOD & Bring Your Own Device \\
\hline $\mathrm{CoU}$ & Context of Use \\
\hline GeoFARA & Geography Fieldwork Augmented Reality Application \\
\hline GIS & Geographic Information System \\
\hline GPS & Global Positioning System \\
\hline GU & GeoFARA's User requirements \\
\hline GUI & Graphical User Interface \\
\hline HCD & Human-Centered Design \\
\hline $\mathrm{HCI}$ & Human-Computer Interaction \\
\hline HE & Higher Education \\
\hline $\mathrm{ICT}$ & Information and Communications Technology \\
\hline IDE & Interface Development Environment \\
\hline IEC & International Electrotechnical Commission \\
\hline ISO & International Organization for Standardization \\
\hline JSON & JavaScript Object Notation \\
\hline LBS & Location-Based Services \\
\hline LOI & Line Of Interest \\
\hline OSM & OpenStreetMap \\
\hline POI & Point Of Interest \\
\hline RQ & Research Question \\
\hline SBSOD & Santa Barbara Sense-Of-Direction \\
\hline SDK & Software Development Kit \\
\hline SQL & Structured Query Language \\
\hline SUS & System Usability Scale \\
\hline UCD & User-Centered Design \\
\hline UCSD & User-Centered System Design \\
\hline UE & Usability Engineering \\
\hline UX & User eXperience \\
\hline VR & Virtual Reality \\
\hline
\end{tabular}


Chapter 1

Introduction 


\subsection{Overview}

This is a PhD dissertation about user-centered design of a mobile augmented reality (AR) application to support spatial cognition during human geography fieldwork in higher education. The purpose of this introductory chapter is to introduce the background (Section 1.2) and to present the problem statement and motivation (Section 1.3), the research objectives and research questions (Section 1.4), as well as the structure of the dissertation (Section 1.5).

\subsection{Background}

The discipline of geography owns a unique perspective to view the world. Strahler's (2013:5) perspectives of geography provide a useful framework for viewing research, education and other practices within the domain of geography. The framework is represented by three dimensions: viewpoint, synthesis and representation (Figure 1.1). As a starting point of this research, it is necessary to project the research topic of this dissertation into this well-developed matrix of geographic perspectives. Educational fieldwork in geo-science, regarded as an integral part of all levels of geography education, provides good opportunities for spatial knowledge acquisition by exploring the physical, human, and physical-human aspects of the real world through the lenses of place, or space, or scale. The exploration can be supported by geographic representations that use visual, verbal, mathematical, digital and cognitive approaches. In this research, the attention is on the dynamic nature of the representation perspective resulting from technological, social and scientific developments. With such a background, a question is then generated: How to optimally make use of representations to enhance the (physical, human, humanphysical) geographical understanding of a certain place/space in an educational human fieldwork setting?

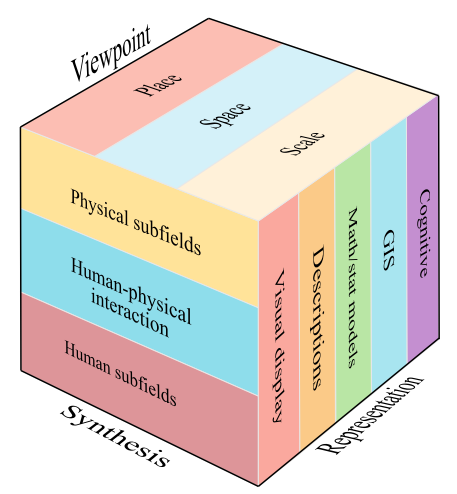

Figure 1.1 The perspectives of geography (Redrawn from Strahler, 2013:5) 
In principle, geographical understanding of a certain area will best be constructed when also learning in the real world. Educational geography fieldwork allows individuals to directly experience the geographical and other aspects of the real world. Geo-fieldwork education greatly relies on various types of visualization tools (such as maps) in support of achieving the educational objectives with enhanced experiences. It will be no surprise that geography fieldwork leaders and developers have discovered that visualization tools have very much helped to improve geographical understanding and learning before, during and after the actual fieldwork. Visual means applied to support field activities can bring indirect experiences that supplement the direct experiences gained through field activities in the real environment. Making connections between direct and indirect experiences to deliver effective fieldwork experiences has long been a fundamental topic for both scholars and practitioners within fieldwork education, particularly within geography fieldwork that values both direct experience gained from the geographic reality and indirect experience gained from representations of geographic reality.

Among the teaching and learning strategies of delivering better fieldwork experience, the appropriate design of the fieldwork itself (e.g., Marvell et al., 2013; Remmen \& Frøyland, 2014) and the proper integration of technology solutions (Jarvis et al., 2016; Welsh et al., 2013) should be highlighted. The focus of this research is on the latter one, namely the proper integration of relevant technologies. The technologies used in fieldwork and the ways of using them are always promoted by general technological innovations. According to the NMC (New Media Consortium) Horizon Report: 2017 Higher Education Edition (URL1), currently various categories of technologies, tools and strategies have a potential relevance for teaching, learning, and creative inquiry in higher education. They are: consumer technologies (e.g., wearable technologies), digital strategies, Internet technologies, learning technologies, social media technologies, visualization technologies, enabling technologies (e.g., natural user interfaces), etc. Amid these technologies there have been significant advancements in mobile technologies, thanks to the increasing availability of smart mobile devices equipped with global positioning system (GPS), cameras, compasses, accelerometers and other built-in sensors. Particularly for geography fieldwork education, leveraging mobile learning technologies has a vast potential to support educational activities. This is because they can combine visual, verbal, and digital representations in a way that allows real-time interaction with the surrounding geographic information.

In this research, the primary considerations for incorporating proper technologies are following the mobile trends and the potential relevance to support spatial cognition during geography fieldwork - mixing the real world (offering direct experience) with additional information (offering indirect experience). Around two decades ago, a reality-virtuality continuum (Figure 1.2) was already proposed by Milgram \& Kishino (1994) to mix the 
real environment with a virtual environment, while AR, in which the virtual augments the real, was placed along this continuum. Later on, AR has been identified as one of the technical trends in education (Dunleavy \& Dede, 2014; Wu, Lee, Chang, \& Liang, 2013) and it has received scientific research attention within geography (Carbonell Carrera \& Bermejo Asensio, 2017; de Almeida Pereira et al., 2017; Gazcón et al., 2018) in recent years. Although AR is a powerful innovative teaching tool in geography and topography (Carbonell Carrera \& Bermejo Asensio, 2017), its potential in teaching is just started. Therefore, the application of AR, in particular mobile AR, within educational geography fieldwork is still in its infancy. This means both opportunities and challenges that are the underlying motivation for the research on mobile AR in this dissertation.

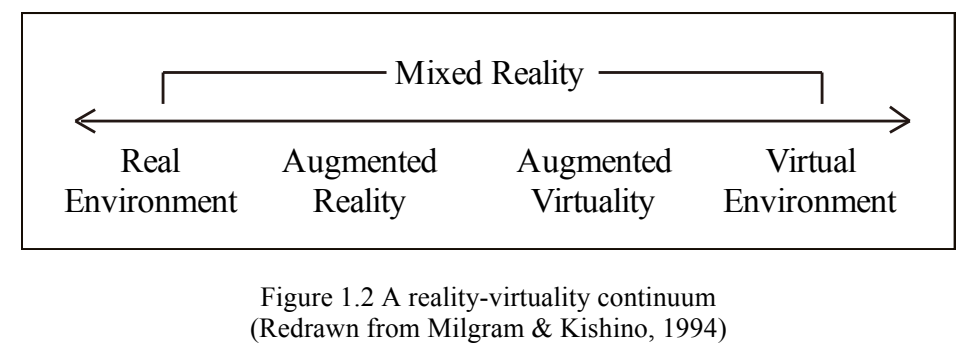

\begin{abstract}
Although the central factor that drives the integration of educational technologies is overall technological innovation (Fletcher et al., 2007), the adoption of technology solutions serving a certain educational purpose can be ineffective when they are not integrated into the learning process in meaningful ways. Therefore, in this research, it will be a challenging task to contribute to the successful use of mobile AR in geography fieldwork. In fact, to effectively use any educational tool for pedagogical purposes, its design requires extensive considerations, which have shifted from technology-driven to user-centered approaches. To meet the challenge of producing a mobile AR tool that is usable and useful, the principle of user-centered design (UCD) should be adopted. This is because the goal of UCD is to improve the usability of the designed products by involving and centering on users during the design process (Thimbleby, 2008). Through adopting a UCD approach in producing a mobile AR product for geography fieldwork use, this $\mathrm{PhD}$ dissertation research covers the connected and iterative UCD activities of design, development and research.
\end{abstract}

\title{
1.3 Problem statement and motivation
}

In a digital revolution era, the emerging information and communication technologies open new opportunities for various application domains. Education in both formal and informal settings should adapt to the fast-paced changes and leverage the newer digital 
technologies accordingly, such as smartphones and AR technologies as mentioned above. With the assistance of appropriate digital technologies in learning, it is very much possible that the educational goals could be achieved in more optimal ways. This research is a case of exploring mobile visual technologies in supporting the achievement of geofieldwork learning goals in higher education. However, Bursztyn et al. (2015:94) stated that "advancements in communication technology have outpaced implementation strategies within higher education.". Therefore, to keep pace with the latest digital technologies, we need to research the implementation of the newer technologies (or their integration with extant solutions) that potentially have a positive impact on the learning outcomes in certain educational contexts. Motivated by the need to bridge the current development of mobile technologies and educational practices, this research attempts to combine the use of maps (a traditional form of visual display within geo-science) with mobile AR (an evolving visual expansion technology) to support the understanding of the space during geography fieldwork. In a broader way, the research contributes to filling the gap between the development of cutting-edge technologies and their implementation in education.

Leveraging technologies in education is ultimately intended to support educational activities in both an effective and an efficient way. Therefore, any educational technology intervention is expected to be both useful and usable for the intended use that otherwise may result in unnecessary cognitive load. The primary consideration for making use of appropriate technologies to support a certain education context is that they can provide more appropriate functionalities that are needed (i.e., technological affordances). However, such a technology-based perspective is less suitable for ensuring that the provided functionalities satisfy the learning goals and the requirements of the actual users (Antonenko, Dawson, \& Sahay, 2017). In this research, the geography fieldwork context is even much more challenging, as it involves complex issues such as the users' mobility and context-awareness. To deal with those user- and use- related issues, taking a userbased/user-centered perspective at the beginning of the design has been advocated, because "in adopting the user-centered design concept, the likelihood of creating useful and effective systems increases.” (Haklay \& Skarlatidou, 2010). However, it can be argued that in contemporary educational research, users are mostly involved when evaluating the educational tools (e.g., Scanlon \& Issroff, 2005; Carvalho, Évora, \& ZemMascarenhas, 2016; Kuhnel et al., 2018), while the actual users of the tools should have been put at the center of the whole design (i.e., a user-centered design process), from understanding their requirements, working environment, and tasks to accomplish, to the final evaluation. Motivated by: (1) the trend of shifting away from technology-based to user-centered perspectives, (2) the advantages of adopting the UCD concept, and (3) the lack of depth in involving users in educational research, this research adopts the UCD approach to design and develop a mobile AR tool to support the spatial cognition process 
during geography fieldwork. The intention is to make such a tool (that combines AR and visualizations) useful and usable, so that it can thus be used effectively and efficiently by the intended users.

\subsection{Research objectives and research questions}

Reviewing the research background as well as stating the problem and motivation drive the formulation of the research objectives and research questions of the dissertation. The overall research objective is to user-centered design a mobile tool (combining AR and visualizations) that supports learning about the space during geography fieldwork. The research objective are in line with UCD's three-step iterative activities that are (1) specifying context of use and user requirements, (2) producing design solutions, (3) evaluating the design. Therefore, the research objectives of this dissertation are three-fold. Each research objective has several specific research questions (RQs) to answer.

Objective \#1: Specify the context of use and user requirements towards a mobile AR application supporting spatial cognition in geography fieldwork.

RQ1: What are the characteristics and learning goals of geography fieldwork in higher education?

RQ2: What is the role of spatial cognition in geography fieldwork?

RQ3: Which visual tools are currently used in geography fieldwork? And why? RQ4: What is the current state of using mobile AR in informal education? What are the limitations and the potential needs to produce a new mobile AR application?

RQ5: What are the characteristics of the context of using a mobile AR application during geography fieldwork?

RQ6: What are the user requirements of a mobile AR application to achieve the goals in geography fieldwork?

Objective \#2: Apply the specified context of use and user requirements in producing design solutions for a mobile AR application.

RQ7: What design solutions can be produced in user-centered design research? And what design solutions can be produced for the mobile AR application? RQ8: What trade-offs can be made from the user requirements to the user interface design to prototype development for the mobile AR application?

Objective \#3: Evaluate the utility and usability of the designed and developed solution with representative users. 
RQ9: What is the utility of the mobile AR application for supporting geography fieldwork learning?

RQ10: What is the usability of the mobile AR application?

RQ11: What are the usability issues of the mobile AR application? What can be done to solve the usability issues and improve the usability?

\subsection{Dissertation structure}

Building upon chapters outlining the research context (Chapter 2) and research methodology (Chapter 3 "Research methodology: the user-centered design approach"), chapters achieving the three identified research objectives follow thereafter. Research objective \#1 is dealt with in part of Chapter 2 "Learning geography with visual tools in geography fieldwork" and Chapter 4 "Specifying context of use and analyzing user requirements". Research objective \#2 is dealt with in Chapter 5 "Producing design solution: conceptual design and prototype development". Research objective \#3 is dealt with in Chapter 6 "Evaluating the design solution". The contributions made to the research objectives as well as reflections and discussion are summarized in Chapter 7 "Conclusion". How each goal is achieved in the corresponding chapter is briefly summarized as below. This $\mathrm{PhD}$ dissertation comprises seven chapters that are progressively organized in the following structure.

Chapter 1 introduces the background and provides the problem statement and motivation, the research objectives and research questions, as well as the dissertation structure.

Chapter 2 extends the research context by connecting the elements of "geography fieldwork", "spatial cognition", and "visual tools and AR". The geography fieldwork that this research focuses on is urban geography fieldwork in higher education. The fieldwork theme is exploring the influence of industrial factors on the field area structure in the city of Enschede (the Netherlands). The exploration of the industrial factors on the structure of an urban area during fieldwork falls into the spectrum of spatial cognition. Taking spatial cognition into consideration also has its practical applications, such as contributing to location-based geo-information display and increasing the usability of the display interface. Based on a literature review and an online survey of investigating the current use of visual tools in (human) geography fieldwork, the chapter concludes with the focus of this research: the combined use of AR with visualizations through a mobile application to support spatial cognition during geography fieldwork.

Chapter 3 provides a comprehensive overview of the user-centered design (UCD) methodology which this research adopts to produce the context-aware mobile application-GeoFARA (that is short for Geography Fieldwork Augmented Reality 
Application). The overview starts with elaborating on the initial developments and the major milestones of the UCD method and its interrelated fields such as human-computer interaction, usability engineering and use experience. The basic principles and the interactive process of UCD are also introduced. In addition, this chapter also reflects on how UCD can be applied in the design of context-aware mobile applications. As a core focus of UCD, usability is also defined, followed by a definition of mobile usability. Finally, both the commonly used UCD methods and techniques in general and those which are specifically used in this research are explained.

Chapter 4 specifies the context of the use and user requirements of GeoFARA that needs to be designed in this research. The context-of-use of GeoFARA is described and specified in terms of the users, user characteristics, goals and tasks, resources, and environment. The user requirements are identified on the basis of a number of sources: (1) reviewing several existing mobile AR applications, (2) an online survey of the current use of tools in undergraduate geography fieldwork, (3) a field experiment comparing the use of paper maps and a mobile mapping tool, (4) an ethnographic study during a real human geography fieldwork, (5) post-fieldwork surveys among undergraduates from two universities, and (6) the use case and task analysis, and (7) use scenario. All the collected user requirements are then summarized and given different priority levels.

Chapter 5 presents the conceptual design and a prototype of GeoFARA. The conceptual design includes the scope and the skeleton. The scope of GeoFARA documents its functionality specifications and content requirements; the skeleton of GeoFARA comprises its user interface and navigation design. The prototype is presented in terms of the data model, software architecture, prototype implementation and development, as well as through some user interfaces and a screen capture video. Compromises made between user requirements and the design and the prototype are also explained.

Chapter 6 reports on the results of evaluating the utility and usability of GeoFARA. First, the purpose of the evaluation is defined, focusing on making use of the utility and usability results to find out the issues of the current design solution for future improvement. The components of the evaluation methodology include the overview of the implementation of the evaluation methods, participants, materials and procedures, as well as of the data collection and data analysis. Responding to the defined evaluation goals, the evaluation results present the findings derived from the preliminary data analysis as well as their discussion.

Chapter 7 revisits the research questions, summarizes the important contributions and reflects this research, as well as recommends future research as an outlook. 
Chapter 2

Learning Geography with Visual Tools in

Geography Fieldwork 


\section{$2.1 \quad$ Introduction}

This chapter outlines the research context of this dissertation within the fields of visualization and geography fieldwork with a special focus on the role of visual tools in undergraduate geography fieldwork activities. Fieldwork teaching and learning are central to all levels of geography education, which cannot be replaced and duplicated by educational activities in the classroom. Visual tools, like maps which are deeply rooted within the geography domain, have a long history in assisting instructors' geographic teaching and learners' geographical comprehension of the real world. How those visual tools work so and how new visual potentials that brought about by recent technological, social and scientific developments, could be applied in future geography fieldwork will be discussed in this chapter.

Section 2.2 introduces the types, the stages, and the objectives of geography fieldwork in higher education (HE), a conceptual model of HE field education, and the fieldwork of this research. Section 2.3 addresses that how spatial cognition fits in geography fieldwork from a geographic perspective and how its application fits in the development of the new visual tool. Section 2.4 builds on literature review and an online survey to present the current use of visual tools and its influence in (human) geography fieldwork. Section 2.5 concludes with the focus of this research - the combined use of augmented reality (AR), a promising interface technology, with visualizations in a mobile application in geography fieldwork.

\subsection{Geography fieldwork in higher education}

Different disciplines can interpret the term 'fieldwork' differently. As the definition described by Lai (1999:8-9), apart from the educational activities adjunct to subjects such as geography, biology, 'fieldwork' can also refer to educational experience in practical situations and research techniques processes of data collection in qualitative research. In this research, fieldwork is interpreted in the context of field educational activities. In georelated domain, the feature of 'field-based' has an impact on how the characteristics and attributes of geography fieldwork are interpreted. Fieldwork for geography education means going out of classrooms to have real field geo-activities. This is in line with the definition given by Lonergan \& Andresen (1988) that fieldwork is "any arena or zone within a subject where, outside the constraints of the four walls classroom setting, supervised learning can take place via first-hand experience". Therefore, the common feature of geography fieldwork is that it is conducted outside the classroom through direct experience and immersion, using the fieldwork environment as a learning source to learn geography. The learning process in the field area is different from that in the conventional 
classroom. In addition to teachers' explanation, geography fieldwork provides students with an opportunity for learning by moving around in a real environment, making their own observations about geography features and spatial patterns, recording geographic information, and relating to theoretical concepts.

The literature on geography education indisputably asserts that fieldwork is an integral part in university-level geography just as it is perceived by Bland et al. (1996:165) that "geography without fieldwork is like science without experiments". The teaching inspection of UK (Her Majesty's Inspectors, 1992) recognized that HE geography fieldwork "greatly enhances students' understanding of geographical features and concepts, and allows students to develop specific as well as general skills”. This statement was confirmed by Boyle et al. (2007) who said it is a general consensus that "fieldwork is good" and by Hsu \& Chen (2010) who stated the understanding of geography would be incomplete without fieldwork.

In spite of the valuable pedagogic role of fieldwork in university geography education (Fuller, 2006; Wall \& Speake, 2012), as Wilson, Leydon, \& Wincentak (2017) pointed out recently that there is limited research on geography fieldwork in HE and a lack of integration of fieldwork into undergraduate geography degrees. Although this is an organizational problem, this $\mathrm{PhD}$ research will conduct a practical study within the domain of geography fieldwork, trying to address the questions of improving the gain of geographic knowledge through making use of assistance tools in university-level geography fieldwork.

\subsubsection{Types of geography fieldwork}

A fieldwork might incorporate a range of field teaching, field trips, field research (Dando \& Wiedel, 1971; Fuller, 2006). From the student viewpoint, Kent et al. (1997) proposed a two-dimensional framework to categorize fieldwork (Figure 2.1). In this framework, field activities are characterized by two continua: observation-participation and dependency-autonomy, thereby generating four different categories. Drawing on Kent et al.'s work, Panelli \& Welch (2005) and Herrick (2010) further defined the four fieldwork types: dependent observation fieldwork is the 'Cook's tour' where students experience passive observation with staff's guide; autonomous observation one is the 'self-guided trails' where students themselves define the parameters of their observations; dependent participation fieldwork is where students engage in more field activities, like data collection, the parameters of which are defined by staff (organizers); autonomous participation fieldwork is where students gain hands-on research experience through individual investigation or (and) group project. 
This classification has been widely applied in fieldwork of different subjects and their subfields, such as geography, biology. For example, some common fieldwork activities (Table 2.1) listed by Maskall \& Stokes (2008) in the environmental and natural sciences can fall into the spectrum of the above fieldwork classification. In Table 2.1, observation and recording of field phenomena and data in earth sciences, and observing the complexity of environmental systems in environmental sciences are typical observational fieldworks, while conducting surveys of human perception and behavior, and investigating human activities that impact on the environment are typical participatory fieldworks.

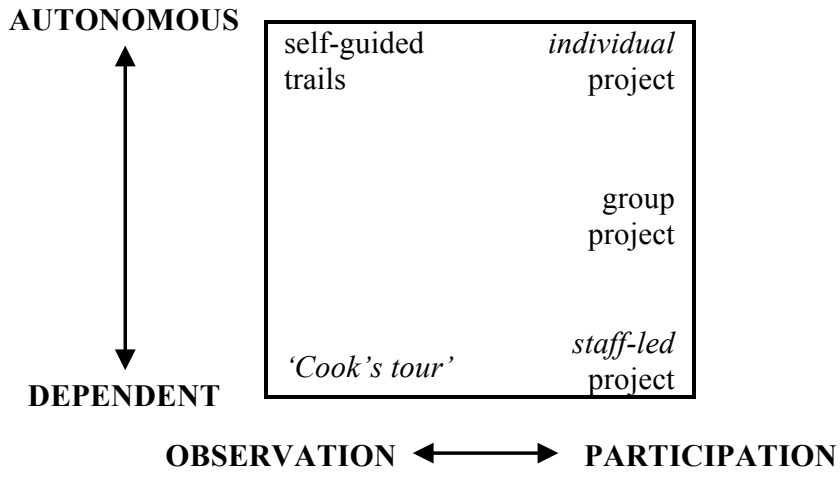

Figure 2.1 Categories of fieldwork (Redrawn from Kent et al. 1997)

Table 2.1 Typical fieldwork activities in the environmental and natural sciences (From Maskall \& Stokes, 2008)

\begin{tabular}{|c|c|}
\hline Disciplines & Field activities \\
\hline Earth sciences & $\begin{array}{l}\text { - Observation and recording of field phenomena and data } \\
\text { - Field description of rocks } \\
\text { - Lithostratigraphic logging } \\
\text { - Equipment-based studies (e.g. geophysical surveys) } \\
\text { - Geological mapping }\end{array}$ \\
\hline Environmental sciences & $\begin{array}{l}\text { - Field survey techniques } \\
\text { - Monitoring environmental quality using portable instrument } \\
\text { - Observing the complexity of environmental systems } \\
\text { - Investigating human activities that impact on the environment }\end{array}$ \\
\hline Geographical sciences & $\begin{array}{l}\text { - Gathering data to investigate spatial patterns and processes } \\
\text { - Conducting surveys of human perception and behavior } \\
\text { - Sampling biophysical characteristics of the landscape } \\
\text { - Relating sample data to wider patterns in the landscape }\end{array}$ \\
\hline
\end{tabular}


In general, one fieldwork could comprise multiple kinds of field activities. However, as argued by Jarvis et al. (2016), within this fieldwork classification, there is a lack of reflections to incorporate the role of using assistance tools like technology while technological elements have been increasingly integrated in fieldwork teaching-learning processes. Responding to this situation, this research addresses the use of technology in fieldwork activities.

Aside from the perspective of student field activity's characteristics, the mode of fieldwork, according to Butler (2008), can be variable depending on the duration and location(s). The duration of fieldwork varies from a single-day at a local area to short residential or longer residential trip at non-local areas or even virtual fieldwork without going to real environment.

I. Non-residential fieldwork. This kind of fieldwork, which is usually completed within one day or less, is useful for learning the local environment within a local area. Nonresidential fieldwork may include collecting samples, such as local river waters, or visiting sites to enhance theory concepts, such as the attribution pattern of the local city (Butler, 2008). In this research, the upcoming geography fieldwork will be this nonresidential option in local areas.

II. Residential fieldwork. Residential fieldwork is carried out beyond the reach of home institution and at non-local areas which have some typical geographical features. It can be a short weekend or a long residential abroad fieldwork (Butler, 2008).

III. Virtual fieldwork. The assistance of visualization hardware and software have given rise of virtual fieldwork. It is seen as a way to support and enhance real fieldwork, but not to replace the real field trips (Butler, 2008; Stainfield et al., 2000). But this research focuses on non-virtual fieldwork instead of virtual fieldwork.

Geography science, a discipline with many branches, is broad, so is geography fieldwork. From the perspective of geography's major sub-disciplines (physical and human geography), there are physical-oriented geography fieldwork and human-oriented geography fieldwork.

I. Physical-oriented geography fieldwork. Within the context of physical geography disciplines in HE, fieldwork provides an opportunity to study and investigate practical aspects of various physical-oriented geographical subjects such as hydrology, geomorphology, geology, biogeography. For instance, hydrology fieldwork could involve activities of teaching and learning hydrological processes of a river, investigating effects of location and environment on the river water. In this research, the fieldwork 
theme will not be related with physical geography, instead, it will focus on the following human-oriented geography.

II. Human-oriented geography fieldwork. Human-oriented geography fieldwork mainly includes fieldwork of its sub-fields, such as economic, cultural, historical, political, urban geography. It deals with practical aspects of geographical environments of human, such as land use, economies, cultural aspects. As indicated above, here this $\mathrm{PhD}$ research is restricted to the fieldwork of human-oriented geography, more specifically, the sub-field of urban geography that studies the attributes (e.g., structures, functions, evolutions) of urban places (towns and cities) from geographic perspectives.

\subsubsection{Objectives of geography fieldwork}

“Fieldwork is purposive; it's done for a reason." (Jackson, 1987:20). Education has multiple objectives, and so is fieldwork education. Empirical and theoretical studies have identified a range of fieldwork objectives in general (e.g., knowledge objectives, skill objectives, attitude objectives) and fieldwork objectives specific to geography (see e.g. Boardman, 1974; Lonergan \& Andresen, 1988; Gold, 1991; Kent et al., 1997; Royal Geographical Society (RGS) of UK, 2009). The early research done by Boardman (1974) who studied how geography teachers perceived fieldwork objectives provides valuable insights into perspectives of examining geography fieldwork objectives. Boardman (1974:160) identified 30 different objectives in the aspects of knowledge (e.g. "to comprehend in the field concepts learnt in the classroom"), skills (e.g. "to orientate a map in the field"), and attitudes (e.g. "to enjoy the study of geography and acquire a deeper interest in this subject”). Based on this early study, more geography-oriented researchers/associations have discussed and summarized the objectives of geography fieldwork, some of which are briefly listed in Table 2.2. Of particular relevance to this research is the knowledge, or cognitive objectives, which are described in Section 2.2.5.

It should be noted that geography fieldwork objectives change over time because georelated disciplines and their paradigms are dynamic. For example, nowadays, objectives of developing geographic information system (GIS) and mobile learning technology skills should be taken into consideration. However, as argued by Munowenyu (2006), despite the dynamic change of objectives, map-related objectives should not change and should be important in teaching/learning geography particularly in the field. From both the dynamic and static standpoints, this research, therefore, is upon field teaching and learning geography that are enabled by the combined use of the latest technological potentials and maps. 
Table 2.2 Summary of different perspectives of objectives of geography fieldwork

\begin{tabular}{ll}
\hline Researchers/Associations & Objectives of geography fieldwork \\
\hline & Acquisition of practical/ methodological skills \\
& Acquisition of knowledge \\
Lonergan \& Andresen & Social growth \\
(1988), Lai (1999) & Application and consolidation of learning \\
& Deepening conceptual development \\
& Appraisal and adoption of attitudes and values \\
\hline & Developing observation skills \\
& Facilitating experiential learning \\
& Encouraging students to be responsible for their own learning \\
& Developing analytical skills \\
& Experiencing real research \\
Gold (1991) & Developing a respect for the environment \\
& Subject-specific objectives \\
& Transferable/enterprise skills \\
& Socialization and personal development \\
\hline \multirow{3}{*}{ Kent et al. (1997) } & Gaining knowledge of geographical processes, landforms \\
& Proficiency in data acquisition and analysis \\
& Creating awareness and appreciation of environments \\
& Appreciation and care of the field environment \\
& Personal, learning and thinking skills \\
\hline &
\end{tabular}

\subsubsection{Stages of geography fieldwork}

No matter what type of a fieldwork is, it would be impossible to carry out a complete fieldwork by just going to the real field. Generally, fieldwork consists of three linked stages: stages of pre-fieldwork, during-fieldwork and post-fieldwork. In fact, in the book Geography Teacher's Guide to the Classroom, a guide of geography field education written by Laws (1990), gives a clear picture of these three stages and their main tasks from both the perspectives of teachers and students (Table 2.3). In addition, considerable scientific publications and HE fieldwork practical cases have also demonstrated the three stages of (geography) fieldwork (see e.g., Maskall \& Stokes, 2008; Hsu \& Chen, 2010; Jarvis et al., 2016). This research will also address the use of the visual tools in these three stages.

Pre-fieldwork. Making preparations for the fieldwork is important and it significantly impacts the benefits gained from the fieldwork (Lonergan \& Andresen 1988). Here, it is worth mentioning that students' familiarization with hardware and software is an absolute necessity to ensure the effective continuation of fieldwork and to avoid any potential cogitative load. 
Table 2.3 Three stages of geography fieldwork (From Laws, 1990)

\begin{tabular}{|c|c|c|}
\hline Stage & Group & Main tasks \\
\hline \multirow[t]{2}{*}{ Pre- } & Teachers & $\begin{array}{l}\text { - Determine the processes of fieldwork. } \\
\text { - Revise essential pre-requisite knowledge and skills. } \\
\text { - Follow all official requirements. } \\
\text { - Inform students and parents of purposes, costs, } \\
\text { arrangements. } \\
\text { - Book site and transport. } \\
\text { - Visit site and plan activities. } \\
\text { - Brief guest speakers. } \\
\text { - Complete risk analysis matrix. } \\
\text { - Compile a list of student names and emergency contact } \\
\text { numbers. }\end{array}$ \\
\hline & Students & $\begin{array}{l}\text { - Be aware of the purposes of fieldwork } \\
\text { - Develop prerequisite knowledge and skills. } \\
\text { - Practice data collection techniques. } \\
\text { - Know group and personal responsibilities. } \\
\text { - Be aware of arrangements and necessary materials and } \\
\text { - equipment. } \\
\text { - Understand safety requirements. }\end{array}$ \\
\hline \multirow[b]{2}{*}{ During- } & Teachers & $\begin{array}{l}\text { - General supervision. } \\
\text { - Provide assistance when required. } \\
\text { - Encourage students to be analytical by raising questions }\end{array}$ \\
\hline & Students & $\begin{array}{l}\text { - Make direct observations e.g. identifying, describing, } \\
\text { measuring etc. } \\
\text { - Collect and record data. } \\
\text { - Use specific field techniques e.g. mapping, etc. } \\
\text { - Make initial analysis and interpretations. } \\
\text { - Be aware of their own and other people's perceptions. }\end{array}$ \\
\hline \multirow[t]{2}{*}{ Post- } & Teachers & $\begin{array}{l}\text { - Provide additional information as required. } \\
\text { - Direct students to other resources to confirm their } \\
\text { findings. } \\
\text { - Evaluate the complete experience }\end{array}$ \\
\hline & Students & $\begin{array}{l}\text { - Organizing information collected. } \\
\text { - Check findings with others. } \\
\text { - Test hypotheses. } \\
\text { - Make generalizations. } \\
\text { - Discuss puzzling issues with others. } \\
\text { - Research unanswered questions. } \\
\text { - Prepare reports and presentations. }\end{array}$ \\
\hline
\end{tabular}


During-fieldwork. Actual hands-on activities in the field are the main component of the whole fieldwork for both the teachers and the students. The overview in Table 2.3 shows a general during-fieldwork stage. Geo-specifically, Table 2.1 lists field activities related with geography fieldwork. Generally, if fieldwork makes use of modern technology and equipment, such as GPS, digital cameras, mobile devices, portable computers, they are used to support and facilitate the activities during this execution stage.

Post-fieldwork. Back from the field, the follow-up stage is also essential for the completeness of fieldwork. For students, normally, they need to make use of the field collected data to write a fieldwork report and reflect the whole fieldwork process individually and (or) in group work.

\subsubsection{A conceptual model of field education}

The above sections describe separately the basic aspects of (geography) fieldwork. However, to organize a fieldwork for this research, it is essential to connect these elements. Israel (2009) did so by developing a conceptual model for field education. In the conceptual model (Figure 2.2), there are two parts: spatial dynamics and student experiences, determining field settings and field activities, respectively. Each of them consists of four dimensions with spatial dynamics being described by venue, mode of inhabitation, range of movements, and character of boundaries (Figure 2.2, left), while student experiences being illustrated by duration, structure of activities, mode of interaction, and impact (Figure 2.2, right).

SPATIAL DYNAMICS

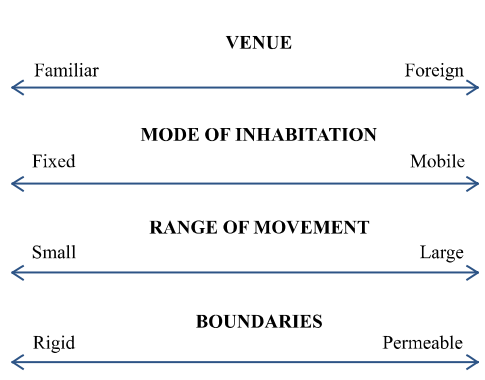

STUDENT EXPERIENCES

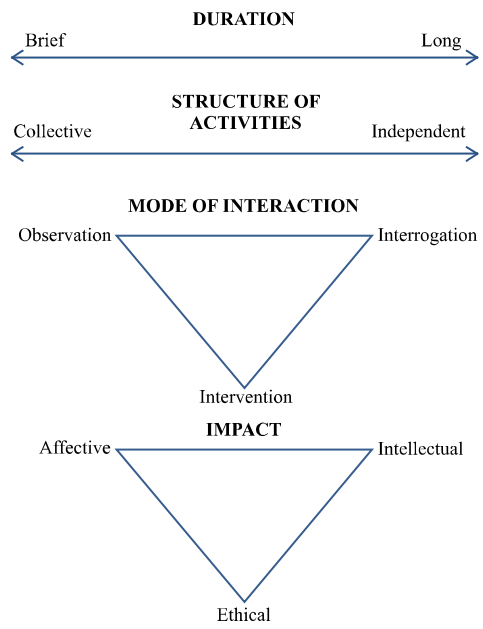

Figure 2.2 Israel's (2009) conceptual model of field education (Redrawn from Israel, 2009) 
According to Israel (2009), any field education program can be categorized in this conceptual model. But we argue that there is a lack of incorporation of using technology, which is similar to the lack of the role of technology in Kent et al.'s (1997) fieldwork classification. Here, therefore a dimension of technology usage (Figure 2.3) that is depicted in a continuum from free to substitutive is added to the aspect of student experiences within Israel's conceptual model. Moreover, for geography fieldwork, to give field settings more detailed descriptions, a dimension of theme (Figure 2.4) from physicaloriented to human-oriented geography is included in spatial dynamics. With the additional dimensions of technology usage and theme, an adjusted conceptual model encompassing ten dimensions (Figure 2.5) is applied to explain the fieldwork of this research.

\section{TECHNOLOGY USAGE}

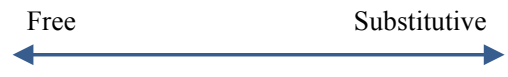

Figure 2.3 An added dimension (technology usage) to Israel's (2009) conceptual model of field education

\section{THEME}

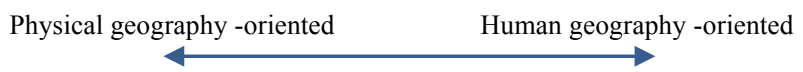

Figure 2.4 An added dimension (theme) to Israel's (2009) conceptual model of field education

\begin{tabular}{|ll|}
\hline \multicolumn{2}{|c|}{ Dimensions of Field Education } \\
Spatial Dynamics: & Student Experiences: \\
Venue & Duration \\
Mode of Inhabitation & Structure of Activities \\
Range of Movements & Mode of Interaction \\
Character of Boundaries & Impact \\
Theme & Technology Usage \\
\hline
\end{tabular}

Figure 2.5 The ten dimensions of the adjusted conceptual model based on Israel's (2009) conceptual model of field education

\subsubsection{Fieldwork of this research - urban geography fieldwork}

As indicated above, the fieldwork that this research focuses on is urban geography fieldwork in HE. And again, the scope and nature of urban geography itself is broad, as illustrated in Figure 2.6 from the book Urban Geography: A Global Perspective by Pacione (2009:19). However, the emphasis of urban geography should be the analysis of 
urban form and arrangement, and understanding the dynamic and changing structure of cities over space and time (Carter, 1995; Hall \& Barrett, 2012; Clark, 2013). Hall \& Barrett (2012) pointed out that the outcome of urban structure is complex historical forces, and the key structures are associated with industrial-related factors. Drawing inspiration from this, the urban geography fieldwork in this research will be examining the industrial factors on the spatial structure of an urban area in the scale of a city level. Figure 6.5 shows the case study area of this research.

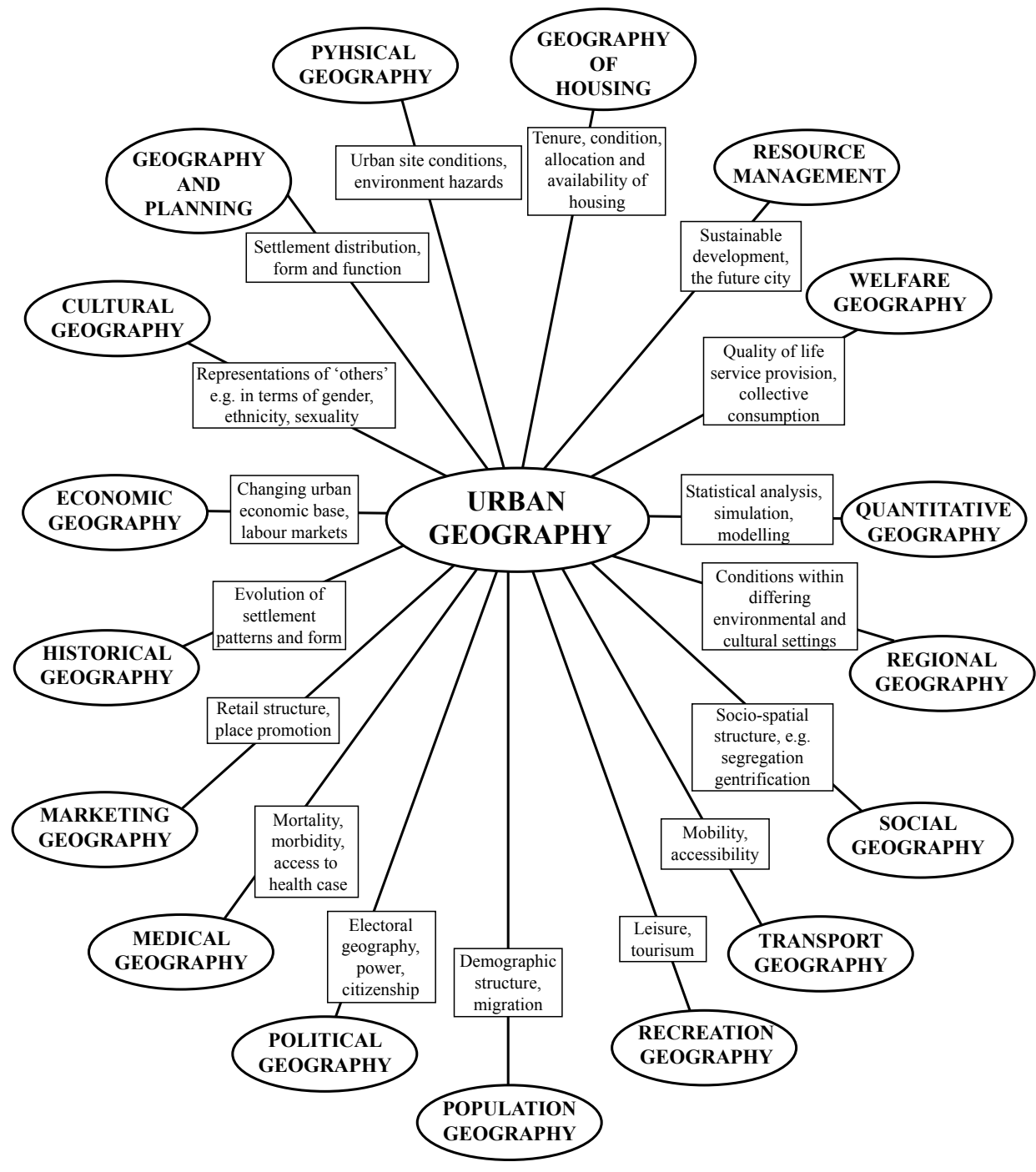

Figure 2.6 The nature of urban geography (Redrawn from Pacione, 2009:19) 
Applying the adjusted conceptual model of field education in Section 2.2.4, the urban geography fieldwork of this research can be characterized by the ten dimensions as shown in Figure 2.7. Under the human geography -oriented theme, the field setting is in a small area named Schuttersveld (Dutch) in the city of Enschede (the Netherlands). The spatial structure of this area (even a large part of the city) is very much influenced by its industrial history (the former textile industry has already largely collapsed, but still with quite some visible remnants, as well as some relatively new developments). The fieldwork area is presented in Chapter 6 as Figure 6.5, the clear boundary of which is formed by the red polygon. As such, the venue is relatively familiar environment and the mode of inhabitation is spatially-fixed which means returning to the starting point within a duration of a few hours after limited spatial range of movements. In addition, in terms of structure of activities and mode of interaction, the learners will mainly independently conduct their own direct field observations. The intended impact is on the intellectual aspect-improving spatial cognition (focusing on the intellectual impact), which will be further explained in next section. During the three stages of the whole fieldwork, technology usage will play a supportive role.

\section{SPATIAL DYNAMICS}

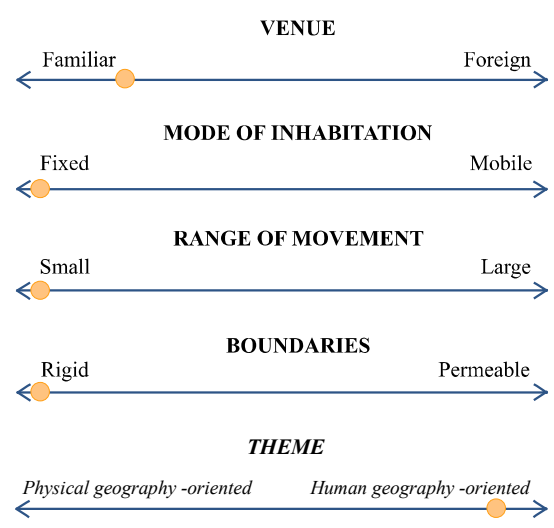

\section{STUDENT EXPERIENCES}

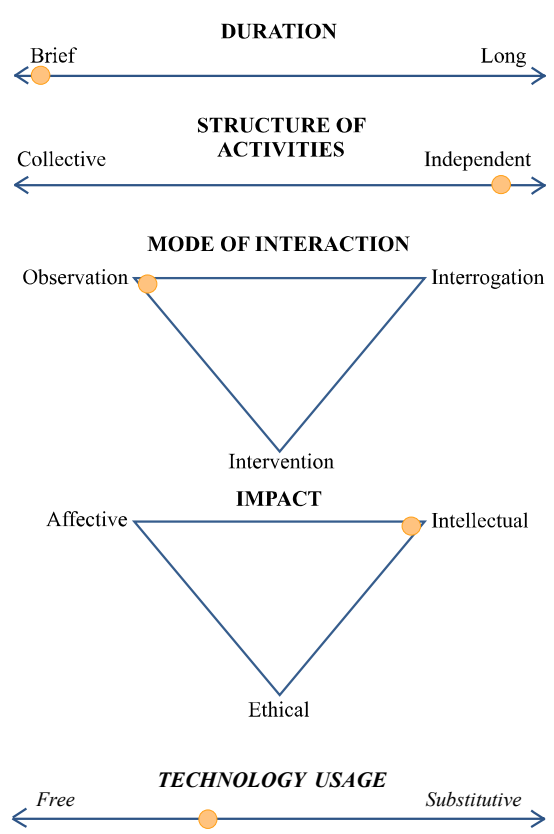

Figure 2.7 The geography fieldwork of this research in the adjusted conceptual model of field education 


\subsection{Spatial cognition in the field: A geographical perspective}

Spatial cognition refers to the processes of spatial information acquisition, storage and retrieval, manipulation, and use by humans, animals or even intelligent machines (Montello, 2001:14771). Human spatial cognition is such mental processes through multiple senses (vision, audition, etc.), forming a mental image of the physical, built, and cultural environment in brain, as illustrated by Golledge \& Stimson (1997:191) in Figure 2.8. Over the past centuries, many disciplines, such as psychology, geography, cartography, architecture, computer and information science, study (human) spatial cognition with different focuses and through different methodologies. In fact, the study of spatial cognition in the broad geography domain first appeared in geography education (Montello, 2001:14772), and then followed by cartography, behavioral geography and more recently GIS. According to Golledge (1993), spatial cognition from geographical perspectives emphases human cognition of spatial patterns of specific geographic features at scales ranging from a small cell to the whole earth surface. This occurs at many occasions, especially in a real outdoor space, such as during purpose-driven geography fieldwork. The exploration of the industrial factors on the structure of an urban area during the fieldwork of this research can fall into the spectrum of spatial cognition from geographic perspectives at the scale of the fieldwork area, which makes this research connect to spatial cognition.

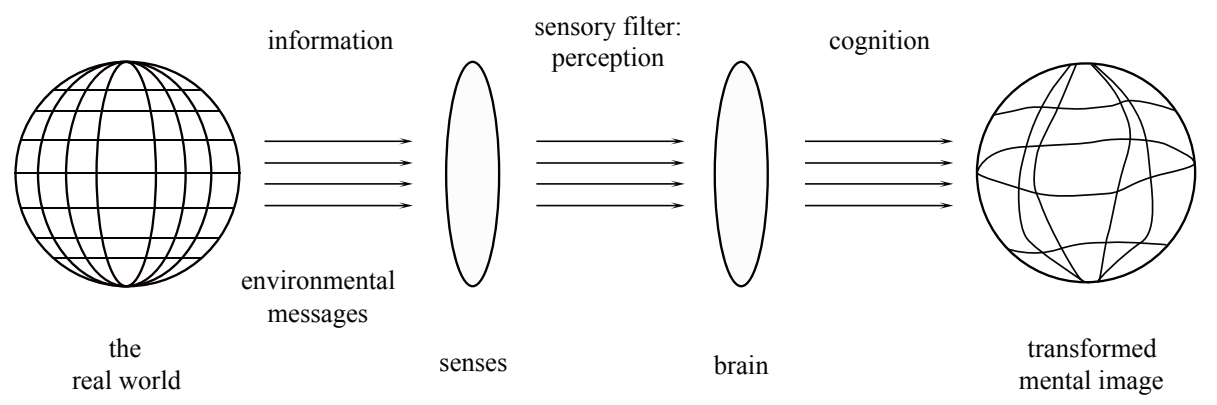

Figure 2.8 The formation of images

(Redrawn from Golledge \& Stimson, 1997:191)

Spatial cognition is built through human senses in different ways, such as via the direct experience of exposure to the fieldwork area in this research. In fact, as concluded by Foulke (1983), learning the geographical environment is believed to be almost only based on the visual experience of human. Undoubtedly, visual experience can be elevated by visual display tools such as all kinds of visualizations (e.g. maps and graphics), and visual extension technologies such as AR and virtual reality (VR). And there are potentials that 
both visual display and visual extension technologies can work together to extend human perception of spatial dimensions (Figure 2.9), especially in geography discipline which is naturally visual and heavily relied on geographical information representations. This research is an attempt to connect both the elements of visual display and visual expansion into one learning tool to promote spatial cognition during the fieldwork.
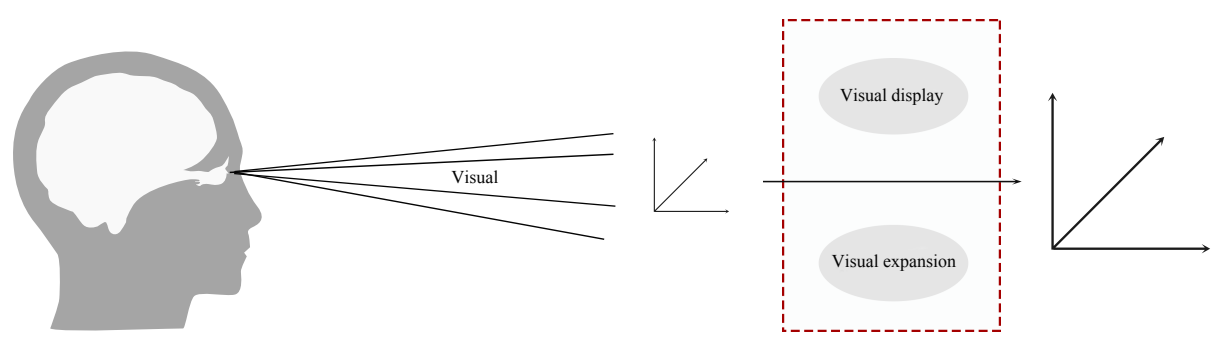

Figure 2.9 The elements of visual display and visual expansion in spatial cognition

Aside from the cognitive purposes of the fieldwork which relate to spatial cognition, another reason for taking spatial cognition into consideration is its practical applications. Montello \& Raubal (2013) have provided an overview of some important applications of spatial cognition research as shown in Table 2.4. Amongst these six important application areas, four of them (labeled in bold in Table 2.4) are closely related to this research. More specifically, fieldwork itself includes typical location-based activities, and spatial cognition during fieldwork requires location-specific geographic and other information of the surrounding. On one hand, location-based services (LBS), and geographic and other information systems can provide geo-information for fieldwork, and further support the completion of the fieldwork tasks. Research about location-based spatial cognition with an assisting tool, on the other hand, can contribute to developing better such services and systems with optimal usability for a specific purpose. Furthermore, all LBS, GIS and other information systems, in general, involve information display. To display more effective information in more efficient ways, understanding how individuals build spatial cognition through interacting with such information may help. For instance, spatial cognition during the fieldwork from a geographic perspective in this research can potentially contribute to providing guidelines of what information should be displayed and how to display it to better support spatial cognition. Regarding the spatial education in Table 2.4, geography fieldwork itself is a spatial education setting. Research on spatial cognition during the fieldwork can help to know how to improve the education program through evaluating the change of individual's spatial cognition, which can be further applied in spatially intensive academic disciplines such as geography and mathematics or even nonacademic occupations such as taxi drivers (Montello \& Raubal, 2013). In sum, it is expected that spatial cognition research in this dissertation would contribute to the application areas of Table 2.4 and beyond. 
Table 2.4 Some important applications of spatial cognition

(From Montello \& Raubal, 2013)

1. Location-based services

2. Geographic and other information systems

3. Information display

4. Architecture and planning

5. Personnel selection

6. Spatial education

\subsection{The use of visual tools in geography fieldwork}

Visual is defined by oxford English dictionary in several ways, of which the most relevant to this research are "of or pertaining to seeing" and "of or involving the use of displayed pictures, maps, etc. for education or informative purposes". Under this definition, in the context of scientific education, visual tools play an important role to aid understanding through graphically representing data, information, scientific phenomena and concepts in paper or digital forms. Such graphically representing processes are so called 'visualize' with the end products - visualizations. Geography is typical visual domain, with a particular need of making complex geographical data and patterns become geographic visualizations (or geovisualizations). Geovisualizations are very broad. For instance, a geovisualization can be a simple sketch or painting depicting the surroundings, any forms of maps, three-dimensional models illustrating regional landscapes, etc. Cartography, the art and science of map-making, has evolved over time and it provides geovisualizations with cartographic principles (Nöllenburg, 2007), which then introduce cartographic visualizations. For the past two decades, growing emphasis has been given to discussing links between visualizations and cartography (see e.g. MacEachren \& Taylor's (1994; 2013) books - Visualization in Modern Cartography). Moreover, the developments of emerging display technologies and digital devices drive the integration of technologies in cartographic visualizations on new platforms, which inspires the perspective of using a new visual tool in the scientific educational context such as geography fieldwork in this research.

However, a range of questions remains unanswered about how to optimally utilize an upto-date visualization tool in geography fieldwork in order to enhance cognition. To a significant extent, the relation between knowledge acquisition and scientific tools has long been an issue in the philosophy of technology and the philosophy of science over recent decades (Madsen \& Rump, 2012). To find out how to use a new visual tool in fieldwork, firstly, we need to know the current situation of the use of visual tools in geography fieldwork, especially in human geography fieldwork. This research addresses such a situation through two aspects: a secondary source analysis of examples of 
visualizations used in human geography fieldwork, and an online survey of the current use of various kinds of information and communications technologies (ICTs) and visualizations in different stages of undergraduate human geography fieldwork.

\subsubsection{A brief summary of visualization tools in human geography field work}

Whilst geography education makes use of all forms of tools, arguably the greatest use is the primary geographic/cartographic visualization tool-maps, especially in outdoor settings (Figure 2.10). In many cases of geography fieldwork, it is relatively easy to find that the use of visualization tools is not limited to maps, but includes many others. Nevertheless, at the time of writing, those visualization tools that are implemented in geography fieldwork have seldom been summarized yet. Making use of available secondary sources, here is an attempt to list the visualization tools used in geography fieldwork. These sources include published scientific papers and books, geography fieldwork instruction materials, websites, textbooks, etc. The secondary source analysis shows that the range of the visualization tools is widespread, and the following examples are the major ones.

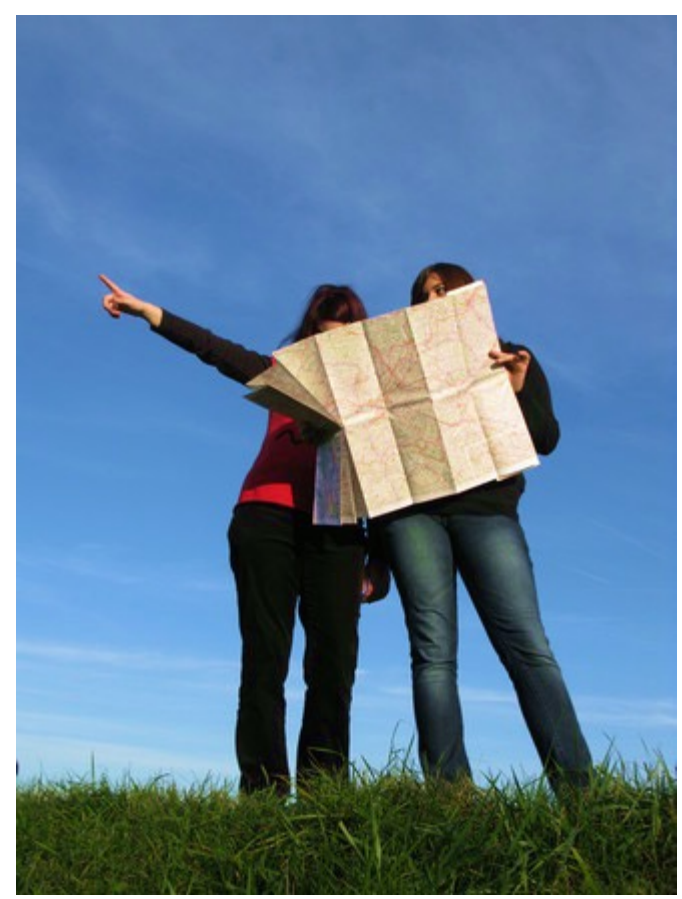

Figure 2.10 Relating the map to the surroundings (Originally from freeimages.com (URL2), obtained from Haklay, 2010:28) 


\section{Maps (Atlases)}

The use of maps/atlases has a long history in educational geography fieldwork. But geography fieldwork does not only make use of printed or photocopied maps, but also employs digital maps such as Google Maps on electronic platforms. And there are many ways in which these maps can help geography fieldwork. Quite a number of existing cases involving the use of maps can be found in secondary sources.

Before going to the fieldwork area, generally, instructors employ (annotated) maps to give students a brief introduction about the geographic background of the fieldwork area, the forthcoming fieldtrip sites, routes and areas, and fieldwork tasks. For example, Google Maps labelled with the main fieldtrip destinations were used during the GeoJourney (URL3) in the fieldwork case of Elkins \& Elkins (2006) as in Figure 2.11.

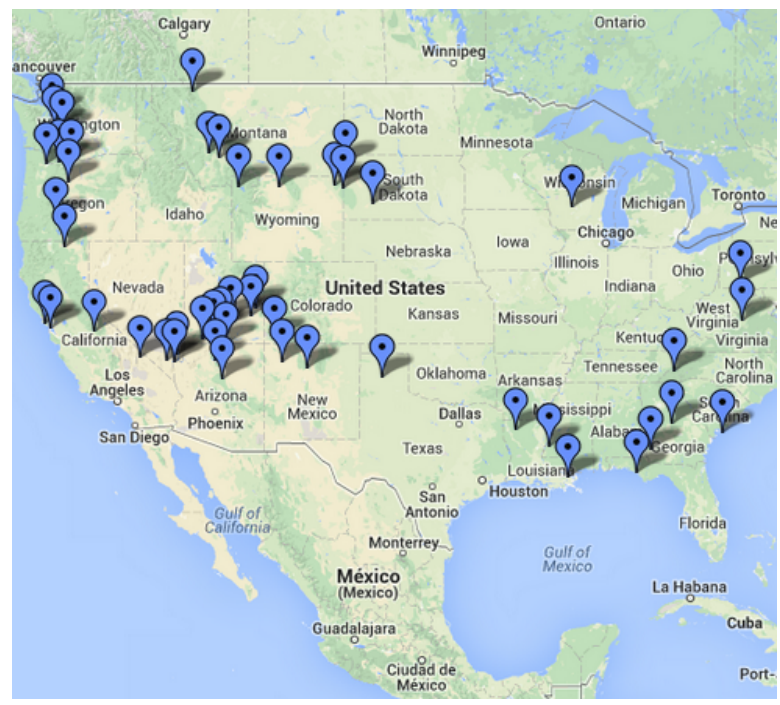

Figure 2.11 An example of maps used to show the upcoming fieldtrip sites during preparation stage

(Obtained from Elkins \& Elkins, 2006)

During the stage in the field, maps are used as a medium to support students to collect data and to reflect on geographic issues in the field. In human geography fieldwork, there are examples of labeling key streets of the fieldwork area on the city map (Rice \& Bulman, 2001:75), land use surveying with the help of historical land use maps and topographic maps (Field et al., 2005). More recently, researchers O'Brien \& Field (2013) used social media (Twitter) and maps (OpenStreetMap (OSM)) together to support students' collaborative land use mapping activities during the geography fieldwork (as shown in Figure 2.12). 


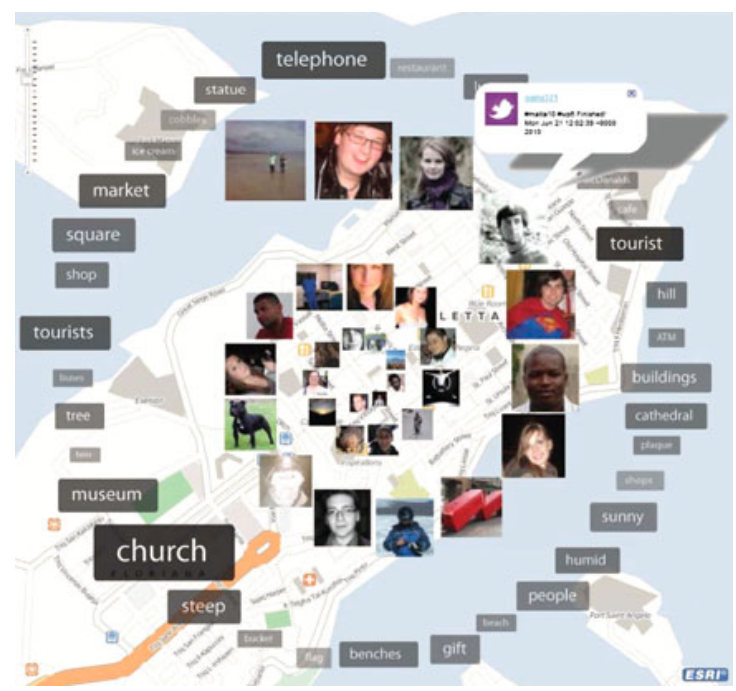

Figure 2.12 An example of maps used during the actual fieldwork stage to support conducting tasks

(Obtained from O’Brien \& Field, 2013)

Coming back from the field, students report and communicate what they have learned. Therefore, after the actual fieldwork, maps are commonly used as base layers by students to present their findings and results by adding collected data (Favier \& van der Schee, 2009; Walcott, 1999). For example, in the study conducted by Favier \& van der Schee (2009), students produced their own maps in ArcGIS (Figure 2.13) with the themes of car traffic patterns and traffic accidents in the field area to present the field exploration results.
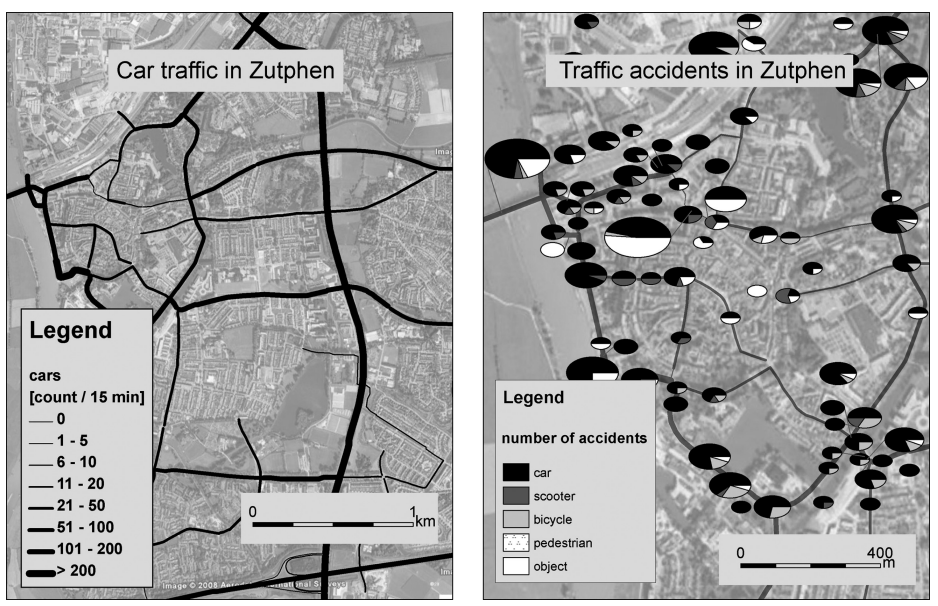

Figure 2.13 An example of maps used after fieldwork to show the fieldwork results (Obtained from Favier \& van der Schee, 2009) 


\section{Photographs and aerial images}

Photographs and aerial images (or satellite images) represent different scales of the surface of the earth. In recent years, digital photos and aerial images are increasingly available for educational uses. There are a number of examples of how photographs are used in human geography fieldwork. For instance, the fieldwork organized by Smith et al. (2000) used both historical photos and new photos of a particular fieldwork plot to construct "temporal chains", helping students to build new insights into the cultural, architectural, and social changes of the field place. Another example of using photos in human geography fieldwork is that students use selected photos (that are taken in the implementation phase of the fieldwork) about human geographic features of the field place to finish the follow-up tasks (Latham \& Mccormack, 2007; Skavhaug \& Andersen, 2013). Moreover, the availability of Internet connections and mobile devices with GPS brings about the technology of geotagging, which empowers users to geotag photographs. For example, Welsh et al. (2012) used geotagged photographs (Figure 2.14) in Flickr within a human geography field project, with the purpose of promoting students' postfieldwork reflection, during which the location information of the photographs acts as a reminder. From Welsh et al.'s field project and beyond (e.g. Hsu \& Chen, 2010), it could be concluded that maps and photographs are sometimes used together in geography fieldwork to enhance visual aids.

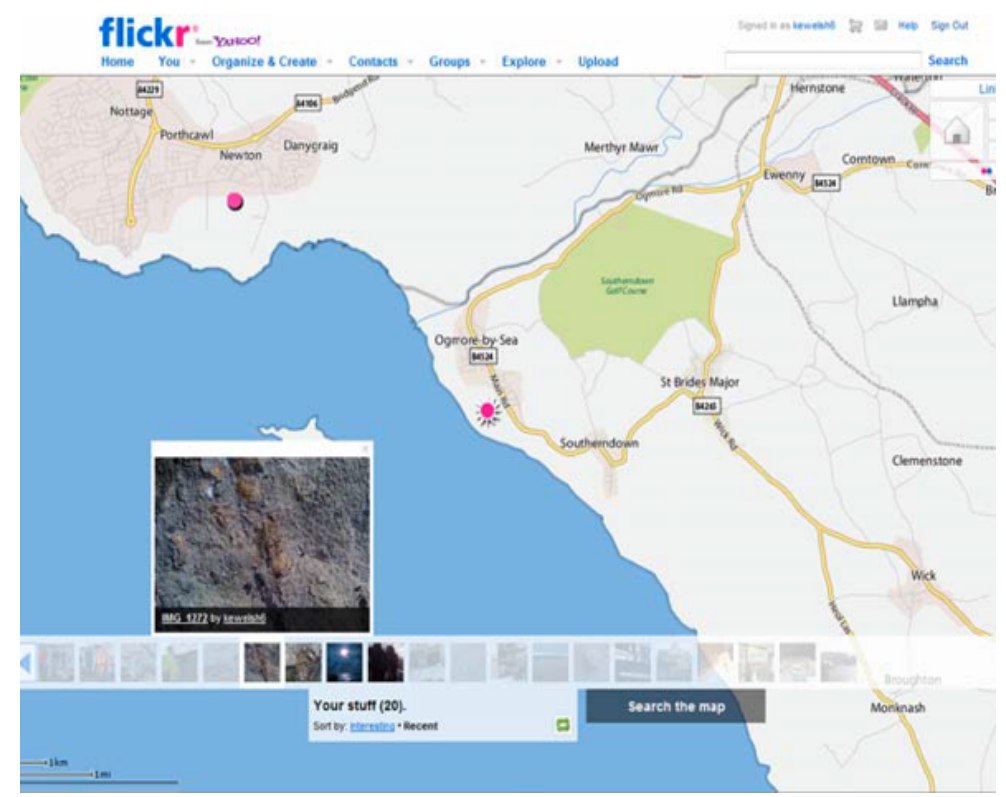

Figure 2.14 An example of photos used in a human geography fieldwork (Obtained from Welsh et al., 2012) 


\section{Videos}

Videos expose all spatial dimensions of reality. However, compared to the use of maps, photos and satellite images in geography fieldwork, less publications and fieldwork cases have addressed the use of videos in geography fieldwork. Amidst those few cases and research, videos are used in two ways: existing videos for basic orientation before going to the field, and recording videos during the actual geography fieldwork.

In the case of Elkins \& Elkins (2006), several videos showing the landscape of the field area and along the fieldwork route were used before the real fieldwork (Figure 2.15). For the stages of during- and after-fieldwork, for example, in the research of Latham \& McCormack (2007), students used video clips to capture the dynamic sense of movement within the urban environment; the work of Dando \& Chadwick (2014) gives an example that students created well-rounded cultural landscape visualizations as films. All these forms of videos, used in different stages of fieldwork, proved to be useful in recording and shaping the geography imagination of the fieldwork places.

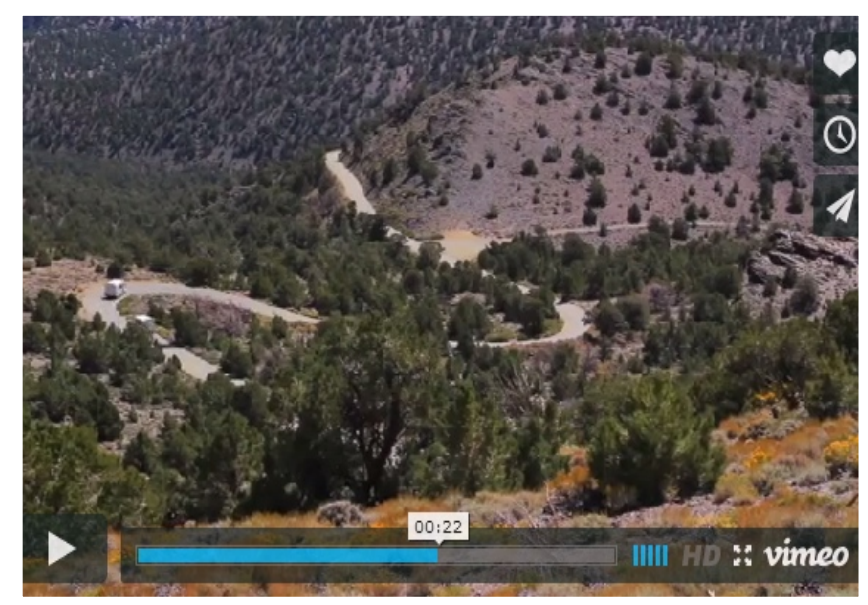

Figure 2.15 An example of videos used in geography fieldwork (Obtained from Elkins \& Elkins, 2006)

\section{Virtual Reality}

In the field of geography, virtual reality (VR) is a tool for representing geographical space (both the physical and human landscape) through human-computer interfaces. It enables different levels of interactions between users and representations. Virtual reality of the actual field could be used for geography fieldwork education as an alternative platform. Pre-fieldwork virtual tours through virtual reality help students get familiar with the field sites, which is the same as the reasons of using almost any visualizations for preparation. 
There are cases of the use of virtual reality for geography fieldwork in, for instance, the research papers of Dykes et al. (1999) and Stott et al. (2014). The virtual reality developed by Dykes et al. (1999) (Figure 2.16) was also used in the actual urban fieldwork stage to collect data for building an urban land use model. Overall, from the existing literature, we discover that VR, be it web-based or desktop-based, was used more often in physical fieldwork than in human geography fieldwork.

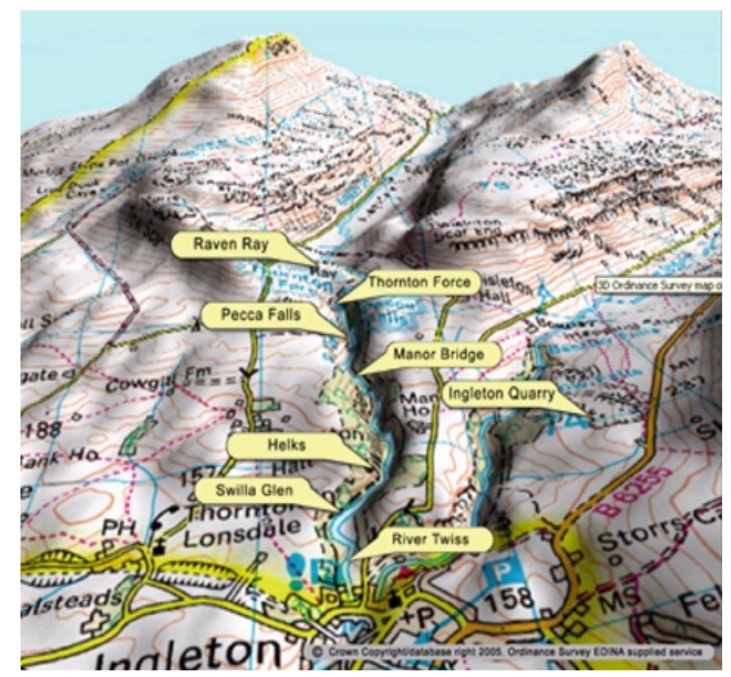

Figure 2.16 An example of virtual reality used in geography fieldwork (Obtained from Dykes et al. 1999)

\section{Other visual tools}

With the rise of using portable digital devices such as smartphones, tablets in field learning, other than the above visualizations tools, some customized integrated systems or applications have been developed and utilized in geography fieldwork as well. Such tools are usually relied on GPS and other mobile sensors such as camera to support location-based fieldwork. Of course, how instructors and students use the developed visual tool very much depends on the objectives and tasks of the fieldwork.

From secondary source analysis it appeared that there are some cases of using personalized visual tools in (human) geography fieldwork. For example, iGeology (URL4), mySoil (URL5), Fieldtrip GB (URL6), developed by organizations, are mobile visual applications that are available for special fieldwork use in special areas. Personalized visual tools can also be found in research papers to support geography fieldwork. For example, NIEmGeo (Chatterjea, 2012) is a mobile application to facilitate collaborative, geo-referenced data collection and post-field data analysis and spatial 
mapping for field-based learning and research; EagleEye (Jong, 2015) is an "integrated outdoor exploratory educational system for supporting field trip activities in geography education"; TerraMobile (Ferreira et al., 2015) is a mobile application for "geographical data gathering and validation in fieldwork". To a certain extent, the functionalities of those tools reflect that the main purpose is to support fieldwork activities in terms of data collection. However, at the time of writing, till now, few such mobile applications have been applied particularly in human geography fieldwork. Only more recently, Jarvis et al. (2016) explored mobile learning on smartphones in undergraduate human geography through making use of a location-based digital mobile visual tool-Mediascape-which can visualize and integrate theoretical urban geographical concepts in new ways.

\subsubsection{Online survey: The use of visualization tools in geography fieldwork}

As a complement of the secondary source analysis, this section presents the results of an online survey on the use of ICTs and visualization tools in real undergraduate human geography fieldwork programs from the perspective of the instructors of the fieldwork. The survey, which was executed around the year of 2014-2015 through Survey Monkey (URL7) (Appendix 1 is the complete survey). The core part of this survey were questions about: what kinds of visualization tool are currently in use before, during and after geography fieldwork; what are the main reasons of using them; what problems have been encountered when using them; which visualization tools would be interested in using in the future. The invitation of this survey was sent through emails to approximately 80 human geography fieldwork leaders as well as several authors of geography-fieldworkrelated published papers. In the end, there were 40 respondents and 34 of them answered that they have ever been involved in or carried out a human geography fieldwork and then they were continually exposed to the rest of the survey. But, regrettably, the response rates of most subsequent questions were around $50 \%$.

The survey results demonstrated that the human geography fieldtrips, part of a human geography course, were conducted both in urban and rural areas. The objectives were different. From the 17 responses on this question, more than half was learning-oriented, and the themes of land use, relation between nature and human beings, and human life ranked on the top three.

Among the 18 responses, half of the teachers stated that they made use of all kinds of ICTs (desktop computers, digital cameras, laptops, GPS, GIS, etc.). Figure 2.17 shows that different visualizations (12 types in total) were used in the three stages of human geography fieldwork, and those visualizations that the teachers were interested to use in the future. 

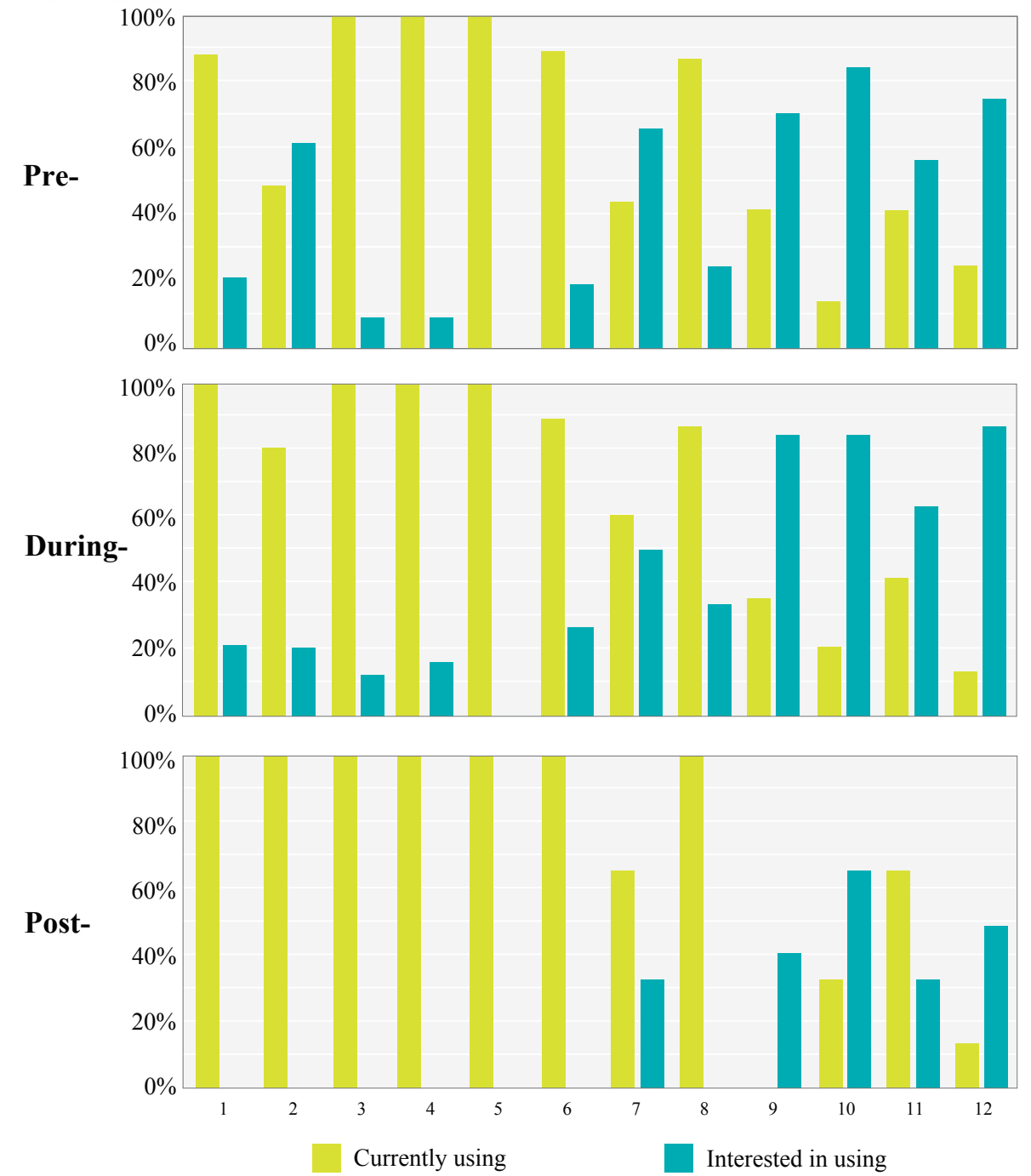

$1=$ Photos of reality (landscape photos, aerial images, sketches, etc.)

$2=$ Videos of reality (e.g., of the landsape of the fieldwork area)

$3=$ Existing traditional 2D road or topographic maps in paper form

$4=$ Existing traditional 2D thematic maps in paper form

$5=$ Paper atlases

$6=$ Existing digital maps on computer, mobile phone or tablet

$7=$ Ready-made neogeography maps (e.g., OpenStreetMap or Flicker map on Internet)

8 = Maps specifically prepared for the fieldwork (for the fieldwork purpose only)

$9=3 \mathrm{D}$ maps (DEM, 3D in Google Earth, etc.)

$10=$ Virtual reality (geo-referenced virtual real worlds for exploring terrain lanscapes, etc.)

$11=$ Interactive visualizations (that can be manipulated with interactions, such as input, panning, zooming)

12 = Dynamic visualizations (displaying changes over space and time, such as urban history. etc.)

Figure 2.17 The current use and interested-to-use of visualizations in the three stages of human geography fieldwork 


\section{The use of ICTs and visualizations in human geography fieldwork}

All responded that they used traditional maps (and atlases) in every stage of the fieldwork. But the instructors did not show much interest in using them alone in the future. Photos, videos and existing digital maps were also widely used, but not as much as traditional paper maps, especially in the preparatory and implementation stages. About half of the respondents indicated that they used neogeography maps like OSM, and they were more interested to use them before the actual fieldwork. 3D maps, virtual reality, interactive and dynamic visualizations were not very much used, but most leaders of the fieldwork would like to use them in the future during the first two fieldwork stages (preparation and execution). As a whole, teachers still employ more traditional visualizations (photos, videos, and maps) than modern ones, but they show much interest in using the relatively new visualization potentials in any stage of the human geography fieldwork.

\section{Reasons of and problems with using the visualizations}

Reasons of using visualizations in the three stages of fieldwork are diversified. Before going to the field, visualizations were used with the main purpose of getting students familiar with the physical and human geography of the fieldwork area and fieldwork tasks. There are also reasons of "basic orientation", "making teaching and learning efficient", and offering "good quality information". During the actual fieldwork, various kinds of visualizations were used for multiple reasons, for example, "to encourage more critical appreciation of place”, and "data gathering simplified". After the fieldwork, visualizations were mainly used to help post-field data processing and visualizing.

From the instructors' perspectives, the biggest problem encountered when using these visualizations was that the visualizations were too old and not so up-to-date. More than half of the respondents also met other problems, such as students lacking the skills of reading maps and producing visualizations, teachers not being able to find the visualizations needed, and lacking available hard- and/or software.

\section{Opinions about alternative visualization tools}

As the main objective of this research is to use a new visual tool to improve spatial cognition in a human geography fieldwork, opinions about alternative visualization tools were also surveyed. 5 out of 9 respondents would be interested in using an alternative visual tool to better support their fieldwork. Regarding the visual tool that will be developed and used in this research, the 5 respondents gave different suggestions. They hope the tool could be real-time, easy-to-use, interactive and open source. They expressed their opinions in the following ways: 
- $\quad$ "Integrated system that can be both operated as a data logger and real-time visualization tool. It should be able to have a self-help component to understand how it works on the go.".

- $\quad$ "Would be helpful to make sure a variety of existing base maps -- for example, satellite imagery/air photos, shaded relief, political units -- could be turned on or off as students add their data (probably mostly vector features).".

- $\quad$ "Should augment reality; Allow text, sound, images i.e., geo-media, to be collected.'.

- "Create 3D map for clarifying the student view.".

- "Open source, mobile device(s)/platforms, flexible to update, easy to use, customizable.".

From both the secondary source analysis and the online survey results, it is demonstrated that various kinds of visualizations are used in different stages of human geography fieldwork. It will be no surprise that the traditional visualizations will continue to be used in geography fieldwork. On the other hand, there is a potential for the development and application of an alternative personalized visual tool that can be used in human geography fieldwork with the aim of improving spatial cognition.

\subsection{Combined use of cartographic visualizations and AR}

Technological developments result in innovation of assisting tools in educational context, accordingly in fieldwork educational context. In fact, geography fieldwork has seen the increasing use of ICTs, especially geospatial ICTs such as GPS, Google Earth. On the other hand, the proper integration of technologies into fieldwork has been highlighted in order to enhance fieldwork learning (Welsh et al., 2013). However, as argued by Meek et al. (2013), the learning technology should be properly designed and developed with specific functions that are relevant to the fieldwork learning. Because the utilization of ICTs in geography education always inevitably integrates with various (cartographic) visualizations (e.g. maps), researchers in the area of geography (fieldwork) education are trying to develop more productive educational tools by optimally integrating the latest technological potentials with visualizations to facilitate geographical knowledge construction (Chaffer, 2015; Hedberg, 2014).

Regarding the latest ICTs, one of the most promising technologies is AR, which, as the very name suggests, augments the real with the virtual. AR enables real-time locationbased interactions (Azuma, 1997) with additional device-generated contextual information (i.e., augmentations) embedded within the real world (i.e., reality). Here, the digital devices could be special wearable glasses, personal computers, or smartphones and tablets; the contextual information could be texts, objects, audios, videos, photos, 
maps, or even data from social media. In this research, we restrict our attention to a mobile AR application on smartphones because of the increasing use of smartphones and the potential of mobile AR supporting learning through delivering immersive experiences in the field.

But this research decides to use mobile AR not just because this new technology is available. Other considerations are: (1) the above secondary source analysis and the online survey show that few mobile AR tools have been applied in geography fieldwork, especially human geography fieldwork; (2) among the results of the online survey, geography fieldwork leaders' positive attitudes and suggestions about developing and using a new visual tool demonstrate that it is necessary and promising to implement AR in geography fieldwork; (3) the proven usefulness of AR in recent fieldwork cases, e.g., ecosystem fieldwork in Kasahara et al. (2014) and cultural science fieldwork in Ternier et al. (2014), further offer empirical evidences. Details about AR in these two fieldworks will come later in Chapter 4.

The above outlined situation in the previous sections indicates the conceptual idea of combined use of cartographic visualizations and mobile AR in one mobile application (Figure 2.18) with the aim of improving spatial cognition in a human geography fieldwork in this research. We name it GeoFARA which is short for Geography Fieldwork Augmented Reality Application.

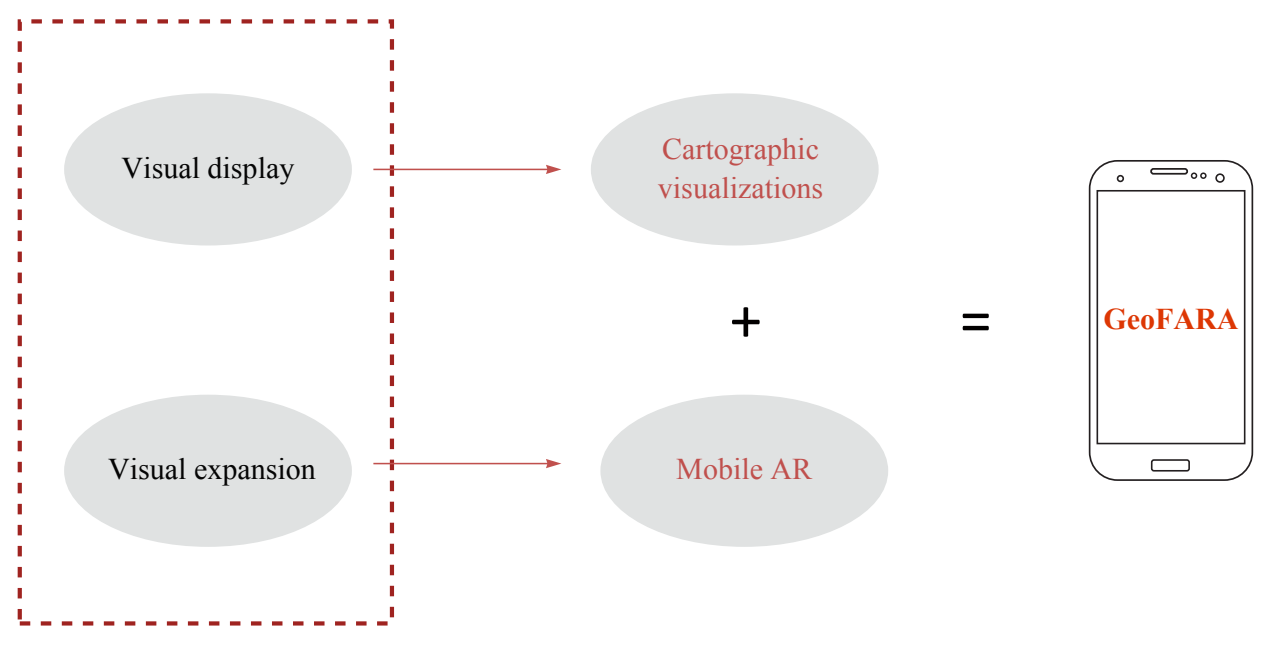

Note: GeoFARA is short for Geography Fieldwork Augmented Reality Application.

Figure 2.18 The combined use of cartographic visualizations and mobile AR in a mobile application-GeoFARA—in this research 


\subsection{Conclusion}

Learning with visual tools has always been a cognitive approach and a pedagogic issue. Within geographic domain, learning geography with cartographic visualizations even becomes a cartographic concern, no matter where the learning activities take place, in classroom or out of classroom. Fieldwork is perceived as being at the heart of geography (Gold, 1991). In fact, it is more challenging to learn with visual tools in geography fieldwork, because the novelty of fieldwork environment might distract the learners' attentions during the one-time field experience (Orion \& Hofstein, 1994). On the other hand, the visual tools might bring students cognitive load. Not surprisingly, when learning with visual tools during a learning-purpose-driven geography fieldwork, spatial cognition occurs because all students' senses are exposed to a real outdoor space. To visual learning tools, the developments of (mobile) ICTs bring new technological potentials that could be used to support geographic learning. The technology AR, as one of the latest and promising mobile ICTs, enables overlaying additional information on reality, and education is asserted as one of most promising application domains of AR (Wu et al., 2013). Mobile AR on smartphones could be used as a "cognitive tool and pedagogical approach” (Dunleavy \& Dede, 2014) to realize location-based learning geography during geography fieldwork.

This chapter introduced the theoretical and practical context of this research by connecting the elements of "geography fieldwork", "spatial cognition", and "visual tools". As it was shown in this chapter, the connections found their way into the scope of this research. In fact, in geography discipline, particular geography education and cartography, it should be the role of both pedagogic and cartographic research to explore and extend new cartographic and technical approaches in order to improve learning with visual tools. This research is an attempt to design, develop, and use a new visual tool (called GeoFARA) that can help improve spatial cognition during geography fieldwork. And vice versa, research on spatial cognition is expected to potentially contribute to improving GeoFARA itself as a learning tool. 
Chapter 3

Research Methodology: A User-Centered Design

Approach 


\subsection{Introduction}

This chapter describes the methodology used to design, develop and evaluate GeoFARA.

In the past two decades, for building visualization products, as Nöllenburg (2007:260) stated, "there has been a shift away from technology-driven visualization towards more human-centered approaches that base on usability engineering principles and apply theoretical results from cognitive research as demanded by Slocum et al. (2001)". This shift involves the concepts of "human-centered approaches" and "usability engineering", which have gained a lot of attention in interactive system or application design and development processes. This research employs a related "user-centered design" (UCD) approach. Applying the UCD approach in this research aims to support the whole design and development of GeoFARA with user-centered activities, so as to fulfill its intended purpose of improving spatial cognition when used during geography fieldwork with good user interfaces.

Section 3.2 outlines the UCD method and its interrelated fields such as human-computer interaction (HCI), usability engineering (UE). UCD, centering the role of users, emerged from HCI research and has been defined by international organization for standardization (ISO). Section 3.3 presents the earlier and ISO principles of UCD, ISO definitions of UCD and its applications. The process of UCD in this research mainly includes three activities: context of use $(\mathrm{CoU})$ and user requirement analysis, conceptual design and prototyping, and evaluation. In addition, this section contains a reflection on how UCD can be applied to mobile applications. Section 3.4 describes the definition of usability and mobile usability, and how this research interprets them. Section 3.5 and Section 3.6 explain the commonly used UCD research methods and techniques in general and those applied in this research specifically. Section 3.7 concludes with a comprehensive overview of the methodology applied in this research, providing the basis for further implementations.

\subsection{HCI, UCD, usability and beyond}

Who are users? According to Sauro and Lewis (2016, originally quoted from Edward Tufte, URL8) and Wikipedia (URL9), the term "user" is mainly used in two industries: computer information systems and drug dealing. Obviously, in this research, users are associated with computer information systems, in particular with human-computer interaction (HCI). HCI focusses on understanding the processes of people using computer systems to improve their designs. The early root of the concept "users" can be found in the 1970s when Hansen (1971) introduced the first principle for interactive system design, 
i.e. "know the user". Since then, the fields of HCI, UCD, usability testing, User eXperience (UX), UE, and other related fields have involved users in various degrees when producing products or systems. Figure 3.1 shows the initial developments and the major milestones of these closely interrelated fields in the past decades.

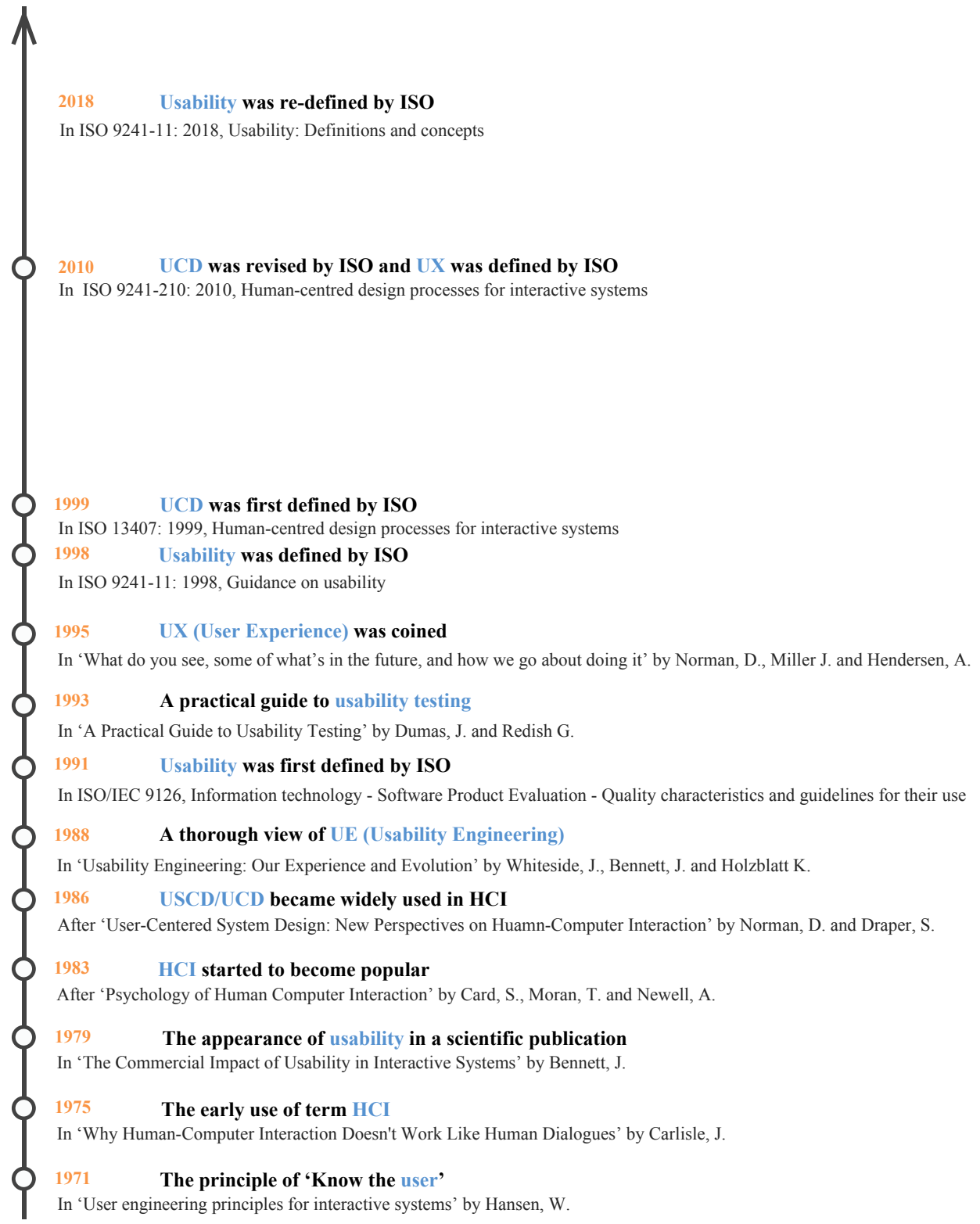

Figure 3.1 Initial developments and major milestones of some user- and usability-related fields since 1971 
The early use of the term HCI dates back to the 1970s (Carlisle, 1975), but HCI gained its real popularity in the 1980 s after Card et al. (1983) explored, in general, the psychological principles of the design of computer systems and human information processing behaviors. In fact, it is believed that psychology, or more precisely, "software psychology" (Shneiderman, 1980) laid the historical foundation of HCI (Carrol, 1997). HCI researchers have always tried to find principles, methods or models to improve the overall 'Interaction' in $\mathrm{HCI}$. For example:

- The star lifecycle model, as proposed by (Hartson \& Hix, 1993), is an evaluationcentered iterative cycle concept with the five stages of task/functional analysis, requirement specification, design, prototyping and implementation. Evaluationcentered means that each stage is evaluated during the product lifecycle process;

- The agile methods (Tumbas \& Matković, 2006) are adaptive and incremental development approaches, which are flexible to deal with users' needs during the entire process;

- The usability engineering life cycle, as proposed by Mayhew (1999), makes use of evaluation results of the conceptual model, the prototype and the final product during the development process.

More details about those methods and models are introduced by e.g. Isaias \& Issa (2015:21-61). Although users are involved in these models or methods, none of themunlike the UCD approach - involves and emphasizes users in a central position within the overall process from the stages of planning and designing to implementing and evaluating the developed product.

Therefore, not surprisingly, the UCD approach has been amongst the most primary and the most commonly used design cycle and even core concept in HCI research (Dix et al., 2004; Haklay, 2010; Noyes \& Baber, 1999; Preece, Rogers, \& Sharp, 2002; Vredenburg et al., 2002). It originated from the concept user-centered system design (USCD) coined by Norman \& Draper (1986) (Figure 3.1). Currently, UCD has become a standard in scientific and commercial publications within $\mathrm{HCI}$ research and beyond, particularly after it was defined by ISO in ISO 13407 (1999), replaced by ISO 9241-210 in 2010 (Figure 3.1). The definition of UCD in ISO 9241-210 (2010) is "an approach to systems design and development that aims to make interactive systems more usable by focusing on the use of the system and applying human factors/ergonomics and usability knowledge and techniques.". In fact, in the two ISO standards, originally, the term human-centered design (HCD) rather than UCD was used. But actually, UCD is regarded as the same process of HCD (Gasson, 2003; Ritter, Baxter, \& Churchill, 2014) and is often used synonymously as HCD (ISO 9241-210, 2010). Therefore, the ISO standards of HCD can also be applied in UCD, which will be introduced in more details in Section 3.3. As 
mentioned in Section 3.1, UCD is often used in the case when specific target users are involved instead of humans in general. Hence, this research has adopted the term UCD.

No matter how the design approach is labelled, any developed system should be at least efficient, effective, easy and even pleasant to use when users interact with it. This is part of the so-called "usability". The extensive appearance of usability in scientific publications is considered associated with interactive systems (Bennett, 1979) (Figure 3.1). Following this path, usability, an important characteristic of the interaction between users and systems (McNamara \& Kirakowski, 2006), has long been one of the major concerns within interactive system design and development (Ferre et al., 2005; Gould \& Lewis, 1985; Hartson \& Hix, 1993). Gould and Lewis (1985) even make the point "designing for usability", and propose that the first principle of such design should be "early focus on users". This principle was later updated by Gould (1995) as "early and continual focus on users" to design usable systems. Obviously, adding "continual" already indicates a strong need for user-focus throughout the whole design process. The principles of "focus on users" in "designing for usability" (Gould \& Lewis, 1995) and “design(ing) usable systems" (Gould, 1995) actually already are "user-centered”, which lays the foundations for the close relationship between usability and UCD. According to Thimbleby (2008), the paramount purpose of applying a UCD approach in design processes is to increase the usability of the interactive system to be developed. At the same time, usability research is essential to support the iterative UCD process.

After this picture of the relationship between UCD and usability, it is necessary to think about the measurement of usability. In a broader context, usability research is a process of testing the usability of a product, be it with or without users. But usability testing within UCD is a process that involves actual users to evaluate to what degree a product meets the specific usability criteria and it is a core part of UCD. There have been theoretical, methodological, and empirical developments in usability testing, resulting in guidelines (Dumas \& Redish, 1993; Dumas, 2003; Lewis, 2006; Rubin \& Chisnell, 2008). The practical guide by Dumas \& Redish (1993) is amongst the earliest guidelines and provides a valuable view on usability testing (Figure 3.1). For example, the five characteristics of a usability test, identified by Dumas \& Redish (1993:21), include: (1) the primary goal is to improve the usability of a product; (2) the participants represent real users; (3) the participants do real tasks; (4) what participants do and say is observed and recorded; (5) after the collected data is analyzed, the real problems of the tested product can be diagnosed and further fixed with the recommended changes.

\subsection{UCD: principles, processes and applications}

As indicated above, UCD has its background in HCI design. This research follows the 
UCD approach in the design and the development of an interactive mobile applicationGeoFARA. The early design principles have been translated into ISO standards which have been updated as the widely-adopted iterative process of UCD. The following section provides an overview of (1) the principles of UCD, (2) the iterative processes of UCD, and (3) the applications of UCD in interactive mobile application design.

\subsubsection{The principles of UCD}

There are different sets of principles that can characterize UCD. Amongst those principles, Shneiderman's (1987) eight golden rules of interface design were later adapted by Molich \& Nielsen (1990) and Nielsen (1994) who proposed the widespread "ten usability heuristics". Norman's (1988) "four basic design principles" and "seven designguidance principles", Gould \& Lewis's (1985) "three principles of design", and Gould's (1995) "four usability design principles" are the early principles of UCD. ISO 13407 (1999) and ISO 9241-210 (2010) also provide principles of UCD, which are based on the principles proposed by Gould \& Lewis (1985) and Gould (1995).

\section{- Eight golden rules of interface design and ten usability heuristics}

The eight golden interface design rules, as proposed by Shneiderman (1987:60-62) three decades ago are:

1. Strive for consistency.

2. Enable frequent users to use shortcuts.

3. Offer informative feedback.

4. Design dialog to yield closure.

5. Offer simple error handling.

6. Permit easy reversal of actions.

7. Support internal locus of control.

8. Reduce short-term memory load.

Based on these design rules, Molich \& Nielsen (1990) developed a list of usability heuristics (which has been finalized in Nielsen (1994)):

1. Visibility of system status.

2. Match between system and the real world.

3. User control and freedom.

4. Consistency and standards.

5. Error prevention.

6. Recognition rather than recall.

7. Flexibility and efficiency of use. 
8. Aesthetic and minimalist design.

9. Help users recognize, diagnose, and recover from errors.

10. Help and documentation.

\section{- $\quad$ Four basic design principles and seven design-guidance principles}

After Norman \& Draper (1986) first proposed the UCD perspective of HCI (Figure 3.1), Norman (1988) further advocated the concept of UCD and describes the four basic design principles as (Norman, 1988: 188):

1. Make it easy to determine what actions are possible at any moment (make use of constraints).

2. Make things visible, including the conceptual model of the system, the alternative actions, and the results of actions.

3. Make it easy to evaluate the current state of the system.

4. Follow natural mappings between intentions and the required actions; between actions and the resulting effect; between the information that is visible and the interpretation of the system state.

To guide designers to transform difficult design tasks into simple tasks with more straightforward principles, Norman (1988:188-189) further provided seven designguidance principles:

1. Use both knowledge in the world and knowledge in the head.

2. Simplify the structure of tasks.

3. Make things visible: bridge the gulfs of execution and evaluation.

4. Get the mappings right.

5. Exploit the power of constraints, both natural and artificial.

6. Design for error.

7. When all else fails, standardize.

\section{- $\quad$ Three principles of design and four usability design principles}

Towards designing for usability, the three core principles provided by Gould \& Lewis (1985) are:

1. Early focus on users and tasks.

2. Empirical measurement.

3. Iterative design.

These three principles of design were updated by Gould (1995) into four usability design principles aiming at designing usable computer systems. The added principle is 
"integrated design", which means that all aspects of usability (such as system functions, user interfaces) should be taken into consideration. The updated and revised usability design principles are:

1. Early and continual focus on users.

2. Early and continual user testing.

3. Iterative design.

4. Integrated design.

It is not surprising that these design principles have in common that they are very much oriented on the users (such as memory ability, making possible errors). But in terms of complexity of operation and implementation, compared to other principles, the principles proposed by Gould \& Lewis (1985) and Gould (1995) are easier to implement and follow, which leads to the international standardized principles of UCD (see below).

\section{- $\quad$ Four and six UCD principles of ISO}

In both of the standards of ISO 13407 (1999) and ISO 9241-210 (2010), prior to the description of iterative UCD activities, several key principles of UCD are stated to ensure the design is user-centered.

In ISO 13407 (1999), the four principles of UCD are:

1. Active involvement of users and a clear understanding of user and task requirements.

2. An appropriate allocation of functions between users and technology.

3. The iteration of design solutions.

4. Multi-disciplinary design.

To replace ISO 13407, ISO 9241-210 (2010) identifies additional UCD principles based on the earlier principles in ISO 13407. These updated principles with detailed explanations are presented below:

1. The design is based upon an explicit understanding of users, tasks and environments. To successfully design an interactive product, during the design process there is a need to understand who the intended users are, what characteristics the users have, what users need to do, and what the users' CoU is. The natures of the users, tasks and environments vary depending on the characteristics of the products that are going to be developed. For example, in this research, the operating system of smartphones should be taken into consideration when designing GeoFARA. 
2. Users are involved throughout design and development. User involvement should not only be part of the design process, as the above principle describes, but should also be expanded from the design process to the development process.

3. The design is driven and refined by user-centered evaluation. During the design process, the design solutions need to be evaluated with users. Users' feedback on either the prototype or the final product is a critical driving force for refined design solutions. That means that the refinement of design solutions cannot be achieved without user-centered evaluation.

4. The process is iterative. From the early planning of a UCD product to the final release, the design process progresses iteratively but not linearly. The design cycles repeat a sequence of interdependent design activities. More details about the iterative design process are described in next Section 3.3.2.

5. The design addresses the whole user experience (UX). Compared to ISO 13407, this principle is a newly identified one. In ISO 9241-210 (2010:7), UX is " $a$ consequence of the presentation, functionality, system performance, interactive behavior and assistive capability of an interactive system, both hardware and software.". Therefore, the design should consider the overall user experience.

6. The design team includes multidisciplinary skills and perspectives. To successfully apply UCD, diversified viewpoints from different disciplines (such as design, management, engineering, programming and research) are needed.

The above fundamental standardized UCD principles take into account extensive user involvement in the iterative design process. In this research project, not all but most of the six UCD principles of ISO 9241-210 (2010) are applied in the design and development of GeoFARA. For example, the principle of including multidisciplinary design teams cannot be followed in this relatively independent $\mathrm{PhD}$ research. And the principle of the whole UX cannot be completely addressed as the main objective of this research is to achieve the goal of GeoFARA in improving spatial cognition during fieldwork with high quality user interfaces, which is only part of UX, but not the overall UX of GeoFARA.

\subsubsection{The interactive process of UCD}

The UCD activities in both the ISO 13407 (1999) and ISO 9241-210 (2010) are the core part of these standards. These activities define the iterative process of UCD. Figure 3.2 and Figure 3.3 show the UCD cycles with the interrelations between the design activities. The two standards have very similar main activities, but the new standard (ISO 9241-210, Figure 3.3) emphasizes more flexible iterative potentials. According to the standard in ISO 9241-210 (2010), the UCD cycle includes five key stages: (1) plan the user-centered design process, (2) understand and specify the CoU, (3) specify user requirements, (4) produce design solutions to meet user requirements, and (5) evaluate the designs against 
requirements. As illustrated in Figure 3.3, among the four main activities from $\mathrm{CoU}$ specification to evaluation, the iteration lies in bringing the evaluation results back into the earlier different design stages if the designed solutions do not meet user requirements.

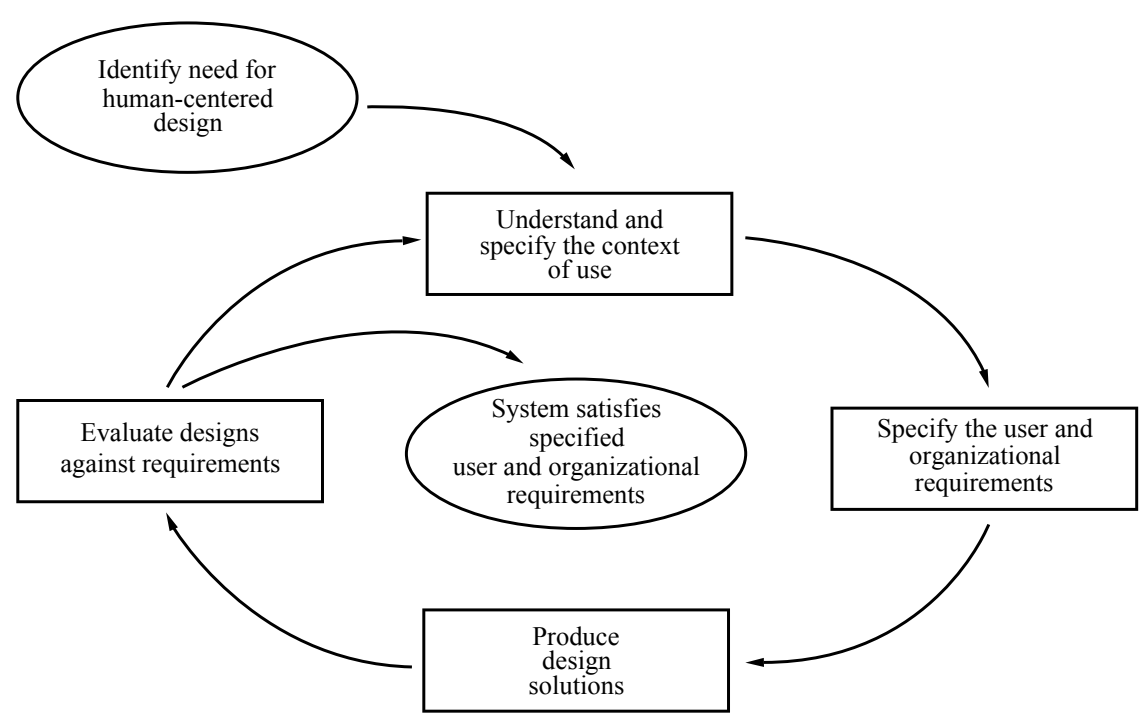

Figure 3.2 The activities and iterative process of UCD in ISO 13407 (From ISO 13407, 1999)

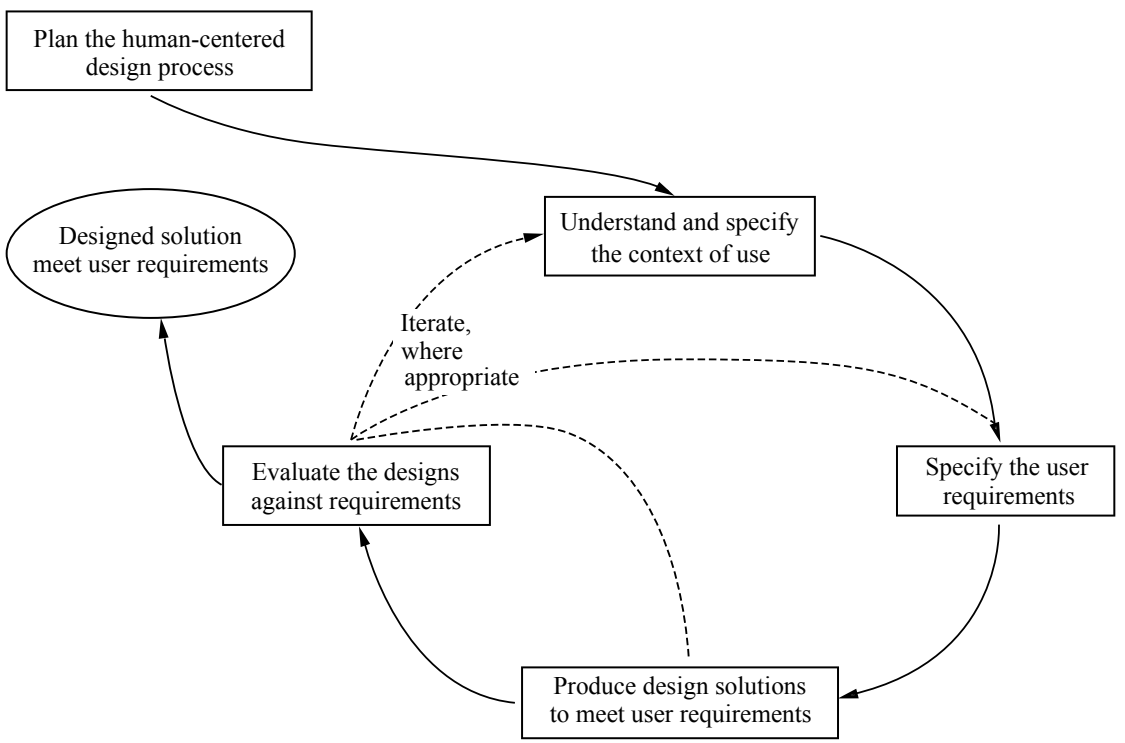

Figure 3.3 The activities and iterative process of UCD in ISO 9241-210

(From ISO 9241-210, 2010) 
In the literature, there are different interpretations of the standardized iterative process of UCD based on the early standard of UCD (ISO 13407, 1999). The UCD cycles identified by van Elzakker \& Wealands (2007) (Figure 3.4) and Haklay (2010:100) (Figure 3.5) are among the well-illustrated iterative UCD processes in relation to this research. Compared to the four main UCD activities in ISO, these two research publications describe UCD as a process mainly containing three linked steps (Figure 3.4, Figure 3.5), i.e. the two steps specifying $\mathrm{CoU}$ and specifying user requirements, are combined. This is because user requirements can be specified by studying potential users and analyzing the use context in which the future interactive product will be used, which is also the first step of UCD in this research project. Based on the outcomes of the user requirement analysis, technology applications like GeoFARA (which combines visualizations and AR), a graphical user interface (GUI) and mobile maps are important elements of conceptual design and prototyping. After the design stage, the next stage is to evaluate whether the design solutions of the second step have met the user requirements, as established in the first step. For GeoFARA, considering its $\mathrm{CoU}$ (on a mobile phone during fieldwork) and its goal (improving spatial cognition), a field evaluation with users will be carried out to test its usability as well as to measure the spatial cognition of GeoFARA's users. The evaluation results could be brought back to either the first step of redefining user requirements or the second step of reproducing design solutions. The decision depends on to what extent the evaluation results meet the defined use and user requirements.

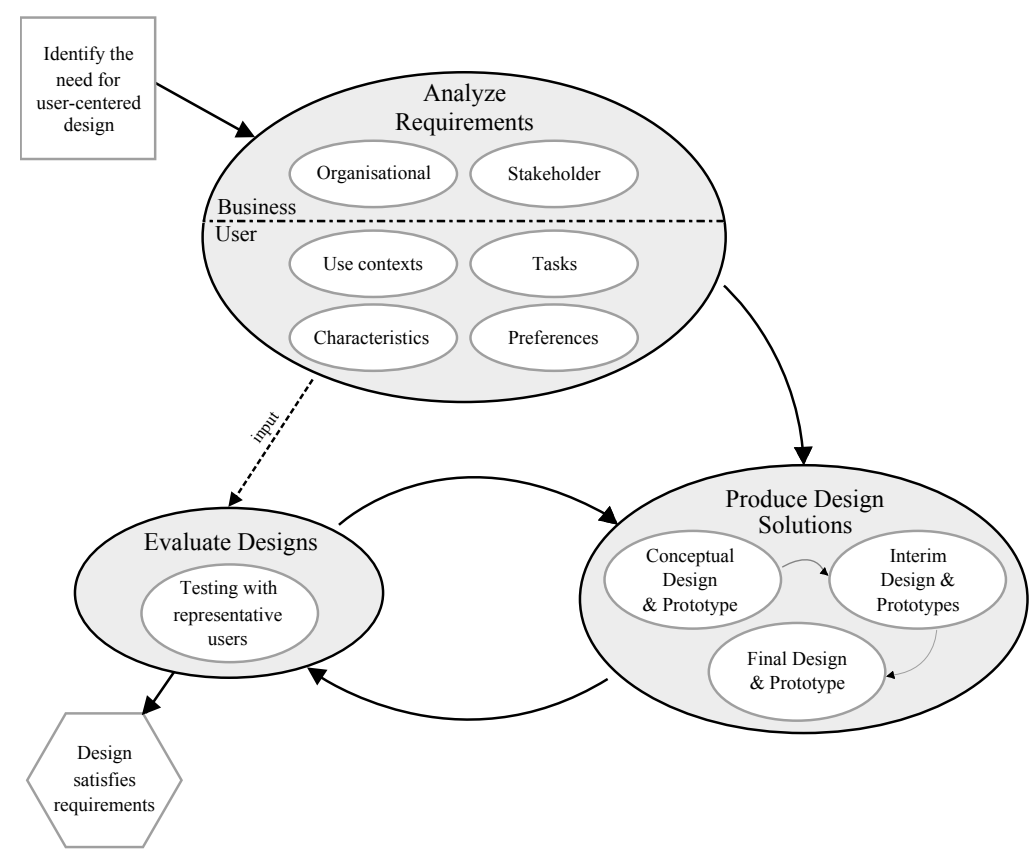

Figure 3.4 The iterative UCD process with detailed activities at each stage (Redrawn from van Elzakker \& Wealands, 2007) 


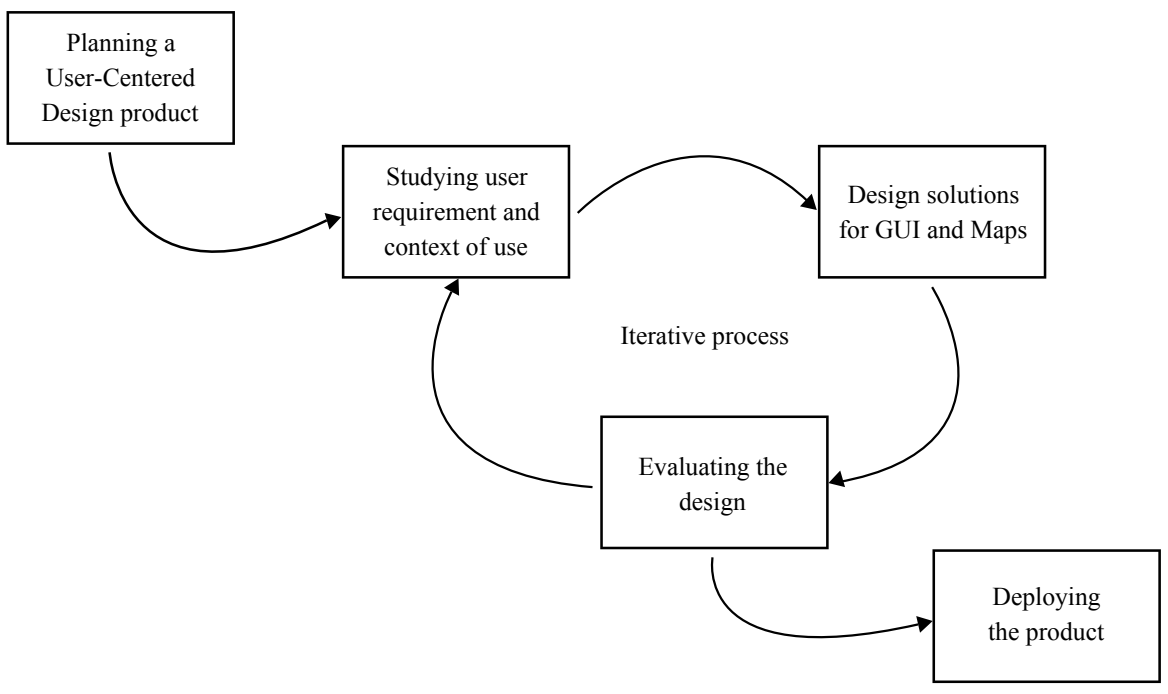

Figure 3.5 The iterative UCD process for geospatial technologies (Redrawn from Haklay, 2010:100)

\subsubsection{Applying UCD in producing mobile applications}

In recent years, thanks to the increasing use of smart mobile devices and the growing availability of wireless Internet connections, there has been an increase in mobile applications and attention for human interaction with them (i.e. mobile HCI). There are two types of mobile applications: context-free and context-aware applications. Designing mobile context-aware applications is the main goal of mobile HCI research (Haklay, 2010:241). Context-aware mobile applications have the capability of providing taskrelevant information and/or services according to the context of use, physical environment and technology (Abowd et al., 1999). Obviously, GeoFARA is such a type of mobile application as it aims at providing augmentations and visualizations of the fieldwork environment for the task of improving the users' spatial cognition when used in the field.

As a core concept of HCI research, the UCD approach is also applicable in designing interactive mobile applications, particularly in designing mobile context-aware applications like GeoFARA. For smartphone application design, the iterative UCD activities that include user requirements analysis, conceptual design and prototyping, and evaluation are as important as they are for any other interactive products. Different factors of applying UCD in mobile phone applications are the aspects of the mobile phone per se and the surrounding environment. Mobile devices have their hardware and software constraints that should be brought into consideration. Moumane et al. (2016) list some of 
those mobile limitations such as mobile context, network characteristics, screen size, display resolution, limited storage capacity and data entry techniques. For example, the display capacity of mobile phones with small screens requires the adaption of human computer interface design to this limitation. All factors related to mobile phones per se are assumed to determine special user requirements and special usability evaluation methods and techniques.

Another special consideration is the factor of the surrounding environment. Compared to the conventional desktop-based HCI, the interactions between users and mobile applications are more linked to the surrounding environment. For mobile applications, the environment also provides information sources such as geographic locations of users and spatial representation contents of applications. Li \& Willis (2006) put the environment dimension together with the dimensions of users and mobile devices into a context-aware interaction model as illustrated in Figure 3.6. In this model, three aspects of interactions - location, interface and representation - are identified among the three dimensions of users, mobile devices, and environment. Therefore, for designing mobile context-aware applications, delivering location-based textual and/or visual representations of the surrounding space through the mobile user interface is central to the design. The factor of the surrounding environment also makes it very necessary to conduct a field-based usability evaluation.

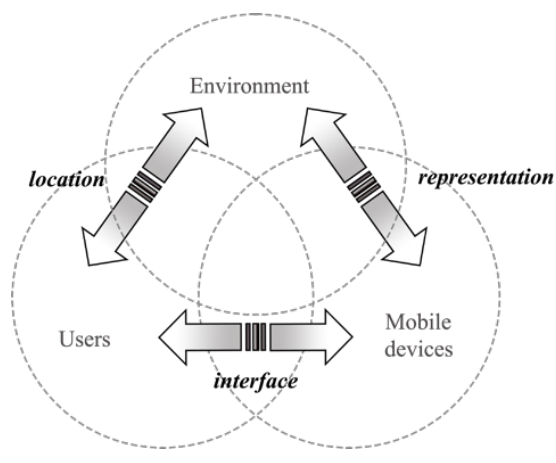

Figure 3.6 A conceptual model of user, mobile devices, and environment interactions (Adapted and redrawn from Li \& Willis, 2006)

In summary, the UCD approach is applicable in mobile application design, but the constraint of mobile devices and the additional consideration of the surrounding environment bring more challenges and differences in the contents and methods of UCD activities. For the specific case of applying UCD in designing GeoFARA, firstly, the CoU in terms of fieldwork area, users, mobile technology, spatial cognition tasks, and specific user requirements need to be analyzed. Then, based on the results of this analysis, the conceptual design will be presented in the form of a mobile phone user interface (based 
on an AR interface) showing location-based representations of the fieldwork area. When users perform tasks with the prototype of GeoFARA in the fieldwork, field-based mobile usability evaluation is conducted based on the interpretation of usability in this research which is addressed in the next section.

\subsection{Usability, mobile usability and mobile application usability}

Usability is the core focus of HCI and the main outcome of applying the UCD approach. It concerns the overall usability level of users performing tasks when interacting with computer systems. However, definitions of usability are not only diverse, but also sometimes lead to confusion with other related terms such as utility, usefulness, or UX. This section addresses these issues. In addition, it deals with how mobile devices and mobile technologies fit into the picture of usability, which results in mobile usability, and particularly, mobile application usability.

\subsubsection{Definitions of usability}

Since the term usability appeared in scientific publications for interactive systems (Bennett, 1979) (Figure 3.1), both a number of researchers from the HCI discipline (Bevan \& Macleod, 1994; Nielsen, 1993; Shackel, 1991, 2009) and ISO (e.g., ISO/IEC 25010, 2011; ISO/IEC 9126, 1991; ISO 9241-11, 1998, 2018) have tried to further refine this concept. The definition provided by Shackel (1991:24) is amongst the very first formal and operational definitions of usability which is "the capability in human functional terms to be used easily and effectively by the specified range of users, given specified training and user support, to fulfill the specified range of tasks, within the specified range of environmental scenarios". From a point of view of system acceptability, Nielsen (1993) defines usability as an important component of a system's practical acceptability under the category of "usefulness", another component of which is utility (Figure 3.7). Further, there are five aspects of usability including learnability, efficiency, memorability, errors, and satisfaction. These five aspects in Nielsen's (1993) definition and the "to be used easily and effectively" in Shackel's (1991) definition indicate the basic attributes of usability, which were later adopted by ISO in its definition. In addition, the difference between the two fundamental qualities of software productsutility and usability - is also worth mentioning. They are treated independently (Figure 3.7) by Nielsen (1993) in terms of the system achieving the user's desired goals or not. According to Nielsen (1993:25), utility refers to "whether the functionality of the system in principle can do what is needed", i.e. useful or not, while usability refers to "how well users can use that functionality", i.e. usable level. For the overall usefulness, utility 
(about the product itself) is a more intrinsic concept than usability (about interactions between users and the product itself), but a useful system with a high utility does not imply and guarantee a usable system with good usability (Grudin, 1992; Yovcheva, 2015:59-60). Therefore, usability must be taken into consideration in all aspects of a software product design.

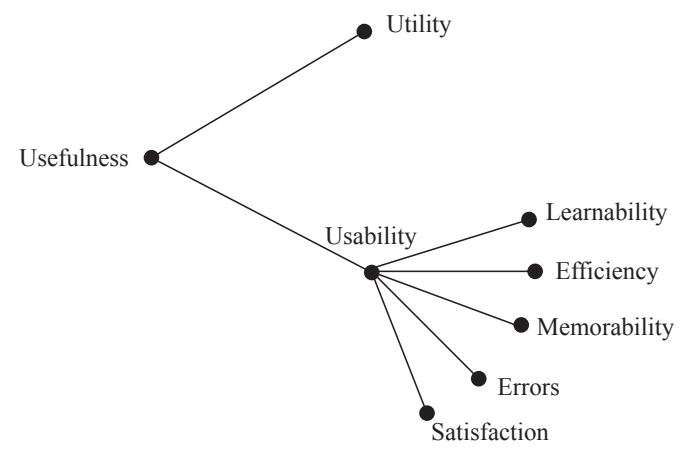

Figure 3.7 Usefulness, utility and usability (Adapted from Nielsen, 1993:25-26)

As mentioned above, these pioneering definitions of usability became the basis for international usability definition standards. In fact, before the authoritative ISO definition of usability in ISO 9241-11 (1998), early in 1991 (Figure 3.1), ISO, together with the International Electrotechnical Commission (IEC), had already defined usability in ISO/IEC 9126 (1991) which has been revised and replaced by ISO/IEC 25010 (2011). The latter standard describes usability as one aspect of software product quality. Different from the software quality perspective, ISO 9241-11 (1998:2) defines usability from the user's point of view as the "extent to which a product can be used by specified users to achieve specified goals with effectiveness, efficiency, and satisfaction in a specified context of use”. This ISO 9241-11 (1998) definition and usability framework (Figure 3.8, updated by ISO 9241-11, 2018) in this standard have most impact (Bevan, 2001) on how usability is interpreted in HCI and UCD. The usability framework (Figure 3.8) in ISO 9241-11 (2018) provides the key usability evaluation dimensions (effectiveness, efficiency and satisfaction) based on identifying the CoU. According to ISO 9241-11 (2018), effectiveness is the accuracy and completeness with which the user achieves specific goals; efficiency is the expenditure of resources (mental or physical effort, time, materials or financial cost) in relation to the level of effectiveness (the accuracy and completeness with which the user achieves goals); satisfaction is the extent of the user's freedom from discomfort, and attitude towards the use of the product. Table 3.1 shows some examples of how to measure these three usability dimensions in detail. After ISO 9241-11's standardization of these three usability goals, other researchers considered 
additional usability goals. For example, Preece et al. (2002) highlighted six usability goals (the inner circle in Figure 3.9) as well as ten UX goals (the outer circle in Figure 3.9) for interactive product design. Despite such more detailed and multiple usability goals, the goals of effectiveness, efficiency and satisfaction in ISO 9241-11 $(1998,2018)$ still proved to be relatively independent and weakly correlated components (FrØkjaer et al., 2000; Hornbæk \& Law, 2007). More importantly, they are the three core usability measurement dimensions among other goals such as learnability and, memorability (Coursaris \& Kim, 2007). In Coursaris \& Kim's (2007) paper about a research agenda for mobile usability, a qualitative review of 45 mobile usability studies was conducted and they found that the appearance rates of effectiveness, efficiency, and satisfaction are $62 \%$, $33 \%$ and $20 \%$ respectively, while learnability and memorability are only reported in $11 \%$ and $2 \%$ of the studies. Therefore, in this research, we adopt the ISO 9241-11 (2018) definition of usability and its usability framework (Figure 3.8).

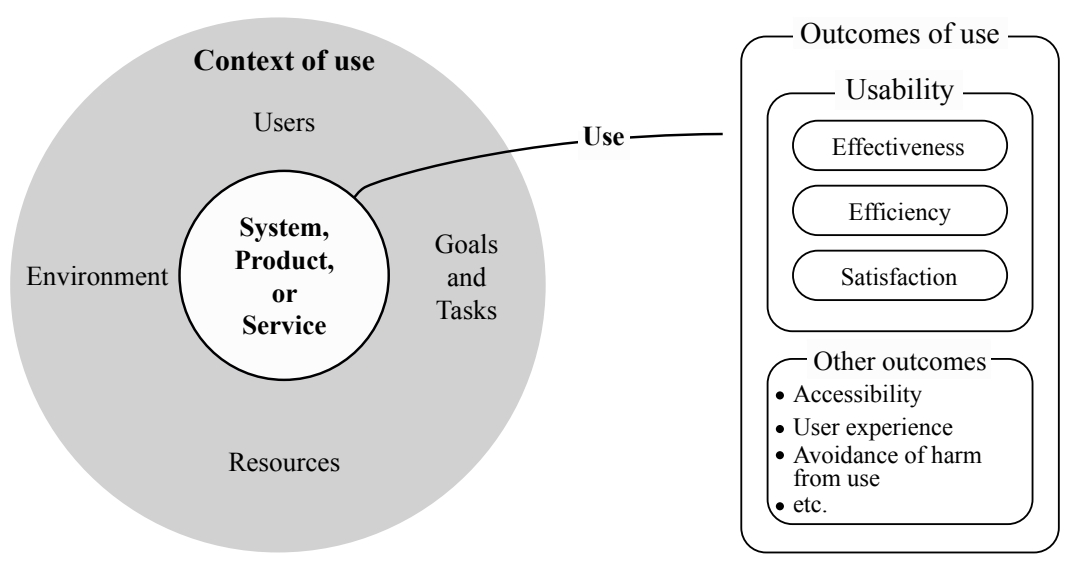

Figure 3.8 Framework of usability (Redrawn from ISO 9241-11, 2018)

Table 3.1 Examples of usability measurement (From ISO 9241-11, 1998)

\begin{tabular}{l|l}
\hline Overall usability & Measurement dimensions \\
\hline \multirow{2}{*}{ Effectiveness } & - Percentage of goals achieved \\
& - Percentage of users successfully completing task \\
& - Average accuracy of completed tasks \\
\hline \multirow{2}{*}{ Efficiency } & - Time/cost to complete a task \\
& - Tasks completed per unit time \\
\hline \multirow{3}{*}{ Satisfaction } & - Monetary cost of performing the task \\
& - Frequency of discretionary use \\
\hline
\end{tabular}




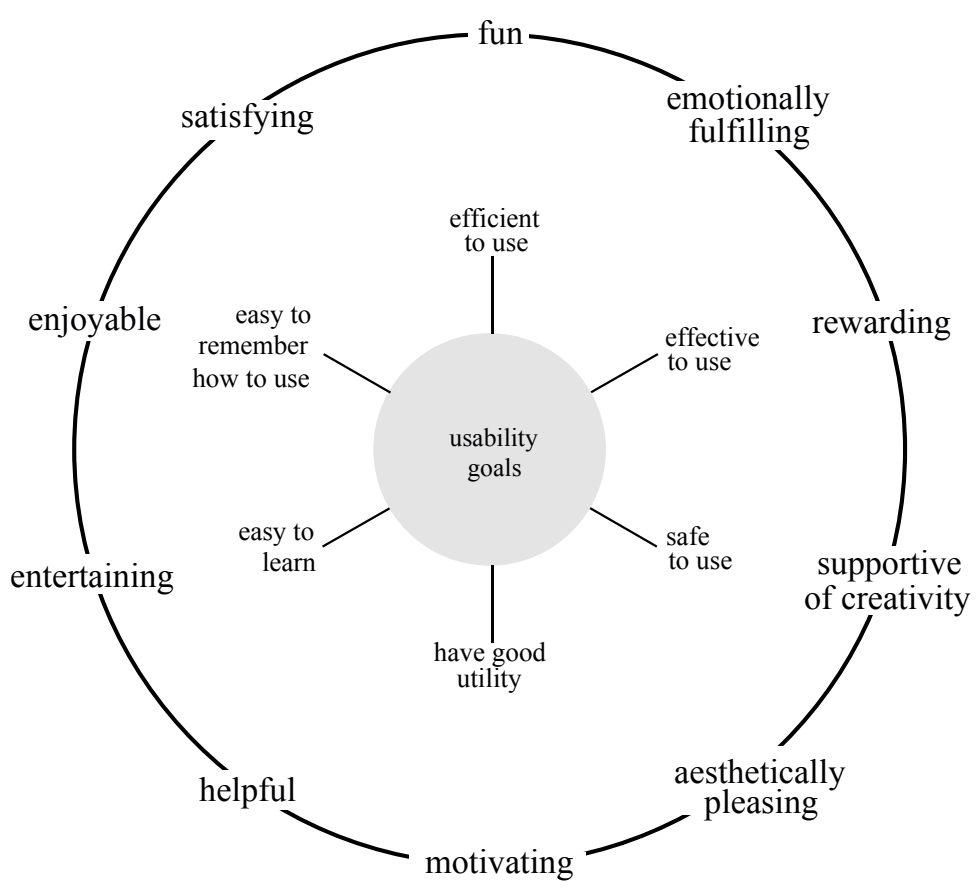

Figure 3.9 Usability goals and user experience goals (Redrawn from Preece et al., 2002:19)

The reason why usability and UX are treated separately by some researchers like Preece et al. (2002) (Figure 3.9) is that UX and usability have different focuses, which can be seen in their ISO definitions. When UCD in ISO 13407 (1999) was revised by ISO 9241210 (2010:3), this new standard also defined UX as "a person's perceptions and responses that result from the use and/or anticipated use of a product, system or service". Therefore, compared to usability's focus on goal achievement through user interaction, UX focuses on the overall users' feelings. Nevertheless, to some extent, UX could include usability (its satisfaction dimension is part of UX), and usability is sometimes even used interchangeably with UX. In line with the objectives of this research, the focus here is on GeoFARA's overall usability of GeoFARA.

\subsubsection{Mobile usability and mobile application usability}

With the increasing use of mobile technologies on mobile devices, the research on usability is expanding from stationary into mobile, often applying UCD for designing mobile products. In order to bring the concept of usability to mobile usability, first of all, there is a need to explore what 'mobile' or mobility is. Around two decades ago, Dahlbom \& Ljungberg (1998) already introduced three modalities of human mobility in using 
mobile information and technologies, which are wandering, travelling and visiting (Figure 3.10). From a geographic perspective, wanderings are mobile activities in a very small scale space, e.g. walking within a building with a mobile indoor navigation system. Travelling is the process of moving from one site to another, in which an example of mobile use is using mobile maps to assist driving. Visiting is a short stay at some location, e.g. the geography fieldtrip of this research with making use of GeoFARA is a typical modality of this kind. These modalities of mobility are regarded as one of the factors affecting mobile ICT use (Kristoffersen \& Ljungberg, 2000), and the other two factors proposed by them are environment (physical and social surroundings) and application (hardware, software, etc.). These three factors are comparable to the elements of users, environment and mobile devices in Li \& Willis's (2006) conceptual model (Figure 3.6) of context-aware interaction.

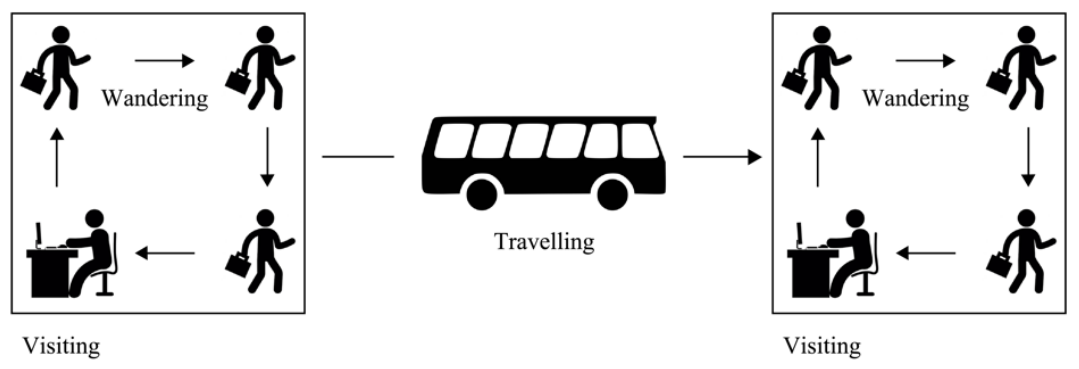

Figure 3.10 Three modalities of mobility (From Dahlbom \& Ljungberg, 1998)

For mobile usability, there are both the usability of the mobile device (the actual hardware and the operating system) and the mobile application usability. Mobile device usability is the extent to which the hardware itself and the operating system are effective, efficient, and of satisfaction. A mobile application is an IT artifact that is specifically developed for a mobile operating system and installed on handheld devices such as smartphones or tablet computers (Delikostidis, 2011; Hoehle \& Venkatesh, 2015). Based on ISO's (ISO 9241-11, 2018) definition of usability (see Section 3.4.1, they suggest to define mobile application usability as the extent to which a mobile application can be used by specified users (with various modalities of mobility) to achieve specified goals with effectiveness, efficiency, and satisfaction in a specified CoU. This research focuses on mobile application usability, i.e. GeoFARA's usability - the extent to which GeoFARA can be used by students (when visiting the fieldwork area) to achieve spatial cognition with effectiveness, efficiency, and satisfaction during the whole fieldwork. In doing so, with respect to overall usability evaluations of mobile applications to date there are challenges, and theoretical and methodological issues, e.g. "much of the research that evaluated mobile application usability was conducted in laboratory settings" (Hoehle \& Venkatesh, 
2015). Therefore, by conducting usability evaluations of the mobile application GeoFARA in field settings, instead of in laboratory settings, this research will contribute to a new and further discussion in mobile application usability research practices.

\subsection{General overview of UCD research methods and techniques}

Under the overall research methodology of the UCD approach, this section presents UCD research methods and techniques in general. Before doing this, it is necessary to be clear about what research methods and research techniques are. According to Kothari (2004:7), research methods refer to "the behavior and instruments used in selecting and constructing research techniques", while research techniques refer to "the behavior and instruments used in performing research operations such as making observations, recording data, processing data and the like". One of the examples given by Kothari (2004) is the research method of participant observation (which will be used as one of the methods in this research) and its corresponding research techniques are, for example, "interactional recording, possible use of tape recorders and photographic techniques". Section 3.6 addresses both research methods and data collection techniques.

Although several international standards provide detailed specifications and guidelines for UCD activities, these standards do not address UCD methods and techniques. But a couple of researchers have discussed and summarized various sets of methods for UCD research (see e.g., Delikostidis, 2011:78; Kveladze, 2015:50; Nielsen, 1993:224; Vredenburg et al., 2002; Rohrer, URL10). It needs to be mentioned that when summarizing UCD methods, different researchers treat the two UCD activities CoU analysis and user requirements analysis differently. For instance, Maguire (2001) provided methods for $\mathrm{CoU}$ analysis and user requirements analysis separately. But considering the clear CoU of GeoFARA in this research, and following ISO 9241-210's (2010) claim of "the specification of user requirements shall include the intended context of use", this research will combine the analysis of $\mathrm{CoU}$ analysis and user requirements as in Figure 3.4 and Figure 3.5. By extending and adjusting the summaries of UCD methods by the above-mentioned researchers, Table 3.2 shows a general overview of commonlyused UCD research methods. These research methods and techniques are also applicable to the user-centered design of mobile applications like GeoFARA, although the methods and techniques in Table 3.2 need some reflection to make them 'mobile', e.g. incorporating the method of mobile eye-tracking for in-depth analysis on how users interact with mobile products. 
Table 3.2 General overview of UCD research methods and techniques

\begin{tabular}{|c|c|}
\hline UCD activities & Methods and techniques \\
\hline $\begin{array}{l}\text { Analyze } \mathrm{CoU} \text { and } \\
\text { user requirements }\end{array}$ & $\begin{array}{l}\text { Context of use analysis } \\
\text { Existing system/competitor analysis } \\
\text { Evaluation of the usage of corresponding products } \\
\text { Stakeholders analysis } \\
\text { Surveys/interviews of existing users } \\
\text { User observation } \\
\text { Contextual inquiry } \\
\text { Diary keeping } \\
\text { Use cases } \\
\text { Task Analysis } \\
\text { Scenarios of use } \\
\text { Personas } \\
\text { Function mapping } \\
\text { Brainstorming } \\
\text { Card sorting }\end{array}$ \\
\hline Produce design solutions & $\begin{array}{l}\text { Card sorting } \\
\text { Affinity diagram } \\
\text { Brainstorming } \\
\text { Storyboarding } \\
\text { Scenario-based design } \\
\text { Parallel design } \\
\text { Participatory design } \\
\text { Paper prototyping } \\
\text { Rapid prototyping } \\
\text { Working interface prototyping } \\
\text { Organizational prototyping } \\
\text { Wizard of Oz prototyping } \\
\text { Design guidelines and standards }\end{array}$ \\
\hline Evaluate designs & $\begin{array}{l}\text { Email surveys } \\
\text { Intercept surveys } \\
\text { Field usability testing } \\
\text { Focus groups } \\
\text { Eye-tracking } \\
\text { Clickstream/log capture and analysis } \\
\text { Thinking aloud } \\
\text { Camera/video } \\
\text { User observation } \\
\text { Performance testing } \\
\text { User feedback } \\
\text { Lab usability testing } \\
\text { System Usability Scale (SUS) } \\
\text { Diary studies } \\
\text { Remote evaluation } \\
\text { Heuristic evaluation } \\
\text { Cognitive walkthrough } \\
\text { A/B testing }\end{array}$ \\
\hline
\end{tabular}


Apparently, there is a wide range of UCD research methods that are available for UCD research projects to choose from. But when it comes to when to use which methods, it requires more detailed insights into these methods. Rohrer (URL10) did so by viewing at some UCD methods in a three-dimensional framework, forming "a landscape of user research methods" (Figure 3.11). The three dimensions are data source (behavioral "what people do" vs. attitudinal - "what people say"), approach type (qualitative (direct) vs. quantitative (indirect)) and context of product use (natural use of product, decontextualized/not using product, scripted use of product, combination/ hybrid). The methods selected in this research are guided by the three dimensions as in Figure 3.11.

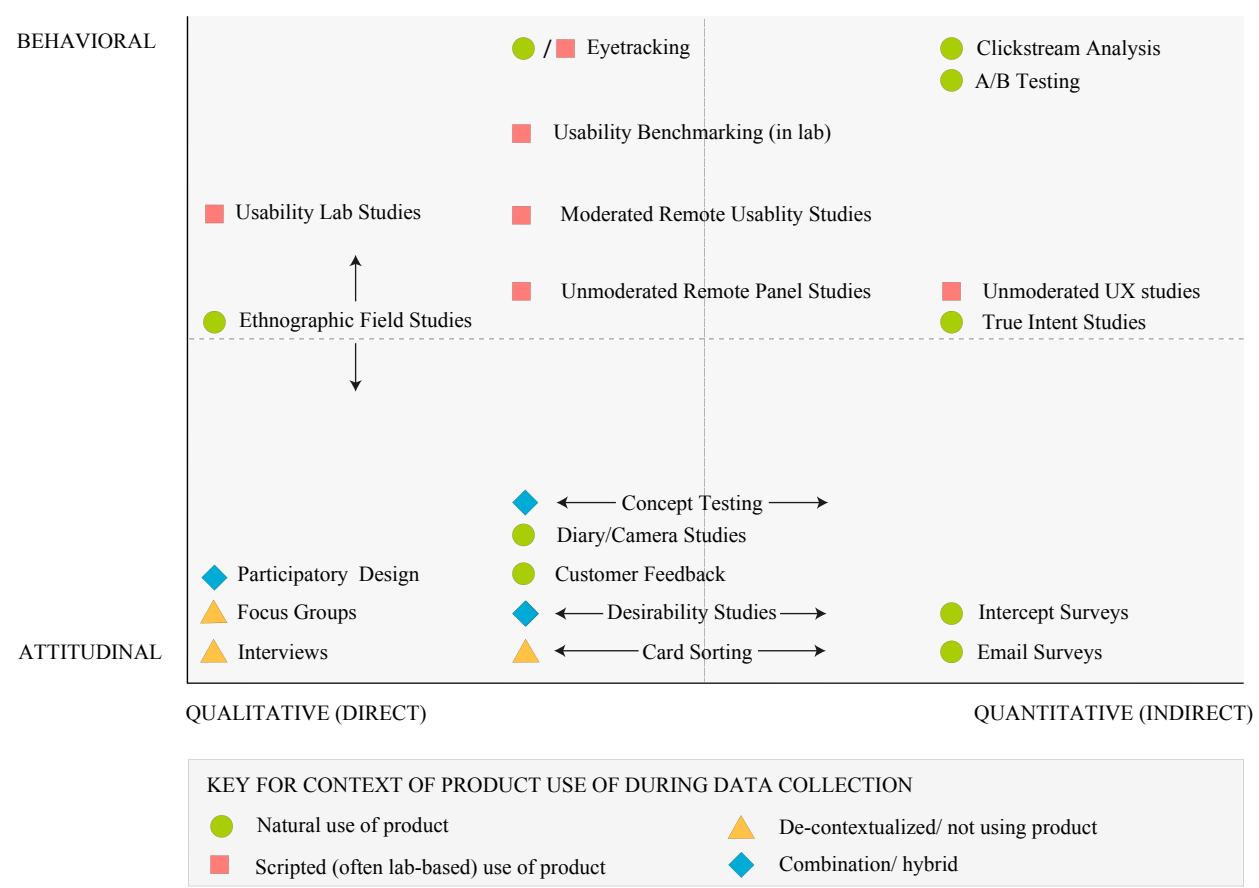

Figure 3.11 A landscape of user research methods (Redrawn from Rohrer, URL10)

Here it is argued that it is the objectives and the characteristics of different UCD activities and stages that predetermine the associated attributes of data source, approach type and context of product use, which further determine the specific UCD methods. For instance, the main purpose of specifying $\mathrm{CoU}$ and user requirements (there is no actual use of the product) is to collect information about use context and user needs in order to design the basic interfaces and functions for a new product. To this end, using qualitative and attitudinal methods is enough to achieve the goal. For designing GeoFARA, the specific UCD methods and techniques will be presented in the next section. 


\subsection{UCD methods and techniques for GeoFARA}

As indicated above, by applying the methodology of UCD, this research will design and develop a mobile application, GeoFARA, for fieldwork use. For selecting the appropriate methods and techniques for the user-centered design of GeoFARA, specific methods of Table 3.2, and the three high level dimensions of Figure 3.11 together provide a thorough reference. Based on these works, the following sections present the detailed methods of the three UCD activities for developing GeoFARA and the main reasons of choosing them. In order to provide a comprehensive overview of the research methods of this $\mathrm{PhD}$ project, data collection techniques are also presented.

\subsubsection{Stage 1 - Analyzing CoU and user requirements for GeoFARA}

GeoFARA will be used in a certain context. Following ISO 9241-11 (2018), the contextual factors of GeoFARA include its users, goals and tasks, resources, and environment. Following the main goal of GeoFARA (its users want to achieve learning objectives), the users of GeoFARA are the persons who interact with it; the tasks are what users do to achieve their goals; the resources are the equipment, support, etc. that are used when users perform the tasks; the environment is where the interaction takes place. Extending the $\mathrm{CoU}$, the user needs and user requirements for GeoFARA should also be analyzed in order to further design and shape the application. During UCD, the user requirements are derived from the $\mathrm{CoU}$ with user needs as intermediate steps. Table 3.3 shows the methods, the main purposes of choosing the corresponding methods and the associated data collection techniques for specifying GeoFARA's CoU and user requirements. The detailed data collection instruments (Appendix 2 and Appendix 3) will be described in Section 4.4. It can be seen that earlier and in-depth use and user requirements of GeoFARA will be collected by using multiple methods. Compared to the complete set of the methods in Table 3.2, the methods of stakeholder analysis, contextual inquiry, diary keeping, function mapping, brainstorming and card sorting are not selected for GeoFARA, mainly because those methods are either more suitable for design activities within a team (e.g., stakeholder analysis, brainstorming) or extensively require involving users (e.g., diary keeping, card sorting), while this $\mathrm{PhD}$ research is a solely independent design research work, and it is unrealistic for this research to involve users with a long time-span. Applying the selected methods in Table 3.3 should lead to the usage of existing mobile AR fieldwork application as well as the $\mathrm{CoU}$ and user requirements for GeoFARA in terms of its operating environment, users and user characteristics, user tasks, functional and interface requirements, etc. All the results are essential for the next step-producing design solutions of GeoFARA. The implementation of the methods and techniques for analyzing the $\mathrm{CoU}$ and user requirements of GeoFARA (Table 3.3) is presented in Chapter 4. 


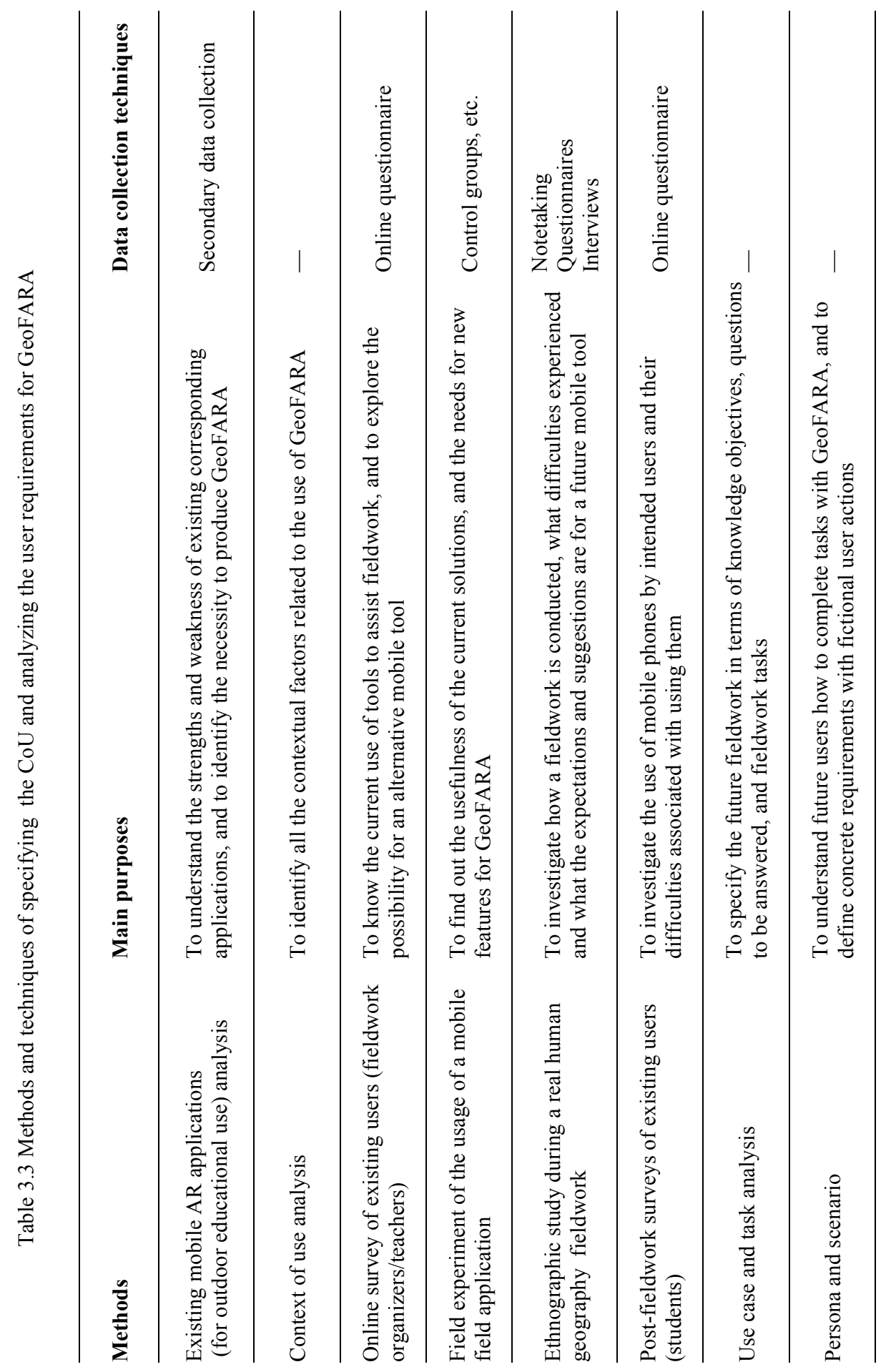




\subsubsection{Stage 2 - Producing design solutions of GeoFARA}

After analyzing the $\mathrm{CoU}$ and user requirements, the next step is to produce potential design solutions, which can lay the foundation for further developing the design of GeoFARA. Design solutions of GeoFARA cannot only be produced by drawing on its $\mathrm{CoU}$ and user requirements, but also based on general design and usability guidelines and standards. According to ISO 9241-210 (2010), design solutions should become concrete by making use of, for example, scenarios, simulations and prototypes. This includes a first stage of conceptual design, followed by and another important activity - prototyping, i.e. producing design solutions beyond the conceptual design. Following this, producing design solutions for GeoFARA will include a conceptual design (the design of its contents, interactions and user interfaces) as well as the production and development of a prototype. As shown in Table 3.2, there are a number of methods and techniques that can be used to produce design solutions for GeoFARA. Here, scenarios-based design, rapid prototyping, working interface prototyping as well as design guidelines and standards are selected to design and prototype GeoFARA (Table 3.4). The reasons for not selecting other methods in Table 3.2 are similar to the ones (unrealistic for this research due to the limited core research, design and development member, impossible to extensively involve in potential users) in the stage of analyzing $\mathrm{CoU}$ and user requirements (Section 3.6.1). In addition, to save time for this research, low-fidelity prototype of GeoFARA will not be produced, therefore, methods, such as paper prototyping, will not be employed. The data involved in this stage is not directly related to how to produce design solutions, but mainly the textual introduction, images and maps of the fieldwork as part of GeoFARA's contents. Those data will be collected via Internet searching, old books, local museum (URL11), etc. Therefore, Table 3.4 presents only the selected methods and their purposes, without presenting data collection techniques in detail.

Table 3.4 Methods of producing design solution of GeoFARA

\begin{tabular}{ll}
\hline Method & Main purpose \\
\hline Scenario-based design & $\begin{array}{l}\text { To specify concrete functionalities for GeoFARA, and to } \\
\text { design contents, interactions and user interfaces }\end{array}$ \\
\hline Rapid prototyping & $\begin{array}{l}\text { To visually construct a relatively middle-fidelity prototype } \\
\text { of GeoFARA with limited functionalities and static user } \\
\text { interfaces in a visual development environment, and to } \\
\text { demonstrate how GeoFARA looks like in a simple way }\end{array}$ \\
\hline Working interface prototyping & $\begin{array}{l}\text { To produce an operational prototype of GeoFARA with } \\
\text { sufficient functionalities and interactivities }\end{array}$ \\
\hline Design guidelines and standards & $\begin{array}{l}\text { To make use of previous design experiences to guide the } \\
\text { design of GeoFARA, and to ensure the consistency of the } \\
\text { design aligning with other mobile applications }\end{array}$ \\
\hline
\end{tabular}


In scenario-based design, the scenarios are different from the scenarios used in analyzing user requirements. Four different kinds of scenarios may be distinguished: problem scenarios, activity scenarios, information scenarios and interaction scenarios (Rosson \& Carroll, 2002). Among them, problem scenarios are used to analyze parts of the use and user requirements (see Table 3.3), while activity, information and interaction scenarios are mainly employed during the scenario-based design process to make design solutions in terms of concrete functionalities, contents and user interfaces of the designed product. In this research, all the scenario information will be merged into one scenario (Section 4.6) for both specifying the user requirements and producing design solutions for GeoFARA. And in order to make the solution more concrete and to communicate the conceptual design with actual users, a prototype of GeoFARA needs to be developed. In this research, first, the method of rapid prototyping (Table 3.4) will be used to simply demonstrate how GeoFARA looks like with limited functionalities and just static user interfaces. To further develop an operational prototype of GeoFARA, the method of working interface prototyping will be applied in a programming environment to construct a high-fidelity prototype of GeoFARA with sufficient functionalities and interactivities for the following usability evaluation. During the process of producing design solutions for GeoFARA, the application of relevant design guidelines and standards involves making use of previous design experiences, and ensuring consistency of the design of GeoFARA with mobile applications in general. The implementation of the methods and techniques (Table 3.4) is presented in Chapter 5.

\subsubsection{Stage 3 - Evaluating the prototype of GeoFARA}

Evaluating the designed and developed product is an important and essential part of the overall UCD process. The evaluation should be based on the users' perspective, i.e. the evaluation should be user-centered. An important starting point of a user-centered evaluation is to define what goals to achieve. The goals lay the foundation for the entire evaluation. Further, they determine the follow-up selection of evaluation methods. In this research, the goal of the evaluation focuses on making use of the utility and usability results to find out the issues of the current design solution for proposing improvement recommendations. The main evaluation goals will be described in detail in Section 6.2. There is a set of research methods to choose from to evaluate a user-centered design solution (see Table 3.2) and each of them is particularly suitable to reach specific evaluation objectives. Following ISO 9241-210 (2010), an appropriate combination of evaluation methods should be used to obtain comprehensive and meaningful evaluation results in practice, and the selection of evaluation methods should be based on the evaluation goals. A mixed use of multiple evaluation methods will be applied in evaluating GeoFARA to get combined insights into its utility and usability. Table 3.5 provides a brief overview of the methods and techniques for evaluating GeoFARA. 


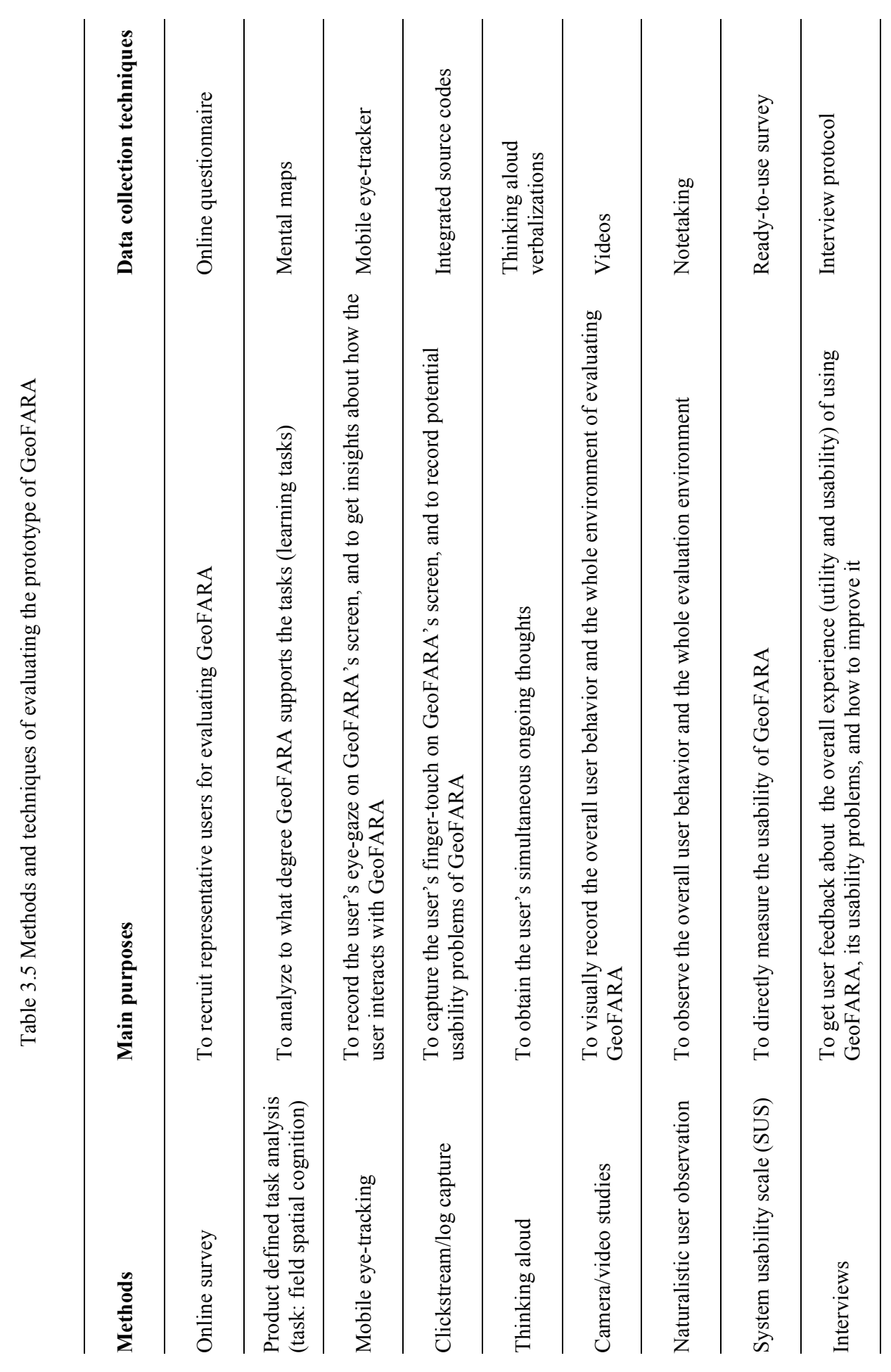


Every user-centered evaluation starts with recruiting test participants that includes finding, selecting, inviting and scheduling the test participants. Recruiting participants will be accomplished through the survey method. Prior to the actual evaluation, an email survey (URL12, Appendix 7 is the complete survey) will be performed in order to establish the basic background characteristics of the participants (age, country of origin, experience with mobile maps, knowledge of AR, etc.). In terms of the questions in the survey, following Haklay's (2010:220) suggestions about the user study of geospatial technologies, "of particular importance is understanding the existing spatial knowledge of the expected users and those who are recruited from the evaluation", therefore, the survey will also include questions that could influence the performance with respect to the spatial cognition tasks, such as the familiarity with the fieldwork area. The prefieldwork background survey results will be used not only as criteria for the assessment of the suitability for participation, but also as potential factors that could be used for the interpretation of the evaluation results. In particular, the participants' self-reports of their spatial abilities will be revealed by their completions of the Santa Barbara Sense-ofDirection (SBSOD) scale (Appendix 8) and their drawing of a pre-fieldwork mental map of the fieldwork area (Appendix 9).

During the actual evaluation session, the participants will be asked to explore the textile remnants in the fieldwork area with the help of GeoFARA. Several complementary methods will be incorporated in order to gather various data and information about the users themselves, the users' interactions with GeoFARA as well as the users' physiological and cognitive processes during interactions. These methods include mobile eye-tracking, clickstream/log capturing, thinking aloud, camera/video recording, user observation, as well as product defined tasks (field spatial cognition). Participants will not be asked to perform certain interaction tasks, therefore, the methods of performance testing and walkthrough (in Table 3.2) will not be used to evaluate how the participants will complete tasks. A Tobii mobile eye tracker device will be used to capture participants' eye movements within the real field environment, including the screen of GeoFARA (Section 6.3.2), while thinking aloud will be employed to obtain the participants' ongoing thoughts. Both the mobile eye tracking and the thinking aloud will be recorded by the mobile eye tracker. In addition, interaction log tracking, along with timestamps, will record the participants' interactions with GeoFARA and field walk tracking, along with timestamps, will record their walking routes. Since GeoFARA is used offline, all the tracking will be first saved on the client, and at the time of an active connection to the server, all the data will be pushed to the server. Back from the fieldwork, participants will be again asked to draw a post-fieldwork mental map (Appendix 11) of the fieldwork area. After this, the participants will be asked to fill the System Usability Scale (SUS) (Brooke, 1996) (Appendix 12), consisting of ten usability rating questions, to directly measure the usability of GeoFARA. At the end of the whole evaluation with each participant, an 
interview (Appendix 13) will be conducted to get additional information on the experience of the participant in using GeoFARA to support their field activities. During the interview, participants will be also asked to give general feedback and suggestions on how to improve the design of GeoFARA. During the whole field study, camera/video recording and naturalistic user observation will be used to record and observe the overall user behavior when using GeoFARA. The implementation of methods in Table 3.5 is presented in Chapter 6.

\subsubsection{Reliability and validity}

There now is a need for a methodological consideration of the UCD methods and techniques applied to GeoFARA, i.e. their reliability and validity. The reliability of UCD methods and techniques refers to the measurement of the consistency of UCD results across different UCD researches (or researchers) (Hartson et al., 2003). Following Hartson et al.'s (2003) and Haklay's (2010) arguments, there is a lack of standard criteria for reliably comparing different methods and techniques of UCD research. In addition, it can be argued that agreement among UCD researchers is more useful than correlation of reliability measures. Therefore, in this research, the reliability of UCD methods and techniques is not addressed because the selected methods are based on largely agreed and broadly accepted UCD research methods (See Table 3.2).

Another consideration is the validity of UCD methods and techniques. Validity is a measurement of how well methods and techniques reflect their intentions (Hartson et al., 2003). There are four kinds of validity: statistical conclusion validity, internal validity, external validity, and construct validity (Haklay, 2010). Statistical conclusion validity is mainly concerned with the degree to which statistical conclusions are reliable. Internal validity is about the degree to which relationships between independent and dependent variables (i.e., cause and effect) is solid, while external validity concerns the extent to which the research results can be applied to other cases (i.e., generalized). Construct validity is the degree to which a measurement and a concept/construct correspond. In the user-centered design of GeoFARA, the two important methods are: (1) field observation, surveys, and interviews during an actual fieldwork for analyzing the user requirements for GeoFARA; (2) field testing in a real geography fieldwork for evaluating GeoFARA. These methods have the obvious advantage of being externally valid as they are applied in real settings. In this research, adopting the claims of Yovcheva (2015) and Haklay (2010), other aspects contributing to an increase of the external validity of the UCD methods are: (1) the field-based tasks (spatial cognition through using GeoFARA) are specific enough to measure and can be completed in a short amount of time (less than one hour in the field); (2) the measurement of the users' geographic knowledge prior to and after the actual geography fieldwork. 


\subsection{Conclusion}

UCD, putting users in the central position of the whole design process, has been amongst the most commonly used approach and core concept in HCI research. This research adopts the UCD approach in the design and development of GeoFARA, a mobile application for supporting the spatial cognition of students during a human geography fieldwork. The main purpose of selecting this approach is to increase the overall usability of GeoFARA.

This chapter started with a basic outline of the interrelated concepts of UCD, HCI, UE, usability and UX. Among these concepts, UCD gained a wide attention by ISO, and was defined and addressed in several ISO documents in terms of its principles and the iterative processes. According to ISO, the main interactive activities of UCD include: (1) CoU and user requirement analysis, (2) conceptual design and prototyping, and (3) usability evaluation. This has been broadly adopted when applying the UCD approach in the design of interactive products. The UCD approach is also applicable in mobile application design. But for applying UCD in mobile applications, particularly context-aware applications such as GeoFARA, all aspects of users, environment, and mobile devices need to be fully taken into consideration, no matter under which modalities of user mobility (wandering, travelling or visiting). The geography fieldwork of this research in which GeoFARA is applied is a modality of visiting in an area. Besides, for mobile usability, a distinction can be made between mobile device usability and mobile application usability. This research is about mobile application usability, i.e. GeoFARA's usability-the extent to which GeoFARA can be used by students to achieve spatial cognition with good usability during the whole fieldwork.

There is a wide range of UCD methods and techniques that are available for specific UCD research projects to choose from. Table 3.3, 3.4 and 3.5 present the methods and techniques selected for GeoFARA in the stages of analyzing its $\mathrm{CoU}$ and user requirements, producing its design solutions, and evaluating its usability, respectively. Their implementation will be described in a more detailed way in Chapter 4, Chapter 5 and Chapter 6. 
Chapter 4

Specifying the Context of Use and Analyzing the

User Requirements 


\subsection{Introduction}

The reasons of producing GeoFARA using a combination of AR and maps for geofieldwork education are driven by many factors (explained in Section 2.5), and the main purpose of GeoFARA is to support situated learning in the field with immersive experience. To meet the challenge of designing and developing the interactive mobile fieldwork tool GeoFARA, the UCD approach is adopted in this research. This UCD approach has been introduced in the previous chapter. UCD is a fundamental concept for designing interactive systems products, starting with specifying their context of use (CoU) and their use and user requirements. This chapter reports on the results of the $\mathrm{CoU}$ and user requirements analysis towards GeoFARA to support geography fieldwork.

Section 4.2 establishes, from literature studies, the current state of the design and use of mobile AR in (informal) education (mainly in fieldwork). Particularly, five researchbased mobile AR fieldwork applications are reviewed in terms of mobile platform, purposes, interface, and implementation. Section 4.3 describes $\mathrm{CoU}$ attributes of GeoFARA, including the users and their characteristics, the goals and tasks, the resources (mainly hardware) as well as the environment of GeoFARA. Section 4.4 presents the preliminary user requirements, as collected through an online survey, a field experiment, an ethnographic study during a real human geography fieldwork, and two post-fieldwork surveys. Thereafter, in Section 4.5, a specific human geography fieldwork will be introduced as the use case for GeoFARA in terms of the objectives, questions to be answered during the fieldwork and the fieldwork tasks. Section 4.6 presents a use scenario of GeoFARA based on a persona, and Section 4.7 summarizes and prioritizes all the user requirements of GeoFARA. The concluding Section 4.8 indicates that the user requirements for GeoFARA will be used to produce the design solution.

\subsection{Existing mobile AR application analysis}

Educational contexts generally can be categorized into two basic branches: (1) formal classroom-based education, (2) informal out-of-classroom-based education. Because the geography fieldwork in this research falls in the latter category, in the following, we will briefly review existing literature on the use of (mobile) AR tools in informal educational settings regarding the platforms, the purposes, and the outcomes of using them.

\subsubsection{Mobile AR in education}

In the scientific domain and beyond, AR-based technologies have been visible for quite 
some time already. Around half a century ago, Sutherland (1968) developed a Head Mounted Display system to present changing virtual images and objects with users' movements in reality. Because of AR's extraordinary immersive interfaces and unique real-time interactions between real and virtual scenes, AR has served as a transformative tool in fields such as tourism (Kounavis et al., 2012), entertainment (Juan et al., 2011), education (Yuen et al., 2011), etc. Particularly in the education domain, AR can offer cognitive support to learners (Bower et al., 2014). Furthermore, because one of the key pedagogical affordances of AR is the ability to overlay contextual information on reality, the use of AR can support situated learning in the real world (Bower et al., 2014). Increasing amounts of both scientific educational research in AR and AR-related application projects indicate that $\mathrm{AR}$ has already gained much attention in educational research and application. Several studies have summarized the current status and future directions of the use of AR in education (Bower et al., 2013; Yuen et al., 2011; Wu et al., 2013; Dunleavy \& Dede, 2014; Reilly \& Dede, 2019).

Around two decades ago, the first mobile AR application was introduced by Feiner et al. (1997) who created an AR system on a see-through head-worn display with the main purpose of assisting users to explore a university campus with real-time labelling building information and overlaying imagery and navigation information. Although the initial intention of this mobile AR application was not for education, this study opened up possibilities of using mobile AR to support outdoor educational activities. More recently, considerable empirical studies have already been executed that explored the use of mobile AR in the context of informal education (Chien et al., 2019; Poitras et al., 2019; Pombo \& Marques, 2019). Regarding the platform of using AR in out-of-classroom scenarios, smartphones are increasingly preferable comparing to other devices. This is because it is relatively easy to take advantages of the capacities of portable smartphones as well as their wide ownership.

Qualitative and quantitative study outcomes of using mobile AR out of the classroom have shown the advantages of the utilization of mobile AR as an assisting tool. Some of the reported benefits are enhancing students' learning motivations (Kasahara et al., 2014; Pribeanu et al., 2008; Tarng \& Ou, 2012), developing scientific literacy skills (Squire \& Jan, 2007), fostering training skills such as field data collection and conducting field research (Ternier et al., 2014), improving spatial skills (Sánchez Riera et al., 2014), and more importantly, facilitating subject knowledge acquisition and promoting learning outcomes (Tarng \& Ou, 2012; Kasahara et al., 2014).

Despite such positive aspects, like many other ICT potentials, integrating AR in education involves not only opportunities but also challenges. As Wu et al. (2013) indicated, the educational values of AR are not only related to the use of AR itself, but also closely 
subject to "how AR is designed, implemented, and integrated into formal and informal learning settings". In particular, Höllerer \& Feiner (2004) and Bower et al. (2014) indicated that the potential technological, pedagogical and contextual issues are key to the successful application of AR in education. Kerawalla et al. (2006) even found negative educational effects of using AR, such as low student engagement. These issues might be even more true for the use of AR on mobile devices in fieldwork educational settings, because mobile learning tools might bring more cognitive load (Liu et al., 2012), and the novelty of the fieldwork setting might distract the learners' attention (Orion \& Hofstein, 1994). To solve all of these potential issues that otherwise may fail to assist learning, the learning technology should be properly designed with specific functions that are relevant to the fieldwork. There are already some proposed guidelines for designing mobile AR (see e.g. Kourouthanassis et al., 2013; Yuan, 2019). Regarding specifying user requirements for AR applications, there are examples extracting design requirements for classroom-based AR applications, (e.g., Kerawalla et al., 2006) but design requirements for mobile out-of-classroom-based AR have not been suggested yet.

Particularly in human geography fieldwork, no similar AR has been used as an assisting tool up till now, while it appears to be promising to successfully make use of a mobile tool which integrates AR and other visualizations to support human geography fieldwork (as an informal educational setting), provided that such a tool could be well designed by adopting the principles of UCD, the basis of which is the design requirements of the actual users, which are still invisible from existing literature. In this research, to user-centered design the mobile AR tool GeoFARA, the first stage is to collect and analyze the CoU and the user requirements for such a tool.

\subsubsection{Mobile AR applications for outdoor educational use}

There are increasing attention and scientific literature on the use of mobile AR applications to support various field activities. To understand what GeoFARA could add to those existing mobile AR applications, this section reviews five mobile AR applications (Table 4.1) for outdoor educational use that have a purpose that is comparable to that of GeoFARA, i.e. assisting users in understanding the geography of the fieldwork area during field activities.

The selection of these examples was based on more detailed criteria: (1) research-based mobile AR applications from scientific publications that are released after the year 2010; (2) supporting field (geo-) activities in urban areas; (3) using location-based techniques to overlay virtual information; (4) available on smartphones. Below, the selected examples are reviewed in terms of the platform, purposes, interfaces and implementation. 
Table 4.1 Some examples of existing mobile AR applications for geography fieldwork

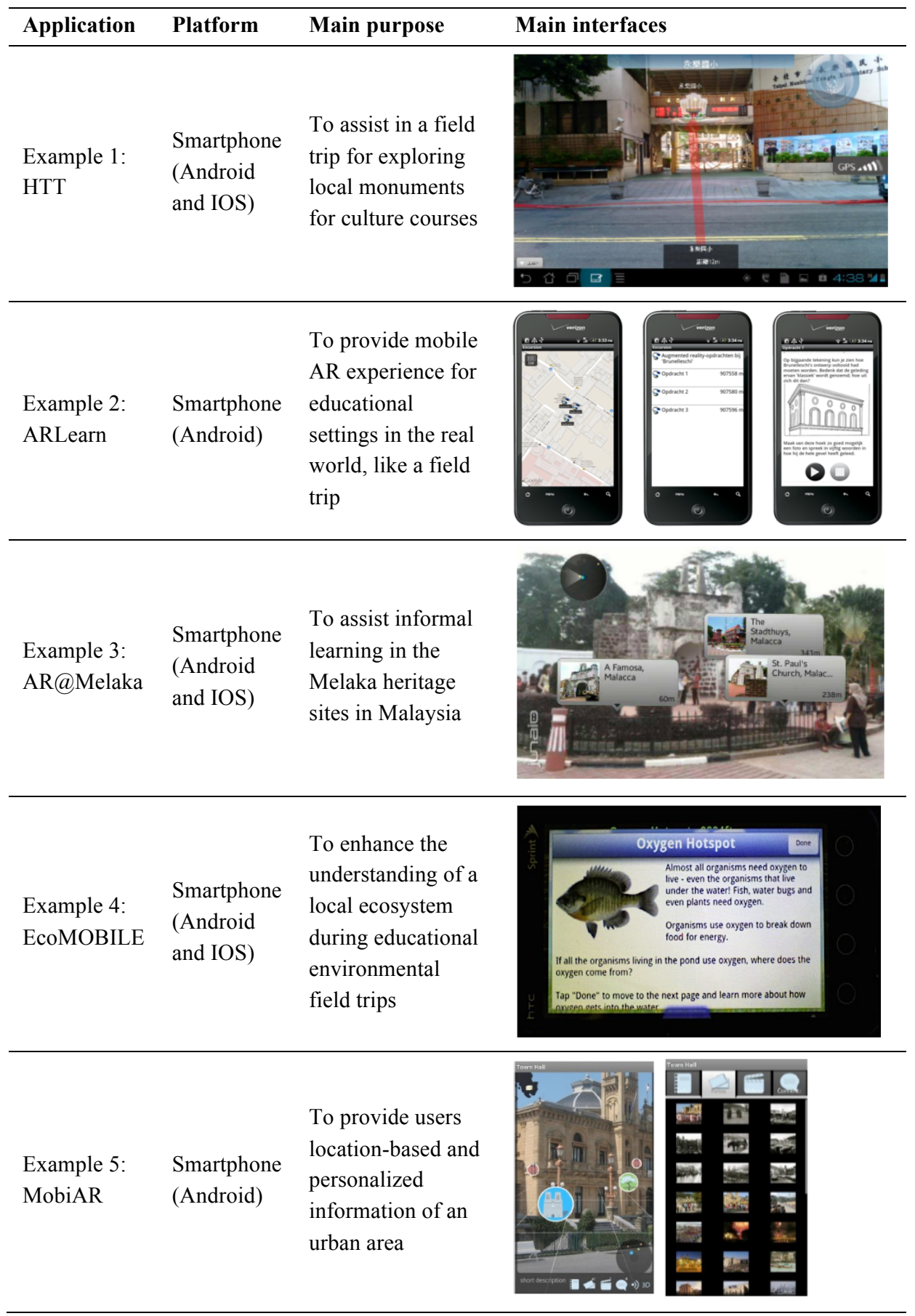




\section{Example 1: HTT}

Tsai \& Huang (2014) introduced the HTT (Historical Time Tunnel) system as a contextaware mobile AR learning platform. It was designed and implemented to support a field trip for exploring local monuments for culture courses through providing students with an immersive experience of disappeared or damaged historical attractions. The immersion was created through AR by augmenting real scenes with multimedia learning material of sounds, images, or video clips. A static field trip map indicating Points of Interest (POIs) was integrated in the platform as learning material. The usability of HTT was tested by comparing the results of post-fieldwork questionnaires of a control group that conducted a traditional field trip with those of an experimental group that used the HTT. The results indicated that the HTT system provided significant assistance to the teacher and can effectively boost students' interest in fieldtrip exploration. Overall, the HTT system achieved a good learning effect. In the AR interface of HTT, 2D icons were used to overlay the multimedia contents. Overlaying 3D models of monuments was suggested, as that is expected to further boost learning.

\section{Example 2: ARLearn}

The ARLearn system developed by the Centre for Learning Sciences and Technologies of the Dutch Open University (Ternier et al., 2014), is a tool suite that is providing different mobile AR experiences for educational settings in the real world by using multimedia capabilities and location-based services on smartphones. In ARLearn, the map view is Google Maps with a satellite image layer showing the users' current location and ARLearn objects. In the research by Ternier et al. (2014), ARLearn was applied to support mobile location-based learning during a cultural sciences fieldwork in the city of Florence by augmenting the users' locations with audios. ARLearn also features a note taking functionality, so that students can take pictures, record audios and publish annotations. An evaluation of ARLearn was conducted through questionnaires and analyzing the collected students' fieldwork notes. Overall, the students were positive about the use of ARLearn as a learning tool during the field trip. The tutor of the fieldwork confirmed that the students' post-fieldwork reports were more systematic than those of fieldworks without this tool suite. These results positively support the idea of developing a mobile AR application such as GeoFARA to support location-based learning during fieldwork.

\section{Example 3: AR@Melaka}

AR@Melaka (Pendit et al., 2014; Zaibon et al., 2015) is a mobile AR application to assist visitors to experience enjoyable informal learning while exploring the Melaka heritage 
sites in Malaysia. A conceptual model was proposed to guide the development of AR@Melaka. The model consisted of three main components: mobile AR technology, enjoyable informal learning, and the cultural heritage site. Following the model, four main user interfaces were designed: home page, search page, sign viewer page and information menu page. The contents include a profile, audio, a map and a multiple choice quiz of the Melaka heritage sites. An evaluation was carried out by asking respondents to use the application and fill in a questionnaire afterwards. The results showed that AR@Melaka was easy, fast, useful and helpful in gaining knowledge and supporting enjoyable informal learning. The conceptual model of AR@Melaka provides the basic elements (hardware, content, interface) that can also be applied in the conceptual design of GeoFARA.

\section{Example 4: EcoMOBILE}

In the research of Kamarainen et al. (2013), the project EcoMOBILE (Ecosystems Mobile Outdoor Blended Immersive Learning Environment) was introduced. EcoMOBILE combines an AR experience with the use of environmental probeware, an educational application, during a field trip to a local pond environment. The AR component in EcoMOBILE was created using the FreshAiR (URL13) AR development platform. "Triggers" (also referred to as "hotspots", see Table 4.1) are placed on a map of the physical setting and become accessible to students at the real location in the field. At a trigger location, students can interact with multimedia (including texts, images, audios, videos, 3D models and animations, and multiple-choice or open-ended questions) through an immersive AR experience. Students found that the use of AR supported their recognition of non-obvious or unseen factors as significant actors in ecosystem dynamics. The results showed that the overall EcoMOBILE experience contributed to significant student learning gains.

Augmenting non-obvious or unseen factors into EcoMOBILE enhances students' field learning. Therefore, the conceptual design of GeoFARA should also take into consideration augmentation of those hidden but important parts of the fieldwork area that students might miss during the field trip.

\section{Example 5: MobiAR}

MobiAR (Linaza et al., 2012) is a mobile AR application, aiming at providing users with location-based and personalized information of an urban area. AR interfaces of MobiAR are different in different scenarios. The target user can be anyone who is eager to discover more about some places in a city. MobiAR was evaluated in a scenario of field use in the city San Sebastian, Spain. Quantitative (questionnaires) and qualitative (interviews and 
observations) evaluation methods were implemented. The evaluation aspects included technology-related usability and ease of use of the application, the overall user interface, content quality, information structure and design, information-related usability and user satisfaction. In general, participants found MobiAR was a useful medium to display visual information.

In comparing the map view and the AR view, almost all the users found that the map view was more functional than the AR view during navigation. Therefore, for the navigation functionality of GeoFARA, it is better to design this functionality in the map view instead of in the AR view.

\subsubsection{Analysis of the existing mobile AR fieldwork applications}

A detailed analysis of the above mobile AR applications could lead to potential design decisions for GeoFARA. In summary, the main characteristics of those mobile AR applications are: (1) in AR view, location-based information is overlaid on real time scenes with which users can interact to get further information; (2) map views are different: either static maps or mobile digital maps or just the satellite image layer of mobile maps; (3) all kinds of multimedia, like textual information, images, audios and videos are flexibly included.

However, some limitations were also identified. The design of GeoFARA should try to overcome those limitations. One of the very obvious limitations is that users were only involved in testing the usability of the completed mobile AR applications instead of already during the design stages. During the future design of GeoFARA, users will be involved within the design, development and usability evaluation stages, especially through applying the user requirements in the design solutions producing stage. Another major limitation is that, in the above examples, map interfaces and AR interfaces were always separated and it was hard for users to have a whole urban area overview on a single screen at the same time. To overcome this limitation, the interface design of GeoFARA will try to better integrate map and AR interfaces, giving users both a map view of the fieldwork area and a live view via AR at the same time, and allowing users to flexibly switch between the map and AR view.

\subsection{Specifying the context-of-use for GeoFARA}

It is necessary to understand and analyze the context-of-use (CoU) of products to be designed. The analysis of the $\mathrm{CoU}$ can guide early design decisions, and provide a basis for evaluation (ISO13407, 1999). Maguire (2001) gives a summary of the purposes of 
analyzing the CoU at different stages (Table 4.2). In line with the ISO standards, the CoU analysis focuses on the "specification stage". The purposes of identifying the CoU in this chapter fall into the one "to aid specification of user requirements, and to set usability goals and acceptance criteria”. According to ISO 9241-210 (2010), the outputs of understanding and specifying the CoU activities include a context-of-use description and a context-of-use specification. The CoU description should include four components: (1) the users, (2) the goals and tasks, (3) the resources, and (4) the environments of the system including technical, physical, social, cultural and organizational environment. The CoU specification should be stated in terms of attributes of the above four components. Based on ISO 9241-11 $(1998,2018)$ and Maguire (2001), Table 4.3 lists an example of the components of the $\mathrm{CoU}$ of a product/system/service and the attributes of each component. In this research, the CoU of GeoFARA will be defined by the four aspects provided in Table 4.3: (1) GeoFARA's users and their characteristics, (2) the goals and tasks of GeoFARA, (3) the resources of GeoFARA, and (4) the environment of GeoFARA. However, for any particular case like GeoFARA, not all the attributes of the four aforementioned aspects listed in Table 4.3 are relevant, and even additional attributes may have to be specified under the four components of CoU. For examples, in the case of GeoFARA, the organizational environment (e.g., organizational structure, attitudes, culture) is not applicable and not so relevant when specifying the CoU for GeoFARA in this $\mathrm{PhD}$ research. For the "specification stage" of designing GeoFARA, some of the CoU attributes are very clear. For instance, GeoFARA has both primary users and secondary users-undergraduates and geography fieldwork organizers, respectively; the environment mainly includes the technical environment (hardware, software, network) and physical environment. Overall, Table 4.4 describes the CoU for GeoFARA that are relevant to its design. All those attributes will support the follow-up work: the collection and analysis of the user requirements (as described in the rest of this chapter), the production of design solutions (Chapter 5), and the evaluation of GeoFARA (Chapter 6).

Table 4.2 Purposes of analyzing the CoU at different design stages (Adapted from Maguire, 2001)

\begin{tabular}{ll}
\hline Stage & Purpose \\
\hline Specification stage & $\begin{array}{l}\text { To aid specification of user requirements, and to set usability goals } \\
\text { and acceptance criteria } \\
\text { To ensure high quality design by tailoring the product to the } \\
\text { concept stage }\end{array}$ \\
Testing stage & $\begin{array}{l}\text { To match the context of testing to the context of use } \\
\text { To help project managers or system developers be aware of } \\
\text { Throughout the process } \\
\text { usability issues throughout the design process and to track the } \\
\text { achievement of usability goal }\end{array}$ \\
\hline
\end{tabular}


Table 4.3 An example of the components and their attributes of $\mathrm{CoU}$ (Adapted from ISO 9241-11, 1998, 2008; Maguire, 2001)

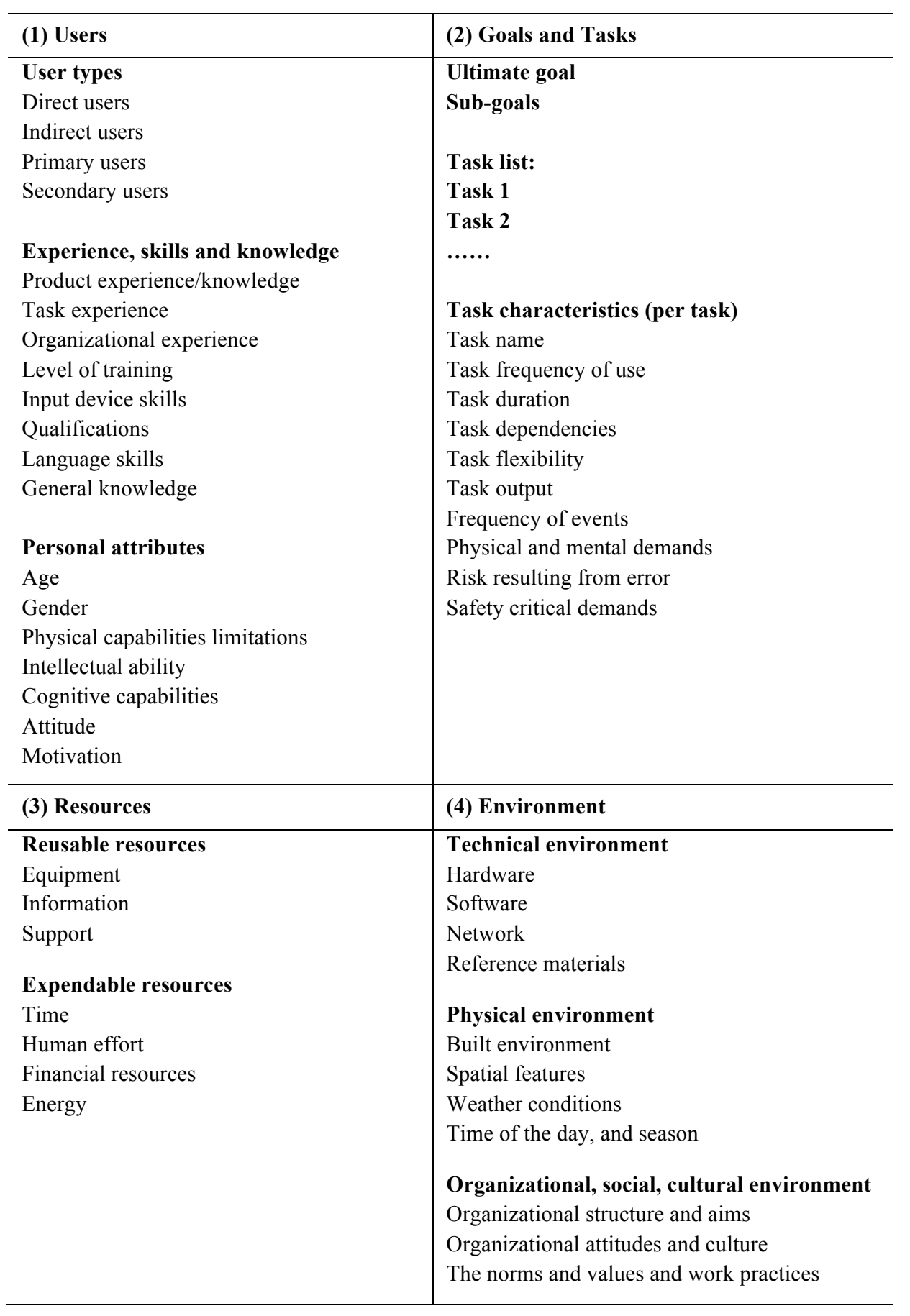


Table 4.4 The CoU of GeoFARA description and specification

\begin{tabular}{|c|c|}
\hline (1) Users & (2) Goals and Tasks \\
\hline $\begin{array}{l}\text { User types } \\
\text { Primary users: } \\
\text { Students who attend a fieldwork } \\
\text { Secondary and indirect users: } \\
\text { Teachers who organize a fieldwork } \\
\text { Experience, skills and knowledge } \\
\text { Product experience/knowledge: } \\
\text { Varies in the frequency of using AR and maps } \\
\text { Task experience: } \\
\text { Varies in using AR and maps on mobile } \\
\text { phone } \\
\text { Language skills: } \\
\text { English and Chinese, but mainly English } \\
\text { Personal attributes } \\
\text { Age and Gender: } \\
\text { Mainly above } 20, \text { both male and female } \\
\text { Cognitive capabilities: } \\
\text { Varies in spatial ability and other cognitive } \\
\text { aspects } \\
\text { Attitude and Motivation: } \\
\text { Mostly motivated to use tools to complete the } \\
\text { fieldwork }\end{array}$ & $\begin{array}{l}\text { Goals: } \\
\text { See Table } 4.6 \text { in Section } 4.5 .2 \\
\text { Tasks: } \\
\text { See Table } 4.7 \text { in Section } 4.5 .3\end{array}$ \\
\hline (3) Resources & (4) Environment \\
\hline $\begin{array}{l}\text { Reusable resources } \\
\text { Equipment: } \\
\text { User's mobile phone } \\
\text { Expendable resources } \\
\text { Time: } \\
\text { To be spent on to complete the fieldwork tasks }\end{array}$ & $\begin{array}{l}\text { Technical environment } \\
\text { Hardware, software, network: } \\
\text { Smartphone } \\
\text { Smartphone's operating system } \\
\text { Smartphone's Internet connection } \\
\text { Physical environment } \\
\text { Built environment, spatial feature: } \\
\text { Depending on the fieldwork area } \\
\text { Weather conditions: } \\
\text { Both comfortable and uncomfortable (rainy, } \\
\text { etc.) } \\
\text { Time of the day, and season: } \\
\text { Day time, any season }\end{array}$ \\
\hline
\end{tabular}




\subsection{Analyzing user requirements through various methods}

Digital tools that support learning should be properly designed with specific functions that are relevant to the learning objectives (Meek et al., 2013). As such, GeoFARA, as a mobile digital tool to support geography fieldwork learning, should be designed with functionalities that are relevant to the geography fieldwork learning objectives. In order to specify the functionalities of GeoFARA, the user requirements should be identified. For GeoFARA, the user requirements were analyzed through both experimental and nonexperimental investigations. They are: 1) an online survey of geography fieldwork teachers about the current situation of using assistance tools; 2) a field experiment in which the use of paper maps and a mobile tool were compared during a geography fieldwork trip; 3) an ethnographic study through questionnaires, interviews and observations in a real human geography fieldwork of Beijing Normal University (BNU); 4) post-fieldwork surveys among undergraduates from BNU (another human geography fieldwork) and Ghent University (a human geography fieldwork).

\subsubsection{An online survey of geography fieldwork organizers}

To know the current use of digital tools to assist fieldwork, and to explore the possibility for an alternative mobile tool from the perspective of geography fieldwork organizers/teachers (the secondary users of GeoFARA), an online survey was executed. The setup and the results of this survey were presented in Section 2.4.2. From the results of this online survey some user requirements could be drawn as well especially from the part that was focusing upon problems with the use of the visualization tools and the opinions about alternative digital tools. From this, it became clear that:

- In GeoFARA, a clear description about how it works should be included;

- GeoFARA should provide different base maps of the fieldwork area;

- GeoFARA should enable the collection of all kinds of geo-media (such as text, sound, images);

- GeoFARA should be easy-to-use and flexible-to-update.

\subsubsection{A field study of examining the usage of an existing mobile application}

To find out the problems with the use of an existing mobile field application compared to the traditional paper maps as well as to identify new features of GeoFARA, a field study 
was carried out during a field excursion in Enschede, the Netherlands. The field experiment was cooperated and supported by a University of Twente MSc thesis research project (Ekpenyong, 2015). In this project, a field experiment was carried out to investigate the use of an existing mobile field mapping application, as compared to the use of traditional paper maps. The area in which the field experiment was executed was the same (see Figure 6.5) as the fieldwork area in which the prototype of GeoFARA will be tested in this $\mathrm{PhD}$ research. The theme of the field mapping exercise was "examining the effects of the textile industry collapse on the geography of part of Enschede". Participants were asked to discover textile industry remnants and relatively new features within the field area and then to mark them as POIs (Point of Interests) either on a paper map or in the Locus (URL14) mobile field mapping application (Figure 4.1). Locus was chosen mainly because it offers a variety of online maps and because it can be used easily in the field without Internet connection. The participants were selected by inviting new students of the Faculty ITC of the University of Twente to answer an online survey which aimed to collect information about potential participants' backgrounds, their mapping experience, computer literacy, knowledge of the Locus field mapping application, etc. In total, 12 students were selected to take part in the field experiment. There were divided into two groups, one group (6 participants) using a paper map (Figure 4.2, left) and the other group (6 participants) using the Locus mobile mapping application on a tablet (Figure 4.2, right).
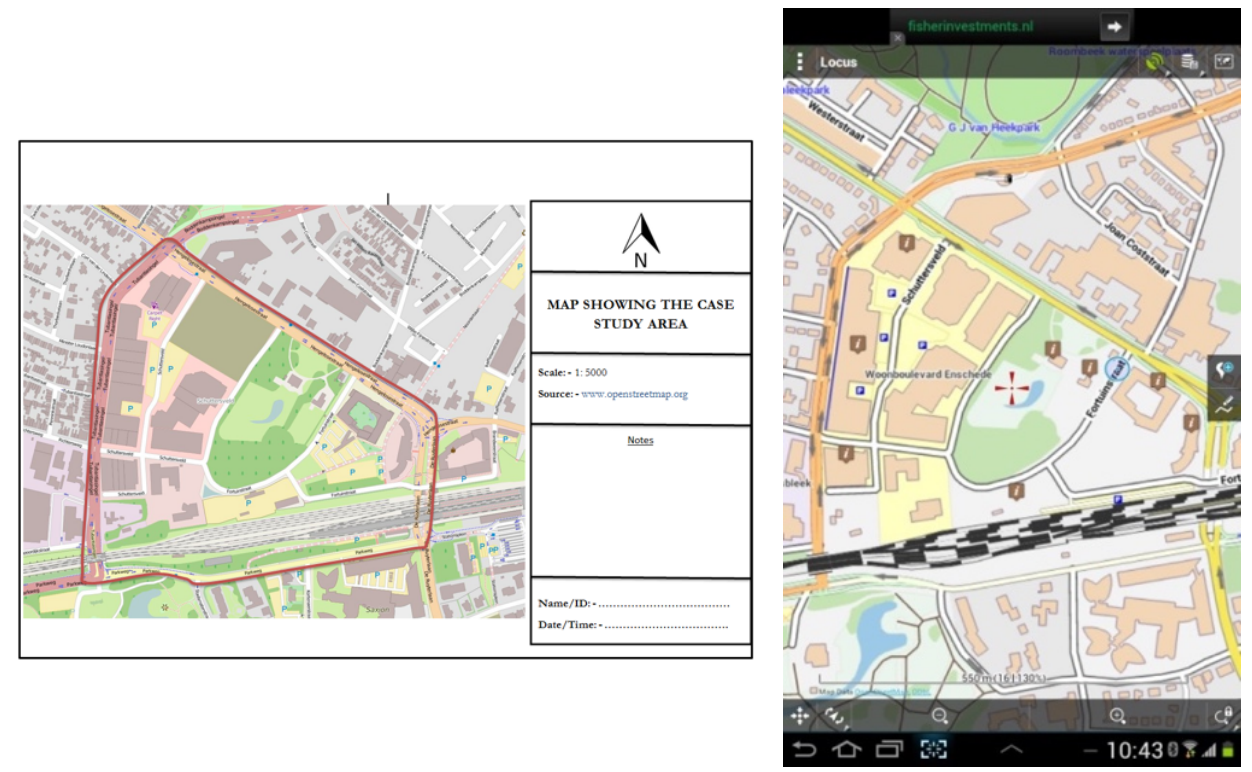

Figure 4.1 OpenStreetMap paper prints (left) and Locus mobile application (right) used in the field experiment

(Obtained from Ekpenyong, 2015) 

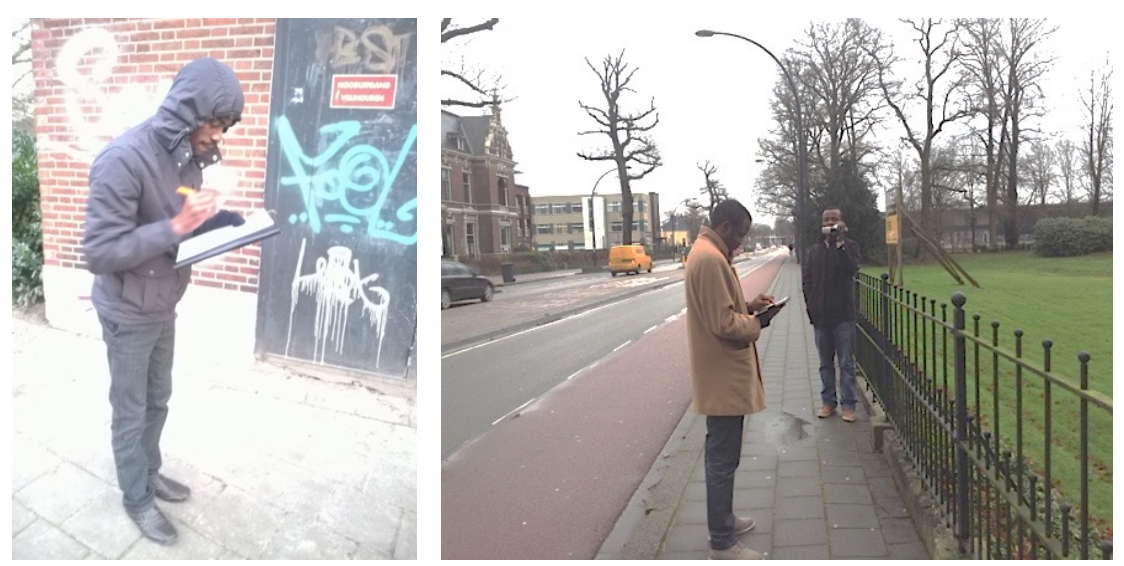

Figure 4.2 Mapping activities with the paper map (left) and the Locus mobile application (right)

(Obtained from Ekpenyong, 2015)

To interpret the participants' geographical understanding of the field experiment area, they were asked to draw mental maps before and after the field activities (Figure 4.3). Participants were instructed on how to draw mental maps of the field experiment area. For example: "On the map, indicate key elements such as pathways (roads, railway tracks etc.); major landmarks (e.g. the ITC building); boundaries and edges; and nodes (roundabouts etc.)", "Indicate important remnants of Enschede's textile history as well as relatively new features which have replaced old historical remnants" (Ekpenyong, 2015), etc. In addition, they were asked to think aloud (i.e., to say whatever they were thinking) during the field mapping activities, as well as during the pre- and post- mental mapping activities. The whole field experiment session of each participant was video recorded.

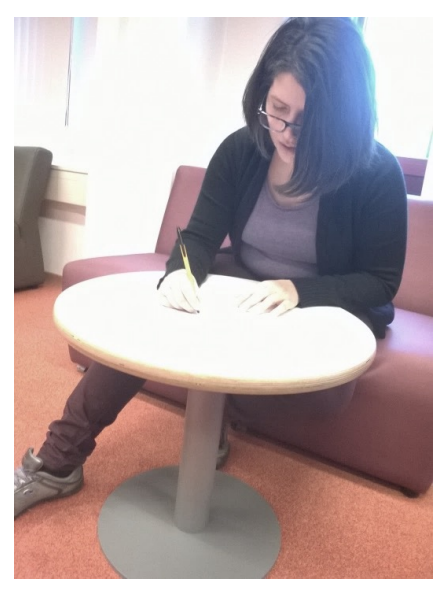

Figure 4.3 A participant were drawing a mental map (Obtained from Ekpenyong, 2015) 
The detailed results of this field experiment are presented in the MSc thesis of Ekpenyong (2015). Derived from this field experiment, for the development of GeoFARA, a number of requirements could be formulated for the development of GeoFARA.

On one hand, new aspects could be identified. In the MSc research, most participants drew point (such as big office buildings and shops) and line features (such as main roads and railway tracks) in their mental maps. We concluded that those drawn points and lines form the basic structure of the field area in the participants' minds. Therefore, to reinforce the impression of the spatial structure and to enhance geographical understanding, augmenting both points and lines of interest could offer visual support in GeoFARA. On the other hand, GeoFARA can learn lessons from the problems that participants met during the use of the Locus mobile field mapping application: All the participants in both groups delivered post-experiment mental maps that were substantially more detailed than the pre-experiment mental maps. However, perhaps surprisingly, after the execution of the field mapping activity, the paper map group got a higher level of improvement in their geographical understanding of the study area compared to the Locus mapping application group. The main reason for this result was that technical issues (such as unexpected system failures, faint screens, etc.) in using Locus distracted the test persons from learning the geography of the field area. Therefore, the technical implementation of GeoFARA should be such that the amount of system failures will be as few as possible.

\subsubsection{An ethnographic study during a real human geography fieldwork}

The main objective of this ethnographic study was to explore the main use and user requirements of a mobile tool to support human geography fieldwork. Here, the "support" included assisting with learning/teaching tasks and with the improvement of the students' geographical understanding. To this end, this study was conducted by attending an undergraduate human geography fieldwork in China (the objective of which included learning about the spatial structure of the fieldwork area) in order to collect data for the use and user requirement analysis for GeoFARA.

\subsubsection{The human geography fieldwork and the users}

The ethnographic study was conducted by attending a joint undergraduate human geography fieldwork that was organized by Beijing Normal University (BNU) within the town Dongshan in the city of Suzhou in Jiangsu province, China in July 2015. The participants were teachers ( 6 in total) and 3rd-year undergraduates (100 in total) from BNU and East China Normal University, and the students were divided into 6 groups. Therefore, the users in this study were both teachers and students. 
This fieldwork was affiliated to a human geography course. The overall objectives of the fieldwork were: (1) to learn about the spatial structure of Dongshan, and (2) to investigate the relations between the natural environment and human activities by conducting group field research within Dongshan. Students' pre-fieldwork activities were learning on their own through an online fieldwork website (URL15). The activities in the field lasted for two days. The first day was a so-called "horizontal fieldwork". Students toured with the teachers while teachers gave lectures in the field to explain the geography, history, architecture, etc. of the town, and students observed and made notes. Besides, students conducted group research work, i.e., field investigations of their topics. The second day was a so-called "vertical fieldwork" in which a local hill was explored. Students learned about the vertical distribution of vegetation through observation and teacher explanations during climbing the hill. Besides, students continued to conduct group investigation work in the field. After the two days in the field, on the third day, students worked in groups on a field research report, and presented that to all the other students and teachers.

\subsubsection{Methods and procedure}

As suggested by Yovcheva et al. (2013), initially formulated use and user requirements can be elicited by using methods such as observation, questionnaires and interviews in comparable future usage settings. The results are a summary of use and user requirements derived from how users currently achieve certain goals, what difficulties users currently experience, as well as expectations and preferences for a future alternative product.

For analyzing user requirements towards the design of a new tool, the first part is to know the general user profile, i.e., the basic characteristics of potential users. In this particular study, the author used questionnaires in the pre-fieldwork stage to establish the basic background characteristics of the participating students (gender, age, major, etc.), their use of mobile phones and tablets, their cartographic background (use of paper and digital maps, difficulties and preferences of using them) and their knowledge about AR. The original English questionnaires (Appendix 2) were translated into Chinese and were then distributed to all the students one day before the actual fieldwork. Before handing out the questionnaires, a brief introduction about the research work and the purpose of the questionnaire survey was given to all the students and teachers.

The method of observation was used in all three stages of the fieldwork (preparation, execution and reporting). The author participated in the whole fieldwork, aiming at observing how teachers and students perform the teaching and learning activities with a focus on the use of (cartographic) visualizations, as well as the difficulties of using these visualizations. The main techniques of gathering the observation data were taking notes, together with taking photos and videos. For example, when teachers used the paper map 
to explain the current location and geographical features, notes and photos were taken by the researcher to establish the type of visualization tool used and the purpose of using.

To formulate what difficulties were experienced when using existing cartographic visualizations and mobile devices in the fieldwork, as well as to justify how an alternative tool could possibly be applied in future, students and teachers were also interviewed during and after the fieldwork. Nine students and four teachers were selected to attend the semi-structured interviews. Teachers were interviewed after they completed the field teaching task, while students were interviewed after executing their post-fieldwork task. Table 4.5 shows examples of questions that were asked during the interviews with teachers and students. The interview conversations were in Chinese and the interview data was recorded in the form of audios using a voice recorder on a tablet.

Table 4.5 Examples of interview questions in the BNU human geography fieldwork

\begin{tabular}{|c|c|}
\hline Category & Questions \\
\hline $\begin{array}{l}\text { The use of cartographic } \\
\text { visualizations } \\
\text { (For teachers and students) }\end{array}$ & $\begin{array}{l}\text { - What cartographic visualizations did you use before, } \\
\text { during and after this fieldwork? } \\
\text { - Why did you use these cartographic visualizations? } \\
\text { In your opinion, in which stage of geography fieldwork, } \\
\text { is the use of cartographic visualizations more important } \\
\text { in helping to improve the geographical understanding of } \\
\text { the fieldwork area: before, during or after? }\end{array}$ \\
\hline $\begin{array}{l}\text { Difficulties with using } \\
\text { cartographic visualizations } \\
\text { and mobile devices } \\
\text { (For teachers and/or students) }\end{array}$ & $\begin{array}{l}\text { Did you experience some difficulties when using these } \\
\text { cartographic visualizations during the fieldwork? What } \\
\text { were those difficulties? (For students and teachers) } \\
\text { What difficulties did you experience when using your } \\
\text { mobile devices during the fieldwork? (For students) }\end{array}$ \\
\hline $\begin{array}{l}\text { Expectations and basic } \\
\text { requirements of a future tool } \\
\text { (For teachers and/or students) }\end{array}$ & $\begin{array}{l}\text { - What do you suggest regarding how to use cartographic } \\
\text { visualizations on mobile phones that could help to } \\
\text { improve your geographical understanding of the } \\
\text { fieldwork area? (For students and teachers) } \\
\text { - What do you suggest regarding how to use cartographic } \\
\text { visualizations on mobile phones that could help to } \\
\text { complete the teaching tasks? (For teachers) } \\
\text { What do you suggest regarding how to use cartographic } \\
\text { visualizations on mobile phones that could help to } \\
\text { complete the field learning tasks (processing data, } \\
\text { visualizing your findings, etc.)? (For students) } \\
\text { What do you think about the possibility to develop a } \\
\text { mobile augmented reality tool combined with the use of } \\
\text { cartographic visualizations for fieldwork use? What are } \\
\text { your basic requirements (functionalities, interfaces.) } \\
\text { towards such a tool? (For teachers and students) }\end{array}$ \\
\hline
\end{tabular}




\subsubsection{User profile}

In total, 93 out of 100 students responded to the questionnaires. The students were doing a major in four different geo-related domains: geography science, GIS, urban planning and land administration. All students had attended cartography and GIS courses.

Among the 93 responses, only 5 students had heard of AR and gave relatively precise descriptions about what AR is. Some of those descriptions were:

- "Combining the reality with virtual world, e.g., Google Glass";

- "Adding real-time object information in the reality".

In terms of ownership of smartphones and tablets, it was found that all students had their own mobile phones, and half of them owned tablets. $64 \%$ of the mobile phone operating systems was Android and $32 \%$ of them was IOS. Students used their phones and tablets for various activities. 80 out of 93 students responded that they had ever used the phones and tablets for learning geography specifically. Among those 80 responses, $56 \%$ said that they learned geography through both websites and applications. Therefore, it becomes clear that it is practical to make use of a mobile learning tool in geography fieldwork. To be more specific, the mobile devices should be mobile phones instead of tablets, and the tool should support the two main kinds of operating systems, i.e., IOS and Android, but developing for Android is a priority.

\subsubsection{Current use of visualizations and mobile devices}

From questionnaires, observations and interviews in the geography fieldwork, information could be derived on how cartographic visualizations and mobile devices are currently used in the three stages of this human geography fieldwork. It was found out that users (mainly students) used traditional maps, digital maps in mobile map applications, satellite images, and photos and videos of reality during this fieldwork.

Regarding the use of maps, in general, students used digital maps on mobile phones more frequently than using them on tablets and using paper maps. In terms of preferences of using paper maps or digital maps on mobile devices, $58 \%$ of the students preferred to use maps on their mobile phones or tablets, and only $18 \%$ preferred the traditional paper maps. The remaining $24 \%$ had no specific preferences.

A number of traditional 2D maps was used, like an administrative map and a land use map of the fieldwork area and also maps with the fieldwork route and landmarks that were visited later during the fieldwork. For the digital maps, Baidu Map (URL16) and 
Gaode Map (URL17) (both are Chinese digital maps products) were mentioned quite often. Students also used mobile map applications to mark some key locations (Figure 4.4 , left). From the interviews with students and teachers, it could be derived that all these maps were used before the actual fieldwork with the purpose of giving a basic geographical understanding of the fieldwork area. During the outdoor fieldwork itself, students used printed paper maps to find their current location (Figure 4.4, middle). Students also checked their current location by using their mobile map applications in the field. Teachers used printed paper maps to assist them to teach the geography of the fieldwork area and to show their current location. After attending field lectures and group investigation activities in the field, students were required to present the investigation results of the group research topics (e.g. the distribution of public utilities). To complete these post-fieldwork tasks, students used maps in their presentations to demonstrate the field survey location/area and to visualize their findings (Figure 4.4, right).
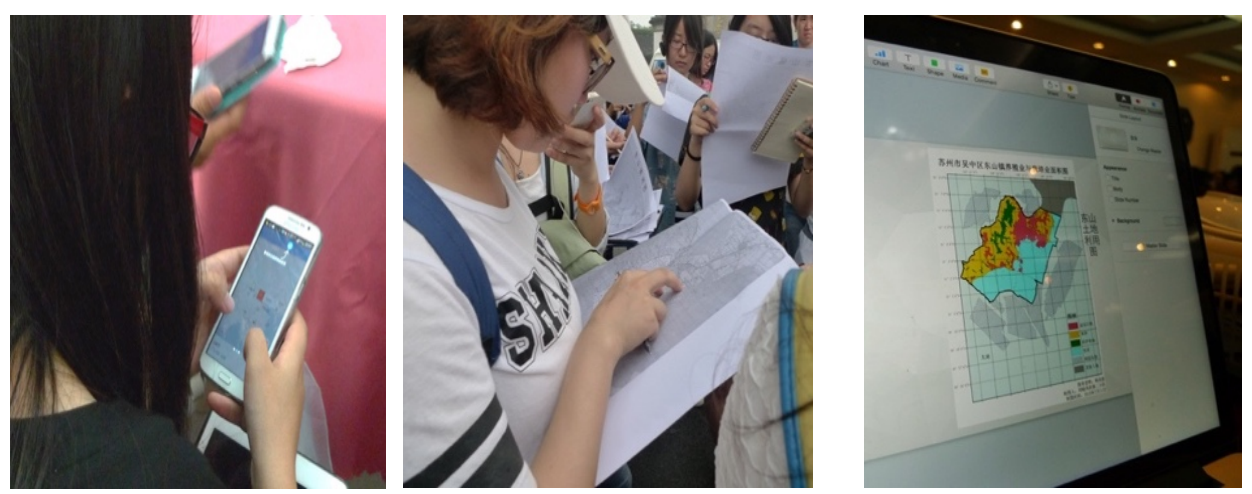

Figure 4.4 Maps used in different stages of the BNU human geography fieldwork

The satellite images that were used in this fieldwork are from two sources: the abovementioned fieldwork website and the switchable satellite image layers of desktop or mobile digital map applications (e.g., the "earth" layer of Google Maps). In this fieldwork, satellite images were mainly used before and after the actual fieldwork. Before going to the field, satellite images were used to give a general aerial view of the fieldwork area and the planned fieldwork route. In the stage of post-fieldwork activities, satellite images were used with the same purpose as using maps, i.e., as layers for post-fieldwork mapping. In general, using satellite images is a supplement to using maps, as satellite images encompass more geo-reality compared to the abstract information shown on maps.

Photos were used in all three stages of this fieldwork, while videos were used only before the fieldwork. A lot of photos of reality are available on the fieldwork website for prefieldwork use, and videos as well. Before going to the field, students browsed the photos 
and videos of the fieldwork area. From the teachers' perspectives, these photos and videos were offered and used because they statically and dynamically illustrate the landscape of the fieldwork area. During the students' activities in the field, they used their mobile phones to take photos of the field landscape. And some of these photos were selected for use in the post-fieldwork presentations. Students also mentioned that the use of photos is necessary to complete the fieldwork tasks, but only few of them indicated the purpose of increasing the geographical understanding of the fieldwork area.

All in all, it was found out that students and teachers currently use more traditional cartographic visualizations (e.g., maps) on different platforms, like mobile devices, computers, or papers. At the same time, the reasons of using them are not the same in every stage of the fieldwork. But the interviews demonstrated a consensus of students and teachers that it is more useful and more important to use these cartographic visualizations (especially maps) during the fieldwork execution stage instead of during the pre- and post-fieldwork stages.

In addition, how students used their mobile phones during the whole fieldwork was also observed, followed by interview questions. It was found out that students used their mobile phones to collect field data (photos, notes, voices, etc.) and to browse digital maps of the fieldwork area, with the purposes of completing fieldwork tasks and assisting their geographical understanding of the fieldwork area, respectively. This should be the starting point for personalizing GeoFARA in this research, i.e., better combining and fulfilling these two purposes.

\subsubsection{Current difficulties of using cartographic visualizations}

More than half of the students experienced different levels of difficulties with using maps on mobile phones and tablets: $7 \%$ of them "always" and $48 \%$ of them "sometimes". These difficulties included inaccuracy of positioning and map contents, out of datedness, low resolution of visualizations, unavailability of offline maps, complicated operation and unfamiliarity with the operation. At the same time, all students have a cartographic education background (obtained through university education in the previous three years).

Next to the map issues, another major problem is that both students and teachers found that the collected data (photos, voices, notes) lack spatial information. One of the teachers pointed that "now, the data collected is so messy and it is very easy to mix the data together and forget where the data was collected". Similarly, a student indicated that "after the fieldwork, I forgot where the photos belong to, because some of them look very similar." Besides, a teacher and a student mentioned the problem of switching between 
different mobile applications. It is time-consuming and troublesome to use different mobile phone applications at the same time.

Therefore, GeoFARA should integrate accurate maps of the fieldwork area and should be easy to operate. All the difficulties that students and teachers were experiencing in this fieldwork give a picture of what aspects should be paid attention to when designing GeoFARA to support fieldwork. It should be tried to avoid and (or) solve those difficulties when developing GeoFARA. Secondly, it became clear that, despite the students' cartographic education background, both a simple operation training on how to use GeoFARA and an introduction to AR are needed before they can use such an application in the field.

\subsubsection{Expectations and requirements towards a future mobile tool}

During the interviews, after briefly introducing what a future alternative mobile tool (GeoFARA) could look like (see Table 4.5), some expectations and requirements were expressed by teachers and students. In general, they were enthusiastic about using such a tool for assisting geographical understanding and completing field learning/teaching tasks. Most of them believed that it would be helpful to use such a tool to assist fieldwork. However, some basic key requirements from teachers and students, as primary and secondary users, should be considered. Analysis of these requirements can suggest initial priorities for the functionalities of GeoFARA.

First of all, there is a strong need of labeling the geo-locations of all collected data, i.e., the users would like to find the various data collected on the interface of a map. A teacher expressed this need in this way: "put all notes, voice recordings and photos in different locations, and at each location, a folder could be found to store all those data". Similarly, another teacher wanted students to create "a small working station" to collect photos, videos, voices, etc. in the field on their mobile phones. There was also a student who indicated a similar need. She said: "I just hope that one (mobile) application could complete all the data collection, and do not want to switch between different applications". It was not surprising to learn about this requirement because it was in line with the found major difficulty of the lack of locational details that the students and teachers experienced during this fieldwork.

In terms of requirements of cartographic visualizations, teachers and students wanted to optionally view various (up-to-date) maps, satellite images and historical geography visualization materials of the fieldwork area. A teacher pointed out that the overlay of different cartographic visualizations is important, but also that these various materials (maps, satellite images, etc.) of the fieldwork area may be viewed optionally. Besides, 
students wanted to be able to see a 3D street view of the fieldwork area because they thought this could improve their geographical understanding. Students also gave some suggestions regarding the needs for collecting data, such as making notes, recording voice data and field walking routes.

In addition, some other requirements were listed, such as group interaction, automatic recommendations and readable materials on the screens of mobile phones. For example, both students and teachers mentioned that they would like to have interactions within the group, reporting the current investigation situations, sharing photos, etc. A student expressed the requirement that this tool should "recommend something based on the current location". One of the teachers said that the materials (like photos and videos) in the tool must be suitable to be viewed on the small screens of mobile phones.

\subsubsection{Summary of the user requirements resulting from the ethnographic study}

The preliminary use and user requirements for GeoFARA resulting from this ethnographic study during a real human geography fieldwork can be summarized as:

1. Integrate various visualizations (photos, old maps, mobile digital maps, satellite images) of the fieldwork area. This is for the purpose of making use of different visualizations to increase the users' geographical understanding of the fieldwork.

2. Enable users to collect various field data (through notes, voice, registration of field walking routes) with geo-locational details. All of those collected photos, notes and voices with geo-locational information can be shown through hyperlinks in the map view.

3. Group interaction. When GeoFARA is used by multiple users, all users may share their current locations, photos, fieldwork progress etc. within the group. This is mainly for supporting group work during fieldwork.

4. Recommend location-based contents. GeoFARA may provide information based on the user's current location.

5. Show legible contents on the screens of mobile phones. In GeoFARA, the scales of maps, the fonts in the text descriptions, the resolutions and sizes of photos, etc. must be suitable for reading on smartphone screens.

\subsubsection{Post-fieldwork surveys among undergraduates of two universities}

To investigate the undergraduates' fieldwork use of mobile phones among intended users and their difficulties associated with using them, two post-fieldwork surveys were 
conducted among students of Ghent University in Belgium and BNU respectively at the end of 2015 .

Ghent University's human geography fieldwork was conducted in November 2015 in Amsterdam (in the Netherlands). The main objective was to recognize and compare the extent of gentrification of certain neighborhoods in Amsterdam. Figure 4.5 shows the fieldwork area as well as the eight specified neighborhoods. After the undergraduates completed their fieldwork, they were invited to answer an online survey (URL18, Appendix 3) that was mainly about the use of mobile phones during the fieldwork. The fieldwork organizer sent the invitation to the online survey on behalf of the author.

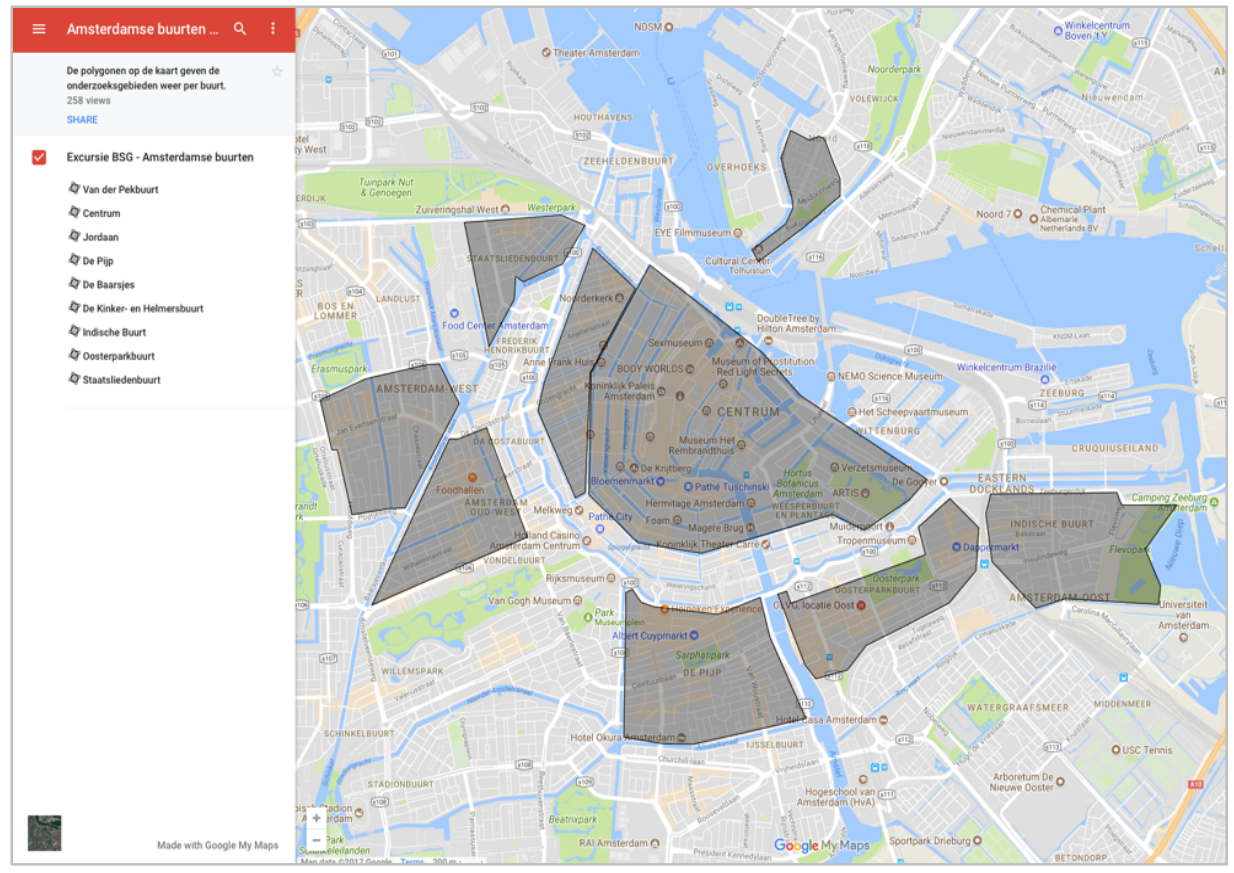

Figure 4.5 The fieldwork areas (in Amsterdam) of the human geography fieldwork organized by Ghent University

(Obtained from this fieldwork preparation material)

At BNU, another (i.e. not the same as that that was presented in Section 4.4.3) human geography fieldwork was conducted in December 2015 in the old embassy area in Beijing (Figure 4.6). The main objective of this particular fieldwork was for students to learn about the urban structure development and its function changes by finding out how the Qing Dynasty's embassy area in Beijing has developed into the present landscape over the past 150 years. 


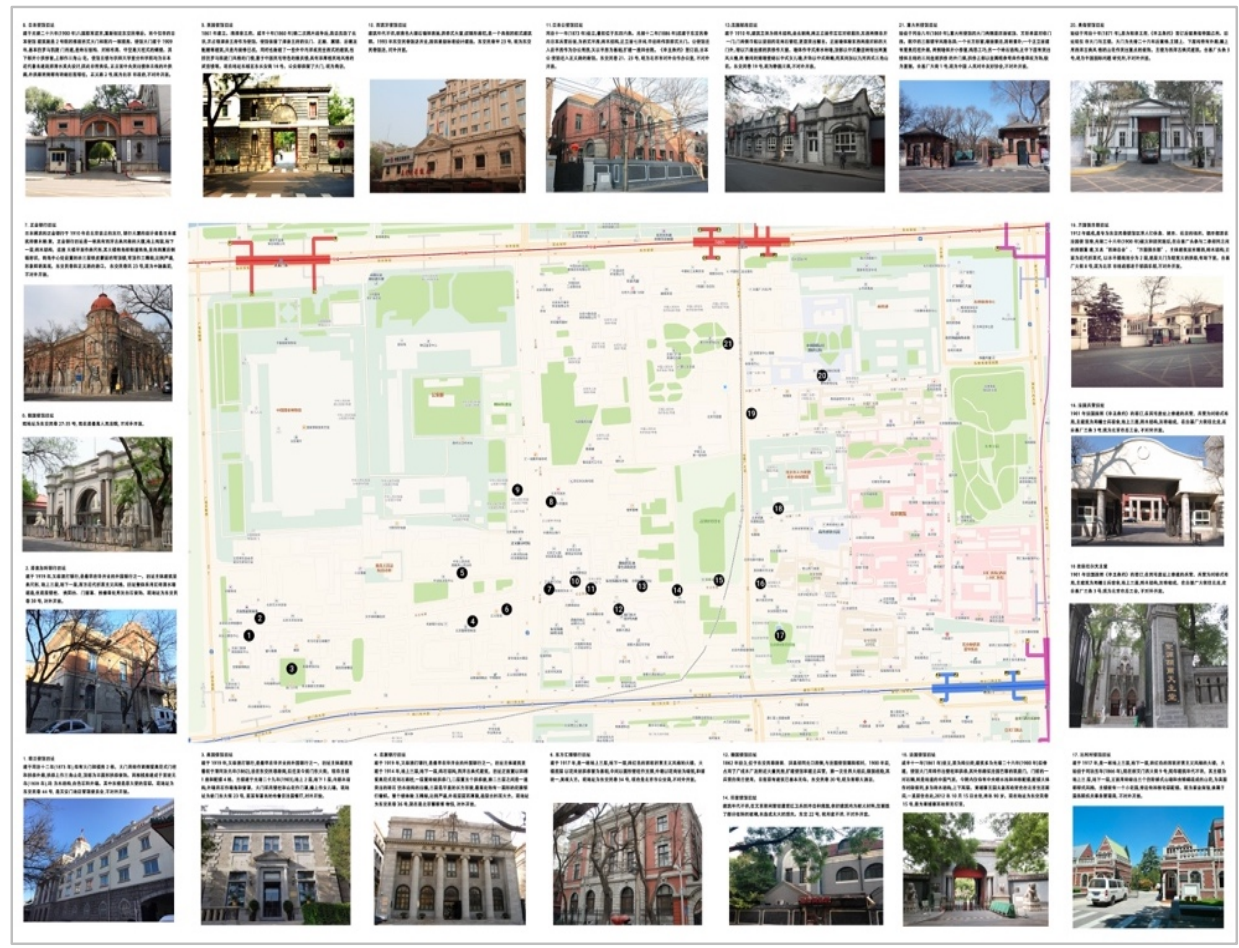

Figure 4.6 The fieldwork areas (in Beijing) of the human geography fieldwork organized Beijing Normal University

(Obtained from this fieldwork preparation material)

In total, 28 undergraduates from Ghent University and 61 undergraduates from BNU responded to the post-fieldwork surveys (the same as the Ghent University, Appendix 3). $69 \%$, respectively $72 \%$ of the Ghent University and BNU students owned smartphones with an Android operating system. 54\% of the Ghent University undergraduates and 50\% of the BNU students used digital maps on their mobile phones during the fieldwork. The conclusion is that Android should be the first consideration for the design of GeoFARA.

With respect to map use, it appears to be very necessary to integrate digital maps as most students think that maps were useful indeed in assisting them to complete the fieldwork tasks and to improve their overall geographical understanding. A 2D "traffic layer" of a digital map should be the default map interface of GeoFARA. One of the big problems for students to use digital maps in their fieldwork was the required Internet connection. Therefore, GeoFARA should preferably integrate offline maps of the fieldwork area so that they can be used offline. Taking photos was another main activity on the students' mobile phones during their actual fieldwork. This means that it also appears to be useful to integrate the photo-taking functionality in the design of GeoFARA. 


\subsection{Use case}

The overview of existing mobile AR applications and the analysis of user requirements obtained from surveys, a field experiment and the ethnographic study already gave insights into the basic design needs of GeoFARA. But to enable GeoFARA to meet the specific fieldwork objectives, and to assist students to answer their fieldwork questions and complete their fieldwork tasks, it is necessary to specify a specific use case from which more use and user requirements can be derived.

As already mentioned in Section 2.2.5, the fieldwork context is that of higher education undergraduates exploring a human geography theme in an urban area. The specific use case for which GeoFARA will be developed and tested is an urban geography fieldwork in which the influence of historical industrial factors on the current spatial structure will be explored. The fieldwork area will be in the city of Enschede, the Netherlands (Figure 6.5). The spatial structure of this city is very much influenced by its industrial history (textile industry which has largely collapsed) and there are quite some visible remnants.

\subsubsection{Learning objectives of the case-study fieldwork}

Under the overall objective of improving the geographical understanding of an urban area, three sub-objectives can be defined for the case study, ranging from obtaining basic geographic knowledge to developing comprehensive geographical understanding. These sub-objectives are: (1) to find out the historical textile industry background of the urban area concerned; (2) to obtain up-to-date geographic information about the urban area; (3) to identify the spatial structure of the urban area and relate it with the historical textile industry development.

\subsubsection{Questions to be answered during the case-study fieldwork}

GeoFARA will focus on assisting fieldwork activities related to increasing the geographical understanding of the fieldwork area before, during, and after the fieldwork. In each stage, some fieldwork questions (Table 4.6) should be answered to meet the fieldwork objectives. If the students are able to find the answers to these questions, it is expected that the learning objectives can be reached. However, due the limited research sources, during the actual evaluation of GeoFARA when a field trip is organized, participants will be only requested to obtain up-to-date geographic information about the fieldwork area during the fieldwork in Table 4.6. This also applies to the fieldwork tasks in Section 4.5.3. 
Table 4.6 Questions that need to be answered to meet the fieldwork objectives

- To find out the historical textile industry background of the urban area (before the fieldwork)

1. What were the geographical factors related with the origins of the main textile industry?

2. Where were the textile industrial architectures and infrastructures located?

- To obtain up-to-date geographical information about the urban area (during the fieldwork)

1. Are the past industrial textile architectures and infrastructures still visible now?

2. Which architectures and infrastructures can be directly related with the past textile industry?

3. What are the current functions of those architectures and infrastructures?

4. What are the distributions of those still visible textile industrial architectures and infrastructures?

5. Which architectures and infrastructures are new compared to those past textile industrial ones?

6. What are the current functions of those textile industrial architectures and infrastructures?

7. Which main roads or railways or waterways can be directly related with the past textile industry?

- To identify the spatial structure of the urban area and relate it with the historical textile industry development (after the fieldwork)

1. What are the distributions of past industrial architectures and infrastructures?

2. What are the road, railway and waterway patterns from the textile industry past till now?

3. How is the current spatial structure shaped by the main textile industrial architectures and infrastructures, road and railway and waterway network?

4. To what degree has the urban spatial structure changed from the textile industry past till now?

5. To what degree did the historical textile industry development influence the present spatial structure?

6. What evidences are there for those influences?

\subsubsection{Fieldwork tasks}

The fieldwork tasks are presented in Table 4.7 as a "to-do-list", giving participants instructions on how to find out the answers to the above questions, and indicating how GeoFARA can assist with the completion of the fieldwork tasks. As mentioned in Section 4.5.2, due to the limitations, the focus of the evaluation will be the fieldwork tasks "during" the fieldtrip stage of Table 4.7. 
Table 4.7 Fieldwork tasks to be executed during the case-study fieldwork and how GeoFARA can assist with that

\begin{tabular}{|c|c|c|}
\hline Stage & Fieldwork tasks & $\begin{array}{l}\text { Role of } \\
\text { GeoFARA }\end{array}$ \\
\hline \multirow{4}{*}{ Before } & Import fieldwork materials, like maps, photos & I \\
\hline & Read and compare old and new maps of the fieldwork area & II \\
\hline & $\begin{array}{l}\text { Mark potential textile industrial remnants on maps for checking and } \\
\text { confirmation during the fieldwork }\end{array}$ & II, III \\
\hline & Plan a fieldwork route & II, III \\
\hline \multirow{6}{*}{ During } & $\begin{array}{l}\text { Compare and match what can be seen in the fieldwork area with the } \\
\text { maps during all field activities }\end{array}$ & II, IV, V \\
\hline & $\begin{array}{l}\text { Confirm that the potential textile industrial artifacts, as identified in } \\
\text { the preparation stage, are indeed remnants of the textile industry }\end{array}$ & $\mathrm{IV}, \mathrm{V}$ \\
\hline & Discover remnants that were not marked yet in the preparation stage & IV, V \\
\hline & Record the current functions of textile industrial remnants & VI \\
\hline & $\begin{array}{l}\text { Discover new architectures and infrastructures that are not related } \\
\text { with the textile industry }\end{array}$ & \\
\hline & $\begin{array}{l}\text { Record the current functions of those non-textile-industry-related } \\
\text { architectures and infrastructures }\end{array}$ & VI \\
\hline \multirow{4}{*}{ After } & Export the collected data for post-fieldwork use & VII \\
\hline & $\begin{array}{l}\text { Use the collected data to draw a map illustrating the current spatial } \\
\text { structure of the fieldwork area with highlighting the remnants of the } \\
\text { textile industrial past }\end{array}$ & \\
\hline & $\begin{array}{l}\text { Summarize the current spatial structure and its change in the forms } \\
\text { of texts including maps and photos }\end{array}$ & \\
\hline & $\begin{array}{l}\text { Address the influence of the city's textile industrial history on the } \\
\text { current urban spatial structure }\end{array}$ & \\
\hline$I$. & \multicolumn{2}{|l|}{ Enabling importing required fieldwork materials from a desktop platform. } \\
\hline II. & \multicolumn{2}{|l|}{ Offering old maps in digital form and digital maps indicating user locations. } \\
\hline III. & \multicolumn{2}{|l|}{ Enabling making annotations on maps. } \\
\hline$I V$ & \multicolumn{2}{|c|}{ Presenting the past of the fieldwork area in forms of old photos, old maps, and texts. } \\
\hline$V$. & \multicolumn{2}{|c|}{$\begin{array}{l}\text { Indicating which architectures and infrastructures are textile industrial remnants and } \\
\text { which are not through points of interest. }\end{array}$} \\
\hline$V I$. & \multicolumn{2}{|l|}{ Recording textual and photo information with geo-locations on digital maps. } \\
\hline VII. & \multicolumn{2}{|l|}{ Enabling exporting collected data to a desktop-based platform. } \\
\hline
\end{tabular}




\subsection{Use scenario}

A use case description such as the one above can be made more specific and concrete by creating hypothetical scenarios of future use. In UCD, scenarios are stories of the users' specific activities with user actions, including elements of who, when, where, what, why and how (Lin \& Okamoto, 2009). Therefore, scenarios are usually written in a narrative form. User tasks can be identified from the scenarios. Considering this and the human geography fieldwork setting of using GeoFARA, a use scenario with a persona can be generated as in Section 4.6.1, followed by the user tasks and the derived user requirements.

\subsubsection{Persona and Scenario}

The scenario setting is that an undergraduate is executing urban geography fieldwork tasks in the city of Enschede as described in Section 4.5. Here, a persona named Maria represents the user group of GeoFARA. Maria is a MSc student, enrolled in a geo-related educational program. She is going to attend a human geography fieldwork in an urban area in Enschede, and she is not yet familiar with this area.

Now Maria starts her actual field activities. Starting walking in the fieldwork area, Maria takes out her phone and checks the mobile map on it. She needs to find her current location, the name of the road she is standing on and which direction she will go. And she also wants to have an overview of the fieldwork area.

Then she starts to walk and explores the fieldwork area. During her walk, she sees some textile industry remnants and some new constructions in the fieldwork area. For those within her range of vision, she needs to find out where they are on the digital map, and, in addition, she wants to read the introduction about the geographies and histories of those textile industry remnants, and see how they looked like in the past. She also takes some photos and makes notes about the visible past industrial architectures and infrastructures on maps, and their current functions. Besides, in order to make a further decision on where to go next, she checks what is included in the rest of the fieldwork area, outside her range of vision. When she arrives at the next location, she repeats doing the same as how she conducted the field activities within her vision range before.

At the end of the fieldwork tour and after getting back from the field, for a reflection on the whole field trip and her post-fieldwork tasks, she again checks all the main roads, remnants and constructions that she has visited, as well as the data, such as photos and notes she has taken during the fieldwork. She also want to view the collected data on a desktop-based web map to complete the post-fieldwork tasks. 


\subsubsection{User tasks and user requirements}

The above scenario includes goals and corresponding user tasks. At the beginning of the field activities, the goal is to orientate, which can be achieved through using mobile digital maps to find the current location, its surroundings, and the direction. This goal exists in the entire fieldwork. During the field exploration, the main goal is to learn about the textile industry remnants and new constructions within the fieldwork area. This can be achieved by completing tasks such as getting the location of the textile industry remnant/the new construction, acquiring information from the introduction (in text, photo, and old map forms) about the textile remnant/the new construction, etc. To achieve the learning goal, the user takes photos of the visible past industrial architectures and infrastructures on maps, and make notes of their current functions. Back from the field, the goal is to view the collected data on a desktop-based web map in order to be able to summarize the findings and draw conclusions. Therefore, the user needs to export the collected data from the mobile phone to computer.

To complete the goals and facilitate the user tasks in this scenario, GeoFARA as a supportive tool could support users such as Maria during the actual fieldwork through the following steps:

- Step 1 - With the help of an up-to-date mobile map in GeoFARA, the user tries to orient himself or herself when first entering the fieldwork area and when walking around.

- Step 2 - In the AR view of GeoFARA, old maps, and textual and image information are overlaid on the reality view through the camera when the user rotates his or her smartphone. From both AR view and map view, the user learns about the textile industry remnants and new constructions.

- Step 3 - The user walks from the current location to the next location.

- Step 4 - The user collects data such as photos, notes of textile industrial remnants and views them on the mobile phone.

- Step 5 - The user exports the collected data and views them on the desktop computer.

The purpose of the above use scenario design is to decide on how the user could use GeoFARA to carry out the tasks. For being capable of supporting the user tasks, the user requirements of GeoFARA can be formulated and specified as follows:

1) Integrating digital mobile maps which show the current location.

2) Viewing information in various formats. First, users should be able to optionally view a street layer and a satellite image layer of digital maps. GeoFARA should 
also allow users to view old maps, and textual and image information from the augmentation in the AR view.

3) Suggesting a route to a destination. GeoFARA should support users to make a decision on where and how to go next.

4) Collecting geo-referenced data. The users must be able to take notes, photos and videos. Further, GeoFARA must allow users to view the collected data.

5) Exporting the collected data and making use of it on a desktop computer after the geography fieldwork.

\subsection{User requirements for GeoFARA}

Following the international standard (ISO 9241-210, 2010) on how to specify user requirements, the use and user requirements analysis and specification for GeoFARA reported in this chapter include requirements derived from user needs (mainly collected through the ethnographic study), functional requirements (functionalities of photo-taking, field data collection, etc.), and other requirements (flexible-to-update, offline digital maps, etc.). But to facilitate the design and implementation of GeoFARA, the above elicited requirements should be categorized and prioritized in order to eliminate overlaps and resolve conflicts. The following two sections first summarize all the use and user requirements for GeoFARA, and then give each of them a priority level to guide the conceptual design and prototype development.

\subsubsection{Summary}

First, the gathered use and user requirements for GeoFARA should be categorized. Such requirements generally are categorized into functional requirements (the functionalities of the product, including the scope of the product, functional and data requirements) and non-functional requirements (the product's qualities, e.g., interface requirements, usability requirements, operational and environmental requirements, performance requirements, etc.) (Robertson \& Robertson, 2013). Following this perspective, Table 4.8 lists the entire set of use and user requirements for GeoFARA, organized and categorized into five classes: functionality, data, usability, environment, and interface requirements. Each requirement has a reference number (U1- User requirement 1, U2 - User requirement $2, \ldots . .$.$) . A column with an indication of the section in which this requirement$ has been described is also added to Table 4.8 for easier tracking of its source. The entire list of user requirements for GeoFARA will be first reduced in the next section by removing overlaps and conflicts, and then prioritized by following the order mandatory requirements, desirable requirements, optional requirements, and possible future enhancements. 
Table 4.8 The entire user requirements for GeoFARA

\begin{tabular}{|c|c|c|c|}
\hline Category & Number & Requirement & Section \\
\hline Functionality & U1 & $\begin{array}{l}\text { Allow all kinds of geo-media collection (text, } \\
\text { sound, images) }\end{array}$ & Section 4.4 .1 \\
\hline Functionality & $\mathrm{U} 2$ & Provide points of interest as augmentation & Section 4.4 .2 \\
\hline Functionality & U3 & Provide lines of interest as augmentation & Section 4.4 .2 \\
\hline Functionality & $\mathrm{U} 4$ & $\begin{array}{l}\text { Allow recording of various field data (notes, } \\
\text { voices, field walking routes) with geo- } \\
\text { locational details }\end{array}$ & Section 4.4 .3 \\
\hline Functionality & U5 & Show collected data in a map view & Section 4.4 .3 \\
\hline Functionality & U6 & $\begin{array}{l}\text { Allow group interaction - users can share } \\
\text { current locations, photos, fieldwork progress } \\
\text { etc. with each other }\end{array}$ & Section 4.4 .3 \\
\hline Functionality & U7 & Recommend location-based contents & Section 4.4 .3 \\
\hline Functionality & U8 & Take photos & Section 4.4 .4 \\
\hline Functionality & U9 & Allow offline use & Section 4.4 .4 \\
\hline Functionality & U10 & $\begin{array}{l}\text { Import required learning and teaching materials } \\
\text { from a desktop platform }\end{array}$ & Section 4.5 .3 \\
\hline Functionality & U11 & Allow annotations on a map & Section 4.5 .3 \\
\hline Functionality & U12 & $\begin{array}{l}\text { Record textual, photo information with geo- } \\
\text { location }\end{array}$ & Section 4.5.3 \\
\hline Functionality & U13 & $\begin{array}{l}\text { Export data collected in the field to a desktop } \\
\text { platform }\end{array}$ & Section 4.5.3 \\
\hline Functionality & U14 & Show user's location & Section 4.5.3 \\
\hline Functionality & U15 & $\begin{array}{l}\text { Augmenting with the past situation of the } \\
\text { fieldwork area }\end{array}$ & Section 4.6 .2 \\
\hline Functionality & U16 & $\begin{array}{l}\text { Suggest a route from the current location to } \\
\text { next destination }\end{array}$ & Section 4.6 .2 \\
\hline Functionality & U17 & Collect geo-referenced data & Section 4.6 .2 \\
\hline Functionality & U18 & $\begin{array}{l}\text { Export the collected data so that they can be } \\
\text { used on a desktop computer }\end{array}$ & Section 4.6 .2 \\
\hline Data & U19 & Description of how GeoFARA works & Section 4.4 .1 \\
\hline Data & $\mathrm{U} 20$ & Different base maps of the fieldwork area & Section 4.4 .1 \\
\hline Data & $\mathrm{U} 21$ & $\begin{array}{l}\text { Integrate various visualizations (photos, old } \\
\text { maps, mobile digital maps, satellite images) of } \\
\text { the fieldwork area }\end{array}$ & Section 4.4 .3 \\
\hline Data & $\mathrm{U} 22$ & $\begin{array}{l}\text { Integrate digital maps with a } 2 \mathrm{D} \text { traffic layer as } \\
\text { the default layer }\end{array}$ & Section 4.4 .4 \\
\hline Data & $\mathrm{U} 23$ & Offline digital maps & Section 4.4 .4 \\
\hline Data & $\mathrm{U} 24$ & Provide old maps in digital form & Section 4.5 .3 \\
\hline
\end{tabular}




\begin{tabular}{llll}
\hline Data & U25 & $\begin{array}{l}\text { Old photos, old maps, and textual introduction } \\
\text { of the past of the fieldwork area }\end{array}$ & Section 4.5.3 \\
\hline Data & U26 & $\begin{array}{l}\text { Additional information about the fieldwork } \\
\text { area beyond points and lines of interest }\end{array}$ & Section 4.5.3 \\
\hline Data & U27 & $\begin{array}{l}\text { Digital mobile maps with both a street layer } \\
\text { and a satellite image layer which show the } \\
\text { current location }\end{array}$ & Section 4.6.2 \\
\hline Data & U28 & $\begin{array}{l}\text { Old maps, and textual and image information as } \\
\text { the augmentation }\end{array}$ & Section 4.6.2 \\
\hline Usability & U29 & Easy-to-use & Section 4.4.1 \\
\hline Usability & U30 & Flexible to update & Section 4.4.1 \\
\hline Usability & U31 & $\begin{array}{l}\text { The amount of system failures is as small as } \\
\text { possible }\end{array}$ & Section 4.4.3 \\
\hline Usability & U32 & $\begin{array}{l}\text { Legible contents (the scales of maps, the fonts } \\
\text { in the text descriptions, the resolutions and } \\
\text { sizes of photos, etc.) }\end{array}$ & Section 4.4.4 \\
\hline Environment & U33 & Android system as the first consideration \\
\hline Interface & U34 & $\begin{array}{l}\text { Integrate AR view and map view on one single } \\
\text { screen, and switch between map and AR view }\end{array}$ & Section 4.2.3 \\
\hline
\end{tabular}

$\mathrm{U} 1=\mathrm{User}$ requirement $1, \mathrm{U} 2=\mathrm{User}$ requirement $2, \ldots \ldots$

\subsubsection{Prioritization}

Often, overlaps and conflicts arise among a set of requirements when they are derived from a number of different sources (Easterbrook, 1994). In the requirements engineering process, it is necessary to identify overlapping and conflicting requirements to make trade-offs between the collected requirements. Once overlaps and conflicts have been eliminated and resolved, the core set of requirements should be selected and prioritized by weighing factors such as importance level, resources, cost and risk. requirements engineering research exists on approaches and strategies for requirements conflicts resolution (see e.g. Van Lamsweerde et al., 1998) as well as requirements prioritization (see e.g. Berander \& Andrews, 2005; Firesmith, 2004). Making use of certain approaches and strategies during these procedures is especially crucial for large and complex interactive systems/products that have extensive user requirements and involve many different stakeholders (such as managers, users, developers), but is not so important to GeoFARA, because the requirements of GeoFARA are not so extensive. Here, after eliminating the overlaps among the requirements for GeoFARA, the conflicts are just resolved by "revisiting initial assumptions" (ISO 9241-210, 2010) of this research and revisiting the main objectives of GeoFARA. In Table 4.8, there are several overlaps between the requirements, e.g., U24 and U28 mention the same requirement of integrating 
old maps. Conflicts between requirements for GeoFARA can be found as well, such as U6 (group interaction) and U9 (offline use). All these overlaps and conflicts have to be removed before selecting and prioritizing the use and user requirements for the design and implementation of GeoFARA. Table 4.9 presents the filtered user requirements for GeoFARA, and they are re-coded as GeoFARA's User requirements 1 (GU1), User requirements 2 (GU2), ......

In addition, prioritization should classify the filtered requirements into different priority levels. Taxonomies of requirements prioritization are organized in different ways. For instance, Braude \& Bernstein (2011:301), and Laplante (2007:77) proposed three levels ('essential'/'mandatory', 'desirable', and 'optional'). This research adopts but extends these three levels to a four-level taxonomy — mandatory (M) requirements, desirable (D) requirements, optional $(\mathrm{O})$ requirements, and possible future enhancements $(\mathrm{E})$. Because of the unknown constraints (technical, time, resources, etc.) during the following design and development stages, an additional level: possible future enhancements (originating from URL19), is added here to record all the possible but now discarded requirements of GeoFARA. The explanations of the four levels of requirements for GeoFARA are as follows:

- M - Mandatory requirements. They have the highest priority and must be built into GeoFARA.

- D - Desirable requirements. They have a medium priority and should be built into GeoFARA unless the costs or the time constraints are too high.

- O - Optional requirements. They have a low priority and may be built into GeoFARA if costs and time allow.

- E - Possible future enhancements. They have the lowest priority but are recorded, and should only be considered after all the above three requirements are built into GeoFARA.

In Table 4.9, the use and user requirements of GeoFARA in each category are sorted by these priority levels from high to low (M-D-O-E).

Table 4.9 The user requirement prioritization for GeoFARA

\begin{tabular}{lllc}
\hline Category & Number & Requirement & Priority level \\
\hline Functionality & GU1 & $\begin{array}{l}\text { Record various field data (notes, voices, field } \\
\text { walking routes, photos) with geo-locational } \\
\text { details }\end{array}$ & $\mathrm{M}$ \\
\hline Functionality & GU2 & Allow offline use & $\mathrm{M}$ \\
\hline Functionality & GU3 & Show user's location & $\mathrm{M}$ \\
\hline
\end{tabular}




\begin{tabular}{|c|c|c|c|}
\hline Functionality & GU4 & $\begin{array}{l}\text { Provide points of interest with their } \\
\text { corresponding past situation as augmentation }\end{array}$ & M \\
\hline Functionality & GU5 & $\begin{array}{l}\text { Import required learning and teaching materials } \\
\text { from a desktop platform }\end{array}$ & $\mathrm{D}$ \\
\hline Functionality & GU6 & $\begin{array}{l}\text { Export data collected in the field so that they } \\
\text { can be used on a desktop platform }\end{array}$ & $\mathrm{D}$ \\
\hline Functionality & GU7 & $\begin{array}{l}\text { Allow group interaction - users can share } \\
\text { current locations, photos, fieldwork progress } \\
\text { etc. with each other }\end{array}$ & $\mathrm{D}$ \\
\hline Functionality & GU8 & $\begin{array}{l}\text { Provide lines of interest with their } \\
\text { corresponding past situation as augmentation }\end{array}$ & $\mathrm{D}$ \\
\hline Functionality & GU9 & Recommend location-based contents & $\mathrm{O}$ \\
\hline Functionality & GU10 & Allow annotations on maps & $\mathrm{O}$ \\
\hline Functionality & GU11 & $\begin{array}{l}\text { Suggest a route from the current location to the } \\
\text { next destination }\end{array}$ & $\mathrm{O}$ \\
\hline Functionality & GU12 & Show collected data in map view & $\mathrm{E}$ \\
\hline Data & GU13 & $\begin{array}{l}\text { Different base maps (old and present) and } \\
\text { photos (old and present) of the fieldwork area }\end{array}$ & M \\
\hline Data & GU14 & Digital maps showing the current location & M \\
\hline Data & GU15 & $\begin{array}{l}\text { Different satellite images (old and present) of } \\
\text { the fieldwork area }\end{array}$ & M \\
\hline Data & GU16 & $\begin{array}{l}\text { Offline digital maps (2D traffic layer as the } \\
\text { default layer) }\end{array}$ & M \\
\hline Data & GU17 & $\begin{array}{l}\text { Textual introduction of the past of the } \\
\text { fieldwork area }\end{array}$ & M \\
\hline Data & GU18 & Description of how GeoFARA works & $\mathrm{D}$ \\
\hline Data & GU19 & $\begin{array}{l}\text { Additional information about the fieldwork area } \\
\text { beyond points and lines of interest }\end{array}$ & $\mathrm{D}$ \\
\hline Usability & GU20 & Easy-to-use & $\mathrm{D}$ \\
\hline Usability & GU21 & Flexible-to-update & $\mathrm{D}$ \\
\hline Usability & GU22 & $\begin{array}{l}\text { The amount of system failures is as small as } \\
\text { possible }\end{array}$ & $\mathrm{D}$ \\
\hline Usability & GU23 & $\begin{array}{l}\text { Readable contents (the scales of maps, the fonts } \\
\text { in the text descriptions, the resolution and size } \\
\text { of photos, etc.) }\end{array}$ & $\mathrm{D}$ \\
\hline Environment & GU24 & Android is the first consideration & $\mathrm{M}$ \\
\hline Interface & GU25 & $\begin{array}{l}\text { Integrate AR view and map view on one single } \\
\text { screen, and switch between AR and map view }\end{array}$ & M \\
\hline
\end{tabular}

GU1= GeoFARA's User requirement 1, GU2 = GeoFARA's User requirement $2, \ldots \ldots$.

$\mathrm{M}$ - Mandatory requirements; D - Desirable requirements; O - Optional requirements;

E - Possible future enhancements 
So, after removing overlaps and conflicts, the 34 initial user requirements for GeoFARA that are presented in Table 4.8 have now been reduced to 25 requirements with specific priority levels in Table 4.9. The priorities of the filtered requirements in Table 4.9 should provide support for the conceptual design and prototype implementation of GeoFARA. But, as noted in the international standard (ISO 9241-210, 2010), the user requirements should be "updated as necessary during the life of the project". Therefore, there might be changes in the finally selected and prioritized user requirements of GeoFARA during the following user-centered design activities due to necessary compromises (such as technical constraints). It may even be so that new user requirements will be added.

\subsection{Conclusion}

Optimal usability is always a goal to pursue when user-centered designing an interactive product. To achieve that goal, firstly, the context-of-use $(\mathrm{CoU})$ as well as the use and user requirements of the designed product should be specified. The design solutions should try to satisfy these requirements. Therefore, in this research, the design solutions of GeoFARA are based on its $\mathrm{CoU}$ and its use and user requirements, targeting at achieving optimal usability.

This chapter extracted the use and user requirements for GeoFARA from a number of sources, starting with reviewing several mobile AR applications in educational settings. To aid the specification of the use and user requirements, the CoU of GeoFARA was first described and specified. Thereafter, this chapter presented the user requirements, as derived from (1) an online survey of geography fieldwork organizers on the current use of tools in undergraduate geography fieldwork, (2) a field experiment in which the use of paper maps and an existing mobile mapping tool were compared, (3) an ethnographic study during a real human geography fieldwork, (4) post-fieldwork surveys among undergraduates from two universities, (5) a use case and task analysis, and (6) a use scenario.

Based on this summary and prioritization of the gathered use and user requirements, the UCD activities will continue with producing design solutions for GeoFARA, including both the conceptual design and the prototype development. The resulting design solutions of GeoFARA will be demonstrated in the next chapter. 
Chapter 5

Producing Design Solution: Conceptual Design and Prototype Development 


\section{$5.1 \quad$ Introduction}

Based on the $\mathrm{CoU}$ and the use and user requirements of GeoFARA that were identified in Chapter 4, this chapter reports on the potential design solutions for GeoFARA at both an abstract and a detailed level. Conceptual design solutions mainly include the design of the user interaction and the user interface, while concrete design solutions comprise wireframes, mock-ups, simulations, prototypes, etc. ISO 9241-210 (2010) also indicates that producing potential solutions requires consideration of the established state of the art in the application domain (mobile applications in the case of GeoFARA), design and usability guidelines and standards, and even possible evaluation results.

The purpose of this chapter is to present design solutions of GeoFARA. This chapter begins by introducing ISO's recommendations for the UCD activity of producing design solutions and Garrett's (2011) model about "The Elements of User Experience", the combination of which can be applied to the design of GeoFARA (Section 5.2). Section 5.3 defines the scope of GeoFARA by documenting its functionality specifications and content requirements. Section 5.4 presents the skeleton of GeoFARA in term of its user interface and navigation design. Section 5.5 describes the implementation and development of a GeoFARA prototype, including data model, software architecture, prototype implementation and development. This section also presents static screenshots and screen captures of the prototype of GeoFARA. Section 5.6 explains the decisions across all the design solutions of GeoFARA. Section 5.7 concludes by summarizing the process of producing design solutions.

\subsection{Guidance on producing design solutions}

Compared to the UCD activities "user requirements analysis" and "usability evaluation", there are relatively few scientific research articles solely discussing producing usercentered design solutions. Some scientific reports on producing design solutions appear in thesis research that focuses on HCI/UCD (see e.g. Delikostidis, 2011). Yet, ISO (ISO 13407, 1999; ISO 9241-210, 2010; ISO 9241-11, 2018) provides recommendations for producing design solutions through describing the design process and its sub-activities. As mentioned in Chapter 3, ISO 9241-210 (2010) supersedes ISO 13407 (1999). Therefore, Section 5.2.1 summarizes the design guidance from the updated standard and describes how it may guide the design of GeoFARA. Despite the relatively few guidelines on producing design solutions from a scholars' perspective, practitioners engage closely with the design of different interactive products from conceptual to detailed levels. This leads to the practical generation of design guidelines. For example, Garrett (2011) proposes a well-known model ("The Elements of User Experience"), which provides a 
clear guiding framework for the user-centered design of web products and beyond (such as the mobile application in this $\mathrm{PhD}$ research). Section 5.2.2 introduces this model. Based on ISO's recommendation on producing design solutions and Garrett's (2011) model, Section 5.2.3 provides an overview of the design solutions of GeoFARA to be produced.

\subsubsection{ISO's recommendations on producing design solutions}

ISO 9241-210 (2010) recommends a set of four activities that are included in producing design solutions for interactive products:

a) Designing user tasks, user-system interaction and user interface to meet user requirements, taking into consideration the whole user experience. Products are tools for users to accomplish goals, and are all about doing tasks (Redish \& Wixon, 2003). Therefore, deciding how users accomplish tasks with the product is needed to identify the interaction objects. To allow access to interaction objects, designing the interaction should also include designing the information architecture of the interactive product. Further, designing the user interface can refine the structure of the product.

b) Making the design solutions more concrete. To communicate the design with stakeholders and users to get early feedback, more concrete design solutions (e.g., simulations, models, mock-ups, prototypes) are required.

c) Altering the design solutions in response to user-centered evaluation and feedback. The costs and benefits of possible changes should be first evaluated to decide whether to make the alteration decision or not.

d) Communicating the design solutions to those responsible for implementation. An explanation and justification of the design solutions should also be prepared.

The above ISO recommendations for producing design solutions can guide user-centered design activities, especially within a design team. In the case of GeoFARA, a relatively independent $\mathrm{PhD}$ research project, producing design solutions will include the above activities.

\subsection{2 "The Element of User Experience" model}

Although ISO provides a complete description for producing design solutions, designing a specific interactive product should not be based on ISO's recommendations only. In the "The Elements of User Experience" model (Figure 5.1), Garrett (2011) identifies five planes from abstract level to concrete level: strategy, scope, structure, skeleton, and 
surface (Figure 5.1, left). Each plane then breaks down into different components (Figure 5.1 , right), from the strategy plane - user needs and product objectives, to the surface plane - sensory design. Between them, there are three important intermediate elements. These elements describe the design from the perspectives of (1) the information of a product, including content requirements, information architecture, navigation, and information design, and (2) the functionality of a product, including functional specifications, interaction design, interface design, and information design.
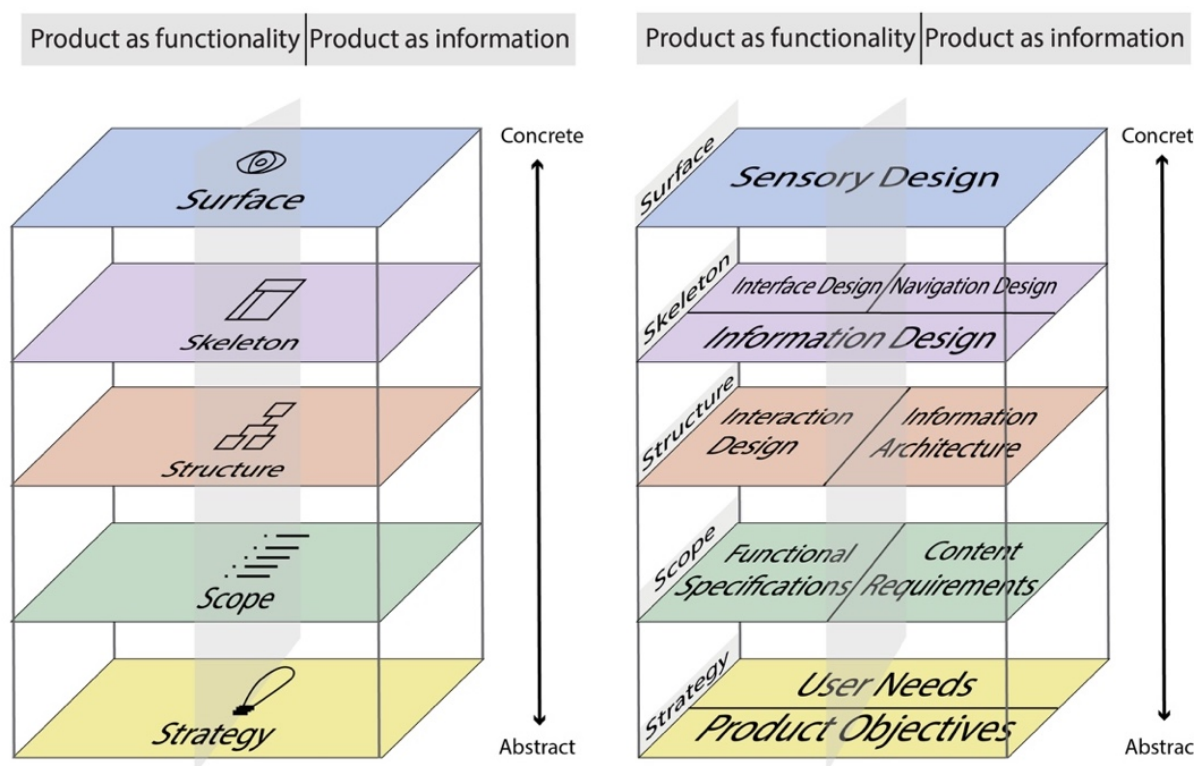

Figure 5.1 "The Elements of User Experience" Model (Redrawn from Garrett, 2011)

This model offers a unique perspective that addresses the duality ("product as functionality" and "product as information") of a product (Garrett, 2011:27). Such a perspective can serve as a useful framework (particularly the three intermediate planes scope, structure, and skeleton) to produce design solutions for GeoFARA, an application that can be considered as both a functionality platform and an information medium. The scope and skeleton planes are included in the design solutions of GeoFARA in this chapter. The strategy of GeoFARA has already been articulated in terms of its objectives (Chapter 2) as well as user needs and user requirements (Chapter 4). Sensory design (visual design) will not be an important consideration prior to the first detailed working prototype implementation of GeoFARA because of the focus on the usability goals, rather than on the UX goals. By providing the duality view of a product (as functionality and as information), Garrett's (2011) model supplements the ISO recommendations on how to produce design solutions. 


\subsubsection{The design solution of GeoFARA}

Based on the above justification, the conceptual design of GeoFARA will be presented from a relatively abstract level (the scope and the skeleton of GeoFARA) to a more concrete level (a working prototype of GeoFARA). Section 5.3 defines the scope of GeoFARA in terms of its functional specifications and content requirements. The user interface design and the navigation between the user interface elements are presented as the skeleton of GeoFARA in Section 5.4. Based on the scope and skeleton of GeoFARA, Section 5.5 deals with the implementation of a GeoFARA prototype. Section 5.6 explains the design decisions across all the design solutions.

\subsection{The scope of GeoFARA}

Through translating user needs and product objectives into what content and functionality the product will provide to the users, the scope of the product is defined (Garrett, 2011). Based on the user requirements summary and prioritization in Chapter 4, this section summarizes GeoFARA's functionality and contents to define its scope in those respects.

Each product has its functionality. In UCD, the functionality is derived from user requirements. It is a systematic and detailed description of what the product should do (Soares et al., 2011). Table 4.9 presents the functional requirements extracted from the user requirements of GeoFARA. As noted in Garrett (2011), the functionality specifications will not always be reflected completely in the final product, as there will always be changes during the implementation. In any case, the priority levels that were originally identified in Table 4.9 will also be kept in order to guide the selection of functionalities during the following design and development activities of GeoFARA.

All products need content support. Contents of a product refer to text, images, video, audio, etc. that are required in order to meet user needs. In the case of GeoFARA, its content can provide users the information they need to meet the fieldwork objectives and to accomplish their fieldwork tasks. Content requirements of GeoFARA can be extracted from the data requirements among the user requirements of GeoFARA (Table 4.9). Two kinds of content requirements (mandatory and desirable) are originally identified from the data requirements (Table 4.9). The mandatory content requirements are indispensable to support the mandatory functionality of GeoFARA, and directly related to the objectives of the fieldwork. The prototype implementation in content will follow the priority level of the content requirements of GeoFARA. Following the priority level, the main contents of GeoFARA are old maps (e.g., Figure 5.2 (a)), digital maps which can show the user's current location (Figure 5.2 (b), OpenStreetMap as an example), old and current photos 
of Enschede (e.g., Figure 5.3), as well as textual introductions about the fieldwork area. The selection of digital mobile maps will be mainly based on the possibilities of integration into a mobile application. In addition, the selection of textual introductions, photos and old maps should be closely related with the textile industry background of Enschede. In each point of interest (POI), the textual introductions, old photos and maps can be presented in the augmentation through AR and map within GeoFARA. Appendix 6 provides the list of all the POIs.

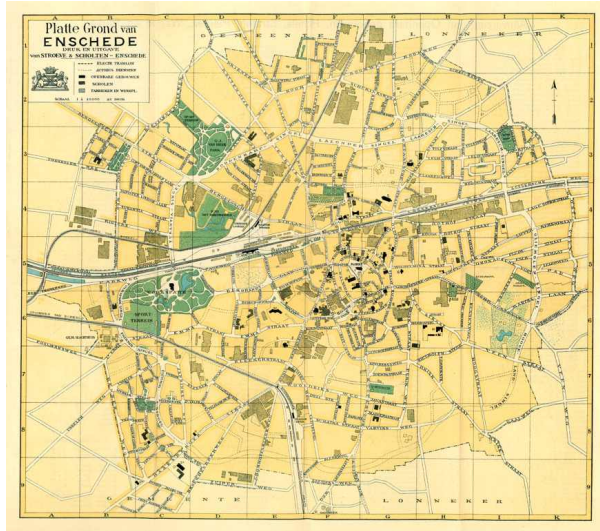

(a)

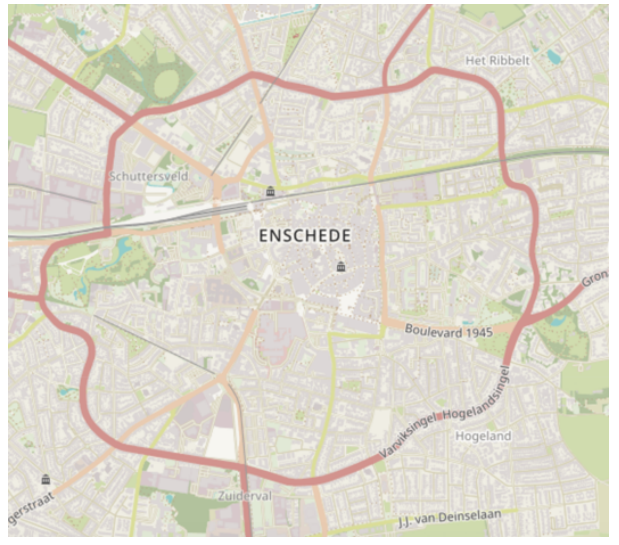

(b)

Figure 5.2 An old map (a) and a digital map (b) of the fieldwork area within the city Enschede (Source: an old map, URL20)

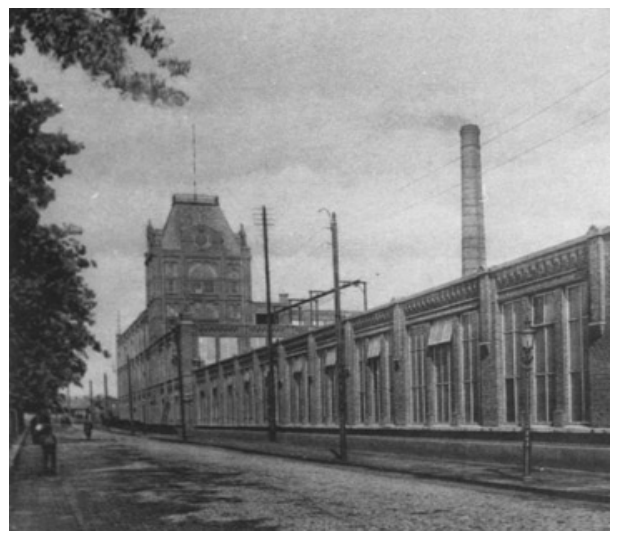

(a)

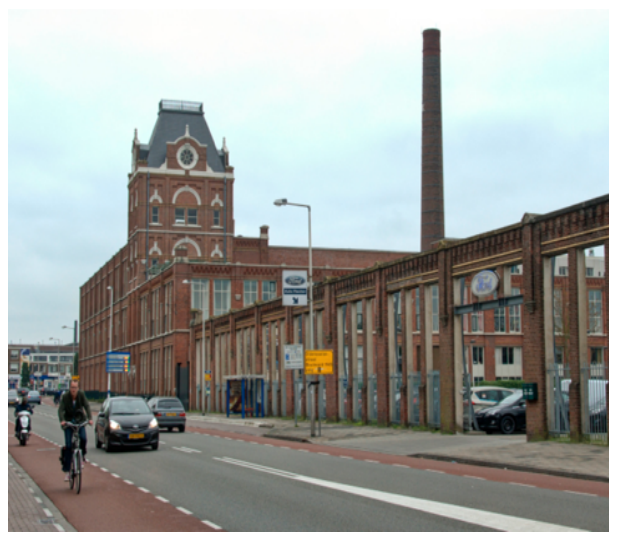

(b)

Figure 5.3 An old (a) and a present (b) photo of Enschede (Source: an old photo, URL21; a present photo, URL22) 


\subsection{The skeleton of GeoFARA}

Section 5.3 defined the scope of GeoFARA, offering a clear picture of what functionality and content should be included. However, this does not yet present how the functionalities and contents will be organized. To refine the scope of GeoFARA, more concrete designs are required. User interface design can define the skeleton of GeoFARA, which is the front-end presentation layer. To communicate the relationship between different user interfaces of GeoFARA, the overall interface architecture will also be provided in this section in the form of a site map. The user requirements of GeoFARA that were presented in Table 4.9 will be considered during the user interface design. Therefore, the implementation process from user requirements to user interface design will be addressed in this section as well.

\subsubsection{User interface design}

This section presents the design of the user interface for GeoFARA, which will consist of several views. They are: "main view", "navigation drawer", "note views" and "photo views". First of all, taking into consideration the environment requirement (GU24: Android is the first consideration, see Table 4.9), GeoFARA should run on an Android operating system. Therefore, as indicated in Section 3.6.3, Android design guidelines (URL23) are followed when designing the user interface of GeoFARA.

\subsubsection{Main view}

The only interface requirement for GeoFARA is integrating a map view and an AR view into one single screen, and allow switching between these map and AR views (GU25 in Table 4.9). Based on this interface requirement, the main view (Figure 5.4) is split by an AR view and a map view. Thus, the main view of GeoFARA provides the user with the ability to perceive information about the surrounding environment through AR and a digital map. Both the AR view and the map view present information about important geographic POIs by means of markers. As shown in Figure 5.4, the elements of the main view consist of an AR view with POIs as augmentation, a map view with POIs as markers and labels, a resize bar, and a collapsed action button. The AR view allows the user to perceive relevant information of POIs within the surroundings, while the map view allows the user to perceive the same information by means of a map which is centered at the current user location. The augmentation of each POI includes the distance from the user's current location to the POI. To allow the user to adjust the split view, a resize bar in the middle of the view enables the user to resize both the AR and the map view respectively, enlarging one of the two views till full-screen and reducing the other one till it is hidden. The collapsed action button is floating above the main view of GeoFARA, following the 
guidelines of Android material design (URL24). This action button is meant for a data recording action. When the action button is clicked, it expands and shows four options: "take note", "view notes", "take photo", and "view photos" (Figure 5.5). Figure 5.5 is GeoFARA's main view with an expanded action button. When the expanded action button is clicked to collapse in this view, the view will be switched to the main view of GeoFARA with again a collapsed action button (Figure 5.4).

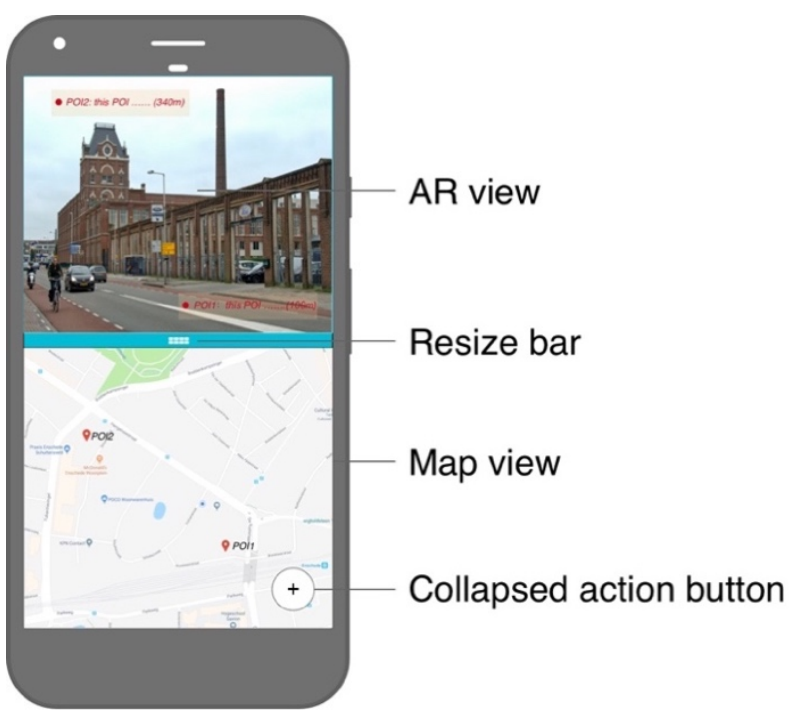

Figure 5.4 GeoFARA's "main view" with the collapsed action button

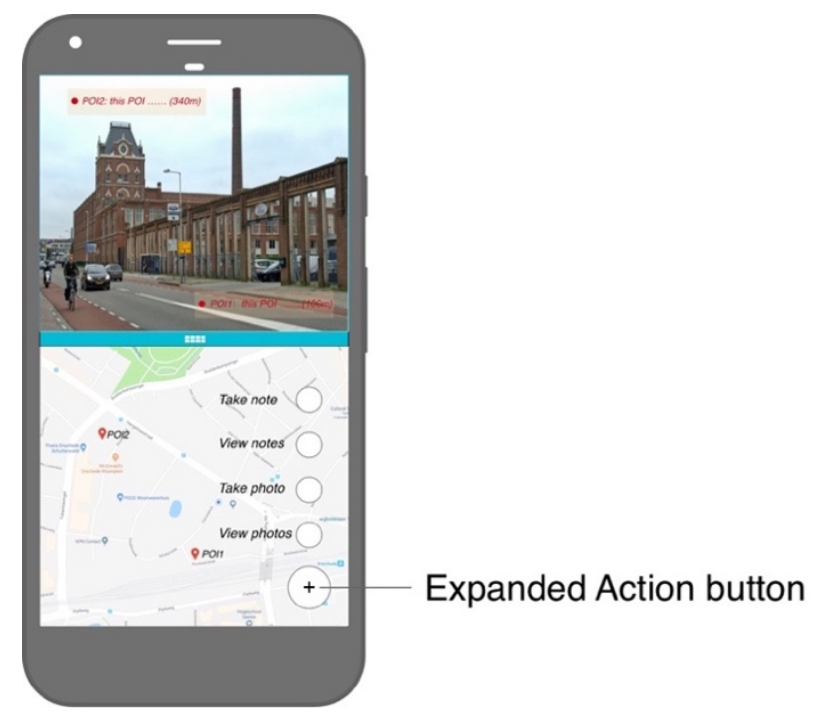

Figure 5.5 GeoFARA's "main view" with expanded action button 
The implementation of the main view of GeoFARA is done on the basis of several user requirements of GeoFARA in addition to the above-mentioned GU25. These requirements are GU1, GU3, GU4, GU9, GU14, and GU16 (see Tables 4.9). The action button floating on the main view is to record two kinds of field data: notes and photos (GU1). The map part of the main view of GeoFARA is a digital map showing the user's current location, which meets GU3, GU14 and GU16. The AR part of the main view of GeoFARA provides POIs as augmentation (GU4 and GU9).

\subsubsection{Navigation drawer}

Clicking a POI inside the AR or map view starts a full-height (of screen) navigation drawer which slides in from the left to display detailed information about the clicked POI (Figure 5.6). Such a design is based on the guidelines of Android navigation drawer design (URL25). The header section of the navigation drawer displays the title of the POI, while the section below contains texts and images. Therefore, the navigation drawer of GeoFARA can display textual introductions, different photos, maps and satellite images that are related to the clicked POI, meeting the content requirements GU13, GU15, GU17 and GU19 (Table 4.9).

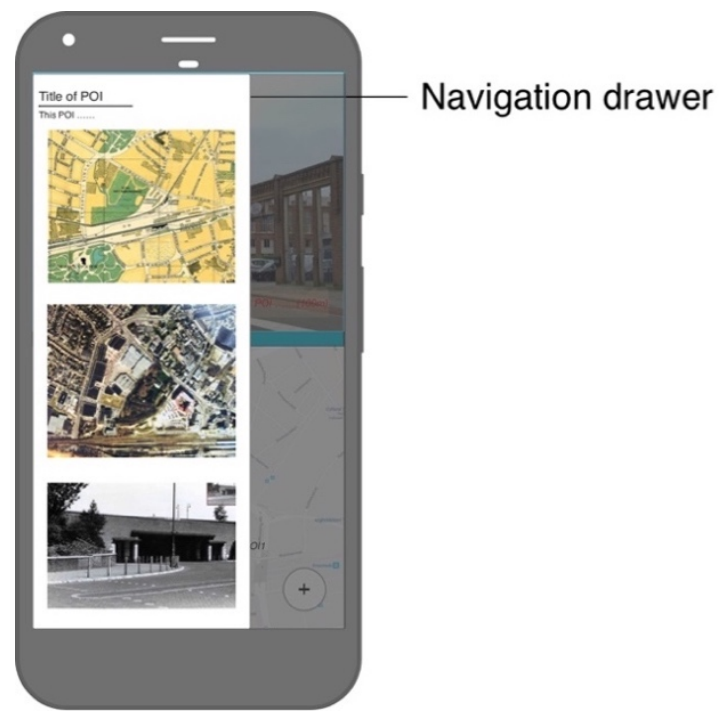

Figure 5.6 GeoFARA's "navigation drawer" view

\subsubsection{Note views}

Once the user clicks the "take note" in GeoFARA's main view (Figure 5.5), the "take note" view (Figure 5.7) is activated; once the user clicks the "view notes" in GeoFARA's 
main view (Figure 5.5), the "view notes" view (Figure 5.8) are activated. The "edit note" view (Figure 5.9) is shown once the user gives the note a name in the "take note" view.

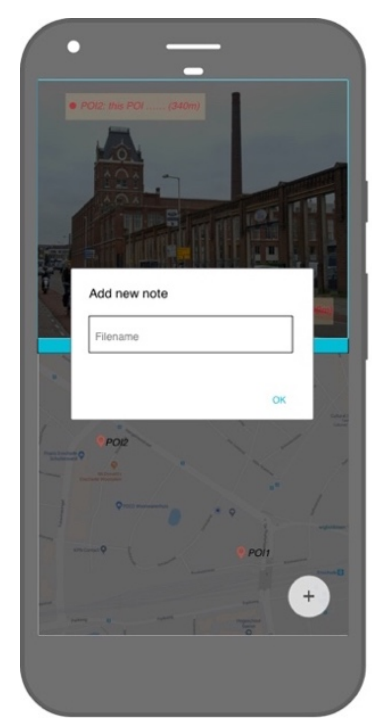

Figure 5.7 GeoFARA's "take note" view

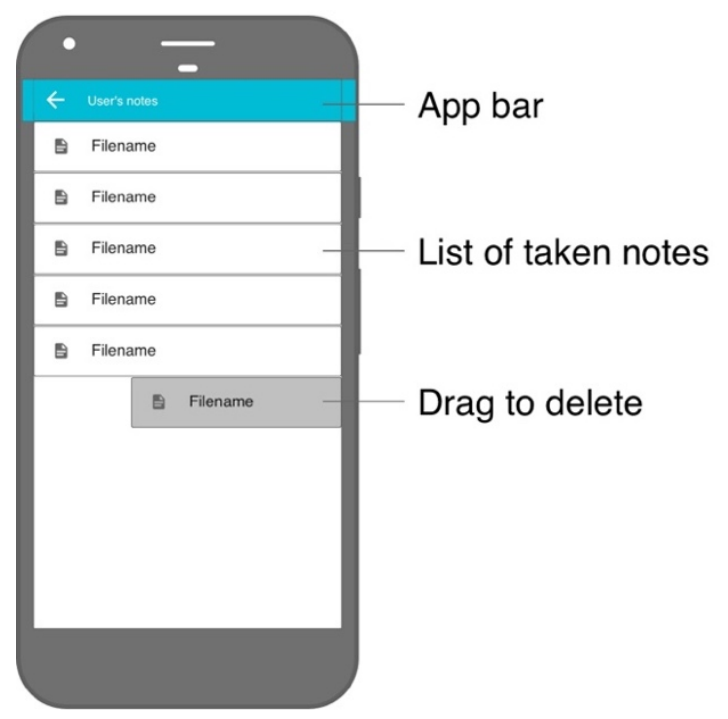

Figure 5.8 GeoFARA's "view notes" view 


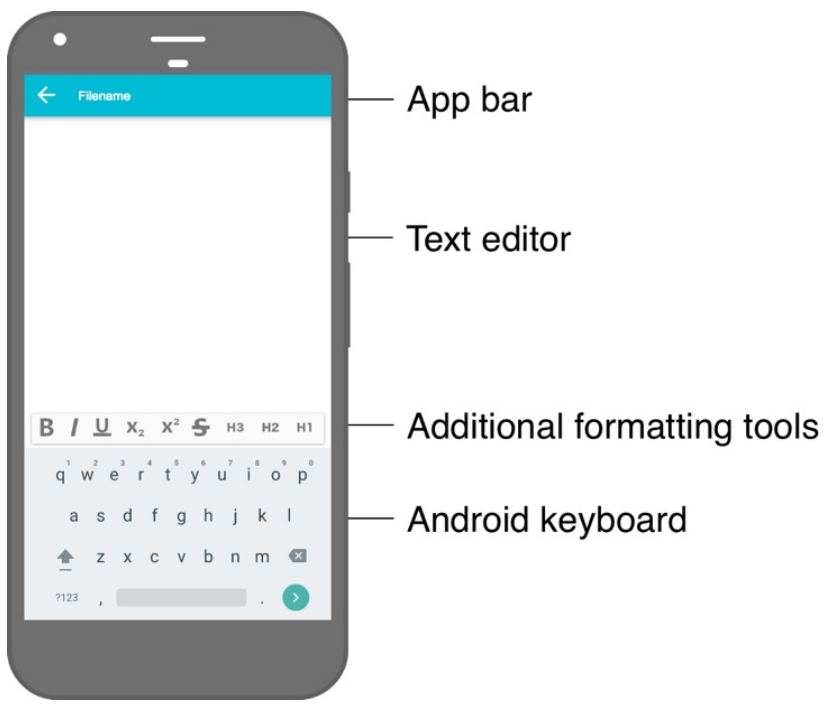

Figure 5.9 GeoFARA's "edit note" view

In the "take note" view (Figure 5.7), there is a simple dialog (URL26) which requires the user to enter the name of the note that is going to be taken. This dialog retains focus until a filename has been entered. Once the user has entered a note name into the text box and clicked the "OK" button, the "edit note" view (Figure 5.9) is activated to allow editing the note content.

In the "view notes" view (Figure 5.8), the heading "user's notes" in the app bar indicates that the current page is about viewing notes. The content area below the app bar displays a list of previously taken notes. A click on one of the notes links back to its corresponding "edit note" view (Figure 5.9). A note can be deleted from the note list by dragging the selected note to the left part of the screen.

In the "edit note" view (Figure 5.9), the user can compose text notes. There are four main UI elements: app bar, text editor, additional formatting tools, and Android keyboard. The app bar (URL27) is used to display the name of the currently edited note. It also provides a back-button to allow returning to the previous screen. Below the app bar, the text editor area displays the text entered in by the user. The Android keyboard provided by the underlying Android system allows users to interact with text input. The keyboard itself does not provide any formatting options, but additional formatting tools (above the Android keyboard) are added to allow users to format the notes.

This design of the whole note views for GeoFARA implements the aforementioned user requirement of recording field notes (part of GU1, see Table 4.9), demonstrating the notetaking functionality. 


\subsubsection{Photo views}

Once the user clicks the "take photo" in GeoFARA's main view (Figure 5.5), the "take photo" view (Figure 5.10) is activated; once the user clicks the "view photos" in GeoFARA's main view (Figure 5.5), the "view photos" view (Figure 5.11) are activated.

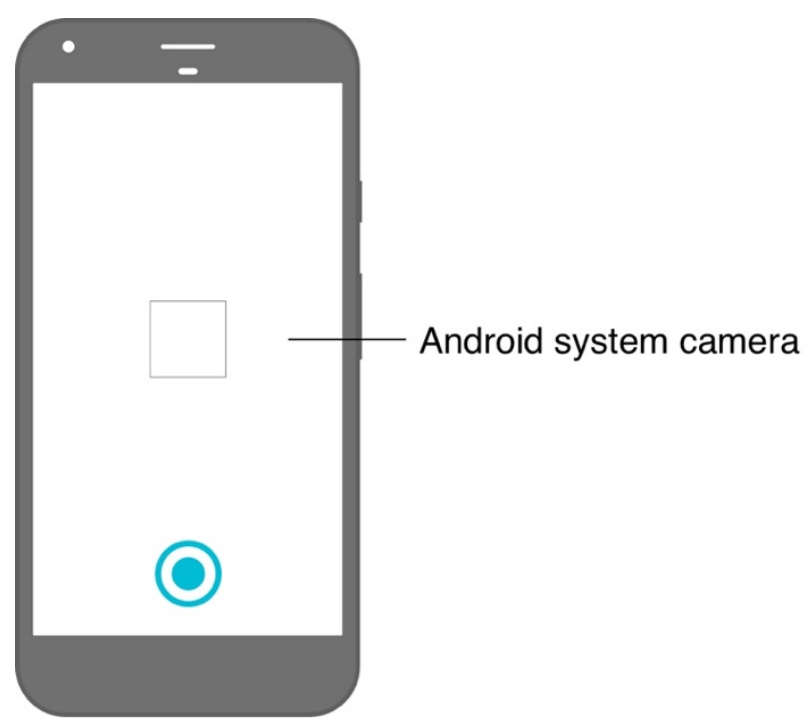

Figure 5.10 GeoFARA's “take photo” view

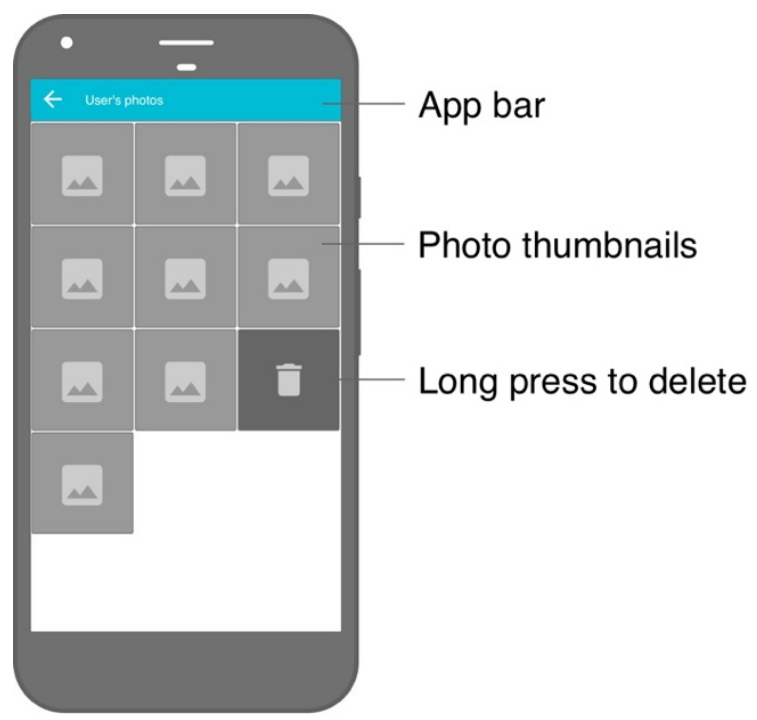

Figure 5.11 GeoFARA's "view photos" view 
The design of the "take photo" view of GeoFARA (Figure 5.10) uses the default camera of the Android system. Using the system camera allows users to use the camera that they are used to. After taking a photo, the camera view retains till the user takes the action of returning to the main view of GeoFARA.

In the "view photos" view (Figure 5.11), the title "user's photos" in the app bar indicates that the current page is about viewing photos. The content area below the app bar displays a grid of thumbnails of all the previously taken photos without addional information. A photo can be deleted by long pressing on one of the thumbnails. Each photo can be viewed in full screen (see the "single image" view in Figure 5.12). The design of the "take photos" view and the "view photos" view in this section implements the user requirement of recording field photos (part of GU1, see Table 5.1). These views demonstrate the phototaking functionality of GeoFARA.

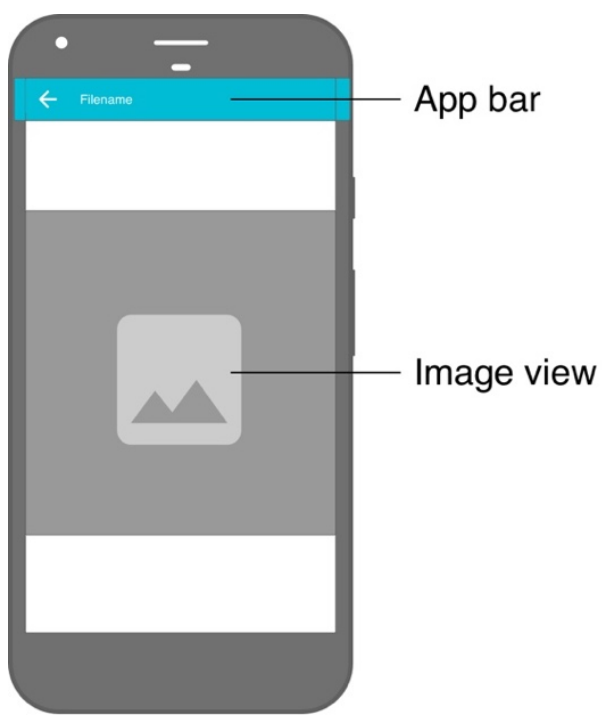

Figure 5.12 GeoFARA's "single image" view

The "single image" view of GeoFARA (Figure 5.12) is to display an image from two channels: a single photo that has been taken and a single map/satellite image/photo from the navigation drawer (Figure 5.6). Therefore, once the user clicks one of the thumbnails in the "view photos" view (Figure 5.11), GeoFARA's "singe image" view is activated. On the other hand, this view can also be activated once the user clicks any image in the navigation drawer of GeoFARA (Figure 5.6). The content area below the app bar displays the image in full screen. Common gestures such as pinch-to-zoom are implemented to navigate through the image. 


\subsubsection{Navigation design}

Navigation design, a specialized form of user interface design (Garrett, 2015), can provide a more complete and structured overview of the application. Site maps, being one of the navigation design tools, are originally used to design information architectures for webs. In a mobile context, a mobile site map can present the overall navigation structure for mobile applications, enabling connection through the mobile product. Figure 5.13 presents a site map of GeoFARA as a navigation design deliverable.

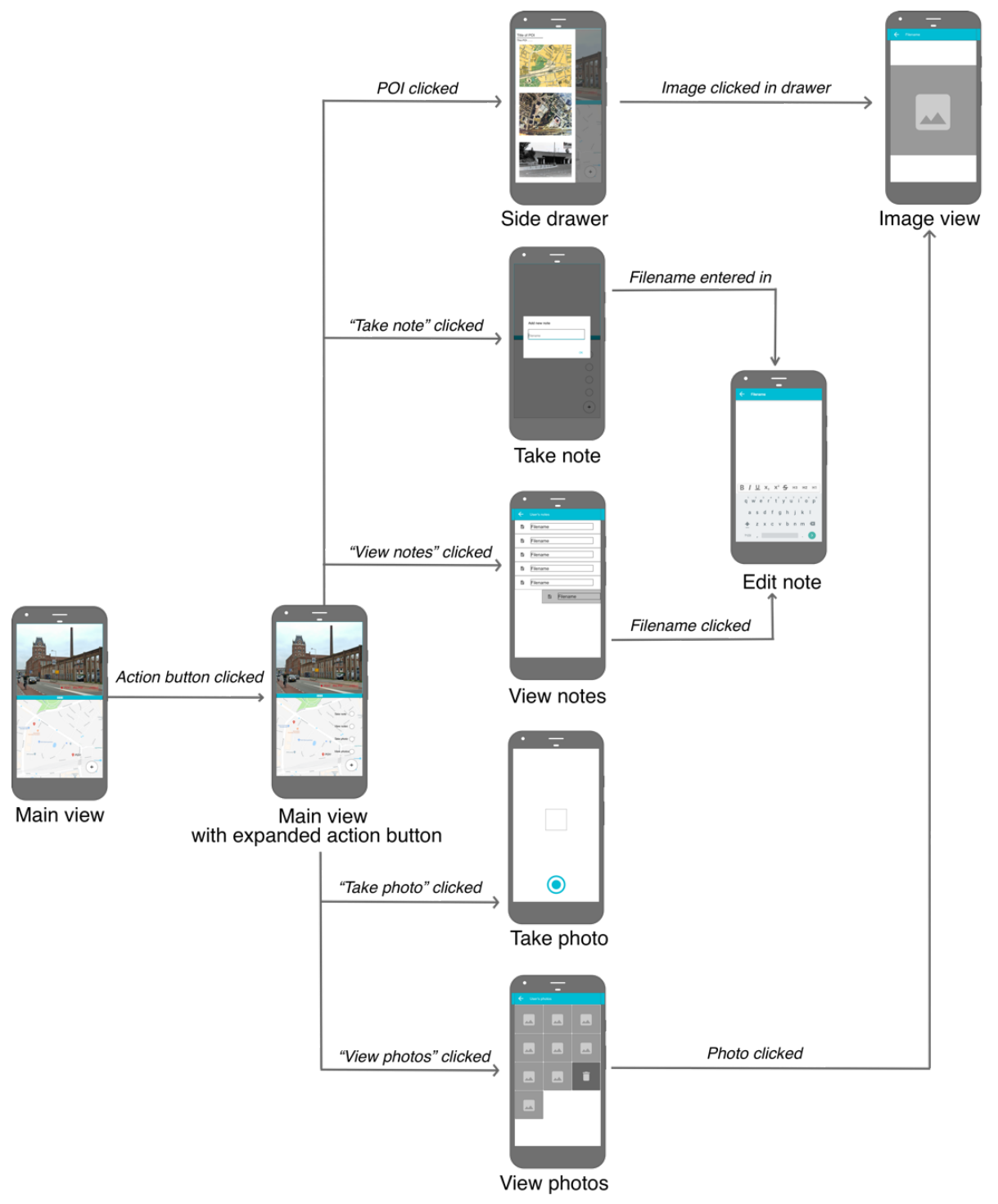

Figure 5.13 The navigation design of GeoFARA: a site map 
The navigation design of GeoFARA is to communicate the relationships between its user interfaces. The interactive elements in the user interfaces of GeoFARA such as the resize bar, app bar, and action button provide navigation points for its navigation design. The navigation design of GeoFARA divides the above user interfaces into three hierarchical levels in its site map: (1) the main view, (2) the navigation drawer as well as the note and photo views (i.e., the actions based on the main view), and (3) the "edit note" view and the single "image view", which are mainly based on the note views and photo views, respectively. Figure 5.13 illustrates the arrangement of GeoFARA's user interfaces as well as the actions that guide the navigation from one of its user interfaces to another. Building on this site map, an interactive prototype of GeoFARA can be further produced.

\subsection{A prototype of GeoFARA}

A prototype of an interactive system is a "representation of all or part of the interactive system, that, although limited in some way, can be used for analysis, design and evaluation" (ISO9241-210, 2010). Following this definition, prototypes can be different across the implementation scale of an interactive system. Various criteria are used to classify prototypes. For example, Preece et al. (1994) describe prototypes from the dimension of fidelity (the level of detail), the two extremes of which are low-fidelity prototype and high-fidelity prototype. Another example is Nielsen's (1993) model of prototyping (Figure 5.14). Nielsen describes two types of prototypes: horizontal (with full features/user interfaces, but no underlying functionality) and vertical (with limited features, but in-depth functionality). Nielsen's two dimensions of prototyping have been widely applied to HCI. In fact, these two kinds of prototype categories are not mutually exclusive. But as proposed by Preece et al. (1994), the two dimensions (features and functionality) of prototypes can even be mapped in the dimension of fidelity: a lowfidelity prototype generally has a low level of detail in both features and functionality, whereas a high-fidelity prototype focuses on both high-level features and in-depth functionality.

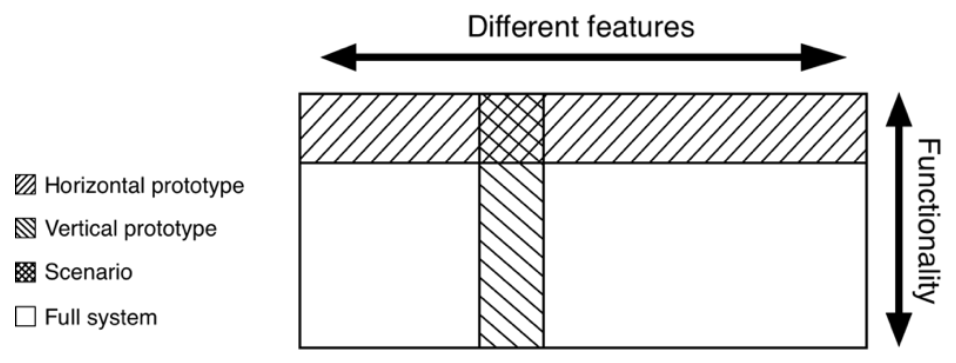

Figure 5.14 The two dimensions of prototyping (Redrawn from Nielsen, 1993:94) 
In UCD, the purposes of producing a prototype for an interactive system are different, from early communication to later evaluation. Therefore, the implementation scale of a prototype depends upon the purpose of using it. At this stage of this research, the purposes of producing a prototype for GeoFARA are to evaluate its usability and get feedback from real users when used in a real use scenario. Driven by such a purpose, a high-fidelity prototype of GeoFARA is required with both a reasonably full breadth of features/user interfaces and a reasonably full depth of functionality, so that users can really interact with such a prototype within the fieldwork area. The prototype of GeoFARA was developed by a computer software developer (see the Acknowledgements). This section presents the actual development of GeoFARA in the programming environment. And a demonstration of the developed prototype of GeoFARA will also be provided in the form of both screenshots (pictures) and screen captures (videos).

Prior to the actual development, an entity relationship diagram, composed of all the entities of GeoFARA and the relationships between them, and the client architecture of GeoFARA, illustrating the overall structure, were produced by the application developer. They are provided in the appendix part (Appendix 4 is the entity relationship diagram; Appendix 5 is the client architecture). Based on the above design solution, data model, client architecture of GeoFARA, a functional prototype of GeoFARA with a working interface was developed. It was built using IntelliJ IDEA (URL28), a Java Interface Development Environment (IDE), and the accompanying Android Studio Plugin.

The overall conceptual idea of GeoFARA is the combined use of visualizations (particularly mobile maps) and mobile AR. Both mobile maps and mobile AR have more than one option that can be selected to produce the map interface and AR interface for GeoFARA. Therefore, at the start of the prototype implementation, it is necessary to decide which map platform and which AR platform should be integrated into GeoFARA. Regarding mobile maps, Google Maps has been integrated into the map view of GeoFARA using Google Maps Application Programming Interfaces (APIs), because it is easy to integrate Google Maps into Android mobile applications, and Android is a platform that is highly supported by Google. The AR experience in GeoFARA is built using the Wikitude (URL29) Software Development Kit (SDK). The two main reasons for selecting this are: (1) Wikitude provides a geo-location AR service, which enables GeoFARA to display geospatial information; (2) The Wikitude SDK offers a free academic EDU license (URL30) with full feature sets.

For integrating the Google Maps API and the Wikitude SDK basic hardware and software requirements had to be met. To enable GeoFARA to successfully run, the basic hardware requirements were that the smartphone should include a camera, GPS, motion sensor (accelerometer), compass and have Internet access. In terms of the Android operating 
system, initially GeoFARA has been developed for Android versions ranging from 4.4 to 7.0 .

The actual development work began after the above decisions about the selection of the map platform and the AR platform as well as the corresponding development tools were made. At the early stages of the development, the author and the developer tested several times the successive versions of GeoFARA in real scenarios and made sure that the already developed parts were functional. In later stages of the prototype development, suggestions for improvement were provided by two experts during informal evaluations (see Section 6.3.4).

An overview of all features included in the final prototype of GeoFARA (that was used in the evaluation), a screen capture of interacting with it within the fieldwork area was recorded with the help of the AZ screen recording tool (URL31). The video is available at Vimeo (URL32).

As shown in these video recordings of the interactions with GeoFARA in the final prototype, there are 17 POIs within the fieldwork area in total that are labelled in both the map and AR view. In the prototype development, the POI information (name, description, latitude, longitude, images, etc.) is transmitted using the HTTP protocol. The request body contains POI information in JSON (JavaScript Object Notation) format. Figure 5.15 shows an example of the introduction (textual explanations and images) of a POI (the building of the Faculty ITC) in GeoFARA.

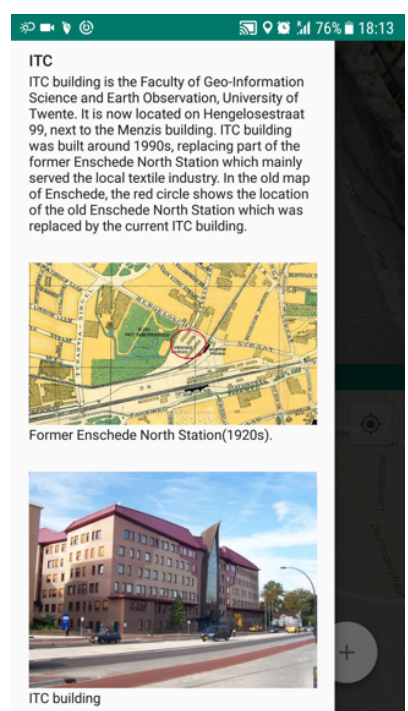

Figure 5.15 An example of the information about a POI in GeoFARA 
Compared to the original conceptual design of GeoFARA, some changes were made during the actual prototype development. For example, in the GeoFARA prototype, in order to limit the amount of POIs that will be displayed on the screen, some new features have been added: a "slider" at the top of the AR view (Figure 5.16, left) and a "radar" (Figure 5.16). They are used to flexibly set a distance radius that determines the field of view, as illustrated by Geiger et al. (2013) (Figure 5.17). Once the radar in the AR view of GeoFARA has been clicked, the slider will be activated for adjusting the radius. Any changes to the radius affect the amount of the visible POIs on the screen. Only POIs inside the field of view (depending on the position of the phone camera and the radius) shall be displayed. After roughly calculating and testing the distance between the mobile device (where GeoFARA is run) and all the physical POIs within the fieldwork area, the maximum distance was set at $0.7 \mathrm{~km}$ (see Figure 5.16, left). This has effectively reduced the overlaps among the total of 17 POIs in the AR view.
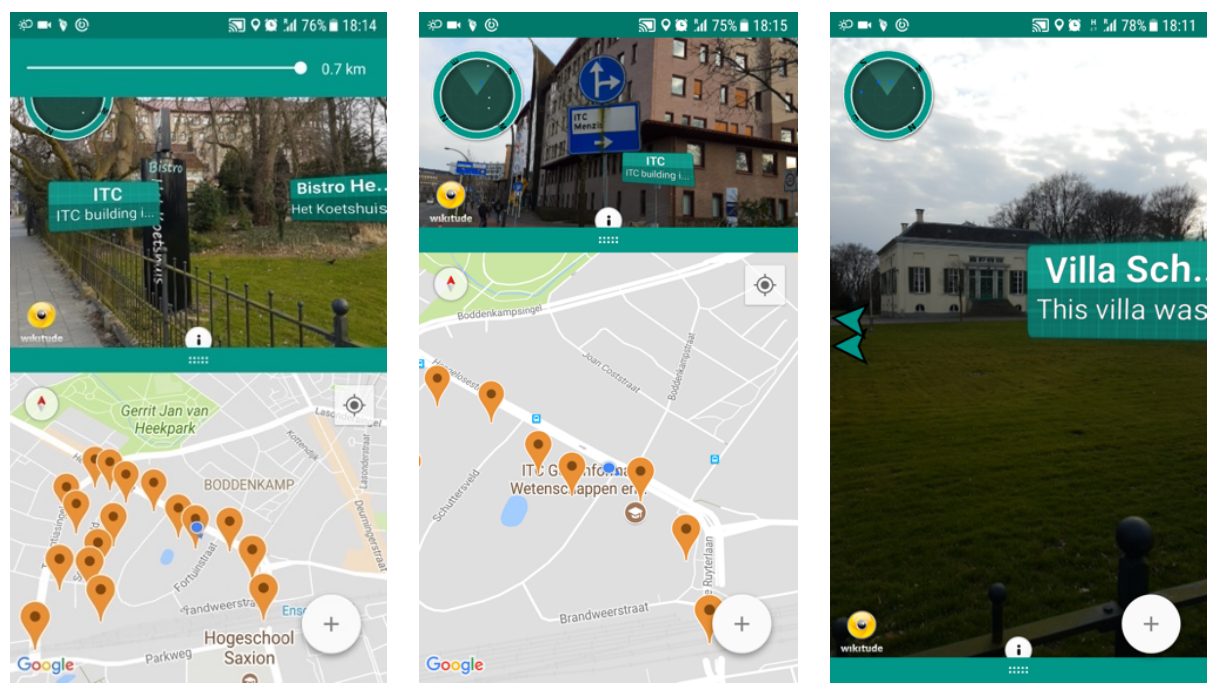

Figure 5.16 The "radar" and the "slider" in the prototype of GeoFARA

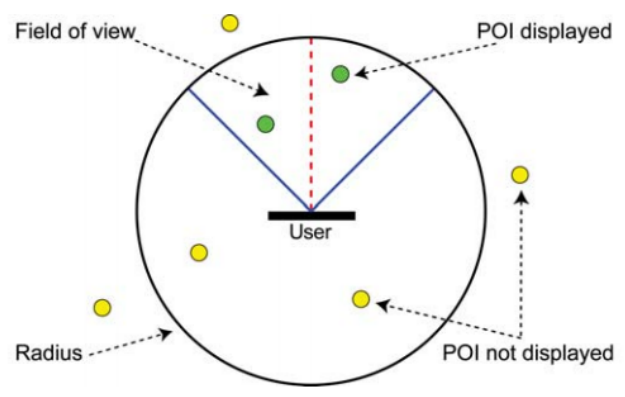

Figure 5.17 Schematic illustration of visible and invisible POIs in AR (Obtained from Geiger et al., 2013) 
One of the GeoFARA's mandatory functionality requirements was to "allow offline use". From a technical perspective, the prototype development attempted to meet this requirement. It was implemented by requiring the user to log in with an active Internet connection and then storing GeoFARA's data in the smartphone's storage space. Figure 5.18 illustrates the login interface. Once the user has logged into GeoFARA with Internet connection, the client saves all the data into the local database for this user account. Therefore, when GeoFARA is used offline, or the same account is logged back in, GeoFARA fully runs relying on the saved data in the local database.

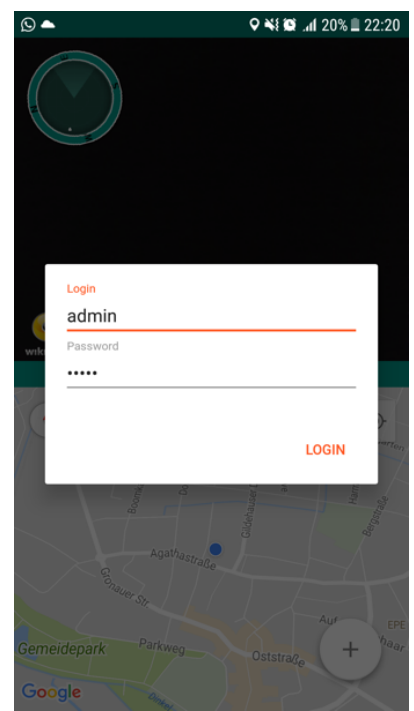

Figure 5.18 The login interface of the prototype of GeoFARA

\subsection{Decisions across the design solution of GeoFARA}

Due to factors such as limited resources (time, expenses, etc.), technical constraints, and potential failure risk, every product has compromises and trade-offs from the requirement analysis to the design and to the development. Making trade-off decisions is an important task in software engineering. In the case of GeoFARA, not all the requirements have been implemented in the user interface design and the prototype development. This section presents and explains the decisions across all design solutions of GeoFARA.

Five types of GeoFARA user requirements were given four different priority levels (see Table 4.9). Firstly, the environment requirement (GU24: Android operating system) and interface requirement (GU25: an interface split by AR and map view) have both been met in the design and development stages of GeoFARA. During the development stage of GeoFARA, attention has been paid to the four usability requirements (Table 4.9, GU20- 
23. GU20: Easy-to-use; GU21: Flexible-to-update; GU22: The amount of system failures is as little as possible; GU23: Readable contents). For example, all the texts and images have been made readable in the prototype of GeoFARA and it should always run without any failures. In the sections presenting the skeleton (Section 5.4) and the prototype (Section 5.5) of GeoFARA contained descriptions of the implemented functionality and content requirements. Those that were not implemented now are explained below.

Functionality requirements account for the majority of user requirements of GeoFARA. But due to some limited resources and technical constraints, the functionality requirements of GeoFARA (Table 4.9) have not been implemented entirely during the design and development activities. Aside from the resources and technical constraints, other factors were also taken into consideration, such as benefits vs. risks, and short-term goals vs. long-term goals.

Three functionality requirements (GU5, GU6 and GU12) were not implemented in the development of GeoFARA due to the limited time available for the development. Although importing and exporting data can be realized using web services, foreseeably, the actual development work would still take quite some time. The time limitation also played a role for the development of the functionality to show the collected data in the map view of GeoFARA. In addition, prior to the first evaluation of GeoFARA with real users, these three requirements were not a short-term goal to achieve. The unimplemented GU11 is neither a relevant short-term goal, because offering navigation is not really an objective of the fieldwork in this research. Technical constraints made it unlikely to implement GU7 (group interaction) and GU8 (providing LOIs) when GeoFARA is used offline in the field. The requirement of making annotations on maps (GU10) was also not implemented due to the limited development time. Besides, from a perspective of maximizing the benefit, allowing the user to make annotations on maps would bring little benefit because the first evaluation of GeoFARA will not ask users to perform such an annotation task (again due to the limited research time).

The majority of the content requirements in the scope of GeoFARA (Table 4.9) has been included in the prototype. Only two of them (GU18 and GU19) were not applied. GU18 (description of how GeoFARA works) was not necessary because the prototype of GeoFARA is relatively easy-to-use. At the same time, sufficient information about the fieldwork area is already provided in the mobile maps and the POIs of GeoFARA, so that no additional information (GU19) was needed.

In summary, after making rational decisions across the design solutions of GeoFARA, the short-term goal of producing a prototype of GeoFARA for evaluating its usability with real users has been achieved, although not all requirements have been implemented. 


\subsection{Conclusion}

This chapter presented the design solutions of GeoFARA, which include its scope, its user interface and navigation design, as well as a working prototype. Methodologically, producing the design solutions relied on theoretical and empirical groundings, for example, following the ISO recommendation on producing design solutions and Garrett's model "The Elements of User Experience" (Section 5.2). The aim of the skeleton of GeoFARA (Section 5.4) was to visualize in what way the user interface design of GeoFARA was based on the collected user requirements (in Chapter 4 and Section 5.3). The user interfaces of GeoFARA were in line with its core functionalities. The user interface design of GeoFARA made use of Android mobile application design guidelines and standards to ensure the consistency of the design of GeoFARA with mobile Android applications. Based on the user interface and navigation design, a working prototype of GeoFARA (Section 5.5) was developed in a programming environment for the purpose of evaluating its usability and getting feedback from real users. Compromises were made between user requirements and the design and the prototype, and these were explained in Section 5.6. Chapter 6 will evaluate this operational prototype of GeoFARA, which is an important and essential part of the UCD process. 
Chapter 6

Evaluating the Design Solution 


\subsection{Introduction}

User-based evaluation of design solutions is an important and essential part of the UCD approach. Its ultimate purpose is to improve the design solutions. The intention of GeoFARA was to help students to learn about the field area during the fieldwork, i.e., to support achieving their learning objective. Therefore, as mentioned in Section 3.6.3, the prototype of GeoFARA will be evaluated in term of both its utility (i.e., its support for the achievement of the defined learning objectives) and usability (i.e., the ease of using it to complete the learning objectives). When evaluating educational technology solutions, some scholars (e.g., Silius et al., 2003; Melis \& Weber, 2003) treat utility as "pedagogical usability". But instead of "pedagogical usability", this research adopts "utility" to avoid confusion with the (technical) usability. To evaluate the developed prototype in the field, multiple methods are adopted in order to get a complete picture of the usefulness of GeoFARA. This chapter reports on the empirical results of the field-based evaluation of the prototype of GeoFARA that was presented in Section 5.5.

In this chapter, the evaluation of GeoFARA comprises four sections: the evaluation goals, the evaluation methods, the data analysis results and a discussion. The overall goals of evaluating GeoFARA are introduced in Section 6.2. Section 6.3 presents the evaluation methods. The subsections include an overview of the evaluation methods, participants, apparatus, materials and procedures, as well as the collected data and data analysis. The results derived from the preliminary data analysis and the discussion are covered in Section 6.4. This chapter concludes with the summary of the evaluation (Section 6.5).

\subsection{The evaluation goals}

As already established in Section 3.6.3, the evaluation of GeoFARA will ask real users (students) to accomplish a real learning task (spatial cognition) with the help of GeoFARA in a real/natural scenario. Following the theoretical basis of UCD research, what will be evaluated are the utility and usability of the developed prototype. In this chapter, the version of GeoFARA that is ready for testing is a relatively early version. Therefore, the purpose of the evaluation in this chapter focuses on making use of the utility and usability results to find out the issues of the current design solution for proposing improvement recommendations. In summary, the main goals of evaluating such an early version of GeoFARA are two-fold:

Goal 1: Examine the utility of GeoFARA.

Goal 2: Evaluate the usability of GeoFARA, resulting in the perceived usability, user interactions with GeoFARA and its use context, usability problems, and possible solutions for improving the design of GeoFARA. 
Goal 1: As introduced in Section 3.4, utility is one dimension of the usefulness of an interactive product, concerning the functionality and the impact. The utility can be interpreted in different ways depending on the objectives of the product. Following Silius \& Tervakari's (2003) framework on evaluating the usefulness of learning environments/products, here, the primary utility of GeoFARA is interpreted as its usefulness for achieving the field learning objectives. Therefore, the utility of GeoFARA will be reflected through the degree to which it helps to build the understanding the former textile industry influence on the spatial structure of the fieldwork area. This requires an understanding and comparison of the users' pre-fieldwork knowledge and their postfieldwork knowledge of the field area. Factors (such as spatial ability of the recruited users) that are pertinent to the performance of learning tasks and experience with the use of geo-technologies (such as the frequency of using mobile digital maps) also need to be taken into account.

Goal 2: As soon as the user starts to interact with GeoFARA, its usability arises. Aside from examining the utility of GeoFARA, assessing its usability with real users, an important part of the user-centered evaluation, is also needed. The most important purpose of applying the UCD approach in producing GeoFARA is to improve its usability. Therefore, assessing the usability is a core evaluation goal. This goal is related to assessing the overall usability, how easy it is to use the user interface features of GeoFARA, and how the users interact with it as well as its use context. Identifying the key usability problems of GeoFARA also falls into the scope of evaluation. Usability problems are a set of negative interaction phenomena (Manakhov \& Ivanov, 2016) that impact the use of an interactive product. In this research, in order to find out what usability issues participants meet in using GeoFARA, discovering the usability problems of GeoFARA will mostly rely on analyzing user behaviors and interviewing the users. The ultimate goal of user-centered evaluation is to improve the design solution. Based on the findings with respect to the usability and the usability problems of GeoFARA, solutions and recommendations on how to improve the present design can be suggested for possible follow-up design and development activities.

\subsection{The evaluation methods}

\subsubsection{Mixed methods to achieve the evaluation goals}

A brief overview of all the methods used in the evaluation of GeoFARA is provided in Section 3.6.3 (Table 3.5). Although Table 3.5 presents the purpose of each method, this section provides detailed descriptions of how the selected methods can relate to achieving the evaluation goals. Table 6.1 summarizes how all of these mixed methods were applied to achieve the evaluation goals. 
Table 6.1 The use of mixed methods to achieve the evaluation goals

\begin{tabular}{ll}
\hline Goal & Methods \\
\hline \multirow{2}{*}{ Goal 1: Examine the utility of GeoFARA } & Mental maps \\
& Interview \\
& System Usability Scale (SUS) \\
Goal 2: Evaluate the usability of GeoFARA & Mobile eye tracking \\
& Thinking aloud \\
& Interaction logs \\
& Interview \\
\hline
\end{tabular}

It is expected that the utility of GeoFARA (Goal 1) would be reflected through a paired comparison of the pre- and post-fieldwork mental maps. Some of the email survey results (e.g., previous familiarity with the fieldwork area), and the spatial ability results (revealed by the SBSOD scale results) would also contribute to the interpretation. In addition, some of the interview results will supplement the interpretation of the utility of GeoFARA. For example, during the interviews, participants were asked "in general, how did GeoFARA help/distract you to learn the geography of the fieldwork area in terms of the influence of past textile history on the current spatial structure?" (see Appendix 13).

The usability of GeoFARA (Goal 2) will be first assessed directly by the SUS results, getting a big picture of its overall usability. In addition, mobile eye tracking, and the thinking aloud indirectly help to understand how users interact with the context-aware GeoFARA and its use context. Furthermore, it is expected that the results of the interaction log tracking analysis and the interviews would provide valuable insights into the usability of the specific user interface features of GeoFARA, particularly the split view of GeoFARA (by AR and maps, see Figure 5.16) since such an interface is new compared to existing mobile AR applications. Participants' answers to the specific questions regarding the usability of GeoFARA during the interviews will also contribute to the assessment of the usability. For example, there were questions like: "What are your general remarks regarding the use of GeoFARA in the field?" (see Appendix 13). The key usability issues of GeoFARA will be primarily identified from the analysis of the user observation, the mobile eye tracking data, as well as the thinking aloud information generated during the evaluation session. Some of the interview results could also support identifying the issues of GeoFARA. Relevant questions during the interviews included, for example: "What elements of the design of GeoFARA didn't you like?", and "What other additional suggestions would you like to make regarding the design of GeoFARA?". Combining all the analysis results, the usability issues will be listed. Recommending actionable solutions for improving the design of GeoFARA will rely on the interview and thinking aloud results obtained from the actual users. 


\subsubsection{Participants}

To evaluate GeoFARA, fourteen participants were recruited from the MSc students of the Faculty ITC of the University of Twente to take part in the real fieldwork. Up on the request of the author, the ITC MSc student association board contacted potential target participants by sending an invitation email (Appendix 7). The email contents included the purpose of the study, as well as the procedure of the entire evaluation (the online survey first and then the field evaluation session for the selected participants). The reason for recruiting ITC MSc students was that their (previous) studies in many cases involve(d) educational geography fieldwork that could be supported by GeoFARA. Therefore, this group of potential participants would match the target users of GeoFARA. In total, 57 students responded to the online survey, while fourteen of them were finally selected to participate in the field evaluation session. The selection was based on the following criteria: (1) the respondents should have normal vision or corrected vision with contact lenses (so to wear the mobile eye tracker); (2) Android should be the operating system that the respondents are familiar with; (3) the highest completed educational degree should be a BSc (Bachler of Science). In addition, a variation of participants was also required in terms of gender, nationality, current study subject, digital map use, mapmaking frequency, familiarity with Google Maps, duration of living in Enschede, knowledge of the fieldwork area, the previous use of AR, and spatial ability revealed by the SBSOD scale (Appendix 8). The background characteristics of the selected participants are shown in Table 6.2. This sample size $(\mathrm{N}=14)$ was sufficient for a qualitative-focused user study. Also, another reason was the sample size was feasible to complete the evaluation within the evaluation time span of two weeks.

Ten characteristics of each selected participant are summarized in this Table 6.2. Each participant had a participant ID (P1, P2, P14). There were seven males and seven females in the test group. They had diverse countries of origin. All the participants were studying in a geo-related MSc program, and the study subjects were: (1) GeoInformatics (5 of 14), (2) Urban Planning and Management (3 of 14); (3) Natural Resources Management (4 of 14); (4) Applied Earth Sciences (1 of 14); (5) Water Resources and Environmental Management (1 of 14). The majority of the participants reported using digital maps either daily ( 8 of 14 ) or weekly ( 5 of 14), and most of them were familiar with Google Maps. The majority of the participants even made maps themselves on a regular basis, either monthly (5 of 14), weekly (3 of 14), or daily (1 of 14). Although all the participants had been living in Enschede for a while (4 of 14 reported more than one year), most of them did not know about the fieldwork area very well (5 of 14 knew what the fieldwork area was before). Moreover, only two participants reported having experience of using an AR application on a smartphone. Regarding the self-reported SBSOD score (Appendix 8) that reflects spatial ability, there were 15 questions 
(responses on seven-level Likert items from strongly agree to strongly disagree) in the SBSOD scale, including both positive and negative items. The scoring procedure was: firstly, the scores of all positively phrased items (1, 3, 4, 5, 7, 9, and 14, see Appendix 8) were reversed, ensuring that a high number indicates more spatial ability and a low number indicates less spatial ability; secondly, the scores for all of the items were summed together, and the total scores were divided by the amount (15) of all questions to get the overall score ranging from 1 and 7 (the higher the score, the better the perceived spatial ability). Overall, the majority of the participants judged that they had relatively high spatial abilities (11 of 14 had SBSOD scores that were above 4 out of 7).

Table 6.2 The characteristics of the participants selected for evaluating GeoFARA

\begin{tabular}{|c|c|c|c|c|c|c|c|c|c|c|}
\hline 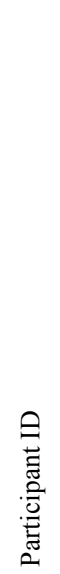 & 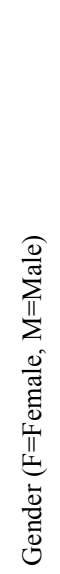 & 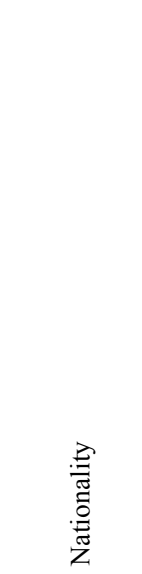 & 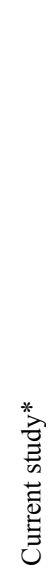 & 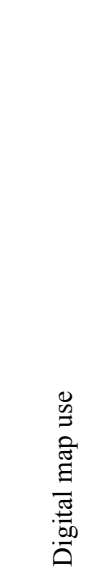 & 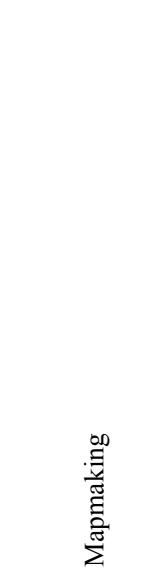 & 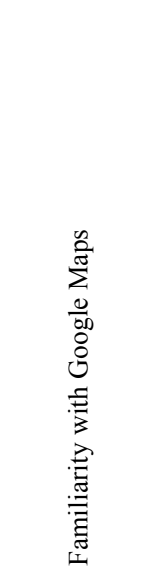 & 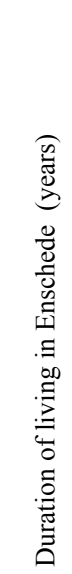 & 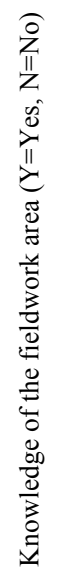 & 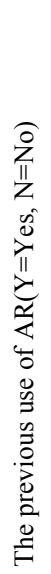 & 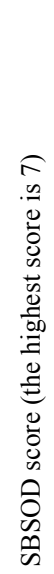 \\
\hline P1 & $\mathrm{F}$ & India & G & Monthly & $2-4$ times/y & Somewhat & $<1$ & $\mathrm{~N}$ & $\mathrm{~N}$ & 5.3 \\
\hline $\mathrm{P} 2$ & $\mathrm{M}$ & Greece & $\mathrm{G}$ & Daily & Monthly & Very & $<1$ & $\mathrm{Y}$ & $\mathrm{N}$ & 5.3 \\
\hline P3 & $\mathrm{F}$ & China & $\mathrm{U}$ & Weekly & Weekly & Moderate & $<1$ & $\mathrm{~N}$ & $\mathrm{~N}$ & 5.3 \\
\hline $\mathrm{P} 4$ & $\mathrm{M}$ & Zimbabwe & $\mathrm{N}$ & Weekly & Daily & Very & $<1$ & $\mathrm{Y}$ & $\mathrm{N}$ & 3.9 \\
\hline P5 & $\mathrm{M}$ & Indonesia & $\mathrm{N}$ & Daily & Monthly & Moderate & $1-2$ & $\mathrm{~N}$ & $\mathrm{~N}$ & 4.6 \\
\hline P6 & $\mathrm{F}$ & Tanzania & $\mathrm{N}$ & Weekly & Monthly & Moderate & $1-2$ & $\mathrm{~N}$ & $\mathrm{Y}$ & 4.1 \\
\hline $\mathrm{P} 7$ & $\mathrm{M}$ & Tanzania & $\mathrm{N}$ & Daily & Weekly & Very & $<1$ & $\mathrm{~N}$ & $\mathrm{~N}$ & 5.7 \\
\hline P8 & $\mathrm{M}$ & Colombia & A & Daily & Monthly & Very & $<1$ & $\mathrm{~N}$ & $\mathrm{~N}$ & 4.5 \\
\hline P9 & $\mathrm{F}$ & China & $\mathrm{U}$ & Weekly & Never & Moderate & $<1$ & $\mathrm{~N}$ & $\mathrm{~N}$ & 3.6 \\
\hline P10 & $\mathrm{F}$ & Indonesia & G & Daily & $<1$ time $/ y$ & Very & $<1$ & $\mathrm{~N}$ & $\mathrm{~N}$ & 4.8 \\
\hline P11 & $\mathrm{F}$ & China & $\mathrm{U}$ & Daily & Weekly & Moderate & $<1$ & $\mathrm{~N}$ & $\mathrm{~N}$ & 3.4 \\
\hline P12 & $\mathrm{F}$ & Brazil & W & Weekly & 5-10 times/y & Very & $<1$ & $\mathrm{Y}$ & $\mathrm{N}$ & 5.5 \\
\hline P13 & $\mathrm{M}$ & Indonesia & G & Daily & Monthly & Very & $1-2$ & $\mathrm{Y}$ & $\mathrm{N}$ & 4.9 \\
\hline P14 & M & Egypt & G & Daily & 5-10 times/y & Very & $1-2$ & $\mathrm{Y}$ & $\mathrm{Y}$ & 4.7 \\
\hline
\end{tabular}




\subsubsection{Apparatus}

Figure 6.1 illustrates the setting of evaluating GeoFARA in the field, showing both the participant and the researcher as well as the main apparatus (the smartphone with GeoFARA and the eye tracking glasses used by the participant, and the tablet with Tobii controller (see below) used by the researcher). This section introduces the devices.

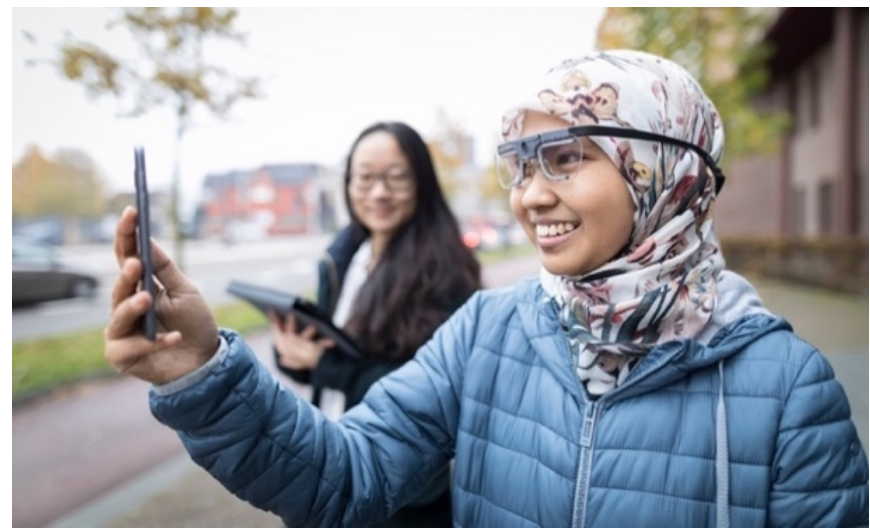

Figure 6.1 The setting of evaluating GeoFARA in the field (front: a participant; back: the researcher)

The smartphone on which GeoFARA was installed for the evaluation was a Samsung Galaxy S7 with the operating system Android 7.0. It was selected because it was an available Android device with sufficient sensors such as compass and accelerometer that supported running GeoFARA. Other specifications of the selected smartphone are listed in Table 6.3.

Table 6.3 The specifications of the smartphone used for evaluating GeoFARA

\begin{tabular}{l|l}
\hline Item & Specification \\
\hline Dimensions & $142.4 \times 69.6 \times 7.9 \mathrm{~mm}$ \\
Display and resolution & $5.1 "$ Flat Quad HD, 1440*2560 \\
Battery & $3000 \mathrm{mAh}$ \\
Memory space & Internal storage $32 \mathrm{~GB}$ \\
\hline
\end{tabular}

As mentioned in Section 6.3.1, the eye tracking and thinking aloud methods were applied in evaluating GeoFARA. The Tobii Pro Glasses 2 (URL33) with integrated eye tracking technology was used to record the eye movements of participants during the evaluation while they were using GeoFARA to explore the fieldwork area. The Tobii Pro Glasses 2 hardware included a head unit (Tobii mobile eye tracker, Figure 6.2(a)) and a recording 
unit (Figure 6.2(b)). The four eye cameras behind the lens and the front scene camera of the eye tracker captured the participants' viewing behaviors while using GeoFARA within the surrounding environment and the microphone recorded the thinking-aloud comments. The recording unit that was powered by an external battery and connected to the eye tracker through a USB cable (Figure 6.2(c)) recorded and saved all the data to a SD card. The Tobii Pro Glasses 2 software included a Tobii Pro Glasses Controller (Figure 6.3) run on a Window tablet (see Figure 6.1, held by the researcher) and Tobii Pro Lab software (Figure 6.4) installed on a Window laptop respectively. The Tobii Pro Glasses Controller enabled the researcher to control and view the eye-tracking data recording process live when used in the fieldwork environment. In addition to the management, the recording calibration and participant management were also done through this controller software. The Tobii Pro Lab software supported the processing of the eye-tracking data. After importing the collected eye-tracking data, Tobii Pro Lab could be used to analyze the data and to visualize the analysis results. Details about how Tobii Pro Lab was used in support of the data analysis are presented in Section 6.3.5.2.

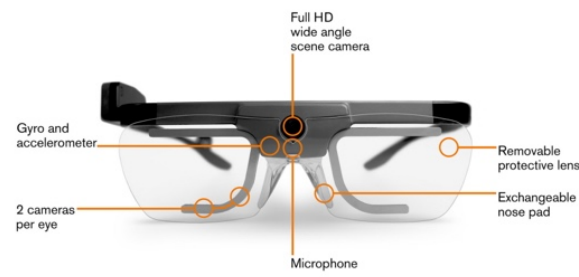

(a)

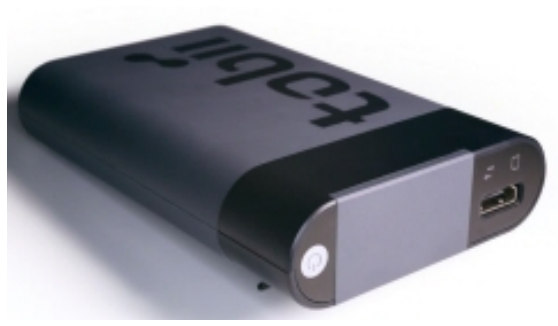

(b)

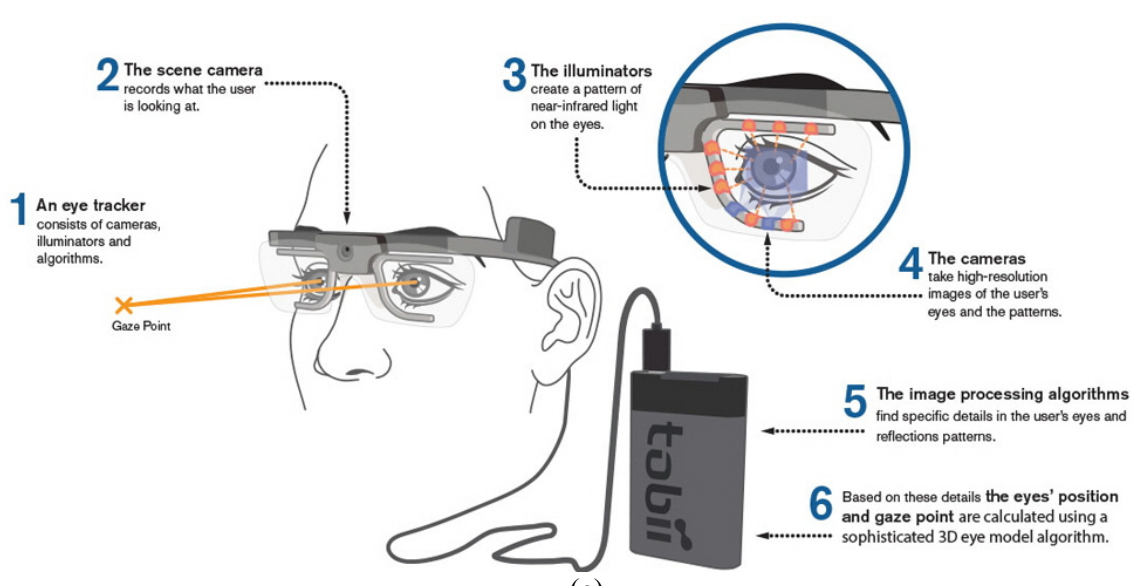

(c)

Figure 6.2 Tobii Pro Glasses 2 hardware

The head unit (a) and the recording unit (b) and how the hardware works $\subset$ Tobii (c) (URL33, URL34) 


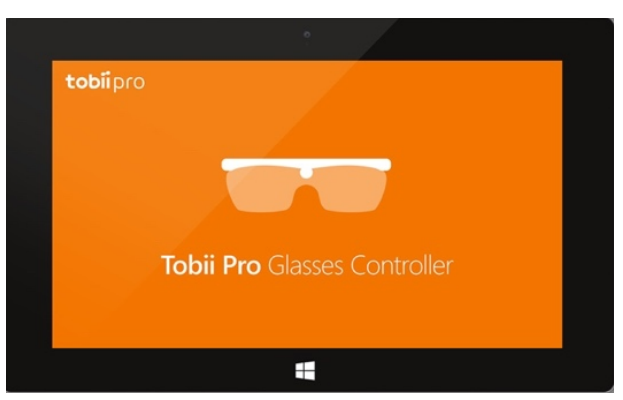

\begin{tabular}{ll} 
Tobii Pro Glasses Controller \\
- & Replay recordings \\
- & Calibration \\
- & Eye image video \\
- & Recorticipant management \\
- & Study management \\
- & Live view \\
- & Video export \\
- & Event logging \\
- & Swaze based exposure \\
\hline &
\end{tabular}

Figure 6.3 Tobii Pro Glasses Controller and its features (URL35)

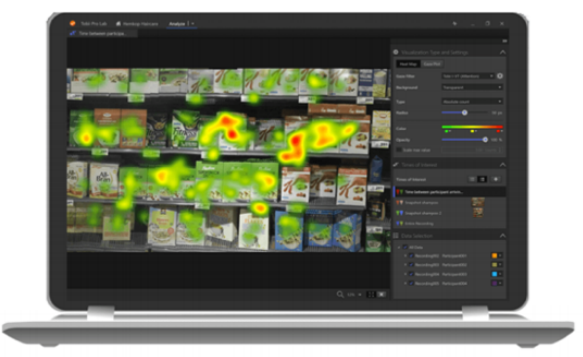

\begin{tabular}{|ll|}
\hline Tobii Pro Lab \\
\hline - & Replay recordings \\
- & Event logging \\
- & Real-world mapping \\
- & Metrics and data export \\
- & Import \& export projects \\
- & AOls with tagging and grouping \\
- & Participant variables \\
\hline
\end{tabular}

Figure 6.4 Tobii Pro Lab software and its features (URL36)

\subsubsection{Materials and procedures}

The entire GeoFARA evaluation study with all the participants was completed over fifteen days in November 2017 within the defined fieldwork area located in Enschede (Figure 6.5). Before starting the study with each participant, printed study instructions, a fully-charged smartphone with GeoFARA installed on it, and the Tobii Pro Glasses were prepared. The instructions (Appendix 10) consisted of a basic introduction about the textile history of Enschede (especially about the area Schuttersveld, Figure 6.5), the purpose of the upcoming fieldwork, as well as the procedures of the GeoFARA evaluation study (drawing pre- and post-fieldwork mental maps as Appendix 9, the spatial ability survey, field tasks, interview, etc.). The smartphone on which GeoFARA ran allowed the researcher to give a demonstration of GeoFARA to the participant. All these work were executed in the office of the researcher (Figure 6.6(a)). After leaving the office, the participants used GeoFARA for completing the evaluation study within the fieldwork area (Figure 6.6(b)). Back from the field, the post-fieldwork activities were conducted in the same office. A voice recording application was used to record the post-fieldwork interview conversations and the participants were asked to draw their post-fieldwork mental maps (Appendix 11). 


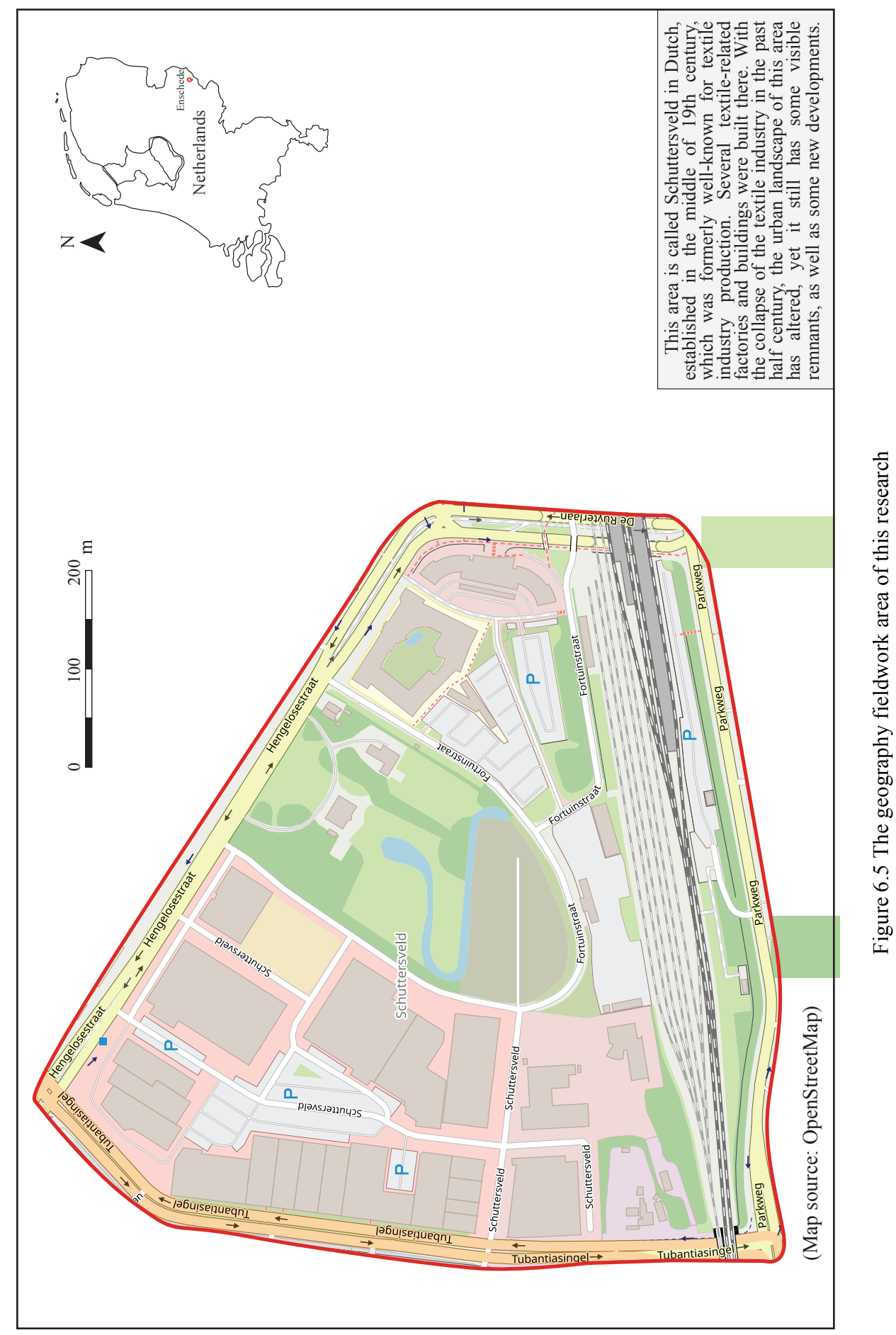




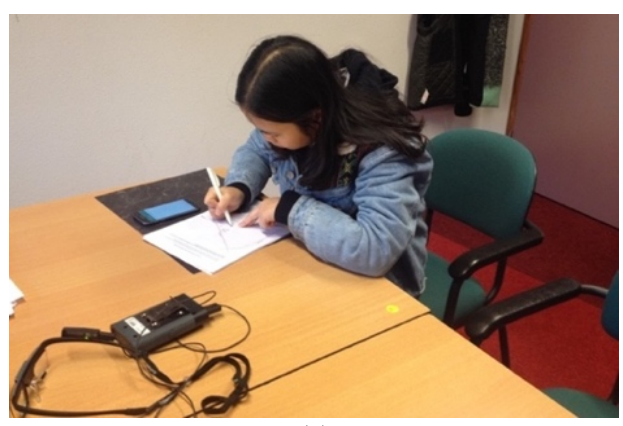

(a)

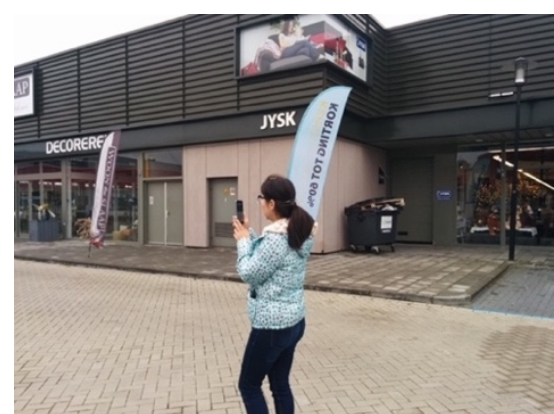

(b)

Figure 6.6 The office setup (a) and the field setup (b) for the GeoFARA evaluation study

Prior to inviting participants to participate in the GeoFARA evaluation, pilot studies with two experts and one potential participant were conducted. The first pilot study with one expert was conducted during the development of GeoFARA; the second pilot study with another expert was conducted after completing the initial development of GeoFARA and setting up the evaluation study. Both the experts have background in usability research of interactive map products. The main purposes of the pilot studies were: (1) get feedback about GeoFARA itself and the materials and procedure of evaluating GeoFARA, (2) revise the materials (the introduction, the survey and interview questions) that were not clear, (3) become familiar with the procedures and the apparatus as the evaluation moderator, (4) estimate the use of the batteries by the smartphone, the Tobii Pro Glasses' recording unit, and the tablet on which the Tobii Pro Glasses Controller was installed, (5) estimate the duration of the complete evaluation study and each session. During the pilot studies, GeoFARA worked quite steadily in all functionalities. Due to the limited time available to implement all the experts' feedback about improving GeoFARA, only some of the feedback was applied to improve GeoFARA. For example, the original overlap of POIs on the AR view was solved after the pilot studies. The prototype of GeoFARA that was presented in Section 5.5.3 was already the version that was improved after the pilot studies. The main feedback about the materials and procedures for the GeoFARA evaluation study was that the task specifications should be provided in a clearer way in both the verbal and paper instructions. It was estimated that the complete study would take approximately 1.5 hours, 45 minutes of which were spent in the field session. The fully-charged batteries of all the apparatus lasted for the full 1.5 hours.

As indicated before, the formal GeoFARA evaluation study with each participant consisted of three sessions. The first session was conducted before the actual fieldwork and began with welcoming the participant in the office. Once the participant was ready, the study instructions (Appendix 10) were handed over to the participant. The participant was asked to read the instructions and then complete the SBSOD survey and draw the pre-fieldwork mental map of the fieldwork area. Following this, the participant was given 
a demonstration of GeoFARA and was encouraged to explore GeoFARA on his or her own. Since both the demonstration and free exploration were not intensive (less than 15 minutes), they were not in a controlled setting, and it is argued that this would not influence the performance of the participants in the field study. The demonstration of GeoFARA and the participants' free exploration were followed by the participant being instructed on how to wear the Tobii Glasses. After properly fitting the glasses, the participants went through a calibration procedure with the help of the Tobii Pro Glasses Controller application on the tablet in the office. All in all, the pre-fieldwork session lasted approximately 20 minutes.

Following this indoor session, the participant was instructed to explore the outdoor fieldwork area with the help of GeoFARA. The participant was encouraged to discover the remnants of Enschede's former textile industry. Furthermore, during the fieldwork session, the participant was required to find out more about the visible influences of the past textile industry on the current spatial structure of this area through direct experience and information provided by GeoFARA. During this field session, open-ended tasks (Appendix 10) that were given to the participants were to discover the remnants of Enschede's former textile industry as well as the relatively new developments and further to find out the visible influence of the past textile industry on the current spatial structure of the fieldwork area. The participants were supposed to complete these tasks through interacting with GeoFARA and the field environment on his or her own. The participant was asked to talk aloud about what he or she was doing and thinking during this task execution. At the start of the field session, after the participant indicated that she or he was starting to use GeoFARA to explore the field environment, the researcher started the recordings (both of the eye movements and of the thinking aloud) through the Tobii Pro Glasses Controller. During the field evaluation study, the researcher was walking together with the participant in the field, but kept an approximately ten meters' distance. This was to make sure that the Glasses the participant was wearing and the Tobii Controller on the tablet held by the researcher remained connected. At the same time, the researcher could manage the data recording process and also remind the participant to talk aloud when necessary. The field session ended with the participant indicating that he or she believed that he or she had completed the fieldwork learning. At that moment, the researcher stopped and saved all the recordings through the Tobii Controller. Overall, most participants spent approximately 30 minutes in the field. The shortest field session lasted only 22 minutes, and none of the field sessions lasted longer than 50 minutes.

After the field study, the researcher and the participant walked back to the office room together and then continued with the post-fieldwork evaluation study activities. The postfieldwork session began with the participant being required to draw another mental map of the fieldwork area in which the remnants of the former textile industry discovered had 
to be included. For drawing the post-fieldwork mental maps, participants were allowed to refer to their notes and the photos that they had taken in the fieldwork (but not to the maps in GeoFARA). After drawing the post-fieldwork mental map, the participant was then asked to complete the GeoFARA usability survey which used the SUS questionnaire (Appendix 12). The completion of the usability survey was followed by a final interview in which the participant was asked some additional questions regarding his or her experience with using GeoFARA (Appendix 13). The entire post-fieldwork session lasted around 30 minutes, with spending no more than 15 minutes on the interview part. After completing the whole evaluation study, each participant was rewarded with a $€ 10$ gift card. For all participants, the entire evaluation study lasted less than 1.5 hours, as planned.

\subsubsection{Data analysis}

A mixed methods approach with various data collection techniques was applied in the GeoFARA evaluation study. The collected data includes: (1) paired mental maps (prefieldwork mental map and post-fieldwork mental map of each participant), (2) mobile eye tracking data, (3) thinking-aloud protocols, (4) SUS usability rating, (5) interaction logs, (6) interview recordings. To generate broad insights into the evaluation results, both qualitative and quantitative analysis techniques were used. This section focuses on presenting how these collected data was analyzed and how the analysis results could contribute to the evaluation of GeoFARA. Section 6.4 presents the mix of the analysis results to get insights into the utility and usability of GeoFARA.

\subsubsection{Mental maps analysis}

The participants' mental maps (Figure 6.7 presents the two mental maps drawn by a participant) were analyzed to try to examine the utility of GeoFARA in learning about the remnants of textile industry (Goal 1). The change of the participants' spatial knowledge after the fieldwork can be reflected by comparing the paired pre- and post-fieldwork mental maps. The hand-drawn mental maps that contained spatial information were interpreted by counting and comparing the numbers of the spatial objects (landmarks, street segments, junctions, and city blocks) as proposed by Wang \& Schwering (2015) (Figure 6.8). Therefore, the metric used to compare the pre- and post-fieldwork mental maps are the numbers of the drawn spatial objects in both maps. The mental map comparison results are presented as Table 6.6 in Section 6.4.1.1. Due to the relatively small sample size $(\mathrm{N}=14)$, statistical analysis was not applied to determine whether there were significant changes between the pre- and post- mental maps. However, it was found that with simple comparison, it is not possible to tell the utility of GeoFARA in helping to discover the remnants of the former textile industry, because together with the influence of GeoFARA, participant's direct experience in the field also played as an input. 


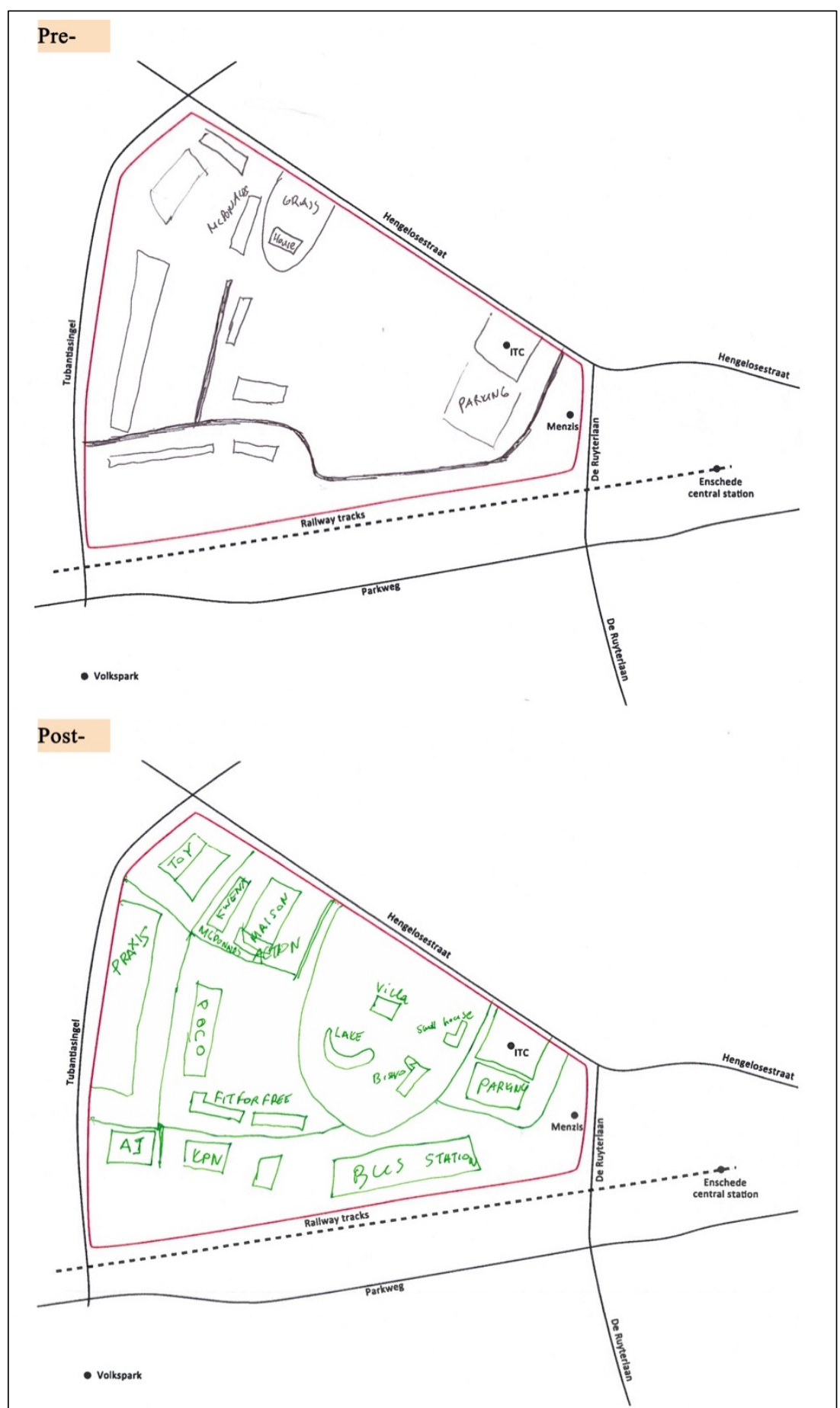

Figure 6.7 The pre-fieldwork and the post-fieldwork mental maps of one participant 


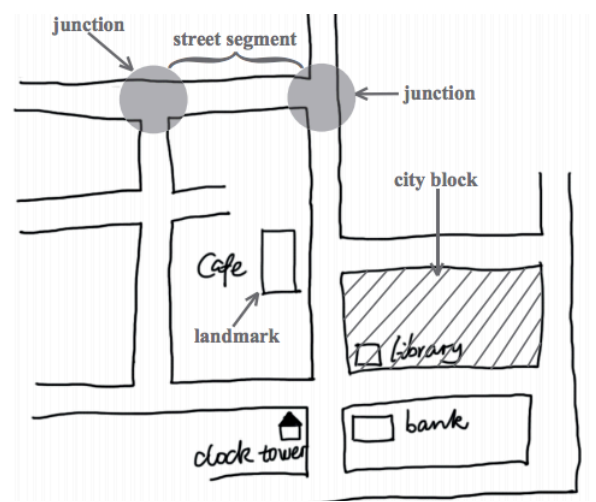

Figure 6.8 Spatial objects defined in a sketch map (Obtained from Wang \& Schwering, 2015)

In order to find out whether GeoFARA contributed to changes in spatial knowledge, several analysis techniques were tried. However, during the process of several analysis attempts, it had already been found that the changes of the mental maps of the field area were gained from both the learning tool GeoFARA and the direct field immersive experience. This is even probably true for spatial learning through any combination of real experience as with spatial representations (such as maps) and immersive tools (such as AR), because it is argued that information/tools which are helping to recognize a place within the same overall environment are simultaneously involved in any context learning. Therefore, no matter how to analyze the combined data (with eye tracking and thinking aloud), it was very hard, even impossible, to derive the sole role of GeoFARA, i.e., separating the utility of GeoFARA from the direct field experience in contributing to the participants' changes in spatial knowledge. In the end, the utility of GeoFARA will be mainly interpreted by the attitudinal data collected from interviews, while the mental maps will be only used to show the changes of participants' cognition of the spatial structure of the fieldwork area, partially reflecting the utility of GeoFARA. More details are presented in Section 6.4.1.1.

\subsubsection{Eye tracking analysis and thinking aloud analysis}

As already mentioned in Section 6.3.4, all participants were asked to wear a mobile eye tracker (Figure 6.1) that detected and recorded each participant's eye movements when they used GeoFARA in the fieldwork area to undertake a free-exploration learning task. The objective of the analysis of the collected eye tracking data is to interpret the patterns of eye movements to support answering the research questions. The collected thinking aloud data would be helpful in this interpretation (in order to find out why a participant looks at something). In this research, not much thinking aloud data were collected in fact, because it appeared to be difficult for most participants to verbalize their concurrent 
thoughts while focusing on using GeoFARA in an open-air environment. At the same time, it was difficult for the researcher (the moderator) to prompt thinking aloud in realtime, as the moderator had to keep a certain distance to the participants so as to not disturb the natural use of GeoFARA. However, the analysis will still try to make use of the limited thinking aloud data together with the mobile eye tracking analysis to get insights about the utility and usability. In addition, the verbalized concurrent thinking aloud will also serve to identify the usability problems of GeoFARA (Goal 2).

The whole eye tracking procedure resulted in a large volume of eye movement data in scenery videos that consisted of gazes on the different objects (including GeoFARA) in the environment. There is a set of eye tracking metrics that can uncover details of the users' visual attention when they are interacting with a product. The main eye movement metrics are the participants' eye fixation positions and durations, as well as the scan path structures. Standard approaches to visualize these eye movements are heat maps and gaze plots (see examples in Figure 6.9). Heat maps express the density of visual attention, while gaze plots reveal the temporal order of where the participants looked at, i.e. fixations and their duration. These two visual techniques are commonly used when the product evaluation environment is a static one. In typical laboratory settings in which products (e.g., fixed to a screen) are evaluated with participants who do not move around, the eye tracking technique is used to find out about the visual attention on product interface elements. This results in insights into product usability. The visual attention results can provide information on which specific interface elements are being noticed/ignored/read/scanned, how often/how long and in which sequence. However, in this research, the evaluation of GeoFARA in the field is executed in a context of constant movement (both the participants and the product). At the same time, the smartphonescreen interface of GeoFARA is much smaller than the full visual view in the real environment. This made it difficult to get accurate information about the visual attention to the detailed user interface elements of GeoFARA. Therefore, in such a setting, it is difficult to utilize heat maps and gaze plots to visualize the eye movement patterns. Besides, as summarized by Raschke, Blascheck \& Burch (2014), both of them have drawbacks: heat maps do not show a sequential order of visual attention and the visual clutter in gaze plots is problematic for effectively conveying eye tracking information. To overcome the above-mentioned drawbacks of eye tracking visualizations, this research employed an automated analysis technique developed by Jiang (2020) to get insights on the usability of GeoFARA. The analysis techniques were based on mapping gaze information of the raw recorded eye tracking videos. The raw frame-based videos (one video for each participant) were first processed using Tobii Pro Lab software to map the gaze positions, gaze directions, gaze orders. Figure 6.10 shows the analytical interface of the software. With the mapped gaze information, then the eye tracking data will also be analyzed to get insights into how participants interacted with GeoFARA as a whole 
mobile device (not with specific user interface elements) and with its use environment. The analysis approach is explained below.

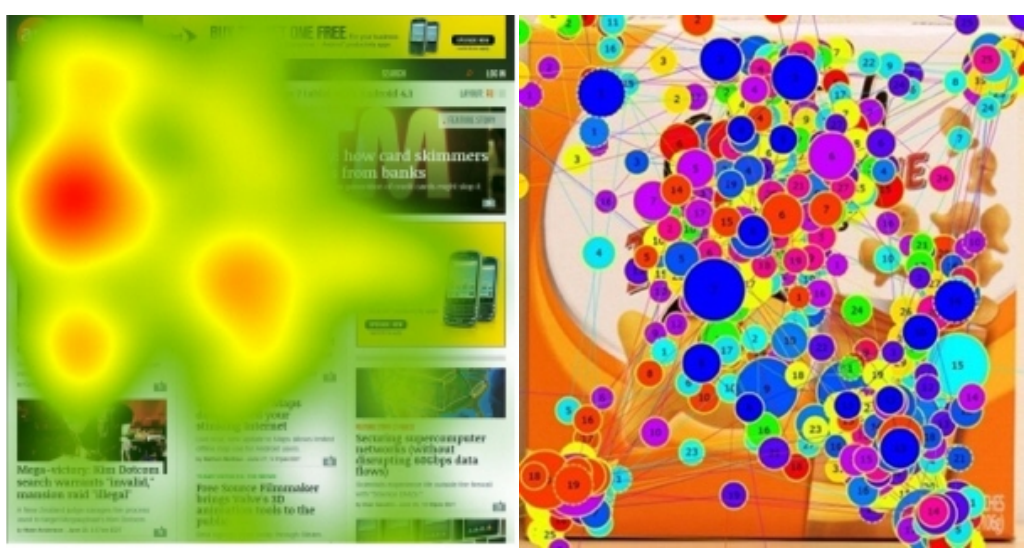

Figure 6.9 Examples of heat maps (left) and gaze plots (right) (Source: URL37)

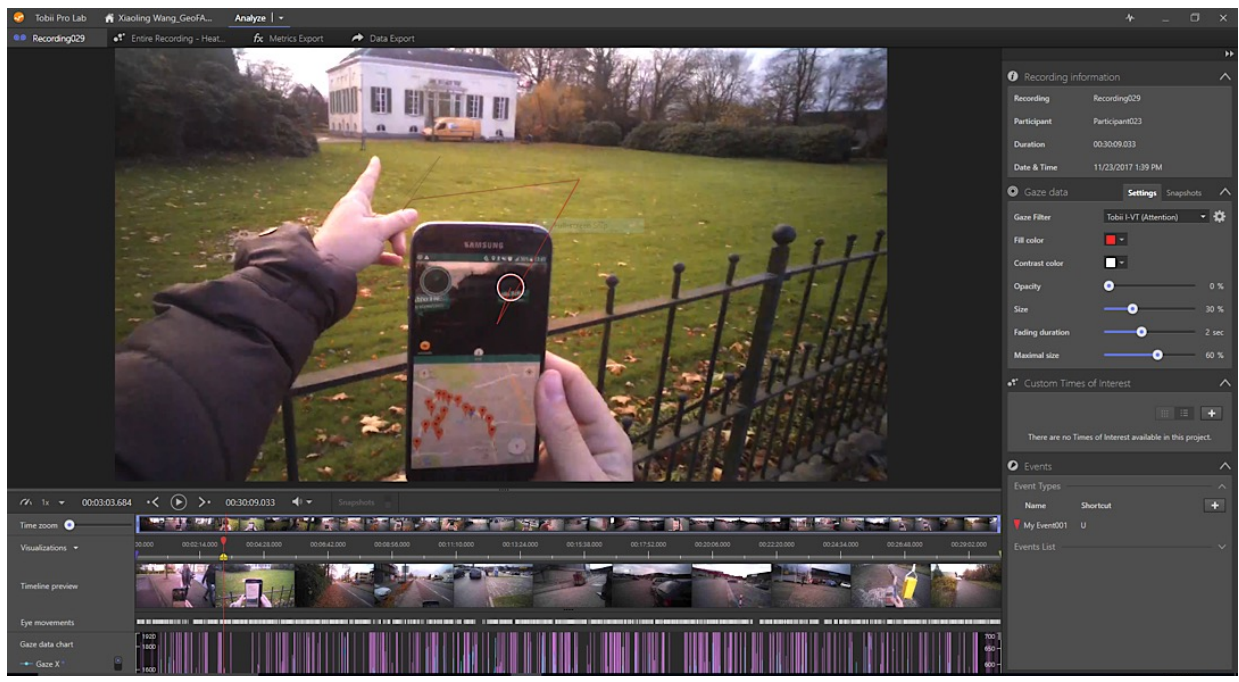

Figure 6.10 A screenshot of using Tobii Pro Lab software to automated map gaze points on the raw eye tracking video

(Middle: the mapped eye tracking video; bottom: gaze data chart along timeline; right: supporting information)

As explained above, there are drawbacks of using the common eye tracking visualizations such as heat maps and gaze plots in analyzing the mobile eye tracking data in this research. Alternatively, to overcome those drawbacks, Jiang (2020) proposed an innovative automated approach to visually analyze eye tracking data. This approach can integrate 
the participants' key eye fixations (and gaze durations) on the mobile application and on objects in the mobile use context into one visualization by automatically mapping the prefiltered fixations that are exported from the Tobii Pro Lab software and mapping the environment objects where the fixation was on. With this visual technique, the mobile eye tracking data can be represented by the gaze duration and their distribution in one visualization. The eye tracking data analysis in this research will adopt this approach to present the participants' eye movement patterns (gaze duration and distribution among different target objects). This approach as proposed by Jiang (2020), on the one hand, can help with understanding the participants' eye fixations on different objects in the eye tracking video; On the other hand, with this approach, the eye tracking data analysis can contribute to a broader view on how users synchronously interact with the environment (the fieldwork area) and with a context-aware mobile application (such as GeoFARA) (see Figure 3.6). More implementations will be explained in Section 6.4.2.3.

\subsubsection{SUS usability rating analysis}

Since the SUS usability rating questionnaire that was used to evaluate the usability of GeoFARA is a ready-to-use questionnaire, the analytical method that will be used in this research is also the same as in the original work (Brooke, 1996). Table 6.4 shows the slightly adjusted questionnaire for evaluating GeoFARA as well as an example of the answers given by one participant and the SUS score. The adjustment was mainly changing the name of the evaluated product into "GeoFARA". The final SUS score of GeoFARA can be interpreted by comparing it to the experience-based standard in terms of acceptability, adjectives, and grades (URL38) as shown in Figure 6.11.

Table 6.4 The SUS usability rating questionnaire for evaluating GeoFARA and an example showing the answers (labelled in blue, underline) given by one participant and the final score

\begin{tabular}{|c|c|c|c|c|c|}
\hline 1. I think that I would like to use GeoFARA frequently. & 1 & 2 & $\underline{\mathbf{3}}$ & 4 & 5 \\
\hline 2. I found GeoFARA unnecessarily complex. & $\underline{1}$ & 2 & 3 & 4 & 5 \\
\hline 3. I thought GeoFARA was easy to use. & 1 & 2 & 3 & 4 & $\underline{\mathbf{5}}$ \\
\hline $\begin{array}{l}\text { 4. I think that I would need the support of a technical person to be able to } \\
\text { use GeoFARA. }\end{array}$ & 1 & 2 & 3 & $\underline{4}$ & 5 \\
\hline 5. I found the various functions in GeoFARA were well integrated. & 1 & 2 & 3 & 4 & $\underline{5}$ \\
\hline 6. I thought there was too much inconsistency in GeoFARA. & $\underline{1}$ & 2 & 3 & 4 & 5 \\
\hline $\begin{array}{l}\text { 7. I would imagine that most students would learn to use GeoFARA very } \\
\text { quickly. }\end{array}$ & 1 & 2 & 3 & 4 & $\underline{5}$ \\
\hline 8. I found GeoFARA very cumbersome/complicated to use. & $\underline{1}$ & 2 & 3 & 4 & 5 \\
\hline 9. I felt very confident using GeoFARA. & 1 & 2 & 3 & 4 & $\underline{5}$ \\
\hline $\begin{array}{l}\text { 10. I needed to learn a lot of things before I could get going with } \\
\text { GeoFARA. }\end{array}$ & $\underline{1}$ & 2 & 3 & 4 & 5 \\
\hline
\end{tabular}




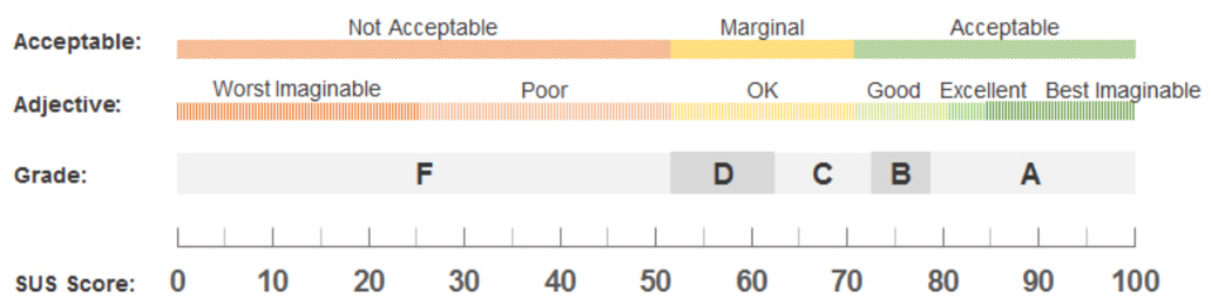

Figure 6.11 Interpreting SUS scores in terms of grades, adjectives, acceptability

To calculate the total SUS score for measuring the overall usability of GeoFARA, the first step was to reverse the answered score for each question to get the contribution. Thereafter, the reversed scores of all questions were summed, and the summed value was then multiplied by 2.5. The purpose of this was to get a SUS score ranging from 0 to 100 . To reverse the original answer of each question, for the oddly numbered questions $(1,3$, 5,7 , and 9), the contribution was the original score given by the participant minus 1 ; for the evenly numbered questions $(2,4,6,8$, and 10$)$, the contribution was 5 minus the original score. After reversing, the contribution of each question ranged from 0 to 4 . GeoFARA's SUS score (ranging from 0 to100) of each participant, as well as the average SUS score, was calculated by summing up the revised scores of the ten questions and multiplying the value by 2.5 . Following this calculation means, the SUS score as an example was calculated in this way: $((3-1)+(5-1)+(5-1)+(5-4)+(5-1)+(5-1)+(5-1)$ $+(5-1)+(5-1)+(5-1)) * 2.5=87.5$. The SUS scores of GeoFARA and their mapping on the three dimensions, acceptability, adjectives, and grades are presented in Section 6.4.2.1.

\subsubsection{Interaction log analysis}

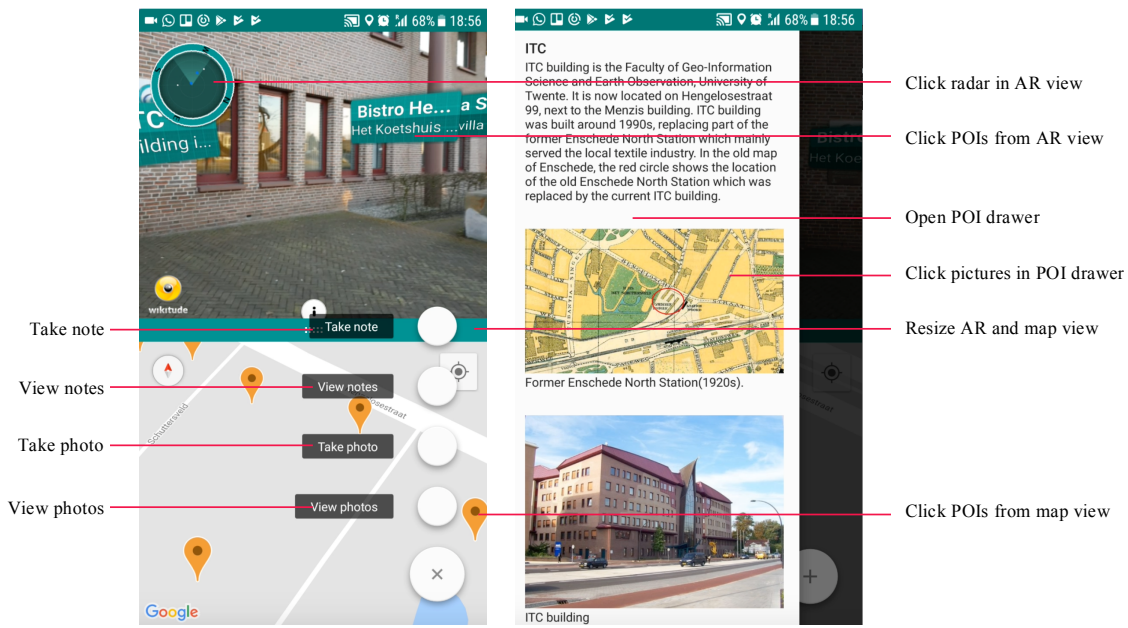

Figure 6.12 The recorded user log actions on GeoFARA 
To know the participants' detailed use of the user interface of GeoFARA, logging data of the users' interactions with GeoFARA was collected by integrated source codes. Since GeoFARA has a relatively simple user interface, only ten key user actions were recorded (Figure 6.12). The collected log data was a list actions of the fourteen participants with timestamps. The metric used for the interaction log analysis is the frequency of actions in using the main user interface features of GeoFARA as well as the associated percentages. To find out the frequency of the listed user actions, a SQL (Structured Query Language) query was used. The log data analysis results are presented in Section 6.4.2.1.

\subsubsection{Interview analysis}

The one-to-one interviews were conducted after the field evaluation sessions, and the recordings of the interview conversations were collected. The analysis of the participants' verbal responses to the interview questions about GeoFARA will be of a qualitative nature. In order to be able to analyze the interview audio data qualitatively, first, the data was transcribed, and then a coding scheme was developed. With the coding scheme, the actual coding and further analysis (based on code frequencies) were executed. Transcribing the interview audio to texts was completed manually in Microsoft Word. There were a total of 14 transcripts (of 14 participants), in each of which every participant's answers to each of the interview questions were transcribed. To analyze the transcripts, a coding scheme is required. In general, how a coding scheme should be developed depends on the research purpose. In this research, the interview method was applied to support all of the evaluation goals. Therefore, as guided by the two evaluation goals, a coding scheme with higher level categories was developed (Table 6.5). Two categories identified respective statements indicating: (1) the utility of GeoFARA; (2) the usability of GeoFARA. Under each code category, several codes (each has a code ID) were established, and the definitions and examples of each code are also provided in Table 6.5.

For the utility category of GeoFARA, codes of the positive influence and negative influence of GeoFARA on the field learning were identified. For the usability category of GeoFARA, there are different characteristics of usability (see Section 3.4.1). The usability characteristic "satisfaction" had two dimensions (positive and negative). The usability measurement in terms of easiness/complexity of use had two codes: "easy to use" and "difficult to use". In the answers to the interview questions, participants met some errors or problems when using GeoFARA. Since it is not necessary to quantify the frequency of the errors or problems (when the majority or all participants ran into the same issues, it will be stated) in a first iterative evaluation, the corresponding verbalized sentences will be directly analyzed and summarized in Section 6.4.2, along with the design recommendations that were proposed by the participants for how to improve GeoFARA. 
Table 6.5 The coding scheme for the interview analysis

\begin{tabular}{|c|c|c|c|}
\hline Code ID & Code Group & Definition & Examples \\
\hline Utility1 & $\begin{array}{l}\text { Positive } \\
\text { influence }\end{array}$ & $\begin{array}{l}\text { Positive impact of } \\
\text { GeoFARA on the field } \\
\text { learning. }\end{array}$ & $\begin{array}{l}\text { "I think with the information } \\
\text { found in the POI, it's really } \\
\text { helpful to learn about the } \\
\text { historical factories in } \\
\text { Enschede." }\end{array}$ \\
\hline Utility2 & $\begin{array}{l}\text { Negative } \\
\text { influence }\end{array}$ & $\begin{array}{l}\text { Negative impact of } \\
\text { GeoFARA on the field } \\
\text { learning. }\end{array}$ & $\begin{array}{l}\text { "But in the beginning, I have } \\
\text { to say it was a little bit } \\
\text { distracting before reading } \\
\text { the map." }\end{array}$ \\
\hline Usability1 & Satisfied & $\begin{array}{l}\text { Participants are satisfied } \\
\text { with using GeoFARA }\end{array}$ & $\begin{array}{l}\text { "In general, it's a good } \\
\text { application. I'm satisfied to } \\
\text { use." }\end{array}$ \\
\hline Usability2 & Not satisfied & $\begin{array}{l}\text { Participants are not } \\
\text { satisfied with using } \\
\text { GeoFARA }\end{array}$ & $\begin{array}{l}\text { "I don't exactly know how } \\
\text { GeoFARA would help me } \\
\text { understanding the area." }\end{array}$ \\
\hline Usability3 & Easy to use & $\begin{array}{l}\text { The interface of GeoFARA } \\
\text { is easy to use }\end{array}$ & $\begin{array}{l}\text { "GeoFARA was quite easy } \\
\text { to use." }\end{array}$ \\
\hline Usability4 & Difficult to use & $\begin{array}{l}\text { The interface of GeoFARA } \\
\text { is difficult to use }\end{array}$ & $\begin{array}{l}\text { "The distance setting is } \\
\text { sometimes difficult to } \\
\text { change." }\end{array}$ \\
\hline
\end{tabular}

\subsection{Results and discussion}

This section presents the key results of evaluating GeoFARA and will be providing insights into the two evaluation goals as described in Section 6.2. Section 6.4.1 first presents the comparisons of pre- and post-fieldwork mental maps. The results about the utility of GeoFARA (as a fundamental dimension of its usefulness) are based on the analysis of the interview data. Section 6.4 .2 provides the evaluation results of the usability of GeoFARA, summarized from the analysis of data from different sources: (1) SUS, (2) mobile eye tracking and thinking aloud, (3) interaction logs, (4) interviews, and (5) user observation.

\subsubsection{The utility of GeoFARA}

\subsubsection{The comparisons of pre- and post-fieldwork mental maps}

As introduced in Section 6.3.4, the participants were asked to draw their mental maps of the field area before and after the fieldwork. Table 6.6 provides the components in each of the participants pre- and post- fieldwork mental maps (the mental maps of P14 were 
not clear enough to analyze, therefore, only 13 participants in total). Comparison of the participants' pre- and post-fieldwork mental maps revealed that they created higher quality post-fieldwork mental maps of the fieldwork area, as the participants included more geo-information (more landmarks, streets, junctions, and city blocks). Overall, on average there were roughly four times as many mental map elements in all participants' post-fieldwork mental maps as in the pre-fieldwork mental maps (Table 6.6). In terms of landmarks, the average numbers of them in the pre- and post-fieldwork mental maps were 3.5 and 12.5 respectively. Two participants (P4, and P11, Table 6.6) even did not include a single landmark in their pre-fieldwork mental maps, while they drew more than ten landmarks in the post-fieldwork mental maps. Regarding the spatial structure, as reflected by the street segments, junctions and city blocks, the four-times increase (from 1 to 5.1 in street segments, from 0.4 to 1.9 in junctions, from 0.9 to 3.5 in city blocks) of the average number of these spatial elements in the post-fieldwork mental maps showed that participants constructed a better spatial structure of the field area after their field exploration. Actually, more than half of the participants did not draw any street segments, junctions, and city blocks before their field trip, while most of them built their postfieldwork mental maps with those elements, although some of them (e.g. P3, P5, and P13) still included none of those elements in their post-fieldwork mental maps.

Table 6.6 Comparing the pre- and post-fieldwork mental maps of each participant

\begin{tabular}{lccc|c|c|c|cc}
\hline \multirow{2}{*}{ Participant } & \multicolumn{2}{c}{ \# of landmarks } & \multicolumn{2}{c}{ \# of street segments } & \multicolumn{2}{c}{ \# of junctions } & \multicolumn{2}{c}{ \# of city blocks } \\
\cline { 2 - 9 } & pre & post & pre & post & pre & post & pre & post \\
\hline P1 & 4 & 17 & 0 & 9 & 0 & 4 & 3 & 4 \\
P2 & 10 & 16 & 3 & 10 & 1 & 4 & 1 & 7 \\
P3 & 1 & 7 & 0 & 0 & 0 & 0 & 0 & 0 \\
P4 & 0 & 11 & 0 & 4 & 0 & 1 & 0 & 5 \\
P5 & 2 & 23 & 0 & 1 & 0 & 0 & 0 & 0 \\
P6 & 6 & 9 & 0 & 7 & 0 & 2 & 0 & 1 \\
P7 & 4 & 10 & 1 & 5 & 0 & 1 & 0 & 1 \\
P8 & 2 & 8 & 5 & 9 & 3 & 4 & 5 & 7 \\
P9 & 2 & 18 & 0 & 8 & 0 & 3 & 0 & 5 \\
P10 & 5 & 12 & 2 & 7 & 1 & 3 & 1 & 4 \\
P11 & 0 & 11 & 0 & 3 & 0 & 2 & 0 & 4 \\
P12 & 4 & 13 & 0 & 4 & 0 & 2 & 2 & 4 \\
P13 & 5 & 10 & 0 & 0 & 0 & 0 & 0 & 2 \\
\hline Total & $\mathbf{4 5}$ & $\mathbf{1 6 3}$ & $\mathbf{1 4}$ & $\mathbf{7 2}$ & $\mathbf{6}$ & $\mathbf{2 7}$ & $\mathbf{1 2}$ & $\mathbf{4 6}$ \\
Average & $\mathbf{3 . 5}$ & $\mathbf{1 2 . 5}$ & $\mathbf{1}$ & $\mathbf{5 . 1}$ & $\mathbf{0 . 4}$ & $\mathbf{1 . 9}$ & $\mathbf{0 . 9}$ & $\mathbf{3 . 5}$ \\
\hline
\end{tabular}

As already mentioned in Section 6.3.5, due to the relatively small sample it does not make much sense to statistically test whether the pre- and the post-fieldwork mental maps differ significantly. However, Table 6.6 generally indicates a quite positive change of the 
participants' mental maps, as such revealing an increase of spatial knowledge. It has been proven that people gain spatial knowledge by spatial navigating experience, learning from the descriptions of the environment and spatial representation (such as maps) (Wender, Wagener-Wender, \& Rothkege, 1997), and in this research participants received both sources of inputs (the field experience and GeoFARA) at the same time. Therefore, it is hard to determine whether the positive change in the participants' mental maps was brought about by GeoFARA only or not. Further understanding is still needed about the influence of the participants' navigation experience within the fieldwork area on this positive spatial knowledge change, particularly the influence in learning about the textile industry remnants of the fieldwork area with the maps and the argumentation of GeoFARA. As indicated in Section 6.3.5.1, after several analysis attempts, no matter how to interpret the mental maps or to combine the mental maps analysis with other data analysis such as eye tracking and thinking aloud, it is very hard to understand the utility of GeoFARA from analyzing the objective-oriented data (mental maps) and behaviororiented data (eye tracking and thinking aloud). In the end, the overall utility of GeoFARA is interpreted by the attitudinal data - interview, presented in Section 6.4.1.2.

\subsubsection{The overall utility of GeoFARA reflected by interviews}

Each participant was interviewed to give general feedback about GeoFARA including how useful GeoFARA is in supporting field learning. Table 6.7 lists the frequency of statements regarding the impact (both positive and negative) of GeoFARA on field learning (i.e., the utility of GeoFARA), particularly learning about the textile remnants of the fieldwork area. As mentioned in Section 6.2, the utility of GeoFARA is concerned with whether its functionality, in principle, can do what is needed during the field trip. In total, two codes (Utility1 and Utility2) are included in the utility category, indicating a positive influence and negative influence respectively. Overall, participants acknowledged the positive impact of GeoFARA (average $=1.2$ statements per participant) much more than the negative aspect (average $=0.1$ ).

Table 6.7 The frequency of codes including utility in the interview analysis

\begin{tabular}{lll}
\hline Code ID & Code Group & Frequency (Average) \\
\hline Utility1 & Positive influence & $17(1.2)$ \\
Utility2 & Negative influence & $2(0.1)$ \\
\hline * Frequency $=$ The number of statements; Average = Frequency/Total participants $(\mathrm{N}=14)$.
\end{tabular}

When participants were asked to give general remarks about the use of GeoFARA in the field, and whether GeoFARA helped or distracted them to learn about the fieldwork area, they made statements about the utility of GeoFARA. All of them emphasized the positive influence of GeoFARA on learning about the spatial structure of the field area, with many 
participants stating that GeoFARA provides "additional and diverse information" through introducing POIs in AR and in the map interface. Only one participant (P1, the background information of whom is shown in Table 6.2) explicitly described a negative influence of GeoFARA and stated that "I do not know how the app helps me to understand this area, because with the map only, I could just understand [the area] fine.". However, no associated background information of this participant (the $1^{\text {st }}$ row of Table 6.2) was found to relate with the negative comments given. In fact, the map only option (switching off the AR view) is possible in GeoFARA. This comment actually provides justification for the design of GeoFARA to have the possible options of map view only, AR view only and AR+Map view. Although the majority of the responses of the participants included the expression "it really helped" or "it's very helpful" to learn about the historical textile factories, two participants stated both a helpful and a distracting role of GeoFARA in the field learning. For instance, one participant stated that "when I have many points [in the AR view], it was distraction, kind of, not so clear", while a second participant mentioned that "in the beginning, there was a bit confusing because I even cannot see those buildings [shown in AR view] in the reality". One possible explanation for this remark is that this participant, for the first time use, did not completely comprehend how AR works. Therefore, on one hand, this feedback should be taken as an individual feedback due to personal background and experience. But, on the other hand, the problem (too much overlay information in the AR view) that was noted by this participant may truly make GeoFARA become distracting, which, in fact, falls into a user interface problem. Section 6.4.2.4 will contain a further discussion regarding all the usability problems. Overall, based on the participants' interviewing feedback with respect to the utility of GeoFARA, almost all participants acknowledged the positive impact; only one participant pointed out a negative impact.

This section reported on the utility of GeoFARA. In conclusion, based on the analysis of the attitudinal feedback from the actual users, GeoFARA (to a certain degree, together with the direct field experience) plays a positive role in supporting the fieldwork goal of learning about the fieldwork area in the case study.

\subsubsection{The usability of GeoFARA}

When evaluating an early prototype of a product, both a usability evaluation and a specification of the usability problems are important. Particularly, for a context-aware mobile application like GeoFARA, it is also necessary to examine how the users interact with both the mobile application and the context itself. This section presents the usability evaluation results based on analyzing the SUS survey data, interaction logs, mobile eye tracking and thinking aloud, as well as interview protocols. 


\subsubsection{The perceived usability of GeoFARA based on the SUS and the interview results}

As introduced in Section 6.3.4, to get a direct measurement result of the perceived usability of GeoFARA, participants were asked to rate its usability by using the SUS survey. Taking an individual perspective of each participant's rating, Table 6.8 shows the SUS score given by each participant and the average SUS score of GeoFARA. To get an overview on to what extent participants agree with each SUS statement by looking at each item in the SUS questionnaire, Figure 6.13 presents how many participants agree/disagree with each dimension of the SUS and the average agreement level.

Table 6.8 The SUS score of GeoFARA rated by each participant

\begin{tabular}{ll}
\hline Participant & SUS score \\
\hline P1 & 60 \\
P2 & 87.5 \\
P3 & 80 \\
P4 & 77.5 \\
P5 & 75 \\
P6 & 82.5 \\
P7 & 75 \\
P8 & 85 \\
P9 & 87.5 \\
P10 & 82.5 \\
P11 & 65 \\
P12 & 92.5 \\
P13 & 72.5 \\
P14 & 95 \\
\hline Average & $\mathbf{7 9 . 8}$ \\
\hline
\end{tabular}

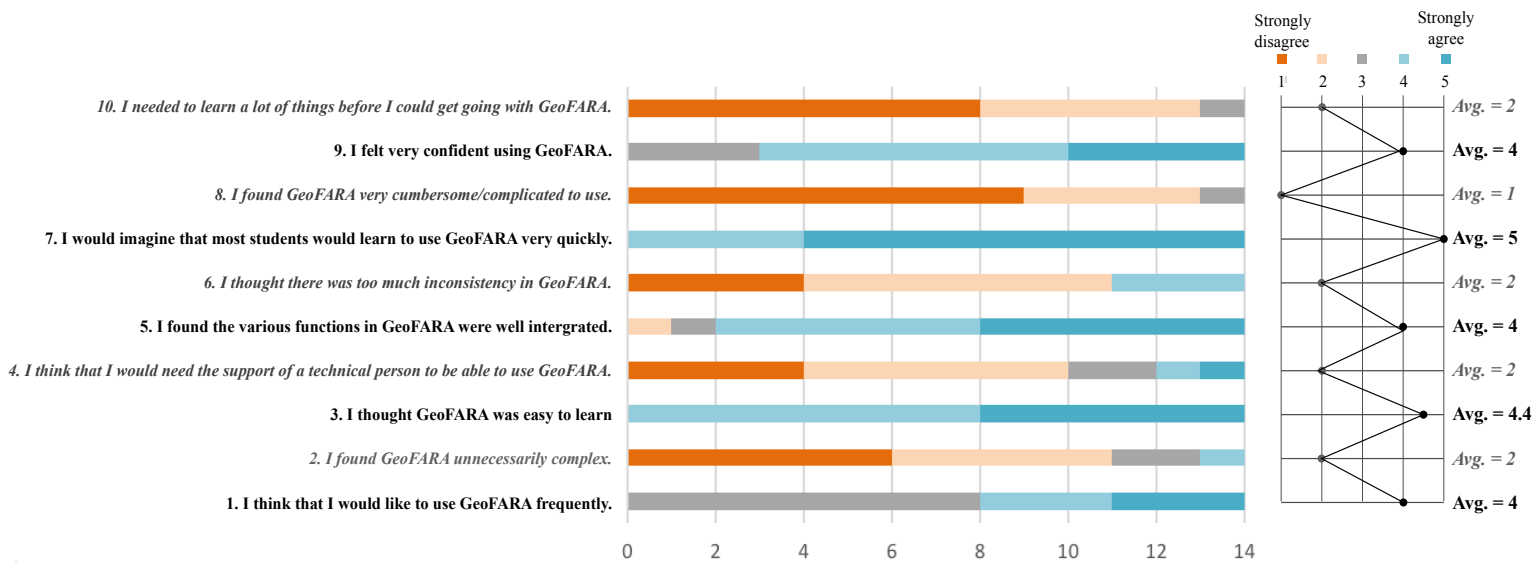

Figure 6.13 Results from the SUS survey of GeoFARA 
Overall, the mean SUS of GeoFARA was 79.8 out of 100, with the highest score being 95 and the lowest 60. According to the official SUS interpretation (URL38), "Based on research, a SUS score above a 68 would be considered above average and anything below 68 is below average.", participants rated the usability of GeoFARA above the average. Only two participants rated scores below the SUS average (P1 rated 60, P11 rated 65). Checking the background information and mental maps of these two participants, it was found that the low SUS rate given by P11 might be associated with her SBSOD score. The SBSOD score of P11, reflecting her spatial ability, is the lowest (3.4 out of 7, Table 6.2) among all the participants. All in all, the average SUS score of GeoFARA is between 70 to 80 , which is considered to be "acceptable", can be described as "good", and falls into the second highest grade "B" (see the classification in Figure 6.11). Therefore, it can be concluded that after the participants used GeoFARA in the evaluation setting (the real fieldtrip), they rated the usability of GeoFARA highly. When SUS is used for academic research and practices, the SUS scores are mostly interpreted by their absolute values (0$100)$ as in Table 6.8. However, this lacks a depth of reflection concerning what each statement in the SUS survey represents. In fact, the ten items for rating in the SUS survey (see Figure 6.16) do reflect various aspects of usability. For example, the positive statements "I thought ... was easy to learn" and the negative statements "I think I would need the support of a technical person to be able to use..." are both about whether GeoFARA is easy to learn. The items "I found ... unnecessarily complex" and "I found ... very cumbersome/complicated to use" reflect whether GeoFARA is easy to use. There are also other items in the SUS reflecting consistency, user confidence, desire to use frequently, etc. In order to have a further and deeper look into the SUS results, Figure 6.16 shows how participants rated each SUS statement individually. The bar chart in the left part of Figure 6.13 shows the numbers of participants across different ratings (from "strongly disagree" 1 to "strongly agree" 5), while the line chart in the right part indicates the average rate of each statement. The results in Figure 6.13 show that, generally, GeoFARA scores high (agreement rating above 4) on positive statements and scores low (agreement rating below 2) on negative statements. This means participants highly agree with a good usability of GeoFARA. The easiness to learn and easiness to use of GeoFARA are rated highest (Avg. $=5$ "strongly agree" for the positive Statement 7 "learn to use ... very quickly" and Avg. $=4.4$ for Statement 3 "easy to learn" / Avg. =1 "strongly disagree" for the negative Statement 8 “... very cumbersome/complicated to use"). In terms of the desire to frequently use GeoFARA, as reflected by Statement 1 "I think that I would like to use GeoFARA frequently", more than half of the participants ( $\mathrm{N}=8$ out of 14) gave a neutral rate (neither agree nor disagree, rating 3 across the Likert scale from 1 to 5). One possible explanation for this neutral rating is that in the case study of this research, GeoFARA is a context-dependent mobile application and the contents of GeoFARA were designed for the fieldwork area Schuttersveld. However, the participants may have not realized that its contents can easily be tailored for any fieldwork area. In 
summary, the positive findings of evaluating the early prototype of GeoFARA with the SUS ratings of the participants help to understand that the design of GeoFARA is perceived by participants as having a great overall usability.

In addition to the usability survey, questions were asked in the post-fieldwork interview to qualitatively investigate the usefulness of and satisfaction with the user interfaces of GeoFARA (e.g., the splitting interface, components in the AR view, etc.). Table 6.9 lists the frequency of statements regarding the usability of GeoFARA.

Table 6.9 The frequency of codes about the usability of GeoFARA in the interview analysis

\begin{tabular}{lll}
\hline Code ID & Code Group & Frequency (Average) \\
\hline Usability1 & Satisfied & $51(3.6)$ \\
Usability2 & Not satisfied & $25(1.8)$ \\
Usability3 & Easy to use & $12(0.9)$ \\
Usability4 & Difficult to use & $2(0.1)$ \\
\hline * Frequency $=$ The number of statements during the interview; \\
\multicolumn{2}{r}{ Average $=$ Frequency/Total participants $(\mathrm{N}=14)}$.
\end{tabular}

In total, four codes (Usability1, .., Usability4) are included in the usability category. Overall, when recalling the actual use of GeoFARA in the field, participants were more satisfied (frequency $=51$, avg. $=3.6$ per participant) than being unsatisfied (frequency $=$ 25 , avg. $=1.8$ ), and GeoFARA was perceived more "easy to use" (frequency $=12$, avg. $=0.9$ ) than "difficult of use" (frequency $=2$, avg. $=0.1$ ). In other words, most participants considered the evaluated prototype of GeoFARA to be an easy-to-use mobile application for performing field learning tasks with a high user satisfaction. One participant stated: "From 1 to 5 scale, I would give 4. In general, more satisfied.", while another participant stated that "I am satisfied with using GeoFARA. If GeoFARA is developed to launch to the app market, I think GeoFARA will be more attractive to me than Google Maps. It offers [more] diverse information than Google Maps.". While several participants complained about aspects such as the slow reaction time, most of the unsatisfactory comments on using GeoFARA came from the usability problems of the user interfaces, such as unclear icons and the clustered POIs in the AR view. The user interface components that participants were not satisfied will be discussed further in the usability problems part in Section 6.4.2.4. The comments on the ease of using of GeoFARA, could be expected because of the simple user interfaces and the limited functionalities. To conclude, both the interview and the SUS survey results demonstrated that the perceived usability of the evaluated prototype GeoFARA is good for the very first prototype, but, still, improvements are needed to solve the usability problems as identified by the participants and observed by the researcher. 


\subsubsection{Interactions with the user interfaces of GeoFARA based on interaction logs}

Next to the usability of GeoFARA as a whole, as reflected by the direct SUS survey and the interview results from the participants' attitudinal perspective, for usability evaluation, it is necessary to add insights about how the participants used the key user interface elements of GeoFARA from the participants' behavioral perspective. In this study, as introduced in Section 6.3.4, all the user actions (ten types in total, Figure 6.12) that were performed by participants on GeoFARA were logged. Table 6.10 shows the general counts and simple statistics of the logged actions all participants during the test session.

Table 6.10 The interaction log analysis results

\begin{tabular}{ll}
\hline User action & Frequency and average \\
\hline Click POIs from AR view & $259(18.5)$ \\
Click POIs from map view & $767(54.8)$ \\
Resize AR and map view & $104(7.4)$ \\
Click radar in AR view & $256(18.3)$ \\
Open POI drawer & $1534(109.6)$ \\
Click pictures in POI drawer & $39(2.8)$ \\
Take note & $43(3.1)$ \\
View the taken notes & $20(1.4)$ \\
Take photo & $47(3.4)$ \\
View the taken photos & $2(0.1)$ \\
\hline$*$ Frequency $=$ The number of the total interactions; \\
Average = Frequency/Total participants $(\mathrm{N}=14)$.
\end{tabular}

Overall, the most frequent user action the participants performed was using the side drawer to read the detailed introduction of the POIs ("open POI drawer", avg. = 109.6), followed by clicking POIs from the map view (avg. =54.8) and the AR view (avg. = 18.5). In the main user interface of GeoFARA, the participants' use of the map view has a significant higher frequency (almost three times more) than the use of the AR view, meaning that participants tended to retrieve the POI information from the mobile digital map instead from the AR view. One possible interpretation is that participants received constantly changing information in the AR view just by changing the mobile phone's camera position whereas more interactions (such as zoom in/out, pan, etc.) were needed to retrieve POI information from the map view. Another possible explanation could be that the map view in GeoFARA provided a better overview of all the POIs so that the participants could click the POIs in the map view anytime. But due to the special characters of AR, how the AR augmented the real environment (i.e., when to show which POIs at where) in the AR view was highly dependent on factors: (1) the user's physical position and the distance with the target POIs, (2) the argumentation range (e.g., within radius $50 \mathrm{~m}$ or $100 \mathrm{~m}$ ) the user's adjusted. This could trigger less interaction of clicking 
POIs in AR view. Interestingly, the user actions "click radar in AR view” and "click POIs in $A R$ view" have very similar frequencies, indicating the possibility that adjusting the augmentation range (via clicking the radar component in the AR view) was always needed when the participants wanted to interact with the POIs in the AR view. In the design of GeoFARA, the splitting view with a resize bar was considered to be a highlight and an innovative user interface compared to existing mobile AR applications. The results of the logged user action "Resize AR and map view" (enlarging map view, and reducing AR view, or vice versa) in Table 6.10 shows that participants were interested in adjusting the splitting view. Regarding the user input actions in GeoFARA, the logged user actions of taking notes and photos have a much lower frequency (avg. = 3.1 only for "take note", avg. = 3.4 only for "take photo") than the retrieval actions (e.g., clicking POIs and reading the POI introductions). This indicates that the participants did not make an extensive use of the user interface of taking notes and photos in GeoFARA when they were asked to use GeoFARA to perform the free exploration usability testing tasks. In summary, the findings of the interaction log analysis show that participants interacted with all the interactive components of GeoFARA and the frequencies of the ten user actions help to understand the use of these user interface elements. Unfortunately, during the evaluation of GeoFARA, most participants did not clearly verbalize (in their thinking aloud) why they interacted with certain user interface elements. Better thinking aloud could have generated more insights into "why to use which user interface element at a certain location". Generally, as stated by Jorritsma (2016), user interaction log data analysis in usability evaluation can be used for guiding other sources of data collection. For example, the $\log$ data analysis in this evaluation has found a more frequent use of the map view to retrieve POI information than using the AR view. This could further guide e.g. the design of post- interview questions for the next iterative evaluation (e.g., a question like "How do you think about retrieving POI information from the AR view and the map view?").

\subsubsection{Simultaneous interactions with context-aware GeoFARA and the use context based on mobile eye tracking}

Eye tracking, be it mobile or desktop-based, is used to record the attention (of the person who wears the eye tracker) on the target objects. In this research, the Tobii mobile eye tracker was used to record the whole interaction process (with GeoFARA and its use context) during every participant's fieldwork activities. As indicated in Section 6.3.5.2, a large volume of eye tracking data was recorded. Therefore, prior to the actual analysis, a rough exploration of analyzing all participants' eye tracking recordings was conducted. However, it has been found that due to the large amount of eye tracking data and the different walking paths of different participants, it appeared not to be realistic to analyze every full eye tracking video of every participant. So the decision was specifically diving into relevant clip(s). To make a decision of which clip(s) can be selected for the further 
analysis, the thereafter explorations were: (1) visualizing the raw eye tracking clips with mapped gaze information (where the participant was looking) in Tobii Pro Lab, and (2) applying Jiang's (2020) automated objects mapping approach (what exactly was been looked at and how long). For example, Figure 6.14 shows that in Tobii Pro Lab, a clip of one participant's eye tracking was processed from the raw eye tracking video to mapping gaze information in the forms of gaze plots and heat maps.

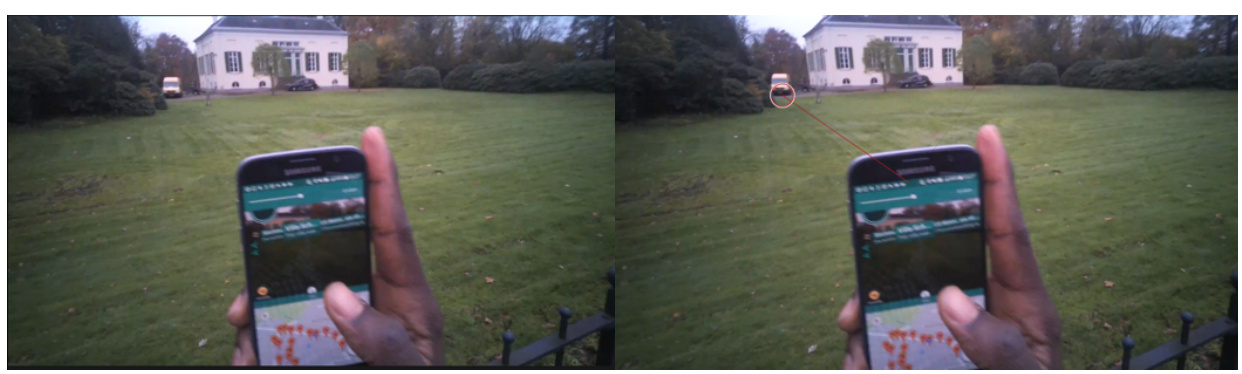

(a)

(b)

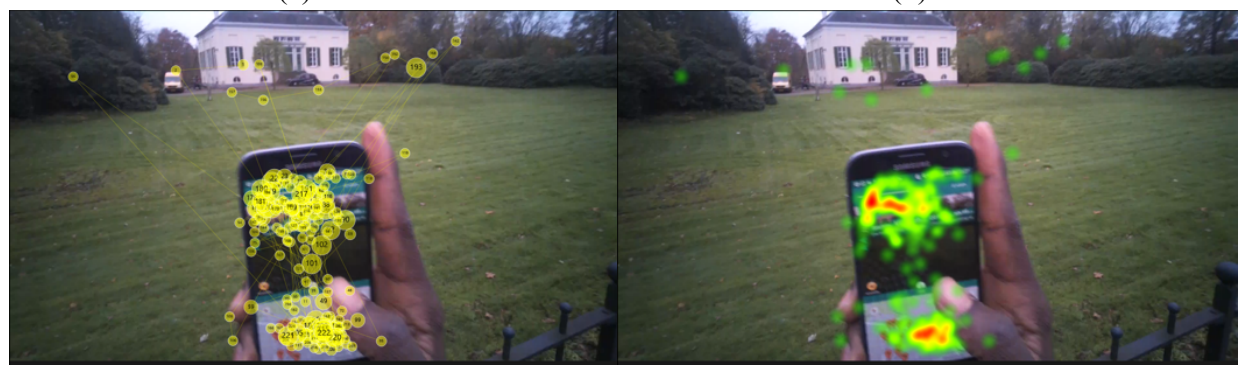

(c)

(d)

Figure 6.14 Processing a clip of one participant's eye tracking while the participant was using GeoFARA around the POI Villa Schuttersveld

(a) The raw eye tracking frame; (b) The gaze mapped eye tracking; (c) The gaze plots representation; (d) The heat maps visualization

After comparing the gaze plots and the heat maps at different POI locations, only the eye tracking clips around the Villa (POI5, see Appendix 6) within the fieldwork area were chosen for further analysis using Jiang's (2020) eye tracking analysis approach. The reasons are: (1) all participants walked passing by this landmark in the unconstrained field evaluation, (2) the heat maps and gaze plots (Figure 6.14 (c) (d)) around this POI show that the eye tracking clips at this point were representative of the interactions with the environment and GeoFARA. At the same time, Jiang's (2020) automated objects recognition model (URL39) was applied to get an overview of the mapped objects in one complete eye tracking session. For example, Figure 6.15 (a) shows the initial results of the eye movement temporal sequence of one participant (P6) between every single detected objects in the fieldwork environment. With this exploration, it has been found that the pre-defined objects recognition model (consisting of more than 100 different 
objects, see URL39) detected too many single objects (for example, 15 in total in Figure 6.15 (a)) in the eye tracking scenery videos. In fact, it is unnecessary to understand how participants interact with every single object for the evaluation of GeoFARA. Therefore, for the further analysis, the target objects were grouped into four different categories: cell phone (GeoFARA), buildings (POIs), surroundings, and others. Figure 6.15 (b) shows the eye movement temporal sequence between the grouped objects.

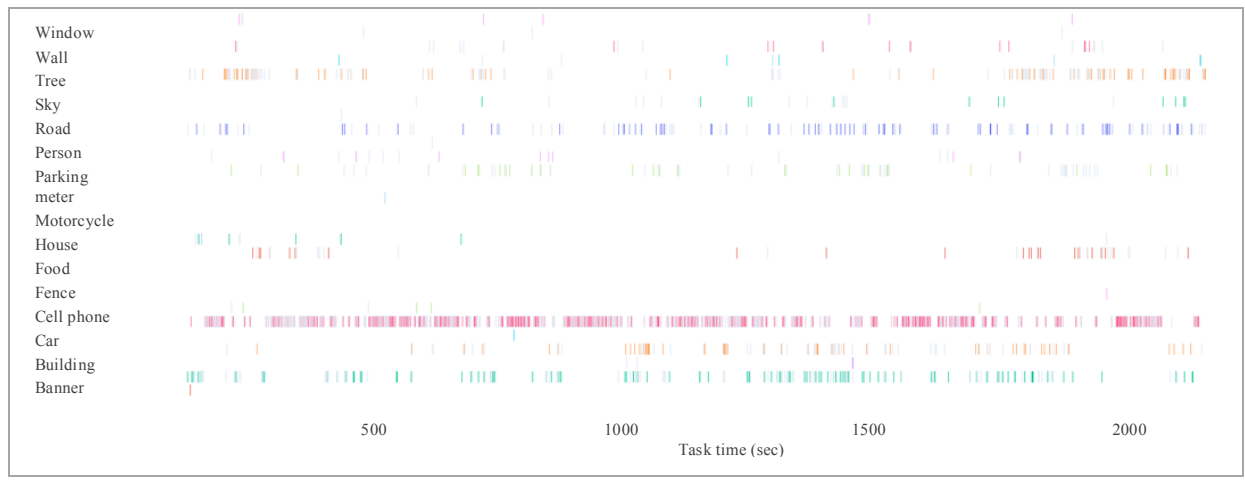

(a)

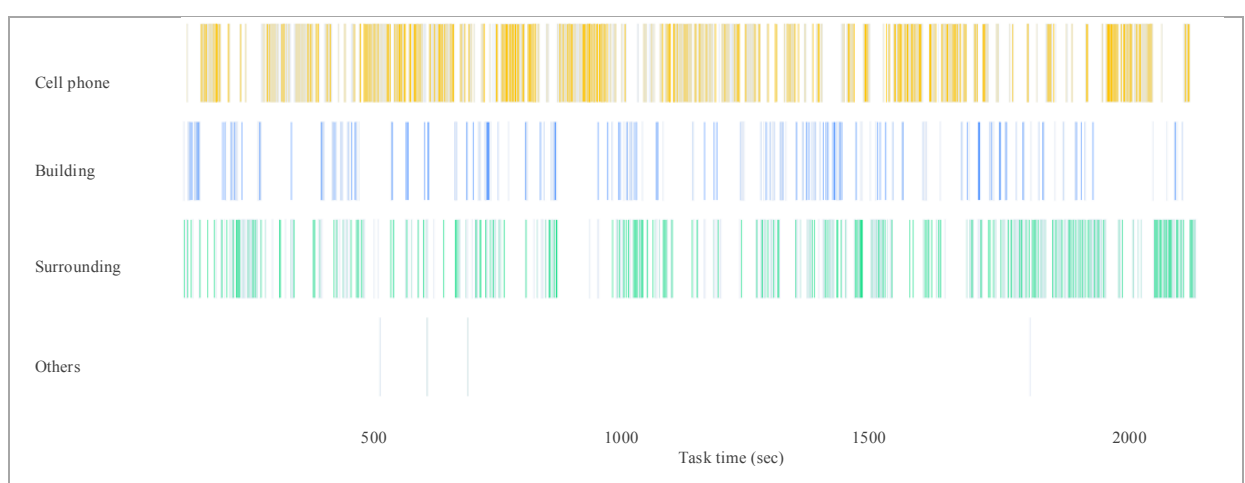

(b)

Figure 6.15 The mobile eye tracking results of one participant (P6) based on applying Jiang's (2020) analysis approach

(a) The eye movement temporal sequence between every single objects; (b) The eye movement temporal sequence between the grouped objects

In this way, Figure 6.16 shows the analysis results of the representative eye tracking around the Villa (POI5) of all participants, demonstrating how they interacted with the mobile application GeoFARA and its use context. With omitting the eye tracking data of two participants due to the low gaze samples (P3: only 9\%, P10: 48\%), the eye tracking data of the remaining 12 participants around one field location (the Villa) was analyzed by using Jiang's (2020) eye tracking analysis approach. Figure 6.16 shows the analysis results: (1) the temporal patterns of the gaze transition sequence between the different 
grouped objects (cell phone(GeoFARA), buildings (POIs), surroundings, others) (the $2^{\text {nd }}$ column, in which the horizontal axis shows time (unit: second) and the vertical axis the classified objects); (2) the duration percentage of the total fixations on each grouped objects (the $3^{\text {rd }}$ column); (3) the mean duration of each fixation (= total duration/total count) on each grouped objects (the $4^{\text {th }}$ column). When comparing the attention shifts between objects that can be reflected by the temporal patterns of the gaze transition, no clear patterns could be discovered, nor at the beginning of the interactions or over the whole time span around the villa POI. However, according to the total and mean fixation duration, it can found that participants fixated on GeoFARA longer than on the rest objects. In other words, GeoFARA attracted longer no-shifting duration than the rest of the surroundings did. Overall, the participants' gazes moved regularly and constantly between the different objects, and most of the participants ( 9 out of 12) were spending more time with looking at GeoFARA ( $>50 \%$ total fixation duration, as can be seen in the pie graphs in the $3^{\text {rd }}$ column of Figure 6.16) than with looking at the target landmark objects $(<50 \%$ total fixation duration) and their surroundings. For most of the participants (such as P4, P5, P6, P8, P9, P11, P12, P14), the interaction with the field objects they needed to learn about was even just contingent with a quick glimpse (see the temporal slots on the object - buildings in $2^{\text {nd }}$ column of Figure 6.16). Summarizing the fixation distribution, it can be generalized that when participants interacted with the context-aware GeoFARA and its use context, the learning tool GeoFARA that was augmenting the reality in the field with overlapping additional information took substantial attention. One explanation for this could be that, in the immersive learning environment, participants extensively relied on GeoFARA instead of on the direct experience of looking at the environment. Another explanation may be that the objects in the real environment can be sensed "live" through the AR view of GeoFARA, which potentially reduced the fixations on the reality. In a broader sense, as drawn from the participants' interactions with GeoFARA and its use context, individual fixation distributions between the mobile devices and the environment were in line with Li and Willis's (2006) conceptual model of context-aware interaction (Figure 3.6), and contributed additional insights to the model. In a word, users tend to interact with the "interface" of the context-aware mobile devices much more than the "location" in the environment. This, in fact, suggests that user interfaces for context-aware mobile application with good usability are of extreme importance for users to complete the intended tasks. 

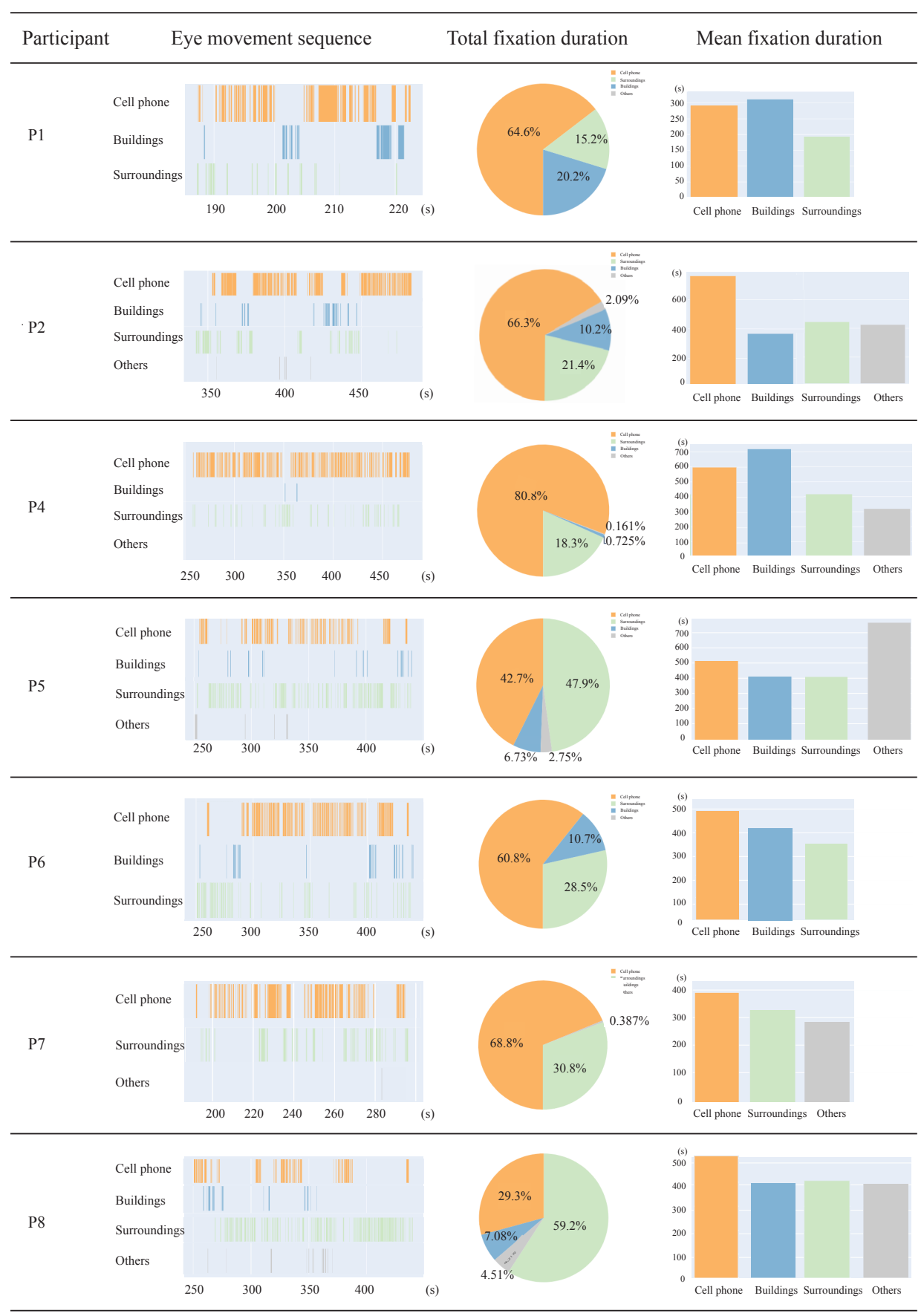

Figure 6.16 The where and when of the participants' gazes on GeoFARA and its use context 
Figure 6.16 (Continued) The where and when of the participants' gazes on GeoFARA and its use context

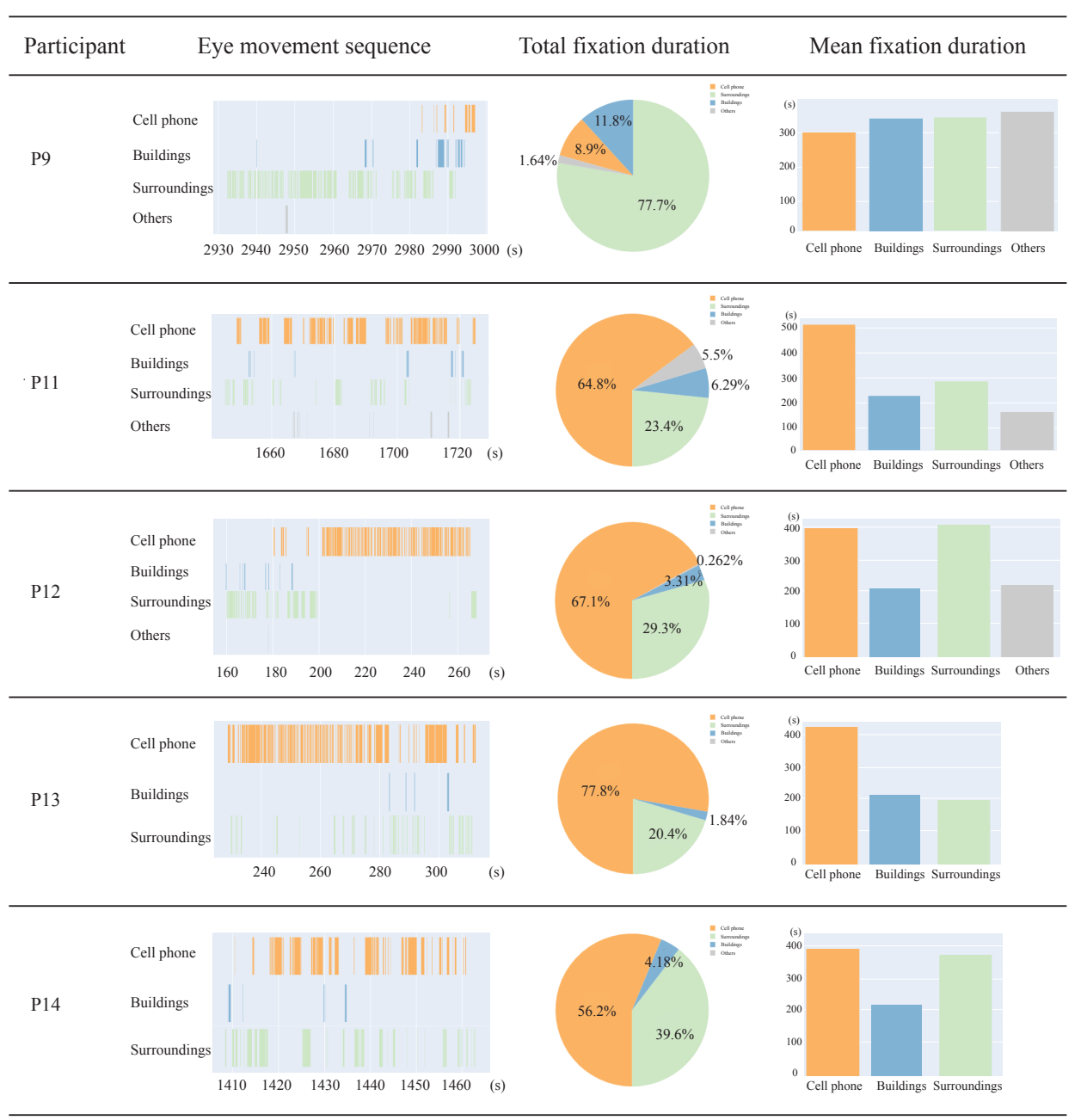

\subsubsection{Usability problems of GeoFARA and design recommendations based on the interview, thinking aloud and user observation}

For initial user-centered designs, it is important to uncover the usability problems and propose related design recommendations. In a user-centered design approach, these results will be used by designers, developers and managers to improve the current design solution. Generally, in order to provide a structured documentation, the usability problems and the corresponding recommendations are grouped, classified, quantified, rated in terms of severity, etc. Severity ratings are even suggested by the ISO (ISO 9241$210,2010)$. In this research, through evaluating the prototype of GeoFARA with users, 
some usability problems were identified from the participants' feedback in the postfieldwork interviews, the real-time thinking aloud during the fieldwork, as well as through participant observation. The identified usability problems may be used for the next iterative design cycle to improve the design of GeoFARA which, thereafter, will be applied in further prototype development. After going through all the identified usability problems for GeoFARA, they were grouped by following Tarkkanen et al.'s (2015) usability problem types classification (11 in total): (1) missing, (2) misinterpreted, (3) positive, (4) inadequate, (5) unexplored, (6) misplaced, (7) unnecessary, (8) technical (9) problematic, (10) preferenced, (11) misaligned. But not every problem in this classification was found in the usability problems of GeoFARA. Table 6.11 demonstrates the usability problems of GeoFARA related to the specific user interfaces. The types of usability problems and the sources from which the problems were being identified are also included, together with the corresponding design recommendations. Figure 6.17 illustrates two of the usability problems of GeoFARA, as captured in the mobile eye tracking videos. First, it should be noticed that participants did not point out any usability problems of the map view of GeoFARA. An explanation for this is that the map view of GeoFARA makes use of the Google Maps interface and not many adjustments have been made to it. Also, no problems have been reported on the side bar showing the detailed introductions of the POIs. The main usability problems appeared with the AR view, the "take note", "view notes", "take photo" and "view photos" interfaces of GeoFARA. One of the problems was the overlapping/clustering of POI icons in the AR view. However, this was expected to happen because the augmentation of GeoFARA had to show a large amount of POIs (17 in total) on half a smartphone screen, which might be an unavoidable issue for the AR technology. Although this problem can be eliminated by adjusting the visible distance (the smaller the range is, the less overlapping/clustering there is). An improvement recommendation would be to put the icons of POIs at different height of the screen within the AR view. Interestingly, most of the usability problems (ID1, ID2, ID3, ID6, ID7 in Table 6.11) were revealed from the thinking aloud, and some of them (ID1, ID6, ID7) were again repeated by the participants in the post-fieldwork interview. Those being mentioned in more than one data collection source should be given much attention in the following design improvements. 
Table 6.11 Usability problems of GeoFARA and design recommendations

\begin{tabular}{|c|c|c|c|c|c|}
\hline ID & $\begin{array}{l}\text { User } \\
\text { interface }\end{array}$ & Usability problems & $\begin{array}{l}\text { Usability } \\
\text { problem } \\
\text { Types }\end{array}$ & $\begin{array}{l}\text { Source } \\
\text { (TL: Thinking aloud; } \\
\text { PI: Post-fieldwork } \\
\text { Interview; } \\
\text { UO: User Observation) }\end{array}$ & $\begin{array}{l}\text { Design } \\
\text { recommendations }\end{array}$ \\
\hline 1 & POIs in AR & $\begin{array}{l}\text { Many POIs cluster and } \\
\text { overlap }\end{array}$ & Problematic & TL, PI, UO & $\begin{array}{l}\text { Present the icon of } \\
\text { each POI at different } \\
\text { height within the AR } \\
\text { view }\end{array}$ \\
\hline 2 & POIs in AR & $\begin{array}{l}\text { A dynamic distance from } \\
\text { the current location to the } \\
\text { target POI is demanded } \\
\text { but not yet available at all }\end{array}$ & Missing & $\mathrm{TL}$ & $\begin{array}{l}\text { Add a distance number } \\
\text { showing how far it is } \\
\text { from the user's } \\
\text { location to the POI }\end{array}$ \\
\hline 3 & AR view & $\begin{array}{l}\text { All the augmentation (the } \\
\text { POIs, the dots in the radar } \\
\text { of the AR view) are gone } \\
\text { after using the note/photo } \\
\text { taking interface. }\end{array}$ & Technical & $\mathrm{TL}$ & Repair this error \\
\hline 4 & Resize bar & $\begin{array}{l}\text { The affordance of the } \\
\text { resize bar is not obvious, } \\
\text { i.e. not easy to notice. }\end{array}$ & Misinterpreted & PI, UO & $\begin{array}{l}\text { Put two arrows (one } \\
\text { up, one down) on the } \\
\text { resize bar to indicate } \\
\text { the AR and map view } \\
\text { being adjustable. }\end{array}$ \\
\hline 5 & $\begin{array}{l}\text { Note/photo } \\
\text { taking icon }\end{array}$ & $\begin{array}{l}\text { The "+" icon for taking } \\
\text { notes/photos is } \\
\text { misinterpreted as the } \\
\text { zooming in function icon } \\
\text { for maps. }\end{array}$ & Misinterpreted & PI & $\begin{array}{l}\text { Change the "+" icon } \\
\text { into textual icon, such } \\
\text { as an icon showing the } \\
\text { text "add". }\end{array}$ \\
\hline 6 & Taking note & $\begin{array}{l}\text { Note name input interface } \\
\text { is misunderstood as the } \\
\text { whole note taking } \\
\text { interface }\end{array}$ & $\begin{array}{l}\text { Misinterpreted } \\
\text { Unnecessary }\end{array}$ & TL, PI, UO & $\begin{array}{l}\text { Use one interface } \\
\text { where users can put } \\
\text { both the note name and } \\
\text { note text together }\end{array}$ \\
\hline 7 & $\begin{array}{l}\text { Taking } \\
\text { note/photo }\end{array}$ & $\begin{array}{l}\text { Not clear whether the note } \\
\text { or photo has been saved } \\
\text { or not }\end{array}$ & Inadequate & TL, PI, UO & $\begin{array}{l}\text { Add a "save" menu } \\
\text { after taking a photo or } \\
\text { note to indicate the } \\
\text { saving status. }\end{array}$ \\
\hline 8 & View photos & $\begin{array}{l}\text { Presentation of all the } \\
\text { taken photos with location } \\
\text { information is necessary }\end{array}$ & Missing & PI & $\begin{array}{l}\text { When viewing photos, } \\
\text { add an option of } \\
\text { viewing where the } \\
\text { photos were taken. }\end{array}$ \\
\hline
\end{tabular}




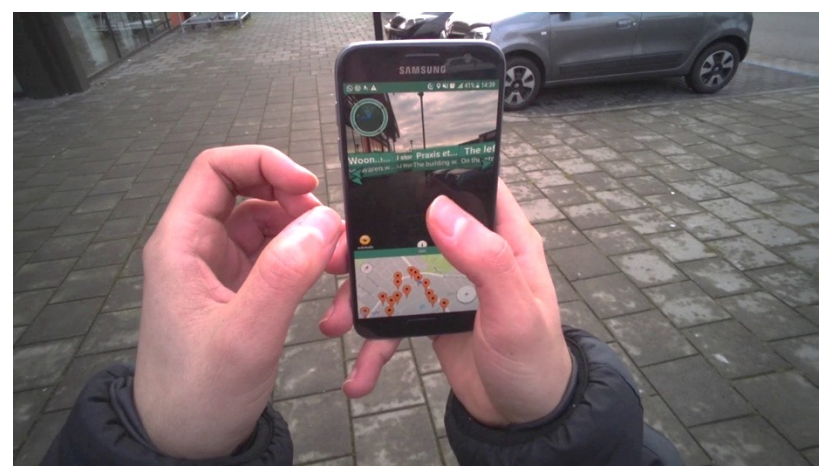

(a)

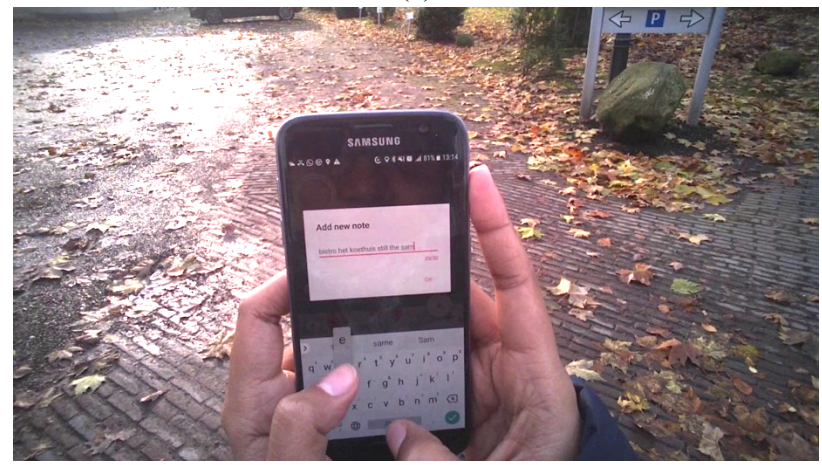

(b)

Figure 6.17 Two of the usability problems of GeoFARA identified from eye tracking

(a) Problematic: The cluster of POIs in the AR view; (b) Misinterpreted: Misunderstanding the note name at the notetaking page

\subsection{Conclusion}

This chapter presented the last user-centered activity within one iterative design cycle evaluating the prototype of GeoFARA in terms of the utility and usability with representative users in its use context. The evaluation of GeoFARA was based on the gathered user requirements towards GeoFARA (as described in Chapter 4) as well as on the conceptual design and the prototype of GeoFARA (Chapter 5). Mixed methods were adopted in the evaluation in order to get an impression of the overall usefulness of GeoFARA, including collecting both behavioral (such as interaction logs, eye tracking) and attitudinal data (such as interviews, systems usability scale surveys) and using both qualitative and quantitative analysis. After presenting the participants' pre- and postfieldwork mental maps, based on the interview feedback given by the participants, the evaluation results suggested that GeoFARA played a positive role (good utility) in supporting learning about the textile history of the fieldwork area. Participants rated 
highly (on average 79.8 out of 100) in the system usability scale (SUS) survey reflecting a good overall usability of GeoFARA. Regarding the use of specific user interfaces of GeoFARA, the interaction log analysis showed that participants more frequently used the map view to retrieve the POI information than using the AR view of GeoFARA. In addition, since GeoFARA is a context-aware mobile application, the mobile eye tracking uncovered patterns of simultaneous interactions with the context-aware mobile application itself and its user context: the participants tended to interact more with the mobile learning tool GeoFARA than with its immersive use environment. Through analyzing the interview and thinking aloud data as well as referring to the user observation, eight usability problems of GeoFARA were summarized and the corresponding design recommendations were also generated.

The following final chapter (Chapter 7) closes with the summary of the entire these contributions and some overall reflections on the $\mathrm{PhD}$ research of user-centered designing the mobile application GeoFARA for geo-fieldwork education. An outlook for future scientific research as well as applied research will also be provided. 
Chapter 7

Conclusion 


\subsection{Introduction}

This dissertation project is a user-centered design (UCD) research. The user-centered designed tool supporting geo-fieldwork education is a mobile application which makes use of a combination of maps and augmented reality (AR). The reasons for producing such a new tool were covered in the research background. The opening chapter introduced the three fundamental perspectives of geography: viewpoint (place, space, scale), representation (cognitive, GIS, models, descriptions, visual display), and synthesis (physical subfields, human subfields, human-physical interaction). While these three dimensions lay the background of this research that is to make use of representations to enhance the (physical, human, human-physical) geographical understanding of a certain place/space in an educational fieldwork setting, technological development is opening new opportunities for geo-representations. Of particular relevance to the representations used in educational geo-fieldwork is augmented reality (AR) that enables a mix of real and virtual environments, delivering immersive experience. Based on such a research context, a mobile application called GeoFARA has been developed as a case study.

Chapter 1 introduced the background, the problem statement and motivation, as well as the research objectives and research questions. Chapter 2 outlined the research context within the fields of visualization and geography fieldwork with a special focus on the role of visual tools in undergraduate geography fieldwork activities. Chapter 3 provided a comprehensive overview of the user-centered design (UCD) methodology used to design, develop and evaluate GeoFARA. Chapter 4 specified the context of use and user requirements of GeoFARA to support geography fieldwork. Chapter 5 presented the design solution of GeoFARA in a conceptual design and a high-fidelity prototype. Chapter 6 reported on the results of evaluating the utility and usability of GeoFARA.

As a concluding part, this chapter first goes back to an overview of the UCD methodology for design research (Section 7.2). After providing this overview, the research objectives and research questions proposed in the opening chapter are responded to, and each research question is revisited (Section 7.3). My personal reflections and a discussion of the limitations are also presented (Section 7.4). An outlook for further basic and applied research is provided in Section 7.5 as a final conclusion.

\subsection{An overview of the UCD methodology for design research}

The research background indicated the trend that when designing a new educational tool while making use of relatively new technology, there should be a shift from technology- 
driven to user-centered approaches. Taking a user-centered perspective, this research explored the theoretical developments of UCD and all the interrelated concepts for design research as well as empirical findings of applying UCD in designing, developing and evaluating the mobile application GeoFARA for geo-fieldwork education.

The review of the UCD approach (Chapter 3) provided an overview of the initial developments and major milestones of UCD and its interrelated concepts-humancomputer interaction (HCI), usability engineering (UE), usability, user experience (UX), etc. In summary, it is roughly half a century after the early principle to "know the user" in interactive system design/development in the early 1970s. With the rise and increasing popularity of HCI, different models and methods (such as the star lifecycle model, agile methods) for HCI design were introduced. The UCD approach became amongst the most primary and the most commonly used design cycles and even core concepts in HCI research. Although the term "usability", as an important character of the HCI of interactive systems, first appeared in a scientific publication around the year 1980, it was then first defined by ISO (ISO/IEC 9126: Information technology - software product evaluation) in 1991. Until 1995, the broadly-used term "UX" (a broader concept than usability) was coined in the empirical practice. After this, the UCD process was first standardized by ISO 13407: Human-centered design processes for interactive systems in 1999. The latest milestone was that usability was re-defined by the ISO 9241-11: Usability - definitions and concepts (2018). Therefore, the development path of the UCD concept and its related fields is from academia to empirical application and then to the international standards. This comprehensive overview provided a clear picture of how the UCD and its related fields initially developed and what the major milestones were during the 50-year development, yielding a clear picture and a quick reference for applying the UCD methodology in HCI design research.

In addition, the principles, processes, outcomes and research techniques for UCD research, and the definitions, dimensions, framework and measurement of usability are provided. Several different sets of principles were reviewed from literature study in Section 3.3.1, including: (1) Shneiderman's (1987) eight golden rules of interface design, which were later adapted by Molich \& Nielsen (1990) and Nielsen (1994) who proposed the widespread "ten usability heuristics", (2) Norman's (1988) "four basic design principles" and "seven design-guidance principles", (3) Gould \& Lewis's (1985) "three principles of design”, and Gould's (1995) “four usability design principles”, (4) ISO 13407's (1999) four principles of UCD and ISO 9241-210's (2010) six principles of UCD. The key stages of UCD are: (1) plan the user-centered design process, (2) understand and specify the context of use, (3) specify user requirements, (4) produce design solutions to meet user requirements, and (5) evaluate the designs against requirements. And the iteration lies in bringing the evaluation results back into the earlier different design stages if the designed 
solutions do not meet user requirements. Once users start to interact with an interactive system, its usability arises. One of the main purposes of applying UCD is to achieve good usability. Therefore, usability can be used to measure the outcomes of the user-centered design of interactive systems. The definitions, dimensions, framework and measurement of usability were provided in Section 3.4. In the latest international standard (ISO 9241$11,2018)$, the framework of usability included both context of use and outcomes of use, the dimensions of usability were still defined in the same way as in ISO 9241-11 (1998): effectiveness, efficiency, and satisfaction. Regarding research methods, a wide range of UCD research methods was presented for different stages of UCD activities, including both qualitative and quantitative research methods and techniques. To guide when to choose which methods, it was identified that all the methods can be mapped across three dimensions according to Rohrer's proposal (URL10). The three dimensions are data source (behavioral - "what people do" vs. attitudinal - "what people say"), approach type (qualitative (direct) vs. quantitative (indirect)), and context of product use (natural use of product, de-contextualized/not using product, scripted use of product, combination/hybrid).

The methods selected for specifying the context of use and analyzing the user requirements for GeoFARA were: (1) existing mobile AR applications analysis, (2) online survey of geography fieldwork organizers on the current use of tools in undergraduate geography fieldwork, (3) field experiment in which the use of paper maps and an existing mobile mapping tool were compared, (4) ethnographic study during a real human geography fieldwork, (5) post-fieldwork surveys among undergraduates from two universities, (6) use case and task analysis, and (7) persona and use scenario. The methods for producing design solutions were: (1) scenario-based design, (2) rapid prototyping, (3) working interface prototyping, and (4) design guidelines and standards. For evaluating GeoFARA, the following methods were selected: (1) online survey to recruit participants, (2) product defined task analysis (using mental maps for data collection), (3) mobile eye tracking and thinking aloud, (4) clickstream/interaction log capture and analysis, (5) video studies, (6) naturalistic user observation, (7) system usability scale (SUS) survey, and (8) post-interviews.

\subsection{Revisit of the research objectives and research questions}

Revisiting the research objectives and research questions (RQ) and summarizing contributions are in line with the main activities of the UCD process: (1) the use context, user needs and user requirements towards a mobile AR tool supporting geography fieldwork, (2) the design solution of the tool based on user requirements, (3) the evaluation of the tool. This section summarizes the results in response to the three 
research objectives and all the research questions related to each research objective. The empirical contributions towards each research objective are summarized, generating key insights into every stage of the UCD activities in designing and evaluating a mobile educational tool.

\subsubsection{The use context, user needs and user requirements}

The first research goal was to specify the context of use $(\mathrm{CoU})$ and the user requirements towards a mobile AR tool supporting spatial cognition in geography fieldwork, broadly, geo-fieldwork education. In particular, this research goal is to address the first research activity when the UCD approach is applied in the design/development of a product, i.e., understand and specify the context of use and the user requirements. The answers to the research questions towards this research objective were covered in Chapter 2 and Chapter 4. While the contributions in terms of the use of mixed methods in specifying use context and user requirements for GeoFARA are theoretical, the contributions made towards this research goal and the specific answers to the research questions are empirical.

RQ1: What are the characteristics and goals of geography fieldwork in higher education?

Geography fieldwork can be categorized from different perspectives: (1) the learner's field activity, (2) duration and locations, (3) the disciplines of geography science. From the learner's field activity perspective, Kent et al. (1997) proposed a two-dimensional framework to categorize fieldwork, generating four main types: dependent observation (Cook's tour), autonomous observation, dependent participation, autonomous participation. In line with the major sub-disciplines of geo-science, there are physicaloriented geography fieldwork and human-oriented geography fieldwork. Similar to any educational activity, the objectives of geography fieldwork are in the aspects of knowledge, skills, and attitudes. However, geography fieldwork objectives change over time. Nowadays, the goals of developing geographic information system (GIS) and mobile learning technology skills should be taken into consideration as well. Despite the dynamic change of objectives, map-related objectives will not change and should be important in teaching/learning geography particularly in the field. Generally, fieldwork consists of three linked stages: the stages of pre-, during-, and post-fieldwork, so is geography fieldwork. A concept model of field education proposed by Israel (2009) was also reviewed. The concept model consists of two parts: spatial dynamics and student experiences. Each of them is shaped by four dimensions with spatial dynamics being described by venue, mode of inhabitation, range of movements, and character of boundaries, while student experiences are being illustrated by duration, structure of activities, mode of interaction, and impact. Two additional dimensions "technology usage" and "theme" were added to categorize the geography fieldwork in this research. 
The answers to this first research question addressed the characteristics and objectives of geography fieldwork, while the geography fieldwork in this research was restricted to the "knowledge" (cognitive) objectives in human geography fieldwork. Overall, the objective of the human geography fieldwork in this research was to examine the influence of past industrial activities on the spatial structure of an urban area. The field setting was an area named Schuttersveld in the city of Enschede (the Netherlands). The spatial structure of this area (even the structure of a large part of the city as a whole) was very much influenced by its industrial history. The former textile industry in this area had largely collapsed, but still with quite some visible remnants, as well as some relatively new developments.

\section{RQ2: What is the role of spatial cognition in geography fieldwork?}

Spatial cognition is a mental process through multiple senses (vision, audition, etc.) to form mental images of the physical, built, and cultural environment in the brain. Human spatial cognition emphasizes human cognition of spatial features at scales ranging from a small cell to the whole surface of the earth. This occurs at many occasions, especially in a real outdoor space such as during geography fieldwork. Therefore, spatial cognition relates to the cognitive purposes of geography fieldwork. In addition, educational research in geography fieldwork setting involving spatial cognition could have some important applications, such as location-based services (LBS), geographic information systems, spatial education and information display. The answers to questions indicated the potential practical applications of studying spatial cognition in geo-fieldwork education in this research work.

\section{RQ3: Which visual tools are currently used in geography fieldwork? And why?}

From both a secondary source analysis and an online survey among human geo-fieldwork organizers (Section 2.4), it was demonstrated that various kinds of visualizations are used in different stages of human geography fieldwork. They include paper and digital maps (atlases), photos, aerial images, videos, virtual reality (VR), and personalized interactive visual tools (e.g., mobile applications, educational systems). Some teachers still employ more traditional visualizations (photos, videos, and maps), instead of modern ones, but they show much interest in using the relatively new visualization potentials in any stage of the human geography fieldwork. According to the online survey, before going to the field, visual tools are used to make students familiar with the fieldwork area and fieldwork tasks. After the fieldwork, they are mainly used to help post-field data processing. However, during the actual fieldwork, they are used for multiple reasons, for example, "to encourage more critical appreciation of place", and "data gathering simplified". According to the online survey, the fieldwork teachers would be interested in using an 
alternative visual tool to improve spatial cognition in human geography fieldwork, which, to a certain degree, justified the value of designing and developing GeoFARA that uses $\mathrm{AR}$ (as a visual expansion) and maps (as a visual display) in this research.

RQ4: What is the current state of using mobile AR in informal education? What are the limitations and the potential needs to produce a new mobile AR application?

The first mobile AR application was introduced by Feiner et al. (1997) who created an AR system on a see-through head-worn display with the main purpose of assisting users to explore a university campus with real-time labelling of building information and overlaying imagery and navigation information. This study opened up the possibilities of using mobile AR to support outdoor educational activities. More recently, there are increasing attention and scientific literature on the use of mobile AR applications to support various field activities. Regarding the platform of using AR in out-of-classroom scenarios, smartphones are increasingly preferable compared to other devices. Five mobile AR applications for outdoor educational use that have a purpose that is comparable to that of GeoFARA were reviewed to understand the limitations of current mobile AR solutions and this lead to the potential design needs for GeoFARA. One of the obvious limitations is that end users were only involved in testing the usability of the completed mobile AR applications instead of already during the design stages. Another major limitation is that map interfaces and AR interfaces are always separated. To overcome these limitations, end users should be involved within the design, development and usability evaluation of GeoFARA, especially through applying the user requirements in the design solutions production stage. The interface design of GeoFARA should try to better integrate map and AR interfaces, giving users both a map view of the fieldwork area and a live view via $\mathrm{AR}$ at the same time.

RQ5: What are the characteristics of the context of using a mobile AR application during geography fieldwork?

According to ISO 9241-210 (2010), the outputs of understanding and specifying the context of use (CoU) include four components: (1) the users, (2) the goals and tasks, (3) the resources, and (4) the environments of the system including technical, physical, social, cultural and organizational environments. The primary and secondary users of GeoFARA are students who attend a fieldwork and teachers who organize a fieldwork. The users (particularly the primary users) vary in experience, skills and knowledge, but are motivated to use tools to complete fieldwork. The main goal of using GeoFARA in the geography fieldwork of this research is to help the users complete the fieldwork teaching and learning objectives. Particularly for the primary users of GeoFARA, the tool supports (1) finding out about the historical industry background of the urban area; (2) obtaining 
up-to-date geographic information about the urban area; (3) identifying the spatial structure of the urban area and relating it with the historical textile industry development. The resources of using GeoFARA are mainly equipment (mobile phone) and time. The environment of GeoFARA involves technical (mobile phone, and its operating system and Internet connection) and physical environment (the fieldwork area, all weather conditions, day time).

RQ6: What are the user requirements of a mobile AR application to achieve the goals in geography fieldwork?

In addition to the requirements generated from reviewing existing mobile AR applications (see the answers to RQ4), six methods were utilized to derive user requirements: (1) an online survey of geography fieldwork organizers on the current use of tools in undergraduate geography fieldwork, (2) a field experiment in which the use of paper maps and an existing mobile mapping tool were compared, (3) an ethnographic study during a real human geography fieldwork in China, (4) post-fieldwork surveys among undergraduates from two universities (one in China, one in Europe), (5) a use case and task analysis, and (6) preparation of a use scenario with a persona. The results were presented in Section 4.3, Section 4.4, Section 4.5, and Section 4.6. Under each method, many different user requirements towards GeoFARA were obtained from both the primary and secondary users (teachers and students), even with overlaps and conflicts. The entire set of 34 user requirements (coded with U1, U2, ..) for GeoFARA was summarized and categorized (Table 4.8) into five classes: functionality, data, usability, environment, and interface requirements. The functionality requirements included, for example, "record various field data (notes, voices, field walking routes, photos) with geolocational details" and "allow offline use". An environment requirement was "Android is the first consideration". After eliminating the overlaps and resolving the conflicts, the final list of user requirements was prioritized by following the order: mandatory requirements, desirable requirements, optional requirements, and possible future enhancements. After this, the 34 initial user requirements were reduced to 25 user requirements for GeoFARA (coded with GU1, GU2, ...) with specific priority levels.

\subsubsection{The design solution}

The second research goal was to apply the specified user requirements in producing a design solution for the mobile AR application supporting geography fieldwork, responding to the stage of producing design solutions in UCD. The design solution of GeoFARA based on applying the user requirements was presented in Chapter 5 . 
RQ7: What design solutions can be produced in user-centered design research? And what design solutions can be produced for the mobile AR application?

Theoretical guidelines for producing design solutions were not commonly addressed in scientific research articles. A general guidance on how to produce design solutions for interactive products was provided from two perspectives: (1) international standard recommendations, (2) a practice model - "The Elements of User Experience" (Garrett, 2011). It was found that ISO 9241-210 (2010) recommends a set of four activities for producing design solutions: (1) designing user tasks, user-system interaction and user interfaces to meet user requirements, taking into consideration the whole user experience, (2) making the design solutions more concrete, (3) altering the design solutions in response to user-centered evaluation and feedback, (4) communicating the design solutions to those responsible for implementation. Garrett (2011) identified five planes in "The Elements of User Experience” model from abstract to concrete levels: strategy (user needs and product objectives), scope (functional specifications and content requirements), structure (interaction design and information architecture), skeleton (information design, interface design, and navigation design), and surface (sensory design). This model served as a useful framework for producing design solutions for GeoFARA.

The strategy of GeoFARA was articulated in terms of its objectives (as well as user needs and user requirements). While the scope of GeoFARA was defined by functional specifications and content requirements, the structure and skeleton of GeoFARA included the interaction design, user interface design and navigation design between the user interface elements. The user interface design consists of several views: main view, navigation drawer, note views, and photo views, as presented in Section 5.4. The "main view" is split by an AR view and a map view. Both the AR view and the map view present important textile history information in the fieldwork area as points of interest (POIs). To allow the user to adjust the split view, a resize bar in the middle of the view enables to resize both the AR and the map view. This innovative user interface of GeoFARA provides a possibility of making good use of AR and maps to connect the reality with the virtual. In addition, there is a collapsed action button floating above the "main view" for possible data (notes, photos) recording actions. The "navigation drawer" sliding in from the screen left is to display detailed information (e.g., textual introductions, different photos, maps and satellite images) about the clicked POI. Once clicking the collapsed action button in the "main view", the "note views" can be triggered to enable the functions of taking and viewing notes. Similar to the "note views", "photo views" can be triggered, including the functions of taking photos and viewing photos. Following the skeleton of GeoFARA, the working prototype of GeoFARA, developed by a computer software developer, was presented as a high-fidelity prototype that was ready for the user-centered evaluation. The entity relationship diagram (Appendix 4) and the client architecture of 
GeoFARA (Appendix 5), produced by the developer, could serve as a potential reference for developing mobile applications for field learning use.

$R Q 8$ : What trade-offs can be made from the user requirements to the user interface design to prototype development for the mobile AR application?

For GeoFARA, trade-offs had to be made during the conceptual design and prototype development, considering factors such as limited resources (time, expenses, etc.), technical constraints, potential failure risk, benefits vs. risks, and short-term vs. long-term goals. Section 5.6 described all the trade-offs made for GeoFARA and the reasons. For example, the unimplemented GeoFARA's user requirements coded with GU11 ("suggest a route from the current location to the next destination") was not a relevant short-term goal, because navigation was not really an objective of the fieldwork in this research. Technical constraints made it unlikely to implement GU7 ("allow group interaction") and GU8 ("provide lines of interest") when GeoFARA is used offline in the field. The requirement to "allow annotations on maps" (GU10) was also not implemented due to the limited development time. After making rational decisions across the design solutions of the product, the short-term goal of producing a product prototype for evaluating with real users had to be achieved, even though not all requirements could be implemented.

\subsubsection{The evaluation}

RQ9: What is the utility of the mobile AR application for supporting geography fieldwork learning??

The utility of GeoFARA was supposed to be reflected by both the comparison of the participants' pre- and post-fieldwork mental maps (whether there were more textile remnants drawn in the post ones) and the participants' attitudinal feedback given during the post-fieldwork interviews. During the data analysis stage, it was found that the comparison of the participants' pre- and post-fieldwork mental maps revealed that they created higher quality post-fieldwork mental maps of the fieldwork area, as the participants included more geo-information (more landmarks, streets, junctions, and city blocks). However, in interpreting the utility of GeoFARA by comparing the pre- and postfieldwork mental maps, two problems were met. One problem was that the participants did not actually focus on mapping/labelling the textile remnants as instructed in the postmental map drawing, instead, they mapped all the landmarks, streets, junctions, and city blocks from their memory. Another problem was the difficulty for the participants of separating the field experience and the learning tool GeoFARA, because participants received both sources of inputs (the field experience and GeoFARA) at the same time. These problems will be further discussed in Section 7.4. On the other hand, each 
participant was interviewed to give general feedback about GeoFARA including how useful GeoFARA was in supporting their learning about the textile history of the fieldwork area. Overall, participants acknowledged the positive impacts of GeoFARA much more than the negative aspects. Therefore, it may still be concluded that GeoFARA (to a certain degree, together with the direct field experience) played a positive role in achieving the fieldwork goals in the case study.

RQ10: What is the usability of the mobile AR application?

The usability evaluation was based on analyzing the SUS survey data, interaction logs, mobile eye tracking and thinking aloud, as well as interview protocols.

Each participant was asked to rate the usability of GeoFARA in the standard SUS survey. Overall, the mean SUS of GeoFARA was 79.8 out of 100. According to the official SUS interpretation, a SUS score between 70 and 80 is considered to be "acceptable" can be described as "good", and falls into the second highest grade "B". The positive findings of evaluating the early prototype of GeoFARA with the SUS ratings of the participants helped to understand that the design of GeoFARA was perceived by participants as having a great overall usability. In addition to the usability survey, questions were asked in the post-fieldwork interviews to qualitatively investigate the usefulness of and satisfaction with the user interfaces of GeoFARA. Most participants considered the evaluated prototype of GeoFARA to be an easy-to-use mobile application for performing field learning tasks with a high user satisfaction. All in all, both the interview and the SUS survey results demonstrated that the perceived usability of GeoFARA is good for the very first prototype, but, still, improvements are needed to solve the usability problems (see the answers to RQ11) as identified by the participants and observed by the researcher.

Interaction logs were also collected to understand how the participants used the key user interface elements of GeoFARA. All the user actions (ten types in total) that were performed by participants on GeoFARA were logged. The ten types of user actions were: (1) click POIs from AR view, (2) click POIs from map view, (3) resize AR and map view, (4) click radar in AR view, (5) open POI drawer, (6) click pictures in POI drawer, (7) take note, (8) view the taken notes, (9) take photo, (10) view the taken photos. Overall, the most frequent user action the participants performed was opening the side navigation drawer to read the detailed introduction of the POIs, followed by clicking POIs from the map view, and clicking POIs from the AR view. This means that participants tended to retrieve the POI information from the mobile digital map instead of from the AR view. Regarding the user input actions in GeoFARA, the logged user actions of taking notes and photos had a much lower frequency than the retrieval actions (e.g., clicking POIs and reading the POI introductions). This indicated that the participants did not make an 
extensive use of the user interface of taking notes and photos in GeoFARA. One possible interpretation is that participants received constantly changing information in the AR view just by changing the mobile phone's camera position whereas more interactions (such as zoom in/out, pan, etc.) were needed to retrieve POI information from the map view. Another possible explanation could be that the map view in GeoFARA provided a better overview of all the POIs so that the participants could click the POIs in the map view anytime. But due to the special characters of AR, how the AR augmented the real environment in the AR view was highly dependent on factors: (1) the user's physical position and the distance with the target POIs, (2) the argumentation range (e.g., within radius $50 \mathrm{~m}$ or $100 \mathrm{~m}$ ) the user's adjusted. This could trigger less interaction of clicking POIs from the AR view.

Mobile eye tracking was used to record the whole interaction process (with GeoFARA and its use context) during every participant's fieldwork activities, and participants were asked to think aloud during the interaction. The eye tracking clips around one POI location within the fieldwork area were chosen for further analysis using an automated eye tracking analysis approach developed by Jiang (2020) to examine how the users interacted with GeoFARA and its context. It was found that participants fixated on GeoFARA longer than on the real objects, i.e., participants extensively relied on GeoFARA instead of on the direct experience of learning in the real environment. Not much thinking aloud data were collected. The limited thinking aloud data analysis was used to identify the usability problems (see the answers to RQ11) of GeoFARA.

RQ11: What are the usability issues of the mobile AR application? What can be done to solve the usability issues and improve the usability?

In total, eight usability issues of GeoFARA were derived from the participants' feedback in the post-fieldwork interviews, the real-time thinking aloud during the fieldwork, as well as through participant observation. The identified usability problems were grouped by following Tarkkanen et al.'s (2015) usability problem types classification: (1) missing, (2) misinterpreted, (3) positive, (4) inadequate, (5) unexplored, (6) misplaced, (7) unnecessary, (8) technical (9) problematic, (10) preferenced, (11) misaligned. The corresponding recommendations for each usability problem are also provided in Section 6.4.2.4. The main usability problems appeared with the AR view and the note/photo taking/view interfaces of GeoFARA. For example, the usability problems related with the AR view of GeoFARA were: (1) the overlapping/clustering of POI icons (problematic), (2) a dynamic distance from the current location to the target POI is demanded but not yet available at all (missing), (3) all the augmentations (the POIs, the dots in the radar of the AR view) are gone after using the note/photo taking interface (technical). 


\subsection{Reflections and discussion}

This dissertation research represents a complete UCD cycle. The work that went well or wrong will have to be reflected on and discussed. This section provides my personal reflections and a discussion of the limitations.

Built upon literature review, the overview of the UCD approach documented the development, the principles, the processes, and the related concepts. The overview connected the inputs of practitioners, scholars, and international standards and may provide a solid reference for future academic research. All in all, since the overview was mainly based on pulling different secondary source data together, this part of the work went smoothly without meeting obstacles and uncertainties. In addition, making use of $\mathrm{AR}$ and maps in combination in geo-fieldwork education, in a broader sense, is a topic of investigating technology-based educational tools. By taking a user-centered perspective instead of a technology-driven perspective in producing the mobile learning tool GeoFARA, this research actively involved different users and stakeholders such as designers, developers, and researchers. Most importantly, the UCD of the GeoFARA research work was progressively finished by following all the stages of this approach, from collecting and specifying user requirements, to producing the design solution based on the collected requirements, and then to evaluating the produced design solution. However, there are some limitations for each research objective and reflections are needed to inspire future better research learning from those limitations to prevent potential failures.

Regarding the first research objective, although the used methods and the specified user requirements were specific to GeoFARA itself and the context, there are several insights into the mixed methods and user requirements that future work can refer to. First, it is important to include both the primary and secondary users in specifying use context and user requirements for a learning/teaching tool. Second, in order to thoroughly collect user requirements in all regards (functionalities, data, usability, environment, user interfaces), it is necessary to make use of multiple methods (both ethnographic and non-ethnographic studies such as use scenarios). Finally, the user requirements collected from various sources should be summarized, categorized, and prioritized to facilitate the following design and implementation, particularly in the first iterative cycle when designing an early prototype. Despite these contributions towards the first research goal, more research work could have been done. Of particular concern is that it would have been useful to derive more user requirements from the secondary users (teachers) of GeoFARA and to execute another ethnographic study in a European human geography fieldwork as an equivalent to the one conducted in China. This means that additional work can be done 
in subsequent research, because such a work may likely shape the mobile application GeoFARA for a broader use.

There is a key reflection in relation with the second research objective. In practice, researchers, designers, and software developers separately share their activities and responsibilities in a team. For an independent academic researcher, it is hard to together own the research, design and development work within the complete series of UCD activities. In this research, the software development work was supported by a developer who was not the researcher. Undoubtedly, within the span of the entire research, it was time-consuming to rely on another independent software developer who helped to develop the high-fidelity working prototype GeoFARA. This, in fact, brought uncertainties to the research, because the researcher was not in complete control of the development process and it always involved back and forth communications between the researcher delivering the user requirements as well as the user interface design and the developer delivering the prototype. In that respect, for a research addressing all the stages of UCD, it would be more feasible and more efficient if the researchers are also capable of developing software by their own to produce working prototype solutions (as an essential part of UCD). On the other hand, much of the development work is not purely scientific.

Regarding the third research objective of evaluating the tool GeoFARA, more reflections and discussion are required to generate deeper insights into the use of mixed methods for the user-centered evaluation of an educational tool. The reflections are provided as below.

First, in general, the usability/UX of the user-centered developed product must be evaluated. This research evaluated the utility (as sort of pedagogical usability) of GeoFARA, and another goal of applying the UCD approach was to achieve good usability. It is important to note that if the user-centered designed tool is meant to be used for an educational purpose, getting a picture of the utility in addition to the usability is deemed necessary given the intention of supporting learning/teaching.

Second, although the user-centered evaluation according to the international UCD standards should be to "evaluate the designs against requirements", the evaluation of GeoFARA did not go back to every user requirement as summarized in Section 4.7. The reason for this was that for an early prototype of GeoFARA, it would be more important to know its overall usability instead of knowing whether GeoFARA meets every implemented user requirement, particularly in an evaluation setting that was just simulating a real geography fieldwork. 
Third, ideally, GeoFARA would have been evaluated in a real university education geofieldwork (similar to the ones described in Section 4.4) consisting of all three stages of a typical fieldwork. In other words, it would have been ideal if GeoFARA would have been evaluated with both primary users (students) and secondary users (fieldwork teachers/organizers) before, during and after an actual fieldwork in which the focus could be on the achievement of the actual learning goals. However, due to time/location restrictions and project resources, the user-centered evaluation of GeoFARA was conducted in a self-organized educational geography fieldwork simulating a real one in which the participants were not optimally engaged. It can be argued that, for a first prototype of GeoFARA in a PhD project research, such an evaluation with mixed methods is sufficient to achieve the evaluation goals. But in a next iterative design cycle in which an improved prototype of GeoFARA will be evaluated, the evaluating setting should be a real geo-fieldwork affiliated to a university geography course. This can be done easily as the contents (such as POIs and their introduction) of GeoFARA can be tailored to any fieldwork in any area.

Fourth, regarding the mixed research methods and the whole study design, there were some limitations. As mentioned above, in interpreting the utility of GeoFARA from the mental maps, one problem was that the participants did not actually map/label textile remnants as instructed in drawing the post- mental maps. Instead, they mapped all the landmarks, streets, junctions, and city blocks they memorized. This was mainly caused by the moderator (the researcher) who did not give sufficient and in time instructions / reminders in addition to the written instructions. Another related problem was that hardly useful think aloud data were generated when participants were drawing the mental maps and during their field sessions. To address those problems, the researcher could have reminded the participants verbally of the required focus on textile remnants and to think aloud actively. To be able to collect better thinking aloud data, a second moderator or additional facilities could have been employed to real-time stimulate the participants to have a constantly active thinking aloud. For example, the participants could be wearing a headset connecting them to a moderator who could send thinking aloud reminders whenever necessary. Another problem was that all the participants received both the inputs of the actual field experience and GeoFARA at the same time, which brought the difficulty of separating the field experience from the experience with the learning tool. Such a difficulty is probably true for spatial learning through any combination of real experience with spatial representations (such as maps) and immersive tools (such as AR). This could have been remedied by having a control group of participants who do not use GeoFARA but who are only exposed to direct field experience, and have another control group of participants who make use of traditional paper maps. Alternatively, due to the mentioned problems in interpreting the mental maps for the utility of GeoFARA, other utility data collection techniques could have been adopted. It may be argued that, in order 
to evaluate a new learning tool like GeoFARA, a user survey including Likert scale questions (similar to SUS) to directly rate the utility of GeoFARA and questions to measure the change of geographical understanding of the fieldwork area would be another supplement to establish more solid and direct results about how well GeoFARA supports the achievement of the intended goals (i.e., the level of utility). In addition, it is also important to note that for evaluating the utility of a new learning tool that makes use of an innovative technology such as AR, the perceived learnability of this technology could influence the results. This makes it necessary to have a control group (mentioned above) of participants using tradition learning tools such as maps.

Fifth, the initial intentions of employing mobile eye tracking to evaluate GeoFARA were to understand how the participants interacted with the interface of GeoFARA, to uncover usability issues, as well as to find out where participants looked at in reality and how they linked the reality with the specific representations on the screen. However, during the data analysis stage, it was found when evaluating the usability of product interfaces used during the mobility of the users, i.e., users constantly move in an immersive environment, the analysis of mobile eye tracking could be quite difficult, even with the eye tracker's proprietary data analysis software (such as Tobii Pro Lab). This is particularly true for a product with small screens such as GeoFARA, and particularly true for the participants' moving path being not pre-defined such as during the evaluation of GeoFARA in this research. In the case study of evaluating GeoFARA, because the evaluation setting was full of "mobiles" (mobile users with different mobility paths, mobile product with a small screen, and mobile usage environment), it was hard to generate clear participants' fixation/scanning path on the interfaces of GeoFARA itself compared to desktop-based products/interfaces. At the end, the actual mobile eye tracking data analysis was used to uncover the usability problems of GeoFARA and to understand how the participants simultaneous interacted with GeoFARA as a whole and its use context. However, the mobile eye tracking data was analyzed to identify how the participants interacted with GeoFARA and its use context (the open-air field environment) by making use of an automated eye tracking analysis developed by another researcher (Jiang, 2020). It turned out that mobile eye tracking, in fact, is a good method to understand the simultaneous interactions with a context-aware product and its use context, although the proprietary data analysis software (Tobii Pro Lab in this research) is not capable of supporting such an analysis. In addition, the mobile eye tracking data could have been used together with better thinking aloud data (as mentioned, this was a limitation of this research) in order to better understand the field learning process, for example, whether the participants first looked for POIs in GeoFARA and then tried to find them in reality or whether they first discovered the remnants in reality and then tried to get more information through GeoFARA, and why the learning process went in a certain way. 
Sixth, although a user-centered designed product must be evaluated with its end users, getting feedback on an early prototype from several experts (in user interaction/interface design) who are not the actual users could also be helpful in the early identification of usability problems, i.e., a heuristic evaluation. In this research, such a usability inspection for GeoFARA was simply executed with two experts during the prototype development and right before the evaluation with users in the pilot tests. However, due to the limited time available to implement all the experts' feedback on improving GeoFARA, only some of the feedback could actually be applied. In the end, the amount and types of usability problems of GeoFARA (as listed in Table 6.11) indicated the necessity of implementing a usability inspection method as well. More importantly, not only heuristic evaluation should be planned and executed, but also time and efforts should be planned in advance to apply all the expert feedback in the prototype prior to the actual evaluation with users.

Finally, although one complete research cycle of the user-centered design of GeoFARA was deeply addressed in this dissertation research, two user-centered iterative cycles are suggested for future research instead of only one iterative cycle in order to add more value to the iterative feature of UCD. In other words, it would bring more benefits to execute a follow-up research activity by applying the design recommendations generated from the first user-centered evaluation to the previous UCD stages (specifying CoU and user requirement, or producing design solutions).

\subsection{Outlook}

This research directly contributes to the awareness of a user-centered perspective in design research with a practical application to the design of a mobile educational tool GeoFARA for geo-fieldwork education. The above section summarizes the results and presents some (critical) reflections. While reflecting on the limitations and the issues of this dissertation research, some recommendations for future research were already proposed. However, to extend in the related fields of such design research, both basic research and applied research require future attention.

First, the UCD topic requires more scientific research attention with practices. The concept of UCD is generated and boosted by practices, particularly by the design of industry-driven/market-driven IT interactive products/systems for which user experience is vital. However, there should be a synergy between the basic scientific UCD research and practical UCD research. Therefore, scholars and practitioners should build a collaborative partnership in connecting the knowledge generated from UX practices and the theory built from academic research on UCD in order to support the development and the dissemination of the UCD mindset. At present, non-academic practices mainly focus on outputting user interface designs to quickly meet the market demands while lacking a 
thorough integration of users from the requirements specification to the evaluation. And although valuable results and insights have been generated from practices, it may not be very easy for academic research to refer to them due to the fact that these practical results are not wide spread in research sources such as scientific publication databases. Probably one of the exceptions bridging practices and research is the UX research and consulting firm Nielsen Norman Group (URL40) that provides research-based UX guidance by studying users around the world as claimed. Taking an academic perspective, for scholars who advocate the "user-centered" approach, it is important to generate insights through user-centered design and evaluation research. These insights should, on the one hand, inform and guide the design and evaluation of user interfaces, and, on the other hand, validate the user-centered design theory by user-centered case studies.

Second, it is necessary to provide an outlook for the use and design of AR in education since this research explored the use of mobile AR (as a visual expansion) in combination with maps in supporting geo-fieldwork education. Regarding the user interface: although the flexible splitting view (by AR and maps) of GeoFARA offers a design solution of innovatively integrating AR and maps in a mobile application, further research should be completed to seek for more possible design solutions (for better combining AR and maps) with good usability through user-centered design research. Further, because of the increasing implementation of "bring your own device" (BYOD) in higher education, follow-up studies should explore the feasibility of using mobile AR on the learners' own smartphones, identifying both challenges and benefits. In a broader sense, there are quite some cutting-edge technologies such as AR enable the connection of the real and the virtual, and it may be appropriate to make use of a mobile AR case study to generate design and use guidelines for interacting with such type of technology.

Finally, UCD research always makes use of mixed methods due to the different stages of UCD activities and different features of the data (attitudinal vs. behavioral, qualitative vs. quantitative). Although it might be not difficult to find practice-based articles discussing the benefits/drawbacks of every single UCD method, future academic studies are still required to get insights into the optimal selection of UCD methods or the combination of mixed methods, so as to better guide "when to use which user/UX/UCD research methods" for researchers. 


\section{Bibliography}

Abowd, G. D., Dey, A. K., Brown, P. J., Davies, N., Smith, M., \& Steggles, P. (1999). Towards a better understanding of context and context-awareness. In H.-W. Gellersen (Ed.), International Symposium on Handheld and Ubiquitous Computing-HUC 1999: Handheld and Ubiquitous Computing (pp. 304-307). Heidelberg: Springer-Verlag.

Antonenko, P. D., Dawson, K., \& Sahay, S. (2017). A framework for aligning needs, abilities and affordances to inform design and practice of educational technologies. British Journal of Educational Technology, 48, 916-927.

Azuma, R. (1997). A survey of augmented reality. Teleoperators and Virtual Environments, 6, 355-385.

Bennett, J. L. (1979). The commercial impact of usability in interactive systems. In B. Shackel (Ed.), Man/Computer Communication (pp. 1-17). Maidenhead: Infotech International.

Berander, P., \& Andrews, A. (2005). Requirements prioritization. In A. Aurum \& C. Wohlin (Eds.), Engineering and Managing Software Requirements (pp. 69-94). Heidelberg: Springer.

Bevan, N. (2001). International standards for HCI and usability. International Journal of Human-Computer Studies, 55, 533-552.

Bevan, N., \& Macleod, M. (1994). Usability measurement in context. Behaviour \& Information Technology, 13, 132-145.

Bland, K., Chambers, B., Donert K., Thomas, T. (1996). Fieldwork. In P. Bailey \& P. Fox (Eds.), Geography Teachers' Handbook (pp. 165-175). Sheffield: Geographical Association.

Boardman, D. J. (1974). Objectives and constraints in geographical fieldwork. Journal of Curriculum Studies, 6, 158-166.

Bower, M., Howe, C., McCredie, N., Robinson, A., \& Grover, D. (2014). Augmented reality in education - Cases, places, and potentials. Educational Media International, 51, 1-15.

Boyle, A., Maguire, S., Martin, A., Milsom, C., Nash, R., Rawlinson, S., ... Conchie, S. (2007). Fieldwork is good: The student perception and the affective domain. Journal of Geography in Higher Education, 31, 299-317.

Braude, E. J., \& Bernstein, M. E. (2011). Software Engineering : Modern Approaches. New Jersey: Wiley \& Sons.

Brooke, J. (1996). SUS-A quick and dirty usability scale. Usability Evaluation in Industry, 189, 4-7.

Bursztyn, N., Pederson, J., Shelton, B., Walker, A., \& Campbell, T. (2015). Utilizing georeferenced mobile game technology for universally accessible virtual geology field trips. International Journal of Education in Mathematics, Science and Technology, $3,93-100$

Butler, R. (2008). Teaching Geoscience through Fieldwork. Plymouth.

Carbonell Carrera, C., \& Bermejo Asensio, L. A. (2017). Augmented reality as a digital teaching environment to develop spatial thinking. Cartography and Geographic Information Science, 44, 259-270.

Card, S. K., Newell, A., \& Moran, T. P. (1983). The Psychology of Human-Computer 
Interaction. New Jersey: Lawrence Erlbaum Associates.

Carlisle, J. H. (1975). Why human-computer interaction doesn't work like human dialogue. ASIS Annual Meeting. Boston, MA.

Carrol, J. M. (1997). Human-computer interaction: Psychology as a science of design. International Journal of Human-Computer Studies, 46, 501-522.

Carter, H. (1995). The Study of Urban Geography. New York: Edward Arnold.

Carvalho, L. R. de, Évora, Y. D. M., \& Zem-Mascarenhas, S. H. (2016). Assessment of the usability of a digital learning technology prototype for monitoring intracranial pressure. Revista Latino-Americana de Enfermagem, 24, e2777.

Chaffer, L. (2015). Integrating spatial technologies into the geography classroom. Geography Bulletin, 47, 7-15.

Chatterjea, K. (2012). Use of mobile devices for spatially-cognizant and collaborative fieldwork in geography. Review of International Geographical Education Online, 2, 303-325

Chien, Y. C., Su, Y. N., Wu, T. T., \& Huang, Y. M. (2019). Enhancing students' botanical learning by using augmented reality. Universal Access in the Information Society, $18,231-241$

Clark, D. (2013). Urban Geography: An Introductory Guide. New York: Routledge.

Coursaris, C. K., \& Kim, D. (2007). A research agenda for mobile usability. In Conference on Human Factors in Computing Systems - Proceedings (pp. 23452350). New York: Association for Computing Machinery.

Dahlbom, B., \& Ljungberg, F. (1998). Mobile informatics. Scandinavian Journal of Information Systems, 1, 227-233.

Dando, C. E., \& Chadwick, J. J. (2014). Enhancing geographic learning and literacy through filmmaking. Journal of Geography, 113, 78-84.

Dando, W. A., \& Wiedel, J. W. (1971). A two-week field course with deferred papers: a possible solution to theproblem of undergraduate field work. Journal of Geography, 70, 289-295.

de Almeida Pereira, G. H., Stock, K., Stamato Delazari, L., \& Centeno, J. A. S. (2017). Augmented reality and maps: New possibilities for engaging with geographic data. Cartographic Journal, 54, 313-321.

Delikostidis, I. (2011). Improving the Usability of Pedestrian Navigation Systems. University of Twente.

Dix, A., Finlay, J., Abown, G. D., \& Beale, R. (2004). Human-Computer Interaction. Harlow: Pearson.

Dumas, J. F., \& Redish, J. C. (1993). A Practical Guide to Usability Testing. Westport: Greenwood.

Dumas, J. S. (2003). User-based evaluations. In J. A. Jacko \& A. Sears (Eds.), The Human-Computer Interaction Handbook: Fundamentals, Evolving Technologies and Emerging Applications (pp. 1093-1117). New Jersey: Lawrence Erlbaum Associates.

Dunleavy, M., \& Dede, C. (2014). Augmented reality teaching and learning. In M. Spector, M. D. Merrill, J. Elen, \& M. J. Bishop (Eds.), Handbook of Research on Educational Communications and Technology (pp. 735-745). New York: SpringerVerlag.

Dykes, J., Moore, K., \& Wood, J. (1999). Virtual environments for student fieldwork using networked components. International Journal of Geographical Information Science, 13, 397-416. 
Easterbrook, S. (1994). Resolving requirements conflicts with computer-supported negotiation. In M. Jirotka \& J. A. Goguen (Eds.), Requirements Engineering: Social and Technical Issues. San Diego: Academic Press Professional.

Ekpenyong, E. E. (2015). The Role of Interactive Mapping in Geography Fieldwork for Improving Geographical Understanding. University of Twente.

Elkins, J. T., \& Elkins, N. M. L. (2006). Improving student learning during travel time on field trips using an innovative, portable audio/video system. Journal of Geoscience Education, 54, 147-152.

Favier, T., \& van der Schee, J. (2009). Learning geography by combining fieldwork with GIS. International Research in Geographical and Environmental Education, 18, 261-274.

Feiner, S., MacIntyre, B., Höllerer, T., \& Webster, A. (1997). A touring machine: Prototyping 3D mobile augmented reality systems for exploring the urban environment. Personal Technologies, 1, 208-217.

Ferre, X., Juriste, N., \& Moreno, A. M. (2005). Framework for integrating usability practices into the software process. In F. Bomarius \& S. Komi-Sirviö (Eds.), Product Focused Software Process Improvement. PROFES 2005 (pp. 202-215). Heidelberg: Springer.

Ferreira, K. R., Vinhas, L., Bogossian, C. H., \& De Carvalho, A. F. A. (2015). A mobile application for geographical data gathering and validation in fieldwork. In A. Abadi, S. R. Humayoun, \& H. Muccini (Eds.), DeMobile 2015 Proceedings of the $3 r d$ International Workshop on Software Development Lifecycle for Mobile (pp. 31-32). Association for Computing Machinery.

Field, J., Grocott, L., Truelove, M., Smith, M., \& Lynch, K. (2005). GIS in the real world: Using mobile technology in fieldwork (MOTIF). In ESRI User Conference. San Diego, CA.

Firesmith, D. (2004). Prioritizing requirements. Journal of Object Technology, 3, 35-47.

Fletcher, S., France, D., Moore, K., \& Robinson, G. (2007). Practitioner perspectives on the use of technology in fieldwork teaching. Journal of Geography in Higher Education, 31, 319-330.

Foulke, E. (1983). Spatial ability and the limitations of perceptual systems. In H. L. Pick \& L. P. and Acredolo (Eds.), Spatial Orientation (pp. 125-141). Bonston: Springer.

FrØkjaer, E., Hertzum, M., \& Hornbæk, K. (2000). Measuring usability: Are effectiveness, efficiency, and satisfaction really correlated? In Conference on Human Factors in Computing Systems - Proceedings (pp. 345-352). New York: Association for Computing Machinery.

Fuller, I. C. (2006). What is the value of fieldwork? Answers from New Zealand using two contrasting undergraduate physical geography field trips. New Zealand Geographer, 62, 215-220.

Garrett, J. J. (2011). The Elements of User Experience: User-Centered Design for the Web and Beyond. San Francisco: New Riders.

Gasson, S. (2003). Human-centered vs. user-centered approaches. Journal of Information Technology Theory and Application, 5, 29-46.

Gazcón, N. F., Trippel Nagel, J. M., Bjerg, E. A., \& Castro, S. M. (2018). Fieldwork in geosciences assisted by ARGeo: A mobile augmented reality system. Computers and Geosciences, 121, 30-38.

Geiger, P., Pryss, R., Schickler, M., \& Reichert, M. (2013). Engineering an Advanced Location-Based Augmented Reality Engine for Smart Mobile Devices. University 
of Ulm.

Gold, J. R. (1991). Fieldwork. In J. R. Gold, A. Jenkins, R. Lee, J. Monk, J. Riley, I. Shepherd, \& I. Unwin (Eds.), Teaching Geography in Higher Education: A Manual of Good Practice (pp. 21-35). Oxford: Basil Blackwell.

Golledge, R. G. (1993). Geographical perspectives on spatial cognition. In T. Gärling \& R. G. Golledge (Eds.), Behavior and Environment: Psychological and Geographical Approaches (pp. 16-46). North-Holland: Elsevier.

Golledge, R. G., \& Stimson, R. J. (1997). Spatial Behaviour: A Geographic perspective. New York: The Guilford Press.

Gould, J. D. (1995). How to design usable systems. In R. M. Baecker \& J. Grudin (Eds.), Human-Computer Interaction: Toward the Year 2000 (pp. 93-121). San Francisco: Morgan Kaufmann.

Gould, J. D., \& Lewis, C. (1985). Designing for usability: Key principles and what designers think. Communications of the ACM, 28, 300-311.

Grudin, J. (1992). Utility and usability: Research issues and development contexts. Interacting with Computers, 4, 209-217.

Haklay, M. (2010). Interacting with Geospatial Technologies. West Sussex: John Wiley \& Sons.

Haklay, M., \& Skarlatidou, A. (2010). Human-computer interaction and geospatial technologies - context. In Interacting with Geospatial Technologies (pp. 1-18). West Sussex: John Wiley \& Sons.

Hall, T., \& Barrett, H. (2012). Urban geography. Oxford: Routledge.

Hansen, W. J. (1971). User engineering principles for interactive systems. In AFIPS Conference Proceedings (pp. 523-532). New York: Association for Computing Machinery.

Hartson, H. R., Andre, T. S., \& Williges, R. C. (2003). Criteria for evaluating usability evaluation methods. International Journal of Human-Computer Interaction, 15, 145-181.

Hartson, H. R., \& Hix, D. (1993). Developing User Interfaces: Ensuring Usability through Product \& Process. New York: John Wiley \& Sons.

Hedberg, J. G. (2014). Extending the pedagogy of mobility. Educational Media International, 51, 237-253.

Her Majesty's Inspectors. (1992). A survey of geography fieldwork in degree courses: Summer 1990-Summer 1991.

Herrick, C. (2010). Lost in the field: Ensuring student learning in the "threatened" geography fieldtrip. Area, 42, 108-116.

Hoehle, H., \& Venkatesh, V. (2015). Mobile application usability: Conceptualization and instrument development. Management Information Systems Quarterly, 39, 435472.

Höllerer, T. H., \& Feiner, S. K. (2004). Mobile augmented reality. In H. A. Karimi (Ed.), Telegeoinformatics: Location-Based Computing and Services (pp. 1-39). Boca Raton: CRC Press.

Hornbæk, K., \& Law, E. L. C. (2007). Meta-analysis of correlations among usability measures. In Conference on Human Factors in Computing Systems - Proceedings (pp. 617-626). New York: Association for Computing Machinery.

Hsu, T. Y., \& Chen, C. M. (2010). A mobile learning module for high school fieldwork. Journal of Geography, 109, 141-149.

Isaias, P., \& Issa, T. (2015). Information system development life cycle models. In High 
Level Models and Methodologies for Information Systems (pp. 21-40). New York: Springer.

ISO/IEC 25010. (2011). Systems and Software Engineering — Systems and software Quality Requirements and Evaluation (SQuaRE) - System and Software Quality Models.

ISO/IEC 9126. (1991). Software Enginnering — Product Quality.

ISO 13407. (1999). Human-Centered Design for Interactive Systems.

ISO 9241-11. (1998). Ergonomic Requirements for Office Work with Visual Display Terminals (VDTs) - Part 11: Guidance on Usability.

ISO 9241-11. (2018). Ergonomic of Human-System Interaction — Part 11: Usability: Definitions and Concepts.

ISO 9241-210. (2010). Ergonomics of Human-System Interaction - Part 210: HumanCentred Design for Interactive Systems.

Israel, A. L. (2009). Geographies of learning: Place, space, and embodied experience in higher education field courses. Pennsylvania State University.

Jackson, B. (1987). Fieldwork. Chicago: University of Illinois Press.

Jarvis, C., Tate, N., Dickie, J., \& Brown, G. (2016). Mobile learning in a human geography field course. Journal of Geography, 115, 61-71.

Jiang, Y. (2020). A solution to analyze mobile eye-tracking data for user research in GI science. University of Twente.

Jong, M. S. Y. (2015). Context-aware geography field trip with EagleEye: Teachers' first experience. In Smart Learning Environments: Lecture Notes in Educational Technology (pp. 77-93). Heidelberg: Springer.

Jorritsma, W., Cnossen, F., Dierckx, R. A., Oudkerk, M., \& Van Ooijen, P. M. A. (2016). Post-deployment usability evaluation of a radiology workstation. International Journal of Medical Informatics, 85, 28-35.

Juan, M. C., Furió, D., Seguí, I., Rando, N., \& Cano, J. (2011). Lessons learnt from an experience with an augmented reality iPhone learning game. In 8th International Conference on Advances in Computer Entertainment Technology (pp. 1-8). New York: Association for Computing Machinery.

Kamarainen, A. M., Metcalf, S., Grotzer, T., Browne, A., Mazzuca, D., Tutwiler, M. S., \& Dede, C. (2013). EcoMOBILE: Integrating augmented reality and probeware with environmental education field trips. Computers \& Education, 68, 545-556.

Kasahara, M., Takano, K., \& Li, K. F. (2014). A personalized learning system with an AR augmented reality browser for Ecosystem Fieldwork. In Proceedings International Conference on Advanced Information Networking and Applications (pp. 89-97). Washington, DC: IEEE Computer Society.

Kent, M., Gilbertson, D. D., \& Hunt, C. O. (1997). Fieldwork in geography teaching: A critical review of the literature and approaches. Journal of Geography in Higher Education, 21, 313-332.

Kerawalla, L., Luckin, R., Seljeflot, S., \& Woolard, A. (2006). "Making it real": Exploring the potential of augmented reality for teaching primary school science. Virtual Reality, 10, 163-174.

Kothari, C. R. (2004). Research Methodology: Methods and Techniques. New Delhi: New Age International.

Kounavis, C. D., Kasimati, A. E., \& Zamani, E. D. (2012). Enhancing the tourism experience through mobile augmented reality: Challenges and prospects. International Journal of Engineering Business Management, 4, 1-6. 
Kourouthanassis, P. E., Boletsis, C., \& Lekakos, G. (2013). Demystifying the design of mobile augmented reality applications. Multimedia Tools and Applications, 74, 122.

Kristoffersen, S., \& Ljungberg, F. (2000). Mobility: From stationary to mobile work. In K. Braa, C. Sorensen, \& B. Dahlbom (Eds.), Planet Internet (pp. 137-156). Lund: Studentlitteratur.

Kuhnel, M., Seiler, L., Honal, A., \& Ifenthaler, D. (2018). Mobile learning analytics in higher education: Usability testing and evaluation of an app prototype. Interactive Technology and Smart Education, 15, 332-347.

Kveladze, I. (2015). Space - Time Cube Design and Usability. University of Twente.

Lai, K. C. (1999). Geographical fieldwork as experiential learning : A multiple case study of secondary school field trips in Hong Kong. Queensland University of Technology.

Laplante, P. A. (2007). What Every Engineer Should Know about Software Engineering. Boca Raton: CRC Press.

Latham, A., \& Mccormack, D. P. (2007). Digital photography and web-based assignments in an urban field course: Snapshots from Berlin. Journal of Geography in Higher Education, 31, 241-256.

Laws, K. (1990). Learning geography through fieldwork. In J. Fien, R. Gerber, \& P. Wilson (Eds.), Geography Teacher's Guide to the Classroom (pp. 134-145). Melbourne: Palgrave Macmillan.

Lewis, J. R. (2006). Usability testing. In G. Salvendy (Ed.), Handbook of Human Factors and Ergonomics (pp. 1275-1316). New Jersey: John Wiley \& Sons.

Li, C., \& Willis, K. (2006). Modeling context aware interaction for wayfinding using mobile devices. In MobileHCI '06: Proceedings of the 8th conference on Humancomputer interaction with mobile devices and services (pp. 97-100). New York: Association for Computing Machinery.

Lin, C. Y., \& Okamoto, M. (2009). The method of user's requirement analysis by participation of the user: Constructing an information system for travelers. In M. Kurosu (Ed.), Human Centered Design -HCD 2009: Lecture Notes in Computer Science (pp. 862-868). Heidelberg: Springer.

Linaza, M. T., Marimón, D., Carrasco, P., Álvarez, R., Montesa, J., Aguilar, S. R., \& Diez, G. (2012). Evaluation of mobile augmented reality applications for tourism destinations. In M. Fuchs, F. Ricci, \& L. Cantoni (Eds.), Information and Communication Technologies in Tourism 2012 - Proceedings of the International Conference (pp. 260-271). Vienna: Springer.

Liu, T.-C., Lin, Y.-C., Tsai, M.-J., \& Paas, F. (2012). Split-attention and redundancy effects on mobile learning in physical environments. Computers \& Education, 58, $172-180$.

Lonergan, N., \& Andresen, L. W. (1988). Field-based education: Some theoretical considerations. Higher Education Research \& Development, 7, 63-77.

Maceachren, A. M., \& Taylor, D. R. F. (1994). Visualization in Modern Cartography. Oxford: Elsevier.

MacEachren, A. M., \& Taylor, D. R. F. (2013). Visualization in Modern Cartography. Oxford: Elsevier.

Madsen, L. M., \& Rump, C. (2012). Considerations of How to Study Learning Processes when Students use GIS as an Instrument for Developing Spatial Thinking Skills. Journal of Geography in Higher Education, 36, 97-116. 
Maguire, M. (2001). Context of use within usability activities. International Journal of Human-Computer Studies, 55, 453-483.

Manakhov, P., \& Ivanov, V. D. (2016). Defining usability problems. In Proceedings of the 2016 CHI Conference Extended Abstracts on Human Factors in Computing Systems (pp. 3144-3151). New York: Association for Computing Machinery.

Marvell, A., Simm, D., Schaaf, R., \& Harper, R. (2013). Students as scholars: Evaluating student-led learning and teaching during fieldwork. Journal of Geography in Higher Education, 37, 547-566.

Maskall, J., \& Stokes, A. (2008). Designing Effective Fieldwork for the Environmental and Natural Sciences. Plymouth.

Mayhew, D. J. (1999). The usability engineering lifecycle. In Conference on Human Factors in Computing Systems - Proceedings (pp. 147-148). New York: Association for Computing Machinery.

McNamara, N., \& Kirakowski, J. (2006). Functionality, usability, and user experience: three areas of concern. Interactions, 13, 26-28.

Meek, S., Priestnall, G., Sharples, M., \& Goulding, J. (2013). Mobile capture of remote points of interest using line of sight modelling. Computers \& Geosciences, 52, 334 344.

Melis, E., \& Weber, M. (2003). Lessons for (pedagogic) usability of eLearning Systems. In Proceedings of World Conference on E-Learning in Corporate, Government, Healthcare, and Higher Education (pp. 281-284). San Diego, CA: Association for the Advancement of Computing in Education.

Milgram, P., \& Kishino, F. (1994). A taxonomy of mixed reality visual displays. IEICE Transactions on Information and Systems, E77-D, 1321-1329.

Molich, R., \& Nielsen, J. (1990). Improving a human-computer dialogue. Communications of the ACM, 33, 338-348.

Montello, D. R. (2001). Spatial cognition. In P. Baltes \& N. Smelser (Eds.), International Encyclopedia of the Social \& Behavioral Sciences (pp. 14771-14775). Oxford: Elsevier.

Montello, D. R., \& Raubal, M. (2013). Functions and applications of spatial cognition. In D. Waller \& L. Nadel (Eds.), Handbook of Spatial Cognition (pp. 249-264). Washington, DC: American Psychological Association.

Moumane, K., Idri, A., \& Abran, A. (2016). Usability evaluation of mobile applications using ISO 9241 and ISO 25062 standards. SpringerPlus, 5, 548.

Munowenyu, E. (2006). Fieldwork in geography: A review and critique of the relevant literature on the use of objectives. The Journal of Doctoral Research in Education, $2,16-31$.

Nielsen, J. (1993). Usability Engineering. San Francisco: Elsevier.

Nielsen, J. (1994). Heuristic evaluation. In J. Nielsen \& R. L. Mack (Eds.), Usability Inspection Methods (pp. 25-62). New York: John Wiley \& Sons.

Nöllenburg, M. (2007). Geographic visualization. In A. Kerren, A. Ebert, \& J. Meyer (Eds.), Human-Centered Visualization Environments. Lecture Notes in Computer Science (pp. 257-294). Heidelberg: Springer.

Norman, D. (1988). The Design of Everyday Things. New York: Basic Books.

Norman, D. A., \& Draper, S. W. (1986). User Centered System Design: New Perspectives on Human-Computer Interaction. New Jersey: Lawrence Erlbaum Associates.

Noyes, J., \& Baber, C. (1999). User-Centred Design of Systems. London: Springer-Verlag. O’Brien, J., \& Field, K. (2013). Developing a geo-collaborative web map to support 
student fieldwork. In A. Moore \& D. Igor (Eds.), Geospatial Visualisation (pp. 139-158). Heidelberg: Springer.

Orion, N., \& Hofstein, A. (1994). Factors that influence learning during a scientific field trip in a natural environment. Journal of Research in Science Teaching, 31, 10971119.

Pacione, M. (2009). Urban Geography: A Global Perspective. New York: Routledge.

Panelli, R., \& Welch, R. V. (2005). Teaching research through field studies: A cumulative opportunity for teaching methodology to human geography undergraduates. Journal of Geography in Higher Education, 29, 255-277.

Pendit, U. C., Zaibon, S. B., \& Bakar, J. A. A. (2014). Mobile AR for cultural heritage site towards enjoyable informal learning: A revised conceptual model. Information Management and Business Review, 6, 239-248.

Poitras, E. G., Harley, J. M., \& Liu, Y. S. (2019). Achievement emotions with locationbased mobile augmented reality: An examination of discourse processes in simulated guided walking tours. British Journal of Educational Technology, 50, 3345-3360.

Pombo, L., \& Marques, M. M. (2019). Learning with the augmented reality EduPARK game-like app: Its usability and educational value for primary education. In K. Arai, R. Bhatia, \& S. Kapoor (Eds.), Intelligent Computing: Proceedings of the 2019 Computing Conference (pp. 113-125). Cham: Springer.

Preece, J., Rogers, Y., \& Sharp, H. (2002). Interaction Design: Beyond Human-Computer Interaction. New York: John Wiley \& Sons.

Preece, J., Rogers, Y., Sharp, H., Benyon, D., Holland, S., \& Carey, T. (1994). HumanComputer Interaction. Reading, MA: Addison-Wesley.

Pribeanu, C., Balog, A., \& Iordache, D. D. (2008). Measuring the usability of augmented reality e-Learning systems: A user - centered evaluation. In J. Cordeiro, B. Shishkov, A. Ranchordas, \& M. Helfert (Eds.), Software and Data Technolgoies: Proceedings of Third International Conference on Software and Data Technologies (pp. 175-186). Heidelberg: Springer.

Raschke, M., Blascheck, T., \& Burch, M. (2014). Visual analysis of eye tracking data. In Handbook of Human Centric Visualization (pp. 391-204). New York: Springer.

Redish, J., \& Wixon, D. (2003). Task analysis. In The Human-Computer Interaction Handbook: Fundamentals, Evolving Technologies, and Emerging Applications (pp. 922-940). New Jersey: Lawrence Erlbaum Associates.

Reilly, J. M., \& Dede, C. (2019). Augmented reality in education. In A. Zhang \& D. Cristol (Eds.), Handbook of Mobile Teaching and Learning (pp. 1337-1351). Singapore: Springer.

Remmen, K. B., \& Frøyland, M. (2014). Implementation of guidelines for effective fieldwork designs: Exploring learning activities, learning processes, and student engagement in the classroom and the field. International Research in Geographical and Environmental Education, 23, 103-125.

Rice, G., \& Bulman, T. L. (2001). Fieldwork in the geography curriculum: Filling the rhetoric - reality gap. Pennsylvania: National Council for Geographic Education.

Ritter, F. E., Baxter, G. D., \& Churchill, E. F. (2014). Foundations for Designing UserCentered Systems. Foundations for Designing User-Centered Systems. London: Springer-Verlag.

Robertson, S., \& Robertson, J. (2013). Mastering the Requirements Process: Getting Requirements Right. New Jersey: Addison-Wesley. 
Rosson, M. B., \& Carroll, J. M. (2002). Scenario-based design. In The Human-Computer Interaction Handbook: Fundamentals, Evolving Technologies and Emerging Applications (pp. 1032-1050). New Jersey: Lawrence Erlbaum Associates.

Royal Geographical Society. (2009). Fieldwork strategies. London.

Rubin, J., \& Chisnell, D. (2008). Handbook of Usability Testing: How to Plan, Design, and Conduct Effective Tests. Indianapolis: John Wiley \& Sons.

Sánchez Riera, A., Redondo, E., \& Fonseca, D. (2014). Geo-located teaching using handheld augmented reality: Good practices to improve the motivation and qualifications of architecture students. Universal Access in the Information Society, $14,363-374$

Sauro, J., \& Lewis, J. R. (2016). Quantifying the User Experience. Boston: Morgan Kaufmann.

Scanlon, E., \& Issroff, K. (2005). Activity theory and higher education: Evaluating learning technologies. Journal of Computer Assisted Learning, 21, 430-439.

Shackel, B. (1991). Usability - context, framework, definition, design and evaluation. In B. Shackel \& S. Richardson (Eds.), Human Factors for Informatics Usability (pp. 21-28). Cambridge: Cambridge University Press.

Shackel, B. (2009). Usability - context, framework, definition, design and evaluation. Interacting with Computers, 21, 339-346.

Shneiderman, B. (1980). Software Psychology: Human Factors in Computer and Information Systems. Cambridge, Massachusett: Winthrop.

Shneiderman, B. (1987). Designing the user interface strategies for effective humancomputer interaction. ACM SIGBIO Newsletter, 9, 6.

Silius, K., \& Tervakari, A. (2003). An evaluation of the usefulness of web-based learning environments: The evaluation tool into the portal of Finnish virtual university. In International Conference on Network Universities and E-Learning (pp. 1-10). Valencia: Editorial de la Universidad Politécnica de Valencia.

Silius, K., Tervakari, A. M., \& Pohjolainen, S. (2003). A multidisciplinary tool for the evaluation of usability, pedagogical usability, accessibility and informational quality of web-based courses. In Proceedings of PEG2003-The 11th International PEGConference: Powerful ICT for Teaching and Learning (pp. 1-10). University of Exeter.

Skavhaug, T. W., \& Andersen, H. P. (2013). Urban fieldwork in geographical education in Levanger, Norway. Norwegian Journal of Geography, 67, 179-183.

Slocum, T. A., Blok, C., Jiang, B., Koussoulakou, A., Montello, D. R., Fuhrmann, S., \& Hedley, N. R. (2001). Cognitive and Usability Issues in Geovisualization. Cartography and Geographic Information Science, 28, 61-75.

Smith, B. K., Blankinship, E., Ashford, A., Baker, M., \& Hirzel, T. (2000). Image maps: Exploring urban history through digital photography. In T. Ishida \& K. Isbister (Eds.), Digital Cities: Technologies, Experiences, and Future Perspectives (Lecture Notes in Computer Science) (pp. 326-337). Heidelberg: Springer-Verlag.

Soares, M. D. S., Vrancken, J., \& Verbraeck, A. (2011). User requirements modeling and analysis of software-intensive systems. Journal of Systems and Software, 84, 328 339.

Squire, K., \& Jan, M. (2007). Journal of Science Education and Technology. Mad City Mystery: Developing Scientific Argumentation Skills with a Place-Based Augmented Reality Game on Handheld Computers., 16, 5-29.

Stainfield, J., Fisher, P., Ford, B., \& Solem, M. (2000). International virtual field trips: A 
new direction? Journal of Geography in Higher Education, 24, 255-262.

Stott, T., Litherland, K., Carmichael, P., \& Nuttall, A. (2014). Using interactive virtual field guides and linked data in geoscience teaching and learning. In V. Tong (Ed.), Geoscience Research and Education (pp. 163-188). Dordrecht: Springer.

Strahler, A. (2013). Introducing Physical Geography. New York: Wiley Textbooks.

Sutherland, I. (1968). A head-mounted three dimensional display. In Proceedings of the December 9-11, 1968, fall joint computer conference (pp. 757-764). New York: Association for Computing Machinery.

Tarkkanen, K., Harkke, V., \& Reijonen, P. (2015). Are we testing utility? Analysis of usability problem types. In Lecture Notes in Computer Science (including subseries Lecture Notes in Artificial Intelligence and Lecture Notes in Bioinformatics) (Vol. 9186, pp. 269-280).

Tarng, W., \& Ou, K. L. (2012). A study of campus butterfly ecology learning system based on augmented reality and mobile learning. In Proceedings of 17th IEEE International Conference on Wireless, Mobile and Ubiquitous Technology in Education (pp. 62-66). Washington, DC: IEEE Computer Society.

Ternier, S., de Vries, F., Börner, D., \& Specht, M. (2014). Mobile augmented reality with audio supporting fieldwork of cultural sciences students in florence. In A. Cerone \& D. Persico (Eds.), Information Technology and Open Source: Applications for Education, Innovation, and Sustainability (pp. 53-63). Heidelberg: Springer.

Thimbleby, H. (2008). Understanding User Centred Design (UCD) for people with special needs. In K. Miesenberger, J. Klaus, W. Zagler, \& A. Karshmer (Eds.), International Conference on Computers for Handicapped Persons - ICCHP 2008: Computers Helping People with Special Needs (pp. 1-17). Heidelberg: Springer.

Tsai, C. H., \& Huang, J. Y. (2014). A mobile augmented reality based scaffolding platform for outdoor fieldtrip learning. In Proceedings - 2014 IIAI 3rd International Conference on Advanced Applied Informatics, IIAI-AAI 2014 (pp. 307-312). Washington, DC: IEEE Computer Society.

Tumbas, P., \& Matković, P. (2006). Agile vs traditional methodologies in developing information systems. Management Information Systems, 1, 15-24.

Van Elzakker, C. P. J. M., \& Wealands, K. (2007). Use and users of multimedia cartography. In W. Cartwright, M. P. Peterson, \& G. Gartner (Eds.), Multimedia Cartography (pp. 487-504). Heidelberg: Springer.

Van Lamsweerde, A., Darimont, R., \& Letier, E. (1998). Managing conflicts in goaldriven requirements engineering. IEEE Transactions on Software Engineering, 24, 908-926.

Vredenburg, K., Mao, J. Y., Smith, P. W., \& Carey, T. (2002). A survey of user-centered design practice. In Conference on Human Factors in Computing Systems Proceedings (pp. 471-478). New York: Association for Computing Machinery.

Walcott, S. M. (1999). Fieldwork in an urban detting: Structuring a human heography learning exercise. Journal of Geography, 98, 221-228.

Wall, G. P., \& Speake, J. (2012). European geography higher education fieldwork and the skills agenda. Journal of Geography in Higher Education, 36, 421-435.

Wang, J., \& Schwering, A. (2015). Invariant spatial information in sketch maps - a study of survey sketch maps of urban areas. Journal of Spatial Information Science, 11, $31-52$.

Welsh, K. E., France, D., Whalley, W. B., \& Park, J. R. (2012). Geotagging photographs in student fieldwork. Journal of Geography in Higher Education, 36, 469-480. 
Welsh, K. E., Mauchline, A. L., Park, J. R., Whalley, W. B., \& France, D. (2013). Enhancing fieldwork learning with technology: Practitioner's perspectives. Journal of Geography in Higher Education, 37, 399-415.

Wender, K. F., Wagener-Wender, M., \& Rothkege, R. (1997). Measures of spatial memory and routes of learning. Psychological Research, 59, 269-278.

Wilson, H., Leydon, J., \& Wincentak, J. (2017). Fieldwork in geography education: Defining or declining? The state of fieldwork in Canadian undergraduate geography programs. Journal of Geography in Higher Education, 41, 94-105.

Wu, H. K., Lee, S. W. Y., Chang, H. Y., \& Liang, J. C. (2013). Current status, opportunities and challenges of augmented reality in education. Computers and Education, 62, 41-49.

Yovcheva, Z. (2015). User-Centred Design of Smartphone Augmented Reality in Urban Tourism Context. Bournemouth University.

Yuan, P. (2019). Design Guidelines for Mobile Augmented Reality Reconstruction. Technical University of Munich.

Yuen, S. C.-Y., Yaoyuneyong, G., \& Johnson, E. (2011). Augmented reality: An overview and five directions for AR in education. Journal of Educational Technology Development and Exchange, 4, 119-140.

Zaibon, S. B., Pendit, U. C., Aida, J., \& Bakar, A. (2015). Applicability of mobile augmented reality usage at Melaka cultural heritage sites. In Z. Jamaludin, N. ChePa, W. H. W. Ishak, \& S. B. Zaibon (Eds.), Proceedings of the 5th International Conference on Computing and Informatics, ICOCI 2015 (pp. 235-240). Sintok: Universiti Utara Malaysia. 


\section{URL}

URL1: NMC Horizon Project is regarded as the longest-running exploration of emerging technology trends. http://cdn.nmc.org/media/2017-nmc-horizon-report-he-EN.pdf. Accessed 27-02-2017.

URL2: Relating the map to the surroundings. http://www.freeimages.com/photo/lost-21306327. Accessed 27-02-2017.

URL3: GeoJourney, a field educational program about environmental and cultural studies. http://www.geojourney.org/alumni/destinations. Accessed 27-02-2017.

URL4: iGeology, a mobile application, providing geological information on British geological maps based on users' locations. http://www.bgs.ac.uk/iGeology. Accessed 2702-2017.

URL5: mySoil, a mobile application, offering European soil information through a comprehensive European soil properties map. http://www.bgs.ac.uk/mysoil. Accessed 2702-2017.

URL6: Fieldtrip GB, a mobile application for data collection, allowing users to collect field data on digital maps in rural and urban areas within UK. http://fieldtripgb.blogs.edina.ac.uk. Accessed 27-02-2017.

URL7: The online survey on the use of ICTs and visualization tools in real undergraduate human geography fieldwork programs. https://www.surveymonkey.com $/ s / 5 M W 37 Q 9$. Accessed 28-02-2017.

URL8: Tufte - "Users". https://www.edwardtufte.com/tufte/advocate_1099. Accessed 1503-2017.

URL9: The term "user" on Wikipedia. https://en.wikipedia.org/wiki/User. Accessed 1503-2017.

URL10: An article "When to use which UX research methods" written by Christian Rohrer from Nielsen Norman Group. https://www.nngroup.com/articles/which-uxresearch-methods/. Accessed 29-04-2017.

URL11: RijksMuseumTwente. https://www.rijksmuseumtwenthe.nl/. Accessed 30-042017.

URL12: Recruiting test persons for evaluating GeoFARA (a mobile application). https://www.surveymonkey.com/r/GeoFARA. Accessed 30-04-2017.

URL13: A location-based storytelling and gaming application. www.playfreshair.com. Accessed 29-07-2017.

URL14: Locas map application. http://www.locusmap.eu. Accessed 30-08-2017.

URL15: The virtual fieldwork offered by Beijing Normal University. http://210.31.68.1:8080/field-trips/human/human_comprehensive/. Accessed 8-12-2015.

URL16: Baidu Maps. http://map.baidu.com/. Accessed 18-10-2017. 
URL17: Gaode Maps. http://ditu.amap.com/. Accessed 18-10-2017.

URL18: Post-fieldwork survey for Ghent University undergraduates.

https://www.surveymonkey.com/r/BHDTYF6. Accessed 25-10-2017.

URL19: The "user requirements document" on Wikipedia.

https://en.wikipedia.org/wiki/User_requirements_document. Accessed 02-02-2018.

URL20: An old map of Enschede. http://www.enschedeinansichten.nl/kaart1923.htm. Accessed 27-06-2017.

URL21: An old photo of Enschede (the Jannink in 1915). http://www.enschedestad.nl/overig/Jannink1915.jpg. Accessed 29-06-2017.

URL22: An old photo of Enschede (the Jannink in 2013).

http://www.fotocommunity.com/photo/enschede-haaksbergerstraat-jannink-texti-m-dewaard/32492417. Accessed 29-06-2017.

URL23: Android design guidelines. https://developer.android.com/design/index.html. Accessed 29-02-2018.

URL24: Android material design. https://material.io/guidelines/components/buttonsfloating-action-button.html. Accessed 29-02-2018.

URL25: Android navigation drawer design.

https://material.io/guidelines/patterns/navigation-drawer.html. Accessed 29-02-2018.

URL26: Android dialog design. https://material.io/guidelines/components/dialogs.html. Accessed 29-02-2018.

URL27: Android app bar design. https://material.io/components/app-bars-top/\#usage. Accessed 29-02-2018.

URL28: IntelliJ IDEA, the Java Interface Development Environment (IDE) used to develop GeoFARA. https://www.jetbrains.com/idea/. Accessed 02-03-2018.

URL29: Wikitude, a mobile AR technology provider. https://www.wikitude.com/. Accessed 02-03-2018.

URL30: Wikitude EDU license for education. https://www.wikitude.com/wikitudeacademy/. Accessed 02-03-2018.

URL31: AZ Screen Recorder.

https://play.google.com/store/apps/details?id=com.hecorat.screenrecorder.free\&hl=en _US. Accessed 02-03-2018.

URL32: The screen captures of demonstrating the prototype of GeoFARA. https://vimeo.com/263052616. Accessed 02-03-2018.

URL33: Tobii Pro Glasses 2: https://www.tobiipro.com/product-listing/tobii-proglasses-2/. Accessed 02-09-2018.

URL34: How the Tobii Pro Glasses 2 work. https://www.tobiipro.com/learn-andsupport/learn/eye-tracking-essentials/how-do-tobii-eye-trackers-work/. Accessed 02-092018. 
URL35: Tobii Pro Glasses Controller. https://www.tobiipro.com/product-listing/tobiipro-glasses-2/. Accessed 02-09-2018.

URL36: Tobii Pro Lab: https://www.tobiipro.com/product-listing/tobii-pro-lab/. Accessed 02-09-2018.

URL37: Examples of heat maps and gaze plots: https://www.tobiipro.com/learn-andsupport/learn/steps-in-an-eye-tracking-study/interpret/working-with-heat-maps-andgaze-plots/. Accessed 02-09-2018.

URL38: Interpreting the SUS scores by the dimensions - grades, adjectives, acceptability. https://measuringu.com/interpret-sus-score/. Accessed 02-09-2018.

URL39: Jiang's automated objects mapping approach.

https://github.com/myhjiang/et_mapping/blob/master/labels/complete_list.txt. Accessed 01-03-2020.

URL40: Nielsen Norman Group. https://www.nngroup.com. Accessed 01-06-2020. 


\title{
Appendix
}

\section{Appendix 1 The online survey on the use of ICTs and visualization tools in real undergraduate human geography fieldwork programs}

\author{
Dear Sir/Madam,
}

My name is Xiaoling Wang. I am a PhD student in Faculty of Geo-Information Science and Earth Observation (ITC), University of Twente, undertaking a $\mathrm{PhD}$ research. To finish this research, I need to know the role of visualizations and ICTs in human geography fieldwork. This research is about the (potential) use of maps, cartographic tools and other visualizations in human geography fieldwork. The type of educational fieldwork I am focusing at is trips to and courses in the field with the objective to help students to learn and better understand the (human) geography of a particular fieldwork area. With this survey I would like to find out what the current role of ICTs and visualizations is in this kind of fieldwork in your university. I would be very grateful if you can spare your valuable time to fill out this questionnaire. The information collected will be for academic purposes only. If you are interested in the outcomes, I will send you the results. Thank you for your time. In case of any questions, please feel free to email me on x.wang-5@utwente.nl.

\section{Background}

1. Your name (optional)?

2. Which university are you working at?

3. In this university, which department (institute) are you working at?

4. Does your department (institute) offer human geography fieldwork for undergraduate or graduate students?

- Yes

- No (if no, please pass this questionnaire to a colleague who is involved in this fieldwork)

5. Have you ever been involved in this human geography fieldwork (fieldtrips, field courses)?

- Yes

- No (if no, please pass this questionnaire to a colleague who is involved in this fieldwork)

\section{Geography fieldwork}

You may be involved in more than one geography fieldwork in your department. If so, please answer all questions below for one particular fieldwork only!

6. What is the destination of your human geography fieldwork (fieldtrips, field courses)?

7. Is the fieldwork in a rural or in an urban area?

- Rural

- Urban

- Both urban and rural

8. About how many days does this human geography fieldwork last? 
- 1 day

- 2 days

- 3 days

- 4-5 days

- More than 5 days

9. Which level of education is this human geography fieldwork for? (Please mark all that apply)

- $1^{\text {st }}$ year undergraduate

- $2^{\text {nd }}$ year undergraduate

- $3^{\text {rd }}$ year undergraduate

- $4^{\text {th }}$ year undergraduate

- Graduate

10. Which course is this human geography fieldwork part of?

- Human geography

- Physical geography

- Cartography

- GeoInformatics

- Other:

11. What is the main objective of your fieldwork?

- Learning-orientated: learning about the geography of the fieldwork area

- Mainly oriented towards field data collection (e.g. measuring, surveying, interviewing, mapping)

- Mainly research-orientated, such as inquiry (including formulating and testing hypotheses, solving problems)

- Other:

12. What themes does your geography fieldwork focus on? (Please mark all that apply)

- Landscape, design, planning (layout of the fieldwork area)

- Key landmarks

- Heritage, historical architecture and buildings

- Historical geography

- Cultural geography

- Land use and the change of land use

- Public transportation networks (buses, trams, traffic flows, etc.)

- Space structure development and expansion over time

- Sustainable aspects (the use of sustainable energy, e.g. wind and solar)

- Human life

- Movements of human beings

- Environmental problems

- The relation between natural environment and human activities

- Other:

13. Does your geography fieldwork involve exploring dynamic aspects (such as movements, changes, processes over space and time, etc.) of the fieldwork area?

- Yes please go to Question 14

- No please go to Question 15 
14. If so, what kinds of dynamic aspects?

15. Does your geography fieldwork use some hardware (digital device) and software?

- Yes please go to Question 16

- No please go to Question 17

16. What types of hardware and software are used in these human geography fieldworks? (Please mark all that apply)

- Desktop computer

- Notebook PC (laptop)

- Tablet

- Mobile phone

- GPS

- Digital camera

- Data logger (to record information such as fieldwork route, etc.)

- Vector graphics mapping software (such as CorelDraw, Adobe Illustrator)

- GIS and cartographic software (such as MapInfo, ArcGIS)

- Ready-made online maps (such as Google Earth or Google Maps)

- Customized software or applications for fieldwork purpose (such as virtual fieldwork area)

- No computer hard- and software at all

- Other:

Normally, fieldwork consists of three stages: preparation for the fieldwork, execution, and reporting on / processing the results afterwards. In the following questions, reference is made to one (or all) of these individual stages.

17. BEFORE geography fieldwork, what kinds of tools and other visualizations are you currently using to prepare for the fieldwork? And what kinds of tools and visualizations would you be interested in to use for human geography fieldwork in the future? (Please mark all that apply)
curtently using interested in using
Photos of reality (landscape photos, aerial images, sketches, etc.)
Videos of reality (e.g. of the landscape of the fieldwork areas)
Existing traditional 2D road or topographic maps in paper form
$\square$ Existing traditional 2D thematic maps in paper form
Paper atlases
$\square$ Existing digital maps on computer, tablet, or mobile phone
$\square$ Ready-made neogeography maps (e.g., OpenStreetMap/Flickr map)
$\square$ Maps specifically prepared for the fieldwork (for the purpose only)
3D Maps (DEM, 3D in Google Earth, etc.)
Virtual reality (geo-referenced virtual real world for exploring terrain, etc.)
Interactive visualizations (that can be manipulated with interactions) 
Dynamic visualizations (displaying changes over space and time)

$\square$ Other:

18. What are the main reasons for using these tools and visualizations in this stage?

19. DURING geography fieldwork, what kinds of tools and other visualizations are you currently using to prepare for the fieldwork? And what kinds of tools and visualizations would you be interested in to use for human geography fieldwork in the future? (Please mark all that apply)

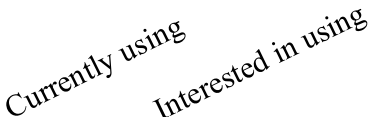

Photos of reality (landscape photos, aerial images, sketches, etc.)

Videos of reality (e.g. of the landscape of the fieldwork areas)

Existing traditional 2D road or topographic maps in paper form

Existing traditional 2D thematic maps in paper form

Paper atlases

Existing digital maps on computer, tablet, or mobile phone

Ready-made neogeography maps (e.g., OpenStreetMap/Flickr map)

Maps specifically prepared for the fieldwork (for the purpose only)

3D Maps (DEM, 3D in Google Earth, etc.)

Virtual reality (geo-referenced virtual real world for exploring terrain, etc.)

Interactive visualizations (that can be manipulated with interactions)

Dynamic visualizations (displaying changes over space and time)

Other:

20. What are the main reasons for using these tools and visualizations in this stage?

21. AFTER geography fieldwork, what kinds of tools and other visualizations are you currently using to prepare for the fieldwork? And what kinds of tools and visualizations would you be interested in to use for human geography fieldwork in the future? (Please mark all that apply)
Curtently using interested in using
Photos of reality (landscape photos, aerial images, sketches, etc.)
Videos of reality (e.g. of the landscape of the fieldwork areas)
Existing traditional 2D road or topographic maps in paper form
Existing traditional 2D thematic maps in paper form
Paper atlases
Existing digital maps on computer, tablet, or mobile phone
Ready-made neogeography maps (e.g., OpenStreetMap/Flickr map)
Maps specifically prepared for the fieldwork (for the purpose only)
3D Maps (DEM, 3D in Google Earth, etc.) 
$\square$ Virtual reality (geo-referenced virtual real world for exploring terrain, etc.)

$\square$ Interactive visualizations (that can be manipulated with interactions)

$\square$ Dynamic visualizations (displaying changes over space and time)

$\square$ Other:

22. What are the main reasons for using these tools and visualizations in this stage?

23. Do students carry out mapping activates in your fieldwork (i.e. making their own maps)?

- Yes please go to Question 24

- No please go to Question 27

24. BEFORE geography fieldwork, what kinds of mapping activities? (Please mark all that apply)

- No mapping activities

- Drawing maps on paper

- Drawing maps using (carto-) graphic software (such as ArcGIS, CorelDraw, etc.)

- Drawing maps by using online mapping services (e.g. making use of online base maps like Google Maps)

- Creating maps by contributing to neogeography projects (such as OpenStreetMap or Flickr map, etc.)

- Other:

25. DURING geography fieldwork, what kinds of mapping activities? (Please mark all that apply)

- No mapping activities

- Drawing maps on paper

- Drawing maps using (carto-) graphic software (such as ArcGIS, CorelDraw, etc.)

- Drawing maps by using online mapping services (e.g. making use of online base maps like Google Maps)

- Creating maps by contributing to neogeography projects (such as OpenStreetMap or Flickr map, etc.)

- Other:

26. AFTER geography fieldwork, what kinds of mapping activities? (Please mark all that apply)

- No mapping activities

- Drawing maps on paper

- Drawing maps using (carto-) graphic software (such as ArcGIS, CorelDraw, etc.)

- Drawing maps by using online mapping services (e.g. making use of online base maps like Google Maps)

- Creating maps by contributing to neogeography projects (such as OpenStreetMap or Flickr map, etc.)

- Other:

27. Which of the following problems with the use of these cartographic tools and visualizations did you encounter before, during or after your fieldwork? (Please mark all that apply)

- Maps or visualizations are too old and not so up-to-date

- The maps, tools and visualizations that I need are not available

- Poor usability

- Students lack the skills to produce (cartographic) visualizations themselves 
- Lack of hard- and/or software

- Problems with the use of hardware in the field

- Students lack the skills required to read maps and other visualizations

- Students have no interests in using cartographic tools and other visualizations

- Teachers have no interests in using cartographic tools and other visualizations

- Other problems (please list as many problems as possible):

28. One of the aims of my research is to develop an interactive and dynamic cartographic visualization tool (which can be used on a portable device) to better support students in their human geography fieldwork. Would you be interested in implementing such a tool?

- Yes please go to Question 29

- Perhaps please go to Question 29

- No please go to Question 30

29. Please give me your suggestions regarding the nature and contents of this interactive and dynamic cartographic visualization to be developed.

30. Please write down your email address in case you are interested in receiving the results of my research.

31. Is there a place where I can find more information about your geography fieldwork? Please provide publication details.

32. Do you know any other departments (institutes) or universities offering human geography fieldwork (fieldtrip, field course) for undergraduate or graduate students?

- Yes

- No

33. If yes, as far as you know, what are the names of these departments (institutes) or universities? (Please fill the form)

\begin{tabular}{|c|l|l|}
\hline & University names & Department (institute) names \\
\hline 1 & & \\
\hline 2 & & \\
\hline 3 & & \\
\hline 4 & & \\
\hline 5 & & \\
\hline
\end{tabular}

THANK YOU VERY MUCH FOR YOUR CO-OPERATION! 


\section{Appendix 2 The pre-fieldwork paper survey during the ethnographic study with a human geography fieldwork organized by Beijing Normal University}

My name is Xiaoling Wang. I am conducting a PhD research in the Faculty of Geo-Information Science and Earth Observation (ITC), University of Twente, the Netherlands. With the questionnaire I would like to briefly answer some questions about your use of maps and your mobile phone and your familiarity of the fieldtrip region. It will take about 4 minutes to complete the survey. Thank you for your time. The information collected will be for academic purposes only.

1. Your name (optional)?

2. You email address (optional)

3. What is your gender?

- Male

- Female

4. What is your year of birth?

5. What is your current major?

6. Do you have a mobile phone?

- Yes

- $\quad$ No (go to question 8)

7. What is the operating system of your mobile phone?

- IOS

- Android

- Windows

- Other:

8. How long have you lived in Beijing?

- Less than 1 year

- 1-3 years

- More than 3 years

9. How often do you go to the region of where this fieldwork will be conducted?

- Once, or less than once per year

- Two to three times per year

- More than three times per year

10. How familiar are you with the region of where this fieldwork will be conducted?

- Not familiar at all

- Slightly familiar

- Somewhat familiar

- Moderately familiar

- Very familiar

11. How often do you use paper maps on your mobile phone?

- $\quad$ Every day

- Several times per week

- Several times per month

- Several times per year

- Seldom 
- Never

12. How often do you use maps on your mobile phone in your daily study?

- Every day

- Several times per week

- Several times per month

- Several times per year

- Seldom

- Never

13. Please list all the digital maps you use daily on your mobile phone:

14. Have you studied the course "Cartography"?

- Yes, and when?

- No

15. Have you studied any GIS-related courses?

- Yes, what are the courses name and when?

- No

16. Have you ever heard about Augmented Reality (AR)?

- Yes

- $\quad$ No (skip Question 17)

17. Please simply describe what $A R$ is:

THANK YOU VERY MUCH FOR YOUR VALUABLE TIME! 


\section{Appendix 3 The post-fieldwork surveys among undergraduates from Beijing Normal University who participated a human geography fieldwork in Beijing (different fieldwork and different students from the one in Appendix 2) and undergraduates from Ghent University who participated a human geography fieldwork in Amsterdam}

My name is Xiaoling Wang. I am conducting a PhD research in the Faculty of Geo-Information Science and Earth Observation (ITC), University of Twente, the Netherlands. With the questionnaire I would like to briefly answer some questions about your use of maps and your mobile phone in the past human geography fieldwork. It will take about 3 minutes to complete the survey. Thank you for your time. The information collected will be for academic purposes only.

1. Do you have a mobile phone?

- Yes

- No, I don't have a mobile phone (please go to Question 3)

2. What is the operating system of your mobile phone?

- IOS

- Android

- Windows

- I don't know

- Other:

3. Did you use paper maps or digital maps on your mobile phone during the fieldwork?

- Yes, only paper maps

- Yes, only digital maps on my mobile phone

- Yes, both paper maps and digital maps on my mobile phone

- No, I didn't use any of them

4. What were your main purposes of using the maps on your mobile phone? (Please mark all that apply)

- $\quad$ Finding where I am within the fieldwork area

- Locating a certain point (e.g., a building) within the fieldwork area

- Checking the information of a certain point I saw in the fieldwork area

- $\quad$ Planning a route from my current location to a certain point

- Navigating to a certain point

- Comparing what I saw in the field with the maps on my mobile phone

5. Which layers did you use within the maps on your mobile phone? (Please mark all that apply)

- Traffic layer

- Satellite layer

- Terrain layer

- Other:

6. What were your main purposes of using the maps on your mobile phone?

Paper maps:

Digital maps on your mobile phone:

Difficulties of using paper maps:

Difficulties of using digital maps on your mobile phone: 
7. Regarding paper maps and digital maps on your mobile phone, what was the most useful in helping you to complete the fieldwork tasks? (Please choose ONE answer below)

- $\quad$ Paper maps

- Digital maps on my mobile phone

- Both paper maps and digital maps on my mobile phone

- $\quad$ None of them

8. Regarding paper maps and digital maps on your mobile phone, what was the most useful for improving your overall geographical understanding of the fieldwork area? (Please choose ONE answer below)

- Paper maps

- Digital maps on my mobile phone

- $\quad$ Both paper maps and digital maps on my mobile phone

- None of them

9. During the fieldwork, except for using digital maps on your mobile phone, what other things did you do with your mobile phone (directly related with your fieldwork)? (Please mark all that apply)

- Making notes

- Recording audios

- Recording videos

- Taking photos

- Using a browser to check additional information I needed

- I didn't have a mobile phone

- I didn't use my mobile phone

- Other:

10. Please list all those difficulties you had (if there were any) when using your mobile phone to do the above things directly related with your fieldwork:

THANK YOU AGAIN FOR YOUR PARTICIPATION IN THIS QUESTIONNAIRE! 


\section{Appendix 4 The entity relationship diagram of GeoFARA}

A data model represents the data structure, which is fundamental to developing mobile applications. There are various kinds of data models, e.g., relational model, network model, entity relationship model, etc. An entity data model is considered to be a suitable option for illustrating how entities relate to each other in a system, which can be graphically represented by an entity relationship diagram. The following figure shows the entity relationship diagram of GeoFARA. It is created by the developer of GeoFARA using the online tool—JDL Studio (https://www.jhipster.tech/jdlstudio/). The entity relationship diagram is composed of all the entities of GeoFARA and the relationships between them. In total, there are eight entities in GeoFARA's entity relationship diagram: User, UserGroup, UserActivity, UserAction, UserText, UserImage, POI, and POICollection. The UserGroup entity is a group of one or more users; the POICollection entity is a set of one or more POIs. Each entity has its attributes. All entities have a numeric ID, and most of the entities have timestamps for their creation, updating and deleting date. This figure also indicates the relationships among the entities. For example, one user has UserText, UserAction, and PoiCollection, while a UserText/UserAction/PoiCollection has at most one user, which is a manyto-one relationship. The diagram employs the $*_{-} 1$ symbol and the $*_{-} *$ symbol to represent a manyto-one relationship and a many-to-many relationship respectively.

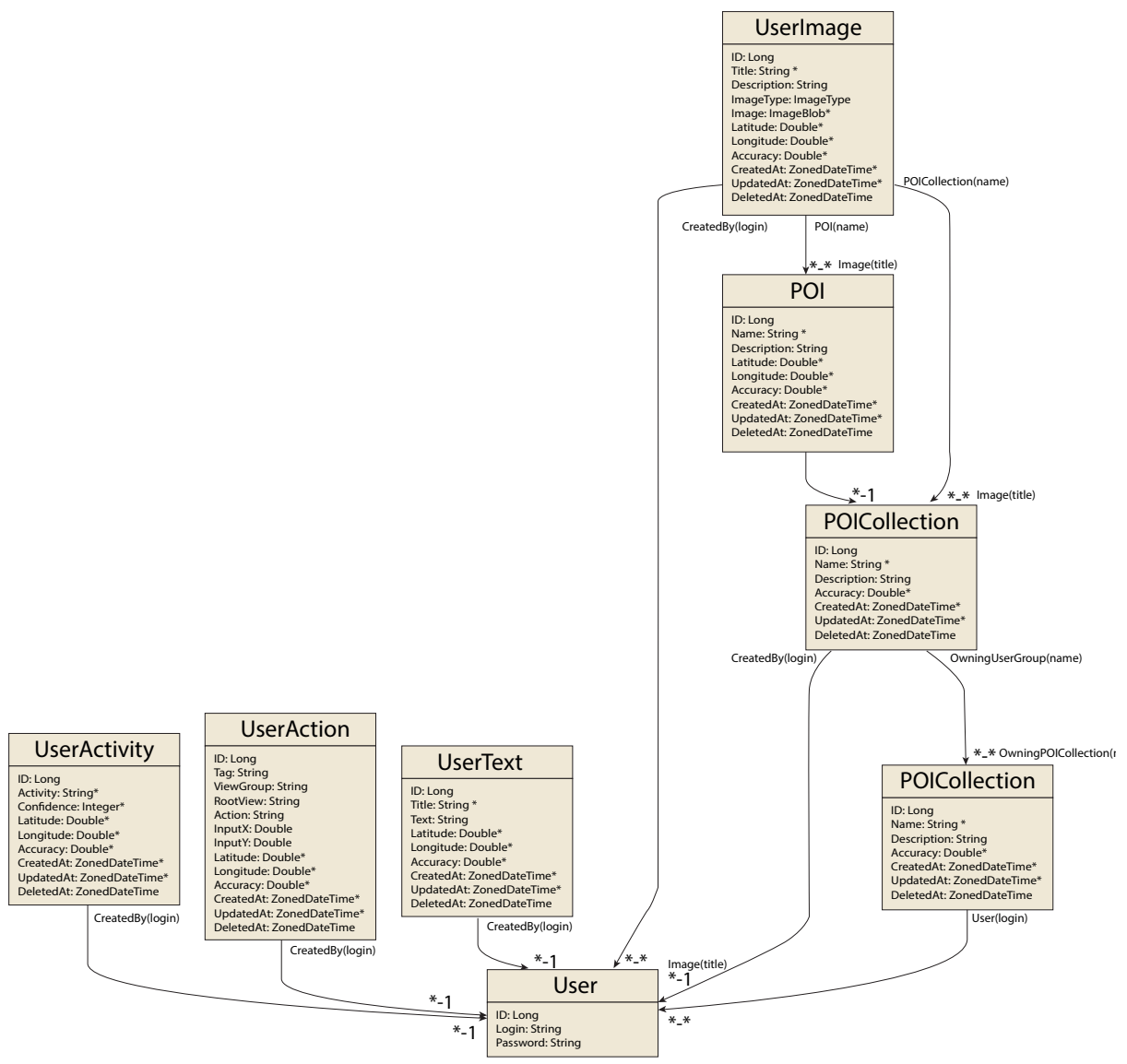




\section{Appendix 5 The client architecture of GeoFARA}

The following illustration, provided by the developer, presents the client architecture of GeoFARA, the creation of which followed common software development principles. It is composed of five layers: view layer, presentation layer, service layer, domain layer, and repository layer. Communication between layers is accomplished through a data stream and an event stream. The event stream (on the left side) goes from the view layer till the bottom repository layer. In response to user input, the data stream (on the right side) flows in the opposite way.

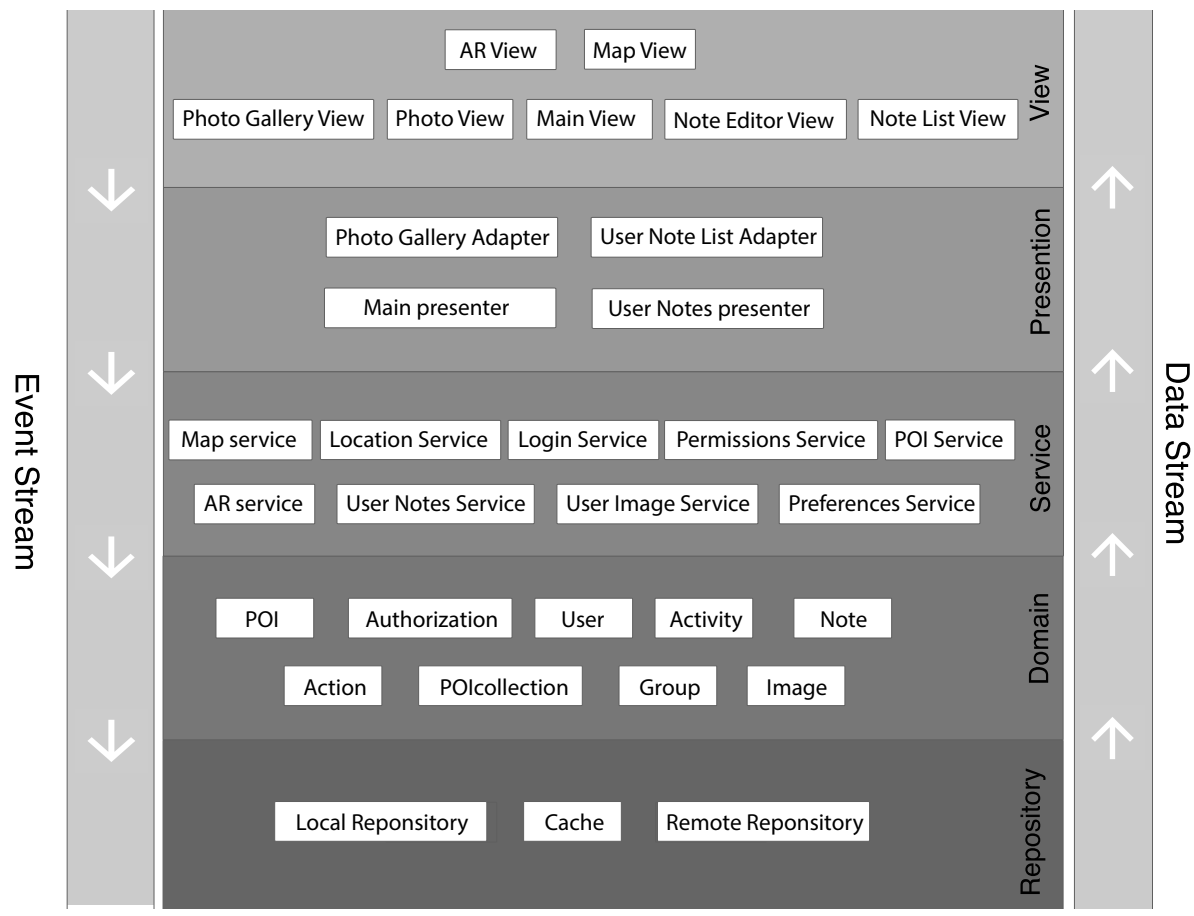

The view layer is the most outer part of GeoFARA's client architecture. It consists of an AR view, map view, main view, photo gallery view, photo view, note editor view, and note list view. It is a visible layer with which the user can interact. Its main purpose is to receive interaction events from the user, such as clicking buttons. The presentation layer is concerned with the view logic, such as list sorting, arranging items, and processing certain input events. It acts as the gateway between the view and the service layer, receiving requests from the upper view layer and sending them to the service layer. The service layer is located between the presentation layer and the domain layer and deals with the business logic. It is responsible for providing services in a consistent way. This layer can coordinate its responses in every operation. For example, it associates POIs and images, so that both of them can be presented in a cohesive context. The domain layer contains object representations of all domain data (POIs, images, notes, etc.). These are independent from the data source (webserver or local database). The repository layer is the deepest layer of the client architecture. It deals with retrieving data from its sources. Thus, it abstracts the underlying data structure. The three classes (local repository, cache, remote repository) in the repository layer access to different data sources. 


\section{Appendix 6 The POIs in GeoFARA}

In total, 17 POIs within the fieldwork area are introduced in GeoFARA. Most of them are the remnants of the former textile industry. The map shows the fieldwork area (Schuttersveld) and the POI locations.

\begin{tabular}{|l|l|l|}
\hline POI ID & POI Name & Whether a remnant or not \\
\hline 1 & ITC building & No \\
\hline 2 & Menzis & No \\
\hline 3 & Princess Beatrix tunnel & Yes \\
\hline 4 & Bistro Het Koetshuis & Yes \\
\hline 5 & Villa Schuttersveld & Yes \\
\hline 6 & Maison Manon & Yes \\
\hline 7 & Kwantum etc. & Yes \\
\hline 8 & Leen Bakker & Yes \\
\hline 9 & ToyChamp & Yes \\
\hline 10 & The left wall & Yes \\
\hline 11 & Praxis & Yes \\
\hline 12 & POCO Woonwarenhuis & Yes \\
\hline 13 & FitForFree & Yes \\
\hline 14 & KPN & Yes \\
\hline 15 & Stichting 55+ & No \\
\hline 16 & AJ store & Yes \\
\hline 17 & Volkspark tunnel & Yes \\
\hline & & \\
\hline
\end{tabular}

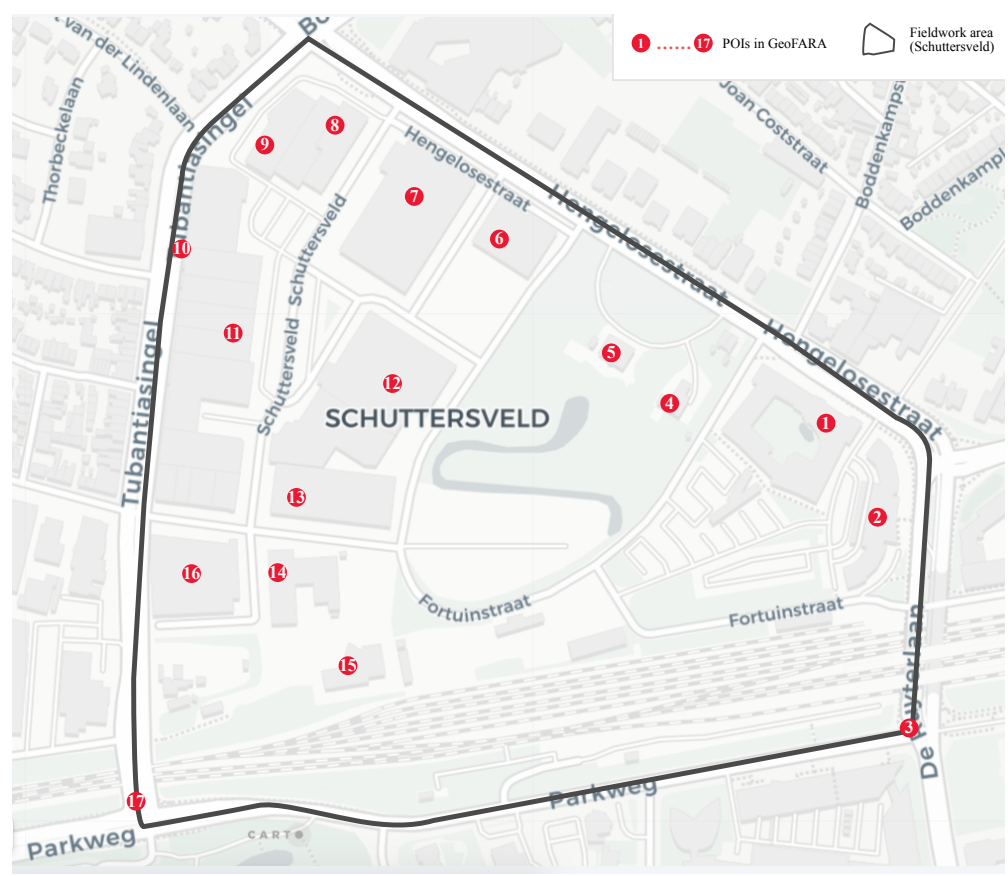




\section{Appendix 7 Recruiting test persons for evaluating GeoFARA (a mobile application)}

Dear student,

I am Xiaoling Wang, a PhD student studying in Faculty of ITC. In my $\mathrm{PhD}$ research, I design a mobile application, called GeoFARA (Geography Fieldwork Augmented Reality Application). This application integrates visualizations and Augmented Reality (AR) to assist learning geography in Enschede. As part of my PhD research, I would like to get some feedback about the overall experience of using this mobile application.

I would like to use this survey to select participants through collecting some of your background information and your map and smartphone use experience to determine your suitability (also in terms your eyesight) to participate in the further study. If you are selected as a participant, you will be invited to use GeoFARA on a prepared smartphone while wearing mobile eye tracking glasses (as in the picture below) during a walk in the Schuttersveld area (around ITC building) to learn about the geography of this area. This field session will be rewarded with a gift.

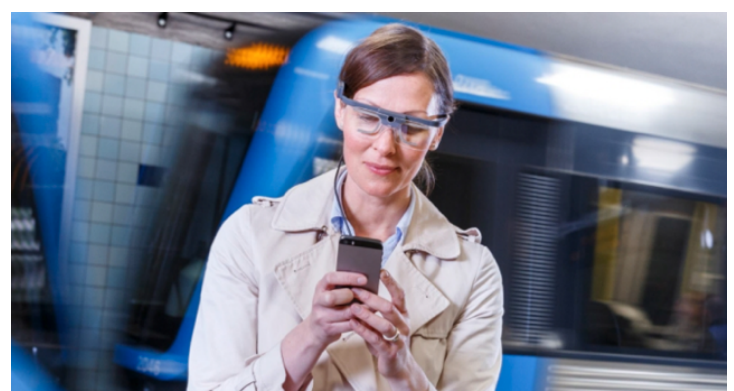

This survey will take around 3 minutes to complete. At the beginning of this survey, your name and email are required, only because you might be further contacted to participate the field test. All the collected information will be strictly kept confidential. Thank you for participating in this survey. In case of any questions, please feel free to email me on x.wang-5@utwente.nl.

1. What is your name and email address?

2. What is your gender?

- Male

- Female

3. What is your age?

- 20 and below

- $21-25$

- $26-30$

- 31-35

- $36-40$

- $41-45$

- $46-50$

- 50 and above 
4. What is your country of origin?

5. Are you near-sighted or farsighted? Or do you have normal vision?

- Only near-sighted

- Only farsighted

- Near-sighted, farsighted and others

- Normal vision

6. If you are corrected to normal vision, do you wear contact lenses or frame glasses daily?

- I have normal vision

- Corrected to normal vision, I wear contact lenses

- Corrected to normal vision, I wear frame glasses

- I don't have normal vision, but I haven't been corrected to normal vision

7. What is your highest completed education level?

- $\quad \mathrm{BSc}$

- $\mathrm{MSc}$

- Others:

8. What is the subject of your current field of study?

- Applied Earth Sciences

- GeoInformatics

- Land Administration

- Natural Resources Management

- Urban Planning and Management

- Water Resources and Environmental Management

- Others:

9. What was the subjects of your previous field of study? (Please mark all that apply)

- Geography

- Environmental Science

- Geo-Information Science (GIS)

- Remote Sensing

- Urban and Regional Planning

- Others:

10. How often do you use paper maps?

- Daily

- Weekly

- Monthly

- 5-10 times per year

- 2-4 times per year

- Once or less than once per year

- Never

11. How often do you use digital maps (such as map applications) on mobile devices?

- Daily

- Weekly

- Monthly

- 5-10 times per year

- 2-4 times per year 
- Once or less than once per year

- Never

12. How often do you produce maps yourself?

- Daily

- Weekly

- Monthly

- 5-10 times per year

- 2-4 times per year

- Once or less than once per year

- Never

13. How familiar are you with using Google Maps?

- Very familiar

- Moderately familiar

- Somewhat familiar

- Slightly familiar

- Not familiar at all

14. How long have you lived in Enschede?

- Less than 4 months

- 4-12 months

- 1-2 years

- 2-4 years

- More than 4 years

15. How often do you come to this area (see the map) in Enschede? And how well do you know about this area?

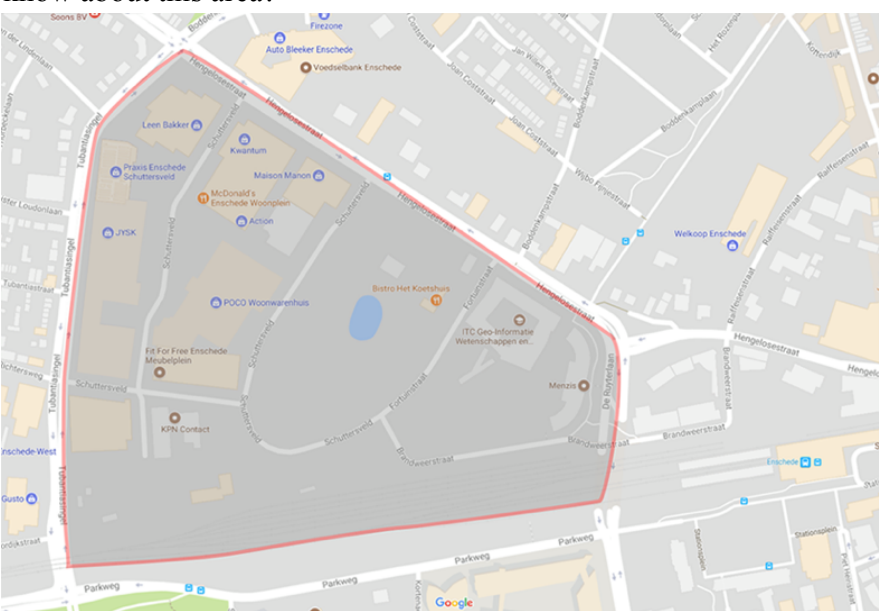

- I come here frequently and know what was here before

- I come here frequently but do not know what was here before

- I come here sometimes and know what was here before

- I come here sometimes but do not know what was here before

- I have never been here but know what was here before

- I have never been here and do not know what was here before

16. Do you have a smartphone? What is the operating system? 
- $\quad$ Yes, with an Android operating system

- $\quad$ Yes, with an IOS operating system

- $\quad$ Yes, with a Windows operating system

- $\quad$ Yes, with other operating system

- No, I don't have a smartphone

17. Are you aware that there are still some visible remnants of Enschede's textile industry?

- $\quad$ No

- Yes, can you give one or two examples of visible remnants of Enschede's textile industry:

18. Have you ever heard about Augmented Reality (AR)?

- $\quad$ Yes

- $\quad$ No

19. Did you ever use an Augmented Reality (AR) application on your smartphone?

- $\quad$ No

- $\quad$ Yes, which AR application(s) did you use on your smartphone:

THANK YOU FOR YOUR PARTICIPATING IN THIS SURVEY. I WILL CONTACT YOU AGAIN SHORTLY. 


\section{Appendix 8 Santa Barbara Sense-Of-Direction (SBSOD) Scale}

This questionnaire consists of several statements about your spatial and navigational abilities, preferences, and experiences. After each statement, you should circle a number to indicate your level of agreement with the statement. Circle " 1 " if you strongly agree, " 7 " if you strongly

disagree, or some number in between if your agreement is intermediate. Circle "4" if you neither agree nor disagree.

1. I am very good at giving directions.

$\begin{array}{lllllllll}\text { strongly agree } & 1 & 2 & 3 & 4 & 5 & 6 & 7 & \text { strongly disagree }\end{array}$

2. I have a poor memory for where I left things. $\begin{array}{lllllllll}\text { strongly agree } & 1 & 2 & 3 & 4 & 5 & 6 & 7 & \text { strongly disagree }\end{array}$

3. I am very good at judging distances. $\begin{array}{lllllllll}\text { strongly agree } & 1 & 2 & 3 & 4 & 5 & 6 & 7 & \text { strongly disagree }\end{array}$

4. My "sense of direction" is very good.

$\begin{array}{lllllllll}\text { strongly agree } & 1 & 2 & 3 & 4 & 5 & 6 & 7 & \text { strongly disagree }\end{array}$

5. I tend to think of my environment in terms of cardinal directions (N, S, E, W). $\begin{array}{lllllllll}\text { strongly agree } & 1 & 2 & 3 & 4 & 5 & 6 & 7 & \text { strongly disagree }\end{array}$

6. I very easily get lost in a new city. $\begin{array}{lllllllll}\text { strongly agree } & 1 & 2 & 3 & 4 & 5 & 6 & 7 & \text { strongly disagree }\end{array}$

7. I enjoy reading maps. $\begin{array}{lllllllll}\text { strongly agree } & 1 & 2 & 3 & 4 & 5 & 6 & 7 & \text { strongly disagree }\end{array}$

8. I have trouble understanding directions. $\begin{array}{lllllllll}\text { strongly agree } & 1 & 2 & 3 & 4 & 5 & 6 & 7 & \text { strongly disagree }\end{array}$

9. I am very good at reading maps. $\begin{array}{lllllllll}\text { strongly agree } & 1 & 2 & 3 & 4 & 5 & 6 & 7 & \text { strongly disagree }\end{array}$

10. I don't remember routes very well while riding as a passenger in a car. $\begin{array}{lllllllll}\text { strongly agree } & 1 & 2 & 3 & 4 & 5 & 6 & 7 & \text { strongly disagree }\end{array}$

11. I don't enjoy giving directions. $\begin{array}{lllllllll}\text { strongly agree } & 1 & 2 & 3 & 4 & 5 & 6 & 7 & \text { strongly disagree }\end{array}$

12. It's not important to me to know where I am. $\begin{array}{lllllllll}\text { strongly agree } & 1 & 2 & 3 & 4 & 5 & 6 & 7 & \text { strongly disagree }\end{array}$

13. I usually let someone else do the navigational planning for long trips. $\begin{array}{lllllllll}\text { strongly agree } & 1 & 2 & 3 & 4 & 5 & 6 & 7 & \text { strongly disagree }\end{array}$

14. I can usually remember a new route after I have travelled it only once. $\begin{array}{lllllllll}\text { strongly agree } & 1 & 2 & 3 & 4 & 5 & 6 & 7 & \text { strongly disagree }\end{array}$

15. Usually, I don't have a very good "mental map" of my environment. $\begin{array}{lllllllll}\text { strongly agree } & 1 & 2 & 3 & 4 & 5 & 6 & 7 & \text { strongly disagree }\end{array}$ 


\section{Appendix 9 Draw your pre- mental map of the Schuttersveld area}

A mental map of a specific geographic area is a map of that area that basically already exists in your mind. Based on the references of the locations of the ITC building, Enschede central station, the railway tracks, and the streets, please draw your mental map of Schuttersveld area within the limits marked in red.

Note: When drawing your mental map, please include as many streets and landmarks (e.g. buildings) as you can, and indicate their locations and names. If you already know that there are some textile remnants within this area, please mark them on your mental map as well.

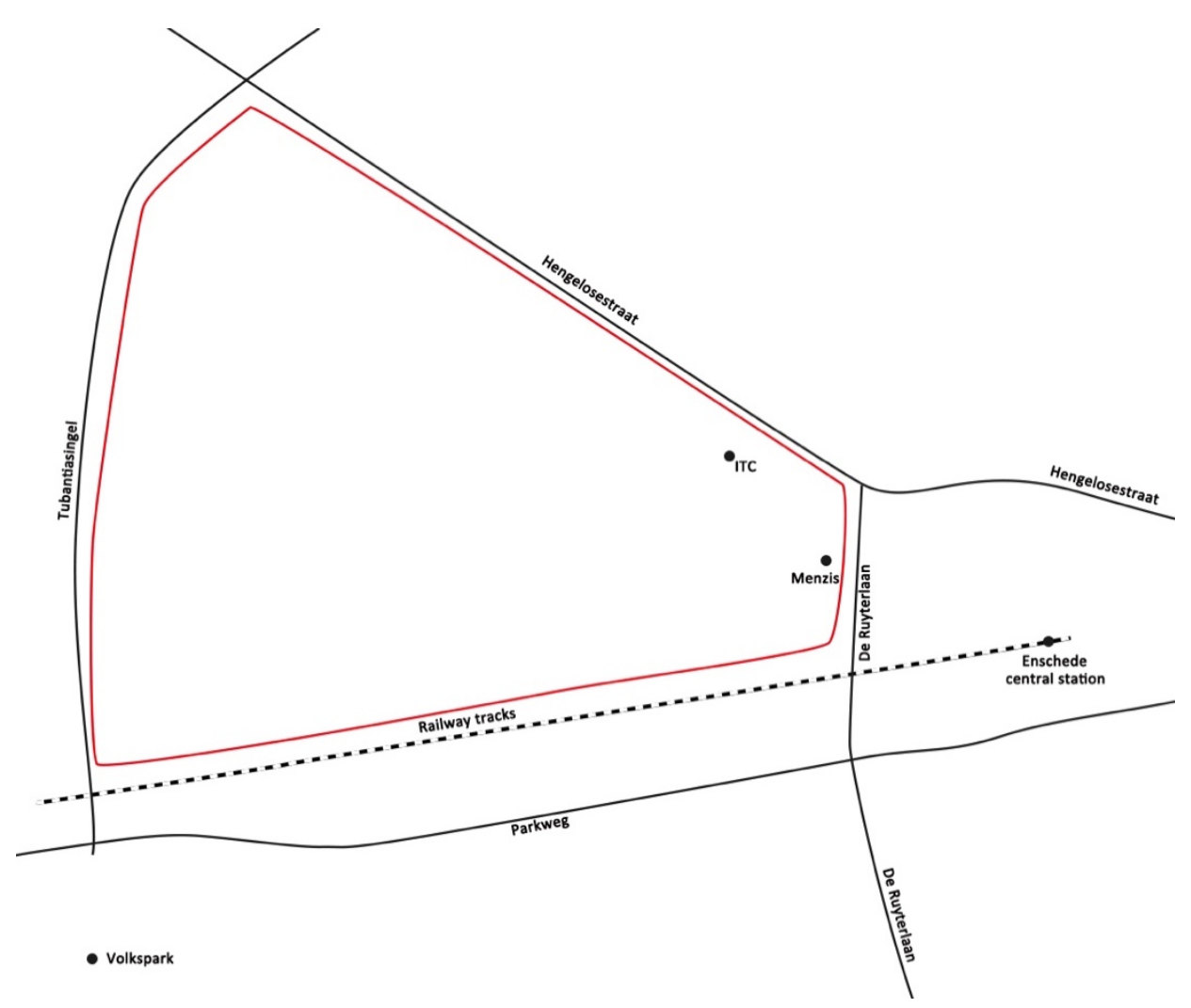




\section{Appendix 10 Instructions for the evaluation of GeoFARA}

\section{Basic introduction about the textile history of Enschede}

Historically, Enschede was a city with a flourishing textile industry. From the early $19^{\text {th }}$ century till around the 1960s, within Enschede and its surroundings, many textile factories were operational, followed by the setup of steam engines, bleaching facilities, railway networks and even textile schools. At the same time, the textile barons (the owners of the textile manufacturing companies) built their own mansions and recreational areas (also for their laborers). Enschede was a city of textiles.

Towards the end of the 19th century, many strikes happened due to the low wages and poor living and working conditions. Thereafter, the two world wars and the great depression brought damage to many of textile factories. Although the textile barons tried to rebuild factories, this did not stop the collapse of the textile industry in Enschede. When it came to 1950-1960, the larger textile factories closed one by one. The whole textile industry of Enschede came to a halt and the manufacturing went to countries with cheaper labor. The rise and fall of the textile industry in Enschede affected the current city urban landscape. Some remnants of the old textile factories and facilities (e.g. park areas and houses) are still visible. Old buildings may have a new function now and there are also some new developments in the city landscape at places where the old factories were demolished. The structure of textile factory blocks may still be visible in the current road pattern or by the locations of new buildings (e.g. in case the old foundations were used to build on).

The purpose of this fieldwork is to expose you to the Schuttersveld area and let you discover remnants and traces of Enschede's former textile industry in an area with many relatively new developments. The main question you will have to solve is that what is the visible influence of the past textile industry on the current spatial structure of this area. Schuttersveld roughly covers the area to the west of the ITC building. During the fieldwork, the mobile application GeoFARA (Geography Fieldwork Augmented Reality Application) which combines AR and other visualizations will assist you in answering the main question.

\section{The activities before going to the field}

Before the actual fieldwork starts, I would like to further learn about your existing knowledge about Schuttersveld area by asking you to draw a mental map of this area. Besides, I would like you to give a self-assessment of your sense of orientation by completing the questionnaire of the 'Santa Barbara Sense of Direction Scale'.

\section{Basic instructions for the upcoming fieldwork}

The overall objective of this field trip within the Schuttersveld area is to improve your geographical understanding with the help of GeoFARA. GeoFARA is a mobile application running on smartphones with Android operating systems. It includes an AR view and maps with POIs (Point of Interests) of the Schuttersveld area. There is additional information about every POI, which appears when you touch a POI marker on the map or a label in the AR view. You can either have a 
look at the map view, or the AR view, or both. It is also possible to have a look at some old maps or an aerial image of the Schuttersveld area.

After the field trip, I will ask you to draw another map of the Schuttersveld area in which you should draw those remnants of the former textile industry you have discovered. These remnants may be individual features, but also, for instance, the structure of the road network or of current building blocks. In order to prepare for draw your map afterwards, with GeoFARA, you can make notes and take photos of remnants of the former textile industry during your walk within the Schuttersveld area. Regarding taking notes in GeoFARA, you can list the features, architectures, infrastructures, roads/streets within the Schuttersveld area that are directly related with the past textile industry. It may also help to list the current functions. New constructions and their functions may also be identified to build up the geographical structure of the area.

During the fieldwork, you will be wearing a mobile eye tracking system. This system will track all your eye movements, i.e. where you are looking at (the screen of the phone, the features in the surroundings, etc.). I am asking you to also think aloud when you perform tasks, that is: speak what is going on in your mind, such as what you are doing, what you are thinking, what you are expecting, etc. Your thinking aloud, your eye movements and everything you are looking at will be recorded. All these recordings will only be analyzed by me and will be kept strictly confidential. After back from the fieldwork, I will ask some questions about the activities you have accomplished.

I am going to show you how GeoFARA works now. During the field trip, if there are any questions regarding how to use GeoFARA, please let me know. 


\section{Appendix 11 Draw your post- mental map of the Schuttersveld area}

Making use of the notes and photos you took with GeoFARA in the field, please draw any remnants of the former textile industry you have discovered in your final map of Schuttersveld area.

Note: When drawing your final map, please include as many streets and landmarks as you can, and indicate their locations, names and/or current functions.

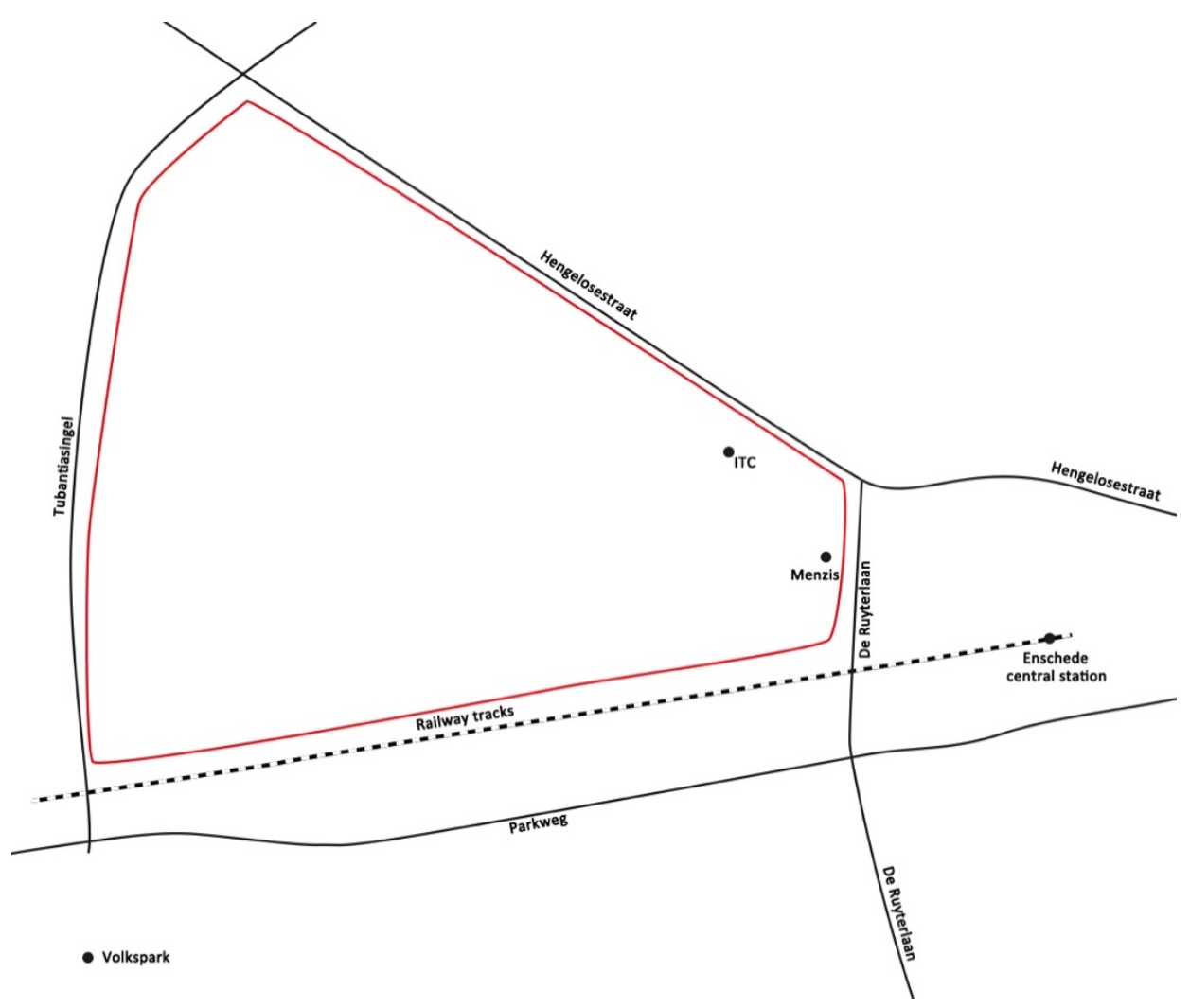




\section{Appendix 12 About your experience of using GeoFARA}

According to your experience of using GeoFARA, please complete the following questionnaire. Each question has 5 response options, from strongly disagree to strongly agree. Please circle a number for each question to indicate your level of agreement. Circle "1" if you strongly disagree with the statement, "5" if you strongly agree, or some number in between if your agreement is intermediate. Circle " 3 " if you neither agree nor disagree.

\begin{tabular}{|c|c|c|c|c|c|}
\hline \multirow{2}{*}{$\begin{array}{l}\text { Statements about GeoFARA } \\
\text { 1. I think that I would like to use GeoFARA } \\
\text { frequently. }\end{array}$} & \multicolumn{3}{|c|}{$\begin{array}{l}\text { Strongly } \\
\text { disagree }\end{array}$} & \multicolumn{2}{|c|}{$\begin{array}{l}\text { Strongly } \\
\text { agree }\end{array}$} \\
\hline & 1 & 2 & 3 & 4 & 5 \\
\hline 2. I found GeoFARA unnecessarily complex. & 1 & 2 & 3 & 4 & 5 \\
\hline 3. I thought GeoFARA was easy to use. & 1 & 2 & 3 & 4 & 5 \\
\hline $\begin{array}{l}\text { 4. I think that I would need the support of a } \\
\text { technical person to be able to use GeoFARA. }\end{array}$ & 1 & 2 & 3 & 4 & 5 \\
\hline $\begin{array}{l}\text { 5. I found the various functions in GeoFARA } \\
\text { were well integrated. }\end{array}$ & 1 & 2 & 3 & 4 & 5 \\
\hline $\begin{array}{l}\text { 6. I thought there was too much inconsistency } \\
\text { in GeoFARA. }\end{array}$ & 1 & 2 & 3 & 4 & 5 \\
\hline $\begin{array}{l}\text { 7. I would imagine that most students would } \\
\text { learn to use GeoFARA very quickly. }\end{array}$ & 1 & 2 & 3 & 4 & 5 \\
\hline $\begin{array}{l}\text { 8. I found GeoFARA very } \\
\text { cumbersome/complicated to use. }\end{array}$ & 1 & 2 & 3 & 4 & 5 \\
\hline 9. I felt very confident using GeoFARA. & 1 & 2 & 3 & 4 & 5 \\
\hline $\begin{array}{l}\text { 10. I needed to learn a lot of things before I } \\
\text { could get going with GeoFARA. }\end{array}$ & 1 & 2 & 3 & 4 & 5 \\
\hline
\end{tabular}




\section{Appendix 13 Post-interview questions}

1. What are your general remarks regarding the using of GeoFARA in the field?

2. In general, how did GeoFARA help/distract you to learn the geography of the Schuttersveld area in terms of the influence of past textile history on the current spatial structure?

3. In general, how satisfied or dissatisfied are you with the use of GeoFARA in the field?

4. How do you like the split view of GeoFARA (i.e, you can see both AR and a map on one screen)?

5. How do you like the way in which information is provided about each POI in GeoFARA?

6. How do you like the functionalities of taking notes, photos in GeoFARA?

7. What elements of the design of GeoFARA did you really like?

8. What elements of the design of GeoFARA did you not like?

9. If you could make one significant change to GeoFARA, what change would you make?

10. What other additional comments/ suggestions would you like to make regarding the fieldwork, the design of GeoFARA or the tasks? 


\section{Summary}

Technological innovations promote and transform the developments of educational technologies and the ways of using them. Within the domain of geography fieldwork education, in which, typically, use is made of maps, it should be the role of both pedagogic and cartographic research to explore and extend new cartographic and technical approaches in order to improve learning and teaching. Recently, mobile augmented reality (AR), augmenting the real with the virtual on mobile devices, is perceived as one of the latest and promising mobile technologies, and education is asserted as one of the most promising application domains of AR. For geo-fieldwork education, a tool making use of the new (AR) and the traditional (maps) could be designed to realize innovative location-based teaching and learning. In designing a new educational tool, there have been little efforts to involve users through the design process, although it is advocated that there should be a shift away from technology-driven approaches towards more usercentered approaches. To contribute to this research gap and to keep pace with evolving technologies, this research, by employing a user-centered design approach, aimed to explore the design and the use of an educational tool which combines maps and AR in a mobile context-aware application (GeoFARA - Geography Fieldwork Augmented Reality Application) for supporting a human geography fieldwork.

To guide the research on the user-centered design of GeoFARA, the theoretical developments and practical applications of the user-centered design (UCD) methodology were established. A large amount of secondary sources about UCD and its interrelated fields such as human-machine interaction (HMI), usability engineering (UE) and use experience (UX) were reviewed. This review revealed the initial developments and the major milestones of the UCD method in academic and practical fields in the past century. The basic principles, the interactive process of UCD, and how UCD can be applied in the design of context-aware mobile applications, and the outcomes (good usability) of applying UCD, were also reviewed. The review resulted in three iterative stages of the user-centered design of GeoFARA: (1) specifying the context of use and analyzing user requirements, (2) producing design solutions in terms of conceptual design and prototype development, (3) evaluating the design solution. The review also provided the commonly used UCD methods that can be applied in each stage, followed by an overview of which methods were selected for designing GeoFARA and why they were selected.

The first research objective was to specify GeoFARA's context of use and user requirements. They were derived from (1) a review of the existing mobile AR applications for outdoor educational use, (2) an online survey of geography fieldwork organizers on the current use of tools, (3) a field experiment making use of an existing mobile mapping 
tool, (4) an ethnographic study during a real geography fieldwork, (5) post-fieldwork surveys among undergraduates, (6) a use case and task analysis, and (7) a use scenario with persona. This resulted in substantial initial user requirements, which were then reduced, categorized, and prioritized due to the practical tradeoffs between different user requirements as well as between the limited research project resources and the necessity of considering all the user requirements in this first iterative design cycle.

The second objective was to produce design solutions. The conceptual design of GeoFARA in terms of its scope (functionality specifications and content requirements) and the skeleton (user interface and navigation design) was presented, based on which a prototype of GeoFARA was developed. Due to factors such as limited resources (time, expenses) and technical constraints, the rational compromises made from the user requirements to the conceptual design to the prototype of GeoFARA were also explained.

The third research objective was to evaluate GeoFARA with its potential users in its use context in order to get insights into its utility and usability. To this end, fourteen representative users were invited to use GeoFARA to perform a learning task in an organized human geography fieldwork simulating GeoFARA's use context. Collecting data from mental maps, interaction logs, mobile eye tracking, thinking aloud, system usability scale (SUS) survey, interview, and user observation, the evaluation results generated insights about the utility and the usability of GeoFARA in supporting the field learning. Analysis of the mental maps and post-fieldwork interviews led to the conclusion that, GeoFARA (to a certain degree, together with the direct field experience) plays a positive role in supporting the fieldwork goal of learning about the fieldwork area in the case study. Regarding the usability of GeoFARA, it was found that: (1) the interview and SUS survey results demonstrated a good usability; (2) interaction log analysis indicated that participants tended to retrieve POI information from the map view instead of from the AR view of GeoFARA; (3) mobile eye tracking data analysis showed that participants fixated on GeoFARA longer than on the situated objects, i.e., participants extensively relied on GeoFARA instead of on the direct experience when learning in the real environment. Several usability problems of GeoFARA were also identified from the participants' feedback in the interviews, the real-time thinking aloud during the fieldwork, as well as through participant observation.

Centering users in designing educational tools continues to grow in research and practice. Following such a trend, this research was a user-centered design scientific research. The comprehensive review of the UCD methodology and the insights generated from the complete design cycle of the mobile application GeoFARA provide theoretical and practical foundations for future scientific research in domains such as HMI, UCD, UX, and usability. 


\section{Samenvatting}

Technologische innovaties bevorderen en transformeren de ontwikkelingen van de onderwijstechnologieën en de manieren om deze te gebruiken. Op het gebied van het aardrijkskundeonderwijs in het veld moet het de taak zijn van zowel pedagogisch als cartografisch onderzoek om nieuwe cartografische en technische benaderingen te verkennen en uit te breiden om het leren en het onderwijs te verbeteren. Recentelijk wordt mobiele augmented reality (AR), waarbij de werkelijkheid wordt aangevuld met het virtuele op mobiele apparaten, gezien als een van de meest veelbelovende mobiele technologieën, en onderwijs wordt beschouwd als een van de meest veelbelovende toepassingsdomeinen van AR. Voor het geo-veldwerkonderwijs zou een instrument kunnen worden ontworpen dat gebruik maakt van het nieuwe (AR) en het traditionele (kaarten) om innovatief locatiegebaseerd onderwijs en leren te realiseren. Om een nieuw educatief instrument te ontwerpen, wordt weliswaar gepleit voor een verschuiving van door technologie gedreven benaderingen naar meer gebruikersgerichte benaderingen, maar er zijn in de praktijk weinig inspanningen geleverd om de gebruikers bij het ontwerpproces te betrekken. Om bij te dragen aan het opvullen van deze leemte en om gelijke tred te houden met evoluerende technologieën, was het doel van dit promotieonderzoek, dat gebruik maakt van een gebruikersgerichte ontwerpbenadering, het verkennen van het ontwerp en het gebruik van een educatief instrument dat kaarten en AR combineert in een mobiele context-bewuste toepassing (GeoFARA - Geography Fieldwork Augmented Reality Application) voor de ondersteuning van sociaalgeografisch veldwerk.

Om het onderzoek naar het gebruikersgericht ontwerp van GeoFARA te sturen werden de theoretische ontwikkelingen en praktische toepassingen van de methodologie $(\mathrm{UCD}=$ user-centered design) vastgelegd. Een grote hoeveelheid secundaire bronnen over UCD en de daaraan gerelateerde onderwerpen, zoals human-machine interaction (HMI), usability engineering (UE) en use experience (UX) werd onderzocht. Het onderzoek bracht de eerste ontwikkelingen en de belangrijkste mijlpalen van de UCD-methode in de afgelopen eeuw aan het licht, op zowel academisch als praktisch gebied. De basisprincipes, het interactieve proces van UCD, en hoe UCD kan worden toegepast in het ontwerp van context-bewuste mobiele toepassingen, en de resultaten (goede bruikbaarheid) van de toepassing van UCD werden ook onderzocht. Deze studie resulteerde in de drie iteratieve stadia van het gebruikersgericht ontwerpen van GeoFARA: (1) het specificeren van de gebruikscontext en het analyseren van de gebruikerseisen, (2) het produceren van ontwerpoplossingen in termen van conceptueel ontwerp en prototype-ontwikkeling, (3) het evalueren van de ontwerpoplossing. De studie leverde ook een overzicht van de over het algemeen gebruikte UCD-methoden en - 
technieken in elke fase op, met daarbij een selectie en verantwoording van de methoden en technieken voor het ontwerpen van GeoFARA.

De eerste onderzoeksdoelstelling was het specificeren van de gebruikscontext en de gebruikerseisen van GeoFARA. Deze zijn afgeleid van (1) een overzicht van de bestaande mobiele AR-applicaties voor onderwijs in het veld, (2) een online enquête onder de organisatoren van geografisch veldwerk over het huidige gebruik van hulpmiddelen, (3) een veldexperiment dat gebruik makte van een bestaande mobiele cartografische tool, (4) een etnografisch onderzoek tijdens een echt geografisch veldwerk, (5) post-veldwerk onderzoek onder studenten van twee universiteiten, (6) een use-case en taakanalyse, en (7) een gebruiksscenario met persona. Dit resulteerde in een substantiële hoeveelheid initiële gebruikerseisen, die vervolgens werd gereduceerd, gecategoriseerd en geprioriteerd op basis van praktische afwegingen tussen verschillende gebruikerseisen en de beschikbare middelen voor het promotieonderzoek en de noodzaak om alle gebruikerseisen in de eerste iteratieve ontwerpcyclus in overweging te nemen.

De tweede doelstelling was het produceren van ontwerpoplossingen voor GeoFARA. Het conceptuele ontwerp van GeoFARA in termen van doelstelling (functionaliteitsspecificaties en inhoudsvereisten) en kader (gebruikersinterface en navigatieontwerp) werden gepresenteerd en op basis daarvan werd een prototype van GeoFARA ontwikkeld. Vanwege factoren als beperkte middelen (tijd, kosten, etc.), en technische beperkingen werden in dit onderzoek ook de rationele compromissen met betrekking tot de gebruikerseisen toegelicht die moesten worden gemaakt in de vertaling van het conceptuele ontwerp naar het prototype van GeoFARA.

De derde doelstelling van dit onderzoek was het evalueren van GeoFARA met haar potentiële gebruikers in haar gebruikscontext om zo inzicht te krijgen in het nut en de bruikbaarheid ervan. Hiertoe werden veertien representatieve gebruikers uitgenodigd om GeoFARA te gebruiken bij een realistische leeropdracht in een georganiseerd geografisch veldwerk waarin de gebruikscontext van GeoFARA werd gesimuleerd. De verzamelde gegevens uit door de deelnemers geproduceerde mentale kaarten, interactielogs, mobiele oogbewegingsregistratie, hardop-denken, onderzoek met de zog. system usability scale (SUS), interviews en gebruikersobservatie leverden inzichten op over het nut en de bruikbaarheid van GeoFARA bij het ondersteunen van het leren in het veld. De analyse van de resultaten uit de mentale kaarten en de interviews na afloop van het veldwerk leidden tot de conclusie dat GeoFARA (tot op zekere hoogte, samen met de directe veldervaring) een positieve rol speelt in de ondersteuning van het veldwerkdoel om te leren over het veldwerkgebied in de case study. Met betrekking tot de bruikbaarheid van GeoFARA kon worden geconstateerd dat: (1) het interview en de resultaten van de SUSenquête een goede gepercipieerde bruikbaarheid van GeoFARA aantoonden; (2) de 
analyse van het interactielogboek aan gaf dat de deelnemers de neiging hadden POIinformatie uit de kaartweergave te halen in plaats van uit de AR-weergave van GeoFARA; (3) de analyse van mobiele oogbewegingsregistratie gegevens aantoonde dat de deelnemers langer op GeoFARA gefixeerd waren dan op de gesitueerde objecten, d.w.z, de deelnemers vertrouwden uitgebreid op GeoFARA in plaats van op de directe ervaring bij het leren in de echte omgeving. Uit de feedback van de deelnemers in de interviews, het real-time hardop-denken tijdens het veldwerk, en door de observatie van de deelnemers werden ook verschillende bruikbaarheidsproblemen van GeoFARA geïdentificeerd.

Het centreren van gebruikers bij het ontwerpen van onderwijsmiddelen blijft toenemen in onderzoek en praktijk. In navolging van deze trend was dit onderzoek een gebruikersgericht ontwerp onderzoek. De uitgebreide studie van de UCD-methodologie en de inzichten verkregen uit de complete ontwerpcyclus van de mobiele applicatie GeoFARA bieden een theoretische en praktische basis voor toekomstig wetenschappelijk onderzoek in domeinen als HMI, UCD, UX en bruikbaarheid. 


\section{Biography}

Xiaoling Wang was born in April 1987 in Shanxi, China. She completed her Bachelor degree (2006-2010) in Geography Science at East China Normal University, and her Master degree (20102013) in Cartography and Pedagogy at Beijing Normal University. Starting September 2013, Xiaoling started her doctoral research at the Faculty of Geo-Information Science and Earth Observation, University of Twente, the Netherlands. Xiaoling is a UXQB

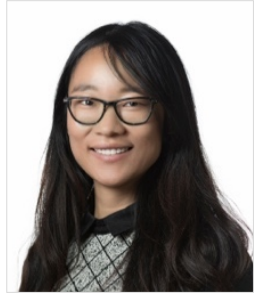
(Usability and User Experience Qualification Board) certified professional, as well as certified by the UX research and consulting firm Nielsen Norman Group. Her work is focused on market/consumer/UX research. Since October 2018, she has been working as a consultant and industry UX researcher specialized within the automotive domain. 
